Florida International University FIU Digital Commons

6-28-2000

\title{
Political corruption in the Caribbean basin : a comparative analysis of Jamaica and Costa Rica
}

Michael W. Collier

Florida International University

DOI: $10.25148 /$ etd.FI14060878

Follow this and additional works at: https://digitalcommons.fiu.edu/etd

Part of the Comparative Politics Commons, Latin American History Commons, Political History Commons, and the Public Affairs, Public Policy and Public Administration Commons

\section{Recommended Citation}

Collier, Michael W., "Political corruption in the Caribbean basin : a comparative analysis of Jamaica and Costa Rica" (2000). FIU Electronic Theses and Dissertations. 2408.

https://digitalcommons.fiu.edu/etd/2408 


\section{FLORIDA INTERNATIONAL UNIVERSITY}

Miami, Florida

POLITICAL CORRUPTION IN THE CARIBBEAN BASIN:

A COMPARATIVE ANALYSIS OF JAMAICA AND COSTA RICA

A dissertation submitted in partial fulfillment of the

requirements for the degree of

DOCTOR OF PHILOSOPHY

in

INTERNATIONAL RELATIONS

by

Michael Wayne Collier

2000 
To: Dean Arthur W. Herriott

College of Arts and Sciences

This dissertation, written by Michael Wayne Collier, and entitled Political Corruption in the Caribbean Basin: A Comparative Analysis of Jamaica and Costa Rica, having been approved in respect to style and intellectual content, is referred to you for judgment.

We have read this dissertation and recommend that it be approved.

Anthony P. Maingot

Eduardo A. Gamarra

Ivelaw L. Griffith

Emily A. Copeland

Nicholas G. Onuf, Major Professor

Date of Defense: June 28, 2000

The dissertation of Michael Wayne Collier is approved.

Dean Arthur W. Herriott College of Arts and Sciences

Dean Richard L. Campbell Division of Graduate Studies

Florida International University, 2000 
(C) Copyright 2000 by Michael Wayne Collier

All rights reserved. 


\section{DEDICATION}

To Gloria. 


\author{
ABSTRACT OF THE DISSERTATION \\ POLITICAL CORRUPTION IN THE CARIBBEAN BASIN: \\ A COMPARATIVE ANALYSIS OF JAMAICA AND COSTA RICA \\ by \\ Michael Wayne Collier \\ Florida International University, 2000 \\ Miami, Florida \\ Professor Nicholas G. Onuf, Major Professor
}

Political corruption in the Caribbean Basin retards state economic growth and development, undermines government legitimacy, and threatens state security. In spite of recent anti-corruption efforts of intergovernmental and nongovernmental organizations (IGO/NGOs), Caribbean political corruption problems appear to be worsening in the post-Cold War period. This dissertation discovers why IGO/NGO efforts to arrest corruption are failing by investigating the domestic and international causes of political corruption in the Caribbean. The dissertation's theoretical framework centers on an interdisciplinary model of the causes of political corruption built within the rule-oriented constructivist approach to social science. The model first employs a rational choice analysis that broadly explains the varying levels of political corruption found across the region. The constructivist theory of social rules is then used to develop the structural mechanisms that further explain the region's levels of political corruption. The 
dissertation advances its theory of the causes of political corruption through qualitative disciplined-configurative case studies of political corruption in Jamaica and Costa Rica. The dissertation finds that IGO/NGO sponsored anti-corruption programs are failing because they employ only technical measures (issuing anti-corruption laws and regulations, providing transparency in accounting procedures, improving freedom of the press, establishing electoral reforms, etc.). While these IGO/NGO technical measures are necessary, they are not sufficient to arrest the Caribbean's political corruption problems. This dissertation concludes that to be successful, IGO/NGO anti-corruption programs must also include social measures, e.g., building civil societies and modernizing political cultures, for there to be any hope of lowering political corruption levels and improving Caribbean social conditions. The dissertation also highlights the key role of Caribbean governing elite in constructing the political and economic structures that cause their states' political corruption problems. 
PREFACE

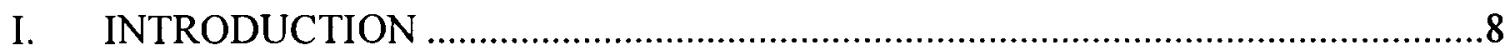

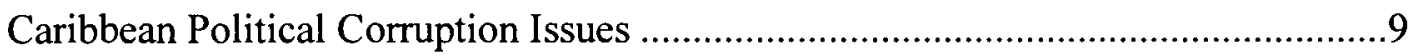

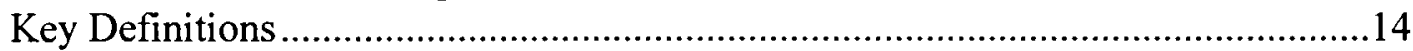

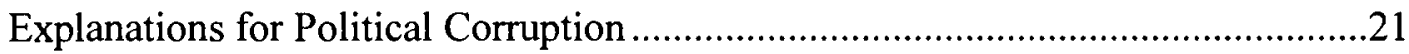

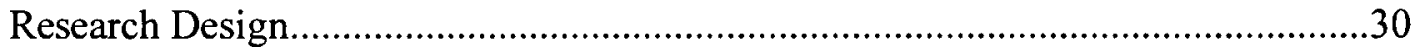

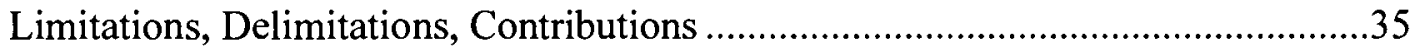

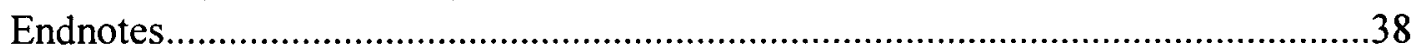

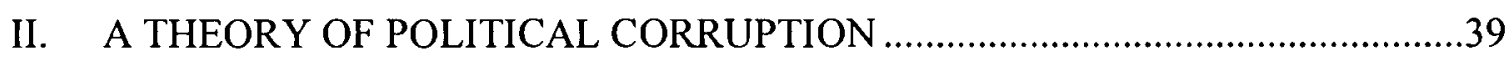

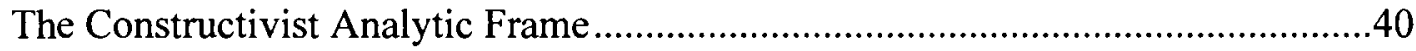

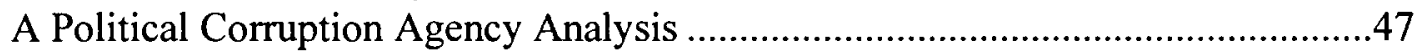

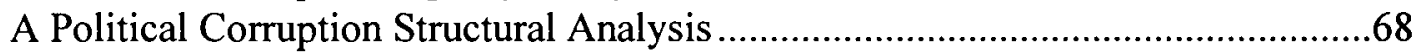

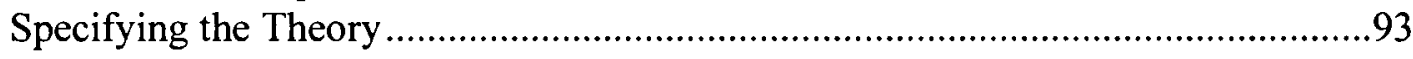

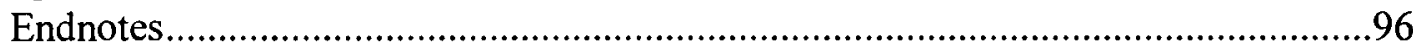

III. A HISTORY OF CARIBBEAN POLITICAL CORRUPTION: 1492-1950 ...........99

Corruption Across the Spanish Main .........................................................................

Corruption in the Colonies of Spain's European Rivals .......................................106

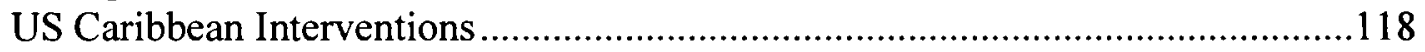

Changing the Caribbean Political Corruption Rules.............................................124

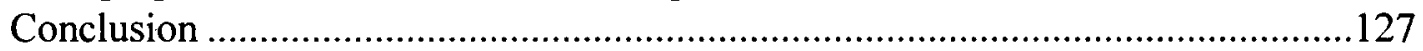

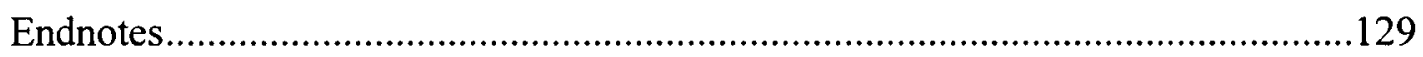

IV. CONTEMPORARY CARIBBEAN POLITICAL CORRUPTION .......................131

Post-World War II Caribbean Structural Development ............................................132

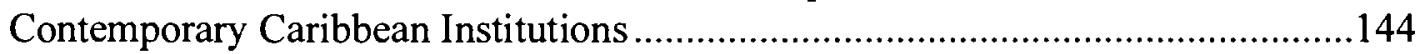

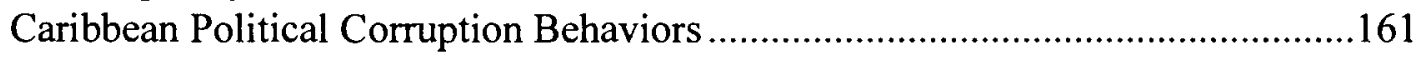

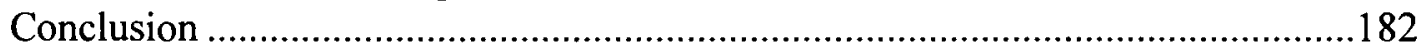

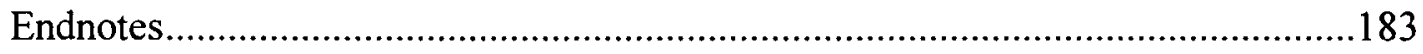

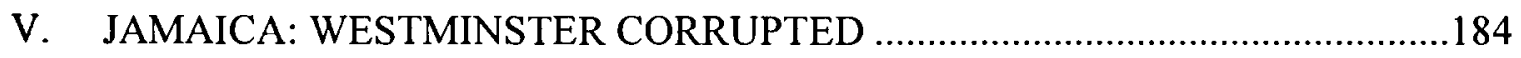

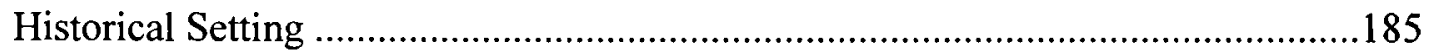

Assessing Contemporary Jamaican Political Corruption.....................................196

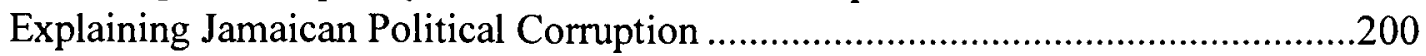

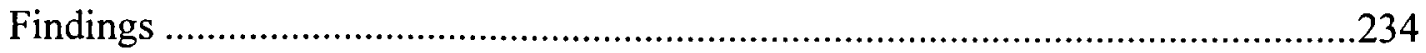

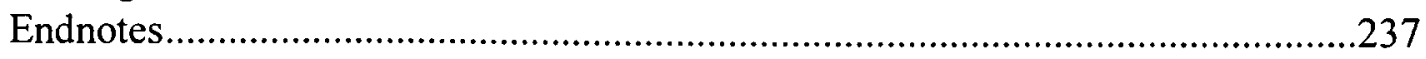




\section{TABLE OF CONTENTS}

(continued)

\section{CHAPTER}

PAGE

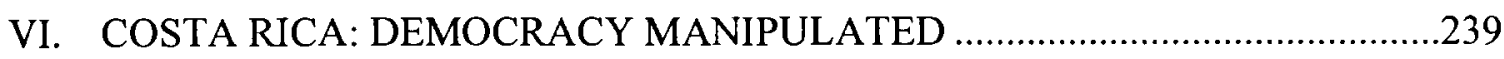

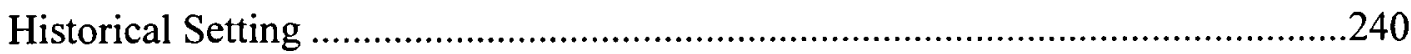

Assessing Contemporary Costa Rican Political Corruption .................................25

Explaining Costa Rican Political Corruption....................................................260

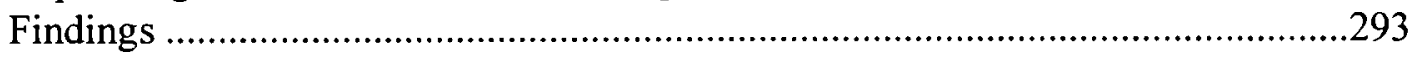

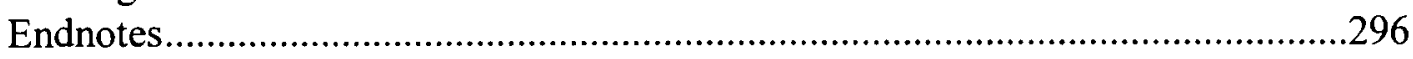

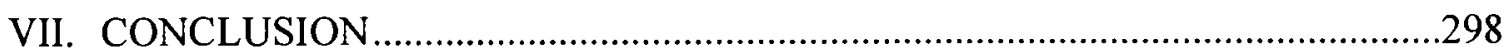

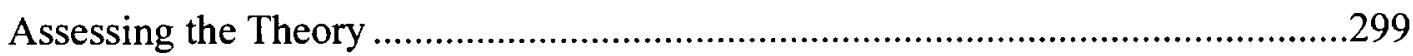

Answering the Political Corruption Questions .........................................................

Situating the Study Within a Larger Context.....................................................319

Key Contributions, Limitations, and Directions for Future Research .....................322

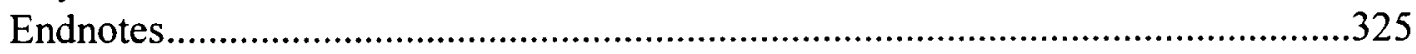

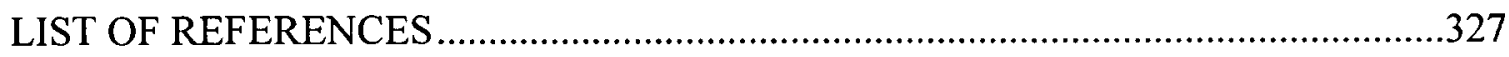

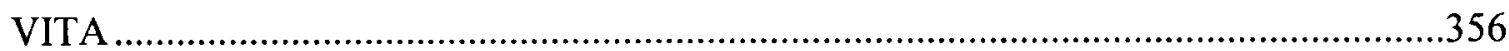




\section{LIST OF TABLES}

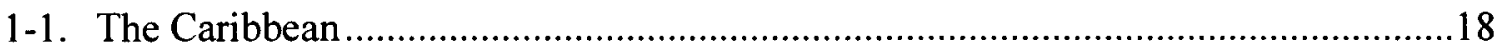

2-1. Constructivist Theory of Social Rules ..................................................................4

2-2. The Incidence and Evaluation of Political Corruption Behavior ..............................55

2-3. Summary of Political Corruption Agency Analysis ...............................................68

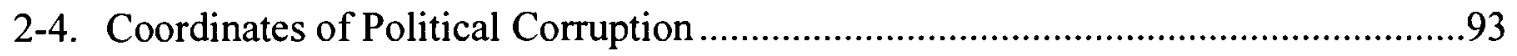

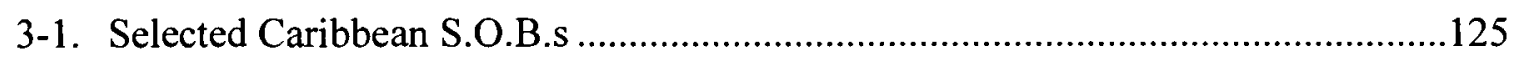

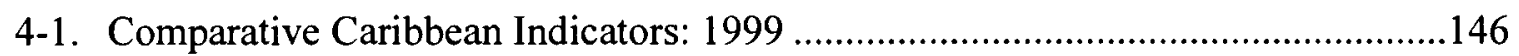

5-1. The Incidence and Evaluation of Jamaican Political Corruption Behavior .............198

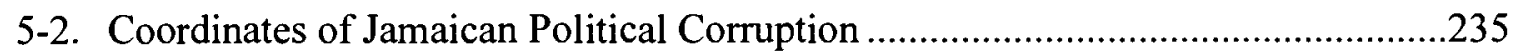

6-1. The Incidence and Evaluation of Costa Rican Political Corruption Behavior .......258

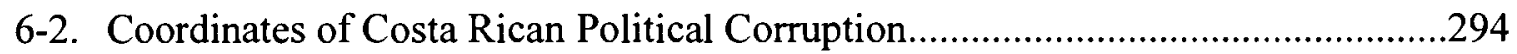

7-1. Coordinates of Political Corruption (reprinted from Table 2-4) .............................300

7-2. Summary of Political Corruption Structural Factors ..............................................306 


\section{Preface}

My first encounter with corruption in the Caribbean occurred just after I began my United States Coast Guard career. On graduating from the US Coast Guard Academy in 1974, I was assigned to the US Coast Guard Cutter Dauntless (WMEC 624) at Miami Beach, Florida. Soon after I reported aboard Dauntless, we were dispatched to the Bahamian capital city of Nassau to retrieve several hundred pounds of seized marijuana that was needed for a court case in Miami. When we moored in Nassau the next day, we found that half the seized marijuana had been stolen the night before from the Bahamian Police jail cell where it was being stored. This was just the first of many personal encounters with Caribbean official misconduct and corruption problems.

Caribbean corruption was an ever-present factor during my career in the US Coast Guard. I spent over 20 years involved in the Drug War, either aboard cutters conducting counter-drug patrols in the Caribbean or in staff jobs providing intelligence support to US and allied counter-drug forces. It was standard practice to consider the corruption factor whenever planning maritime drug interdiction operations with Caribbean governments and before sharing sensitive information with Caribbean officials. It took considerable time to confirm who we could and could not trust in most Caribbean states-and sometimes we never figured it out.

The problem with corruption was especially evident during my assignment as the US Coast Guard Attaché in the US Embassy in Bogota, Colombia, from 1990 to 1992. Corruption was everywhere in Colombia. Some of the corruption was understandable because of the meager salaries the Colombian government paid lower ranking military 
and civilian officials. Even simple interactions with the Colombian bureaucracy, like buying local car insurance, required a small bribe. It was common for Colombian National Police traffic officers to stop automobiles in hopes of extorting bribes in exchange for not issuing trumped-up traffic citations. We also experienced a seemingly endless flow of information into the US Embassy about drug-related corruption in the Colombian military, police, and government agencies. A Colombian naval officer friend offered an explanation for this corruption:

The system makes us corrupt. Selection as a Colombian military or police officer is a ticket to a middle class lifestyle. The salary is not that great, but the social standing that comes with being an officer, plus benefits such as subsidized housing, commissaries, and officer clubs makes for a good life. Unfortunately, the military retirement system does not allow you to continue in this middle class existence after you leave the service. Therefore, to live well after retirement most military and police officers have three options: (1) marry money, (2) work yourself into several foreign assignments and save the inflated per diem [viaticos] that officers living outside Colombia are paid, or (3) be corrupt.

I found my Colombian Navy friend's explanation of his country's military and police corruption quite insightful. It applied equally to Colombian government civil servants who also seemed to be forced into corrupt behavior to prepare for retirement. These insights helped me understand the corrupt behavior of Colombian military, police, and government officials. It also made me wonder what structural factors contributed to the corruption of senior Colombian government officials-people who were mostly from the wealthy upper and upper-middle classes and did not need the resources gained from corruption to ensure a comfortable retirement.

During my Colombia assignment, I also noticed the wide disparity in how US government officials approached the corruption problem. I met numerous members of 
the US law enforcement community who saw the corruption monster under every rock and behind every tree. US law enforcement officials were often paralyzed into inaction by the thought that corruption might compromise one of their ongoing investigations. I found a completely different attitude toward corruption among US officials involved in international development and military aid programs. US aid officials generally ignored the corruption problem, even when there was solid evidence that resources from their aid programs were being pilfered for the personal benefit of Colombian government officials.

The cloud of Caribbean corruption that I saw hovering over US counter-drug and aid programs in the region planted the seed for this dissertation. I was most puzzled by the political corruption occurring in the upper echelons of the Caribbean governing elite. Before beginning my doctoral studies, I read many of the writings of Anthony P. Maingot of Florida International University (FIU) who specializes in US-Caribbean relations and regional security issues including: corruption, drug trafficking, and money laundering. His work further sparked my interest in the subject of corruption and helped steer me toward FIU for my doctoral studies. My future as an FIU doctoral student was sealed by the offer of an Andrew Mellon Foundation Doctoral Fellowship in Caribbean Studies from the FIU Latin American and Caribbean Center.

I am greatly indebted to those who helped me in this dissertation project. I start with my FIU dissertation committee. I owe special thanks to my advisor, Nicholas G. Onuf. He expertly guided me throughout my entire doctoral program. He is also the creator of the rule-oriented constructivist analytic frame that is the intellectual engine of this dissertation. Anyone who reads this dissertation should want to learn more about his 
rule-oriented constructivist approach to social science. I thank Emily A. Copeland who taught me the intricacies of international political economy and without whose help I would have overlooked several inconsistencies in my arguments. I thank Eduardo A. Gamarra who taught me the complexities of democratization and governance. As the Director of FIU's Latin American and Caribbean Center, Dr. Gamarra also graciously supported my fieldwork in Jamaica and Costa Rica. I also thank Anthony P. Maingot and Ivelaw L. Griffith, true subject matter experts on all things Caribbean. Both guided me through my Caribbean area studies, helping me to understand not only the region's diversity, but also the intriguing relationships among political, economic, and cultural factors that make the Caribbean such an exciting place to study. Although not a formal member of my dissertation committee, I also want to thank William O. Walker, III, an expert on US foreign policy and the history of drug trafficking, for reading and commenting on several of my draft chapters.

I owe an intellectual debt to many whose work preceded mine. I rely heavily on the work of several scholars in the development of my theory of the causes of political corruption - a central element of this dissertation. Political culture is one of the key concepts in my theory. Although many scholars have studied political cultures, the work of Daniel J. Elazar had the most influence on my thoughts on this subject. I had the pleasure to meet the late Dr. Elazar and discuss my ideas with him while he was a visiting professor at FIU in 1999. My theory also draws heavily on the corruption scholarship of Arnold J. Heidenheimer, Michael Johnston, and Robert Klitgaard. Dr. Heidenheimer contributes the approach I use to tackle the sticky problem of cultural relativity in 
corruption theory. Dr. Johnston's work identifies the key institutional factors that play a central role in my theory. Dr. Klitgaard provides a powerful agency model for explaining corrupt behavior, one that has become the standard used by intergovernmental and nongovernmental organizations developing anti-corruption policy. The success of my theory of the causes of political corruption is determined by its ability to contribute more to anti-corruption policy development than does Dr. Klitgaard's seminal work.

I owe a debt of gratitude to those who helped me in my field research. I am most indebted to Beth and Martin Aub who were gracious hosts during my fieldwork in Jamaica. Members of the Jamaican chapter of Transparency International and Jamaicans for Justice, the Aubs were instrumental in arranging my interviews with a number of Jamaica politicians and journalists. The Aubs also provided key comments on my case study of political corruption in Jamaica. I thank Orville Taylor, sociology professor at the University of the West Indies, who coordinated my research at that university. I found that anyone doing research on the British West Indies in general, or Jamaica in particular, must spend time in the West Indies Collection of the University of the West Indies-Mona library-it is simply spectacular. I thank Luis Guillermo Solis, political science professor at the University of Costa Rica and Director of The Foreign Service Foundation for Peace and Democracy (FUNPADEM), who coordinated my fieldwork in Costa Rica. Dr. Solis went beyond the call of duty in arranging my Costa Rican housing, providing FUNPADEM office and computer support, scheduling interviews with several Costa Rican government officials, and commenting on my case study of corruption in Costa Rica. 
I must also thank my loving wife Gloria. This Ph.D. is as much hers as mine. She willingly traipsed all over the Caribbean and South America with me during my US Coast Guard career. She supported my plans to return to graduate school in the quest for a Ph.D. after my US Coast Guard retirement. She expertly proofread the final draft of this dissertation and now knows more about political corruption and Caribbean politics than she ever imagined possible. I could not have completed this program without here love and support.

Although there were many who helped me through this dissertation project, any errors remaining in the analysis or facts are my own.

Finally, I want to save the reader from having to search for my particular biases that might affect this dissertation. I admit to being a believer in liberal-democracy and free trade. These beliefs developed over a lifetime of personal and professional experience. I grew-up in a rural area of west-central Missouri. The primacy of democracy, as defined by a mix of individualistic and egalitarian values, permeated the region's institutions. I spent my early professional career in the US Coast Guard, which has its own culture and set of values. I was socialized into a US Coast Guard culture that combines a hierarchical military structure and its associated strict discipline with a strong egalitarian approach to its primary missions of maritime search and rescue and law enforcement. Strengthening the rule of law in developing states in the Caribbean Basin was one of my primary endeavors while serving in the US Coast Guard. My graduate studies also introduced me to the range of world governing and economic systems, allowing me to compare each to the tenets of democracy and free trade. From my early 
life experiences, US Coast Guard service, and graduate studies, I developed a strong belief that liberal-democracy and free trade are the best conditions for the betterment of mankind. 


\section{Chapter 1}

\section{Introduction}

Political corruption has been a Caribbean problem for centuries. It was not until the early 1990 s, however, that the need to address the corruption problem became part of regional political discourse. Under increasing international and domestic pressure to do something about their corruption problems, the 34 Western Hemispheric heads of state and government attending the 1994 Miami, Florida, Summit of the Americas I (all less Cuba) established Combating Corruption as one of the 23 action items in their final declaration. This led to the March 1996 signing of the Organization of American States' (OAS) Inter-American Convention Against Corruption. By the late 1990s, the regional interest in anti-corruption programs appeared to be waning. At the 1998 Santiago, Chile, Summit of the Americas II, the Combating Corruption action item received only minimal discussion. By mid-2000, four years after its initial signing, only 18 OAS member states had ratified the Convention. At the same time, no OAS member had adopted the comprehensive package of domestic legislation required for the Convention's full implementation. The lack of sustained anti-corruption interest was especially evident in the Caribbean where many states neither signed nor ratified the OAS Convention. ${ }^{1}$

Political corruption is an extremely complex behavior constituting a number of social factors. It is not a subject that is easy to study. Disagreements over political corruption definitions, theories, and measurement all contribute to the difficulties in its study. This does not mean that the study of political corruption should be forsaken. 
Instead, we must find new theories and methods to help us understand this complex social behavior.

This study investigates the research question: What are the domestic and international causes of political corruption in the Caribbean? The study argues that we cannot understand the many puzzles about political corruption unless we first have a comprehensive theory of its causes. The study adopts Onuf's (1989) rule-oriented constructivist analytic frame to investigate the research question. The study finds that while international factors such as colonialism, neo-imperialism, transnational corporations, foreign businesses, drug trafficking, etc., contribute to the Caribbean's continuing political corruption problems, the main cause of contemporary Caribbean political corruption are local governing elite who manipulate their society's political and economic development and plunder state resources for their own benefit at the expense of their citizenry. The key role of a state's governing elite in fostering political corruption is a factor that has not been sufficiently emphasized in Caribbean political discourse.

\section{Caribbean Political Corruption Issues}

The end of the Cold War helps explain the recent growing interest in political corruption. In the Western and Soviet Cold War struggle for spheres of influence, political corruption in the superpowers' client states was treated like the proverbial elephant standing in the living room, an anomaly obvious to everyone but that no one dared talk about. The superpowers seldom addressed corrupt behavior in their client states to avoid alienating friendly leaders. Robert McNamara, former President of the World Bank, highlighted the Cold War political incorrectness of raising political 
corruption issues when he asserted in the early 1990s that "the subject of corruption could not have been discussed [in international forums] 20, 15, or even 5 years ago" (quoted in Vogel, 1993).

As post-Cold War trends toward democratization and neoliberal economic reforms lifted the veil of silence surrounding political corruption, international organizations; including the United Nations, World Bank, and International Monetary Fund, among others; confirmed that high levels of political corruption adversely affect societal development. ${ }^{2}$ Political corruption undermines the legitimacy of political institutions (see Ryan, 1998, p. 51; Leiken, 1996, p. 55). It reduces economic growth by diverting state resources toward inefficient (white elephant) projects and away from needed economic infrastructure projects (roads, ports, etc.). High levels of political corruption also reduce economic growth by decreasing investor confidence in corrupt governments, thus lowering foreign and domestic investment rates (see Mauro, 1995, 1996, 1997a, 1997b; Tanzi and Davoodi, 1997, 1998; Tanzi, 1998). It also seriously degrades the welfare of a society's poorest citizens by diminishing the resources allotted to education and health programs and by fostering policies that increase income inequalities (see Mauro, 1997a; Tanzi and Davoodi, 1997, 1998; Tanzi, 1998). Moreover, political corruption becomes a threat to the national security of many societies when, in alliance with transnational criminal organizations, it supports terrorism, arms smuggling, drug trafficking, and money laundering (Leiken, 1996, p. 55).

The post-Cold War openness about political corruption helped uncover numerous examples of the problem that reached the very top of Caribbean governments. In 1992, 
Antigua and Barbuda's prime minister of 11 years, Vere Bird, Sr., agreed not to run again for public office, partly as the result of a string of government corruption scandals dating back to the mid-1980s that implicated either him or his two cabinet minister sons. In 1993, Venezuelan President Carlos Andres Perez was impeached by Congress, and later convicted, on charges he misused a secret US\$17 million government fund to pay for campaign debts and a lavish 1989 inauguration. In 1996, Colombian President Ernesto Samper was charged with knowingly financing his election campaign with US\$6 million donated by the Cali Drug Cartel. Samper was later absolved of these charges by the Colombian Chamber of Deputies, tainted by allegations of their own bribery by the drug lords. Also in 1996, over US\$120 million in unexplained funds were found in the foreign bank accounts of Raul Salinas, brother and political confidant of former Mexican President Carlos Salinas (1988-1994). While Raul Salinas was charged with illicit enrichment, money laundering, and drug-trafficking, his brother Carlos escaped into selfimposed overseas exile. These few examples are just the tip of the much deeper Caribbean political corruption problem.

The increasing post-Cold War exposure of political corruption problems led to the establishment of the Miami Summit of the Americas I Combating Corruption action item and the 1996 OAS Inter-American Convention Against Corruption. The Miami Summit declaration acknowledged that "[c]orruption...weakens democracy and undermines the legitimacy of governments and institutions" (Feinberg, 1997, p. 222). The 1996 OAS Convention calls for a variety of Western Hemispheric state actions intended not only to prevent corruption, but also to strengthen states' abilities to prosecute those suspected of 
corrupt acts (OAS, 1996). Amid a fanfare of international publicity, 21 OAS members initially signed the Convention. One analyst deemed the OAS Convention "the most farreaching document of its kind in the world...the only treaty instrument addressing the problem of corruption...the first cooperative agreement on this issue negotiated by developed and developing countries" (Elliott, 1996, p. 7). As discussed earlier, interest in hemispheric anti-corruption reforms appeared to wane by the late 1990s. This was highlighted in the aftermath of the 1998 Santiago Summit, when The Leadership Council for Inter-American Summitry (1999, p. 13) observed "there is little evidence of implementation [of the 1996 OAS Convention] in the sense of countries bringing their national laws into conformity with the Convention's articles and then enforcing them."

Since the initial signing of the 1996 OAS Convention, Caribbean political discourse related to political corruption presents two general reasons why interest in the subject has waned. First, Caribbean leaders continue to argue that their political corruption problems are due to international and not domestic factors. Caribbean and South American political leaders lobbied to have the Combating Corruption item placed on the 1994 Miami Summit agenda (Fienberg, 1997, pp. 50-51). They intended for this agenda item to deflect the blame for their states' high political corruption levels from domestic factors onto transnational corporations and foreign businesses that were bribing foreign government officials. The Hemispheric leaders were surprised when the majority of the anti-corruption measures called for in the 1996 OAS Convention dealt with domestic and not international reforms. Thus, the OAS Convention undermined the 
populist approach to political corruption intended by hemispheric leaders outside the United States and Canada.

Caribbean leaders regularly adopt populist approaches to their societal problems, such as political corruption, that downplay domestic causes and blame their states' problems on international factors outside Caribbean control. Populist approaches play to strong nationalistic feelings in most Caribbean states and offer that political corruption is a product of the region's history of colonialism and the nineteenth and early twentieth century US interventions. Caribbean leaders are also quick to attribute their political corruption problems to the neo-imperialism of continuing US and European political and economic involvement in the Caribbean. A major target of the Caribbean anti-corruption discourse is Western-based businesses (transnational corporations, etc.) that bribe Caribbean officials in the quest to secure lucrative local government contracts or markets. Caribbean leaders' uncertainty over the effects of neoliberal reforms on political corruption levels is a second area of recent discourse. Many Caribbean leaders are uncomfortable with world trends toward neoliberal economic reform and international financial institution demands for good governance reforms (see IMF, 1997; Wesberry, 1998). As a counter to developed state pressure in these areas, Caribbean leaders are quick to point out that recent regional economic and political reforms coincide with increasing Caribbean political corruption levels. Neoliberal market-based economic reforms, such as lowering tariffs and privatizing state-owned industries, and good governance reforms aimed at strengthening Caribbean democracies, are hypothesized as measures to decrease opportunities for graft and theft of state resources. However, 
Caribbean states implementing neoliberal reforms and transitioning from militaryauthoritarian regimes to representative democracies often experience the opposite effect. For example, Mexico, one of the Caribbean states employing aggressive privatization programs, experienced several of the region's most flagrant corruption scandals. Additionally, Panama's transition from military-authoritarian to democratic rule in the 1990s did little to lessen its political corruption problems.

Are the causes of Caribbean political corruption primarily international as many Caribbean leaders argue? Do neoliberal economic and good governance reforms increase opportunities for Caribbean political corruption? Are there deeper domestic or international factors that cause political corruption? What contributes to the lack of political will and/or political capacity that undermines Caribbean interest in anticorruption reforms? These questions cannot be adequately answered, nor can effective Caribbean anti-corruption policy be devised, without first developing a comprehensive theory of the causes of political corruption.

\section{Key Definitions}

Corruption is a complex, multifaceted, and contentious concept. Among the hundreds of scholarly studies of political corruption, there appear almost as many proposed definitions of this complex phenomenon. The lack of a single accepted definition of political corruption is one reason a comprehensive theory of its causes never emerged. Johnston $(1994$, p. 3) refers to the repeated attempts to conceptualize political corruption as a definitional quagmire and argues that we are unlikely to ever find a satisfactory single definition of corruption (also see Johnston, 1996b; Johnston, 1998, p. 
89; Philp, 1987; and Philp, 1997, pp. 22-30). Many political corruption studies have foundered simply on definitional issues. Gillespie and Okruhlik (1991, p. 77) submit that a definition of political corruption must be "general enough to allow cross-cultural comparison yet precise enough to be empirically useful."

In an attempt to overcome the many conflicting definitions of political corruption, the World Bank takes a reductionist approach and simply defines the concept as the "abuse of public power for private gain" (World Bank, 1997a, 1997b). This World Bank definition addresses public corruption that includes behavior such as bribery, extortion, and theft occurring within public, official, or governmental domains. It does not include private corruption relating to fraud or theft occurring solely within the realm of private commercial or financial transactions. It is all but impossible to explain both public and private corruption behavior in one study, as the two concepts differ in not only the actors involved in the corrupt activity but also in actor incentive structures (willingness and opportunities) to be corrupt. This study focuses only on a selected form of public corruption commonly referred to as political corruption.

Building upon the World Bank definition, this study defines political corruption as the abuse of public power by a governing elite for their private (personal) monetary, material, or non-material gain. Corruption scholars and policy analysts also refer to political corruption as grand corruption, or corrupt behavior by senior government officials who possess the decision-making authority to make policy allocating a state's resources (Moody-Stuart, 1996). Political corruption is differentiated from the second form of public corruption known as bureaucratic-administrative or petty corruption that 
involves mid and low-level government officials who gain personally from their roles in executing government policies and programs. While the interdisciplinary theory of the causes of political corruption developed in this study has some applicability to both private and bureaucratic-administrative corruption, neither of these phenomena is addressed other than anecdotally in this study.

The above definition of political corruption focuses on the governing elite as the principal actors in corrupt or non-corrupt behavior. In conceptualizing a governing elite, this study draws upon the work of Bottomore (1964, p. 12) who notes "in every society there is, and must be, a minority - the "political class" or "governing elite," composed of those who occupy the posts of political command and, more vaguely, those who can directly influence political decisions...(emphasis added)." Bottomore refines his concept of governing elite into two categories - political class and political elite. Political class refers to "those groups which exercise political power or influence, and are directly engaged in struggles for political leadership" (Bottomore, 1964, p. 14). He sees the political elite as a subset of the political class that include "members of the government and of the high administration, military leaders, and, in some cases, politically influential families of an aristocracy or royal house and leaders of powerful economic enterprises" (Bottomore, 1964, p. 14). The political class includes the political elite and "counterelites comprising the leaders of political parties which are out of office, and representatives of new interests or classes (e.g., trade union leaders), as well as groups of businessmen, and intellectuals who are active in politics" (Bottomore, 1964, pp. 14-15). 
This study defines Caribbean in its geopolitical sense that includes those states and territories that touch upon the Caribbean Sea or have similar cultural or demographic characteristics to other Caribbean states. This Caribbean definition is similar to the Caribbean Basin geopolitical conceptualization that United States foreign policy circles began using in the region in the 1980s. This Caribbean definition includes the island states and territories of the Greater and Lesser Antilles, Mexico, Central American states, Colombia, Venezuela, Guyana, Suriname, French Guiana, the Bahamas, and Bermuda. Table 1-1 summarizes the states and territories included in this Caribbean definition. 


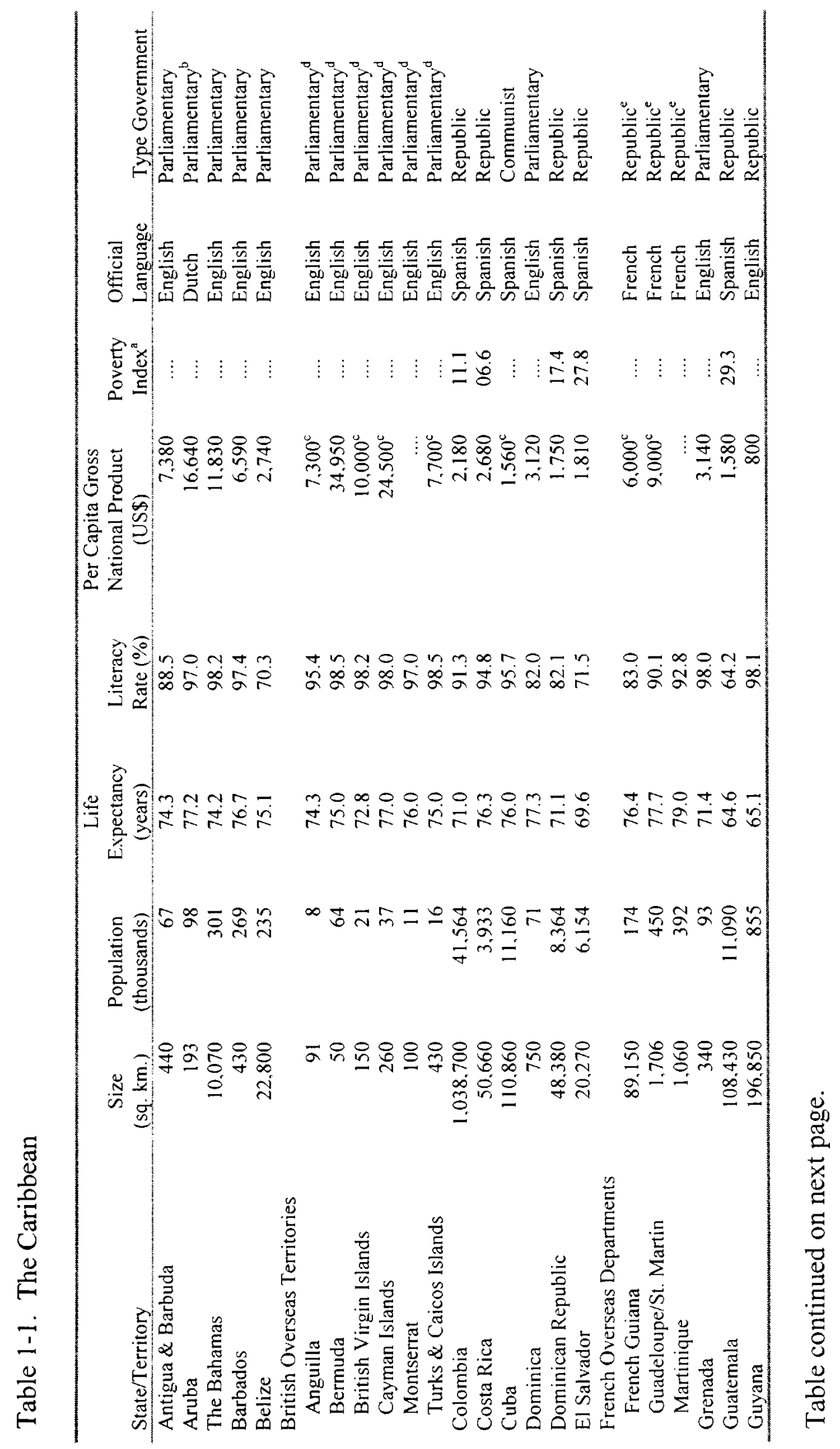




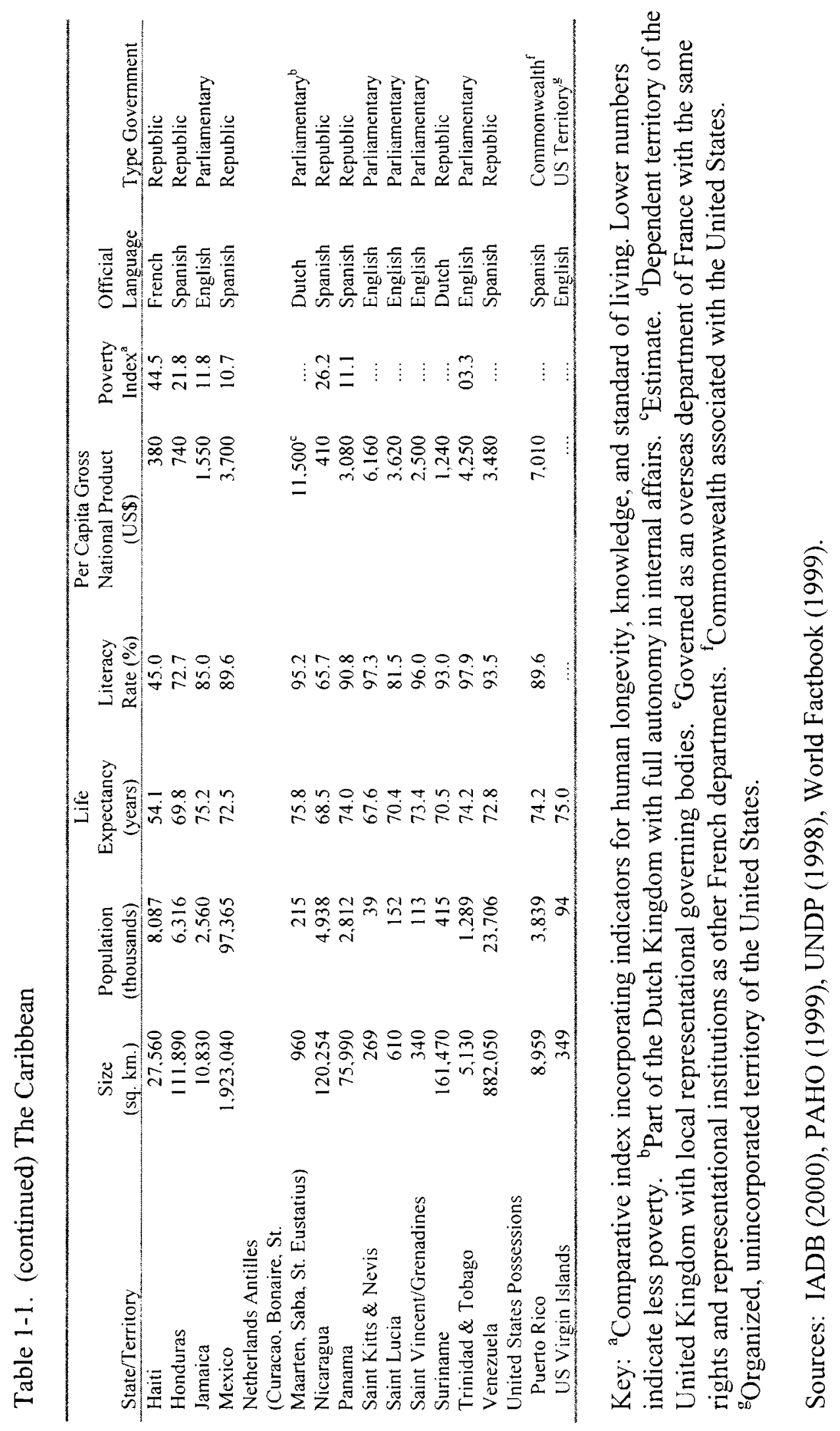


The Caribbean was selected for this study not only because it is the area with the most resistance to the OAS-led corruption reforms, but also because (1) it contains the majority of Western Hemispheric states, and (2) it displays wide diversity. If the study was expanded to the entire Western Hemisphere, the political corruption problems of the medium and small Caribbean states and territories, and their reasons for resisting corruption reforms, could become lost in the analysis of the more serious corruption problems in some of their larger Hemispheric neighbors. Table 1-1 demonstrates the diversity of the Caribbean in terms of state and territory size, population, health, education, incomes, official languages, and type governments. By first building a theory of the causes of political corruption that applies to a region as diverse as the Caribbean, it should take only minor modifications to later revise the theory into one that applies to all of the Western Hemisphere.

Diversity in political corruption levels, this study's dependent variable, is another issue that drew attention to the Caribbean for this study. Not all Caribbean states are systemically corrupt. For example, as Chapter 4 develops, Barbados, Bermuda, the Bahamas, Dominica, and Costa Rica are among the least corrupt states or territories in the Caribbean. On the other hand, Honduras, Panama, Antigua and Barbuda, Aruba, and Haiti are among the most corrupt regional states. One challenge of this study is to develop a theory of the causes of political corruption that is useable across the entire Caribbean. 


\section{Explanations for Political Corruption}

The modern scholarly study of the causes of political corruption began in the 1960s and 1970s, spurred by the inclusion of corruption as an important factor in modernization and democratization studies. Since the 1960s, there have been hundreds of scholarly studies in the academic fields of anthropology, criminology, development studies, economics, financial management, international relations, public administration, political science, and sociology, all attempting to explain the causes and consequences of political corruption. These studies have adopted a variety of theoretical approaches. While the hundreds of mostly single-discipline corruption studies have produced rigorous theorizing and many useful case studies, the overall findings about the causes and consequences of corruption have been quite contradictory (Johnston, 1986, p. 985).

Most scholarly corruption studies consist of single case studies that provide few theoretical generalizations that transfer to the study of corruption in other states. Lancaster and Montinola (1997, p. 185) highlight that "problems of definition, operationalization, and measurement have thus far constrained most students of corruption to ideographic single case studies....the lack of cross-national empirical studies prevents a more complete understanding of general causes of political corruption." Another scholar laments in her bibliography of political corruption that "high expectations about (corruption) theory [are] misplaced by a search for confirming data" (Johansen, 1990, p. 35). This study addresses both the theoretical and empirical problems in corruption scholarship. 
A convenient method for summarizing past corruption scholarship is to categorize it within the ongoing philosophy of science debate over whether agency or structure is the primary explanation for human behavior (see Gould, 1998). Those on the agency side of the debate argue that human agency is the moving force behind the actions, events, and outcomes of the social world (Dessler, 1989, p. 443). The agency argument attributes social behavior to the free will (voluntarism) of individual human agents. Those adopting an agency approach explain variances in social behavior as a result of both the disposition of individual agents and differing incentive structures agents face. Differing incentive structures usually result from varying organizational arrangements. The structure side of the debate is more deterministic. Structuralists argue that social behavior is determined by concrete historical circumstances that condition the possibilities for agent behavior and influence its course (Dessler, 1989, p. 443). Structuralists downplay the role of individual agents in explaining human behavior. Instead, they explain variances in social behavior as primarily the result of differing political, economic, or cultural conditions (institutions) that bound agent behavior.

Figure 1-1 highlights the major agency and structuralist approaches found in the corruption literature. These approaches are described in more detail below. 
Figure 1-1. Agency and Structural Explanations for Political Corruption

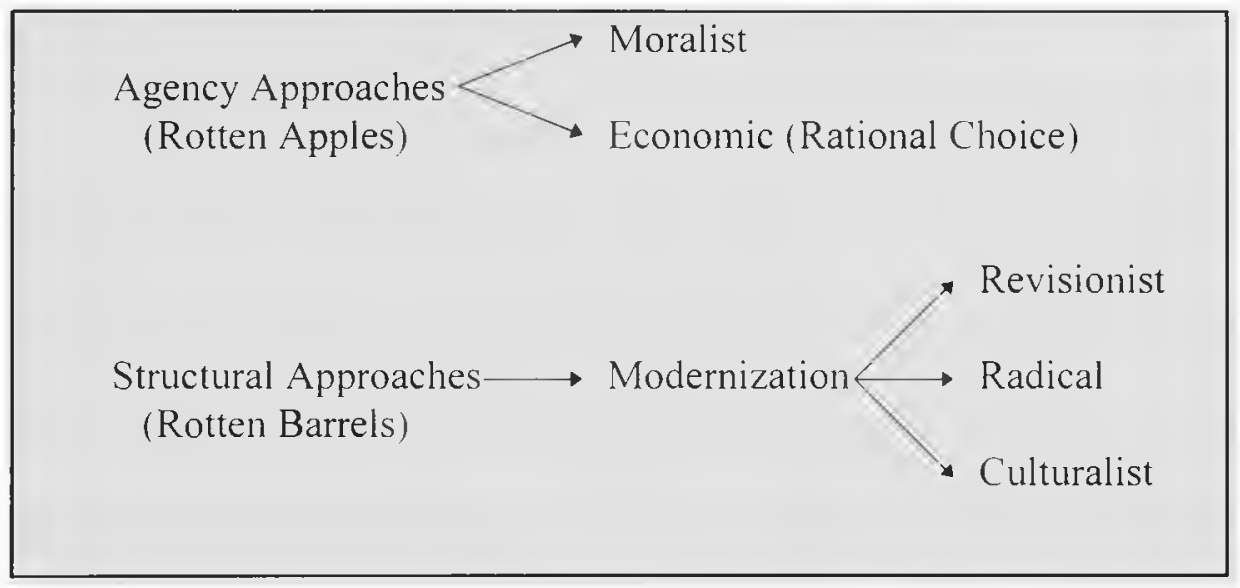

Agency explanations for the causes of political corruption include moralist and economic approaches. The moralist approach adopts a normative stance that views all corruption as bad and corruption's sources as bad individuals. These bad individuals, or rotten apples (see Johnston, 1982, p. 12), are usually depicted as weak-charactered or poorly trained government officials (see Leys, 1965; Caiden \& Caiden, 1977; Bollens \& Schmandt, 1979; Nas, Price \& Weber, 1986; and Alatas, 1990). The economic approach normally refers to rational choice theory explanations for the causes of political corruption. The rational choice approach, in its purest form, refers to behavior by agents designed to further the agent's perceived self-interest, subject to information and opportunity costs (Monroe, 1991, p. 1). The rational choice approach includes a variety of cost-benefit (see Nye, 1967), principal (patron)-agent-client (PAC) (see RoseAckerman, 1978; Lui, 1986; Klitgaard, 1988; Groenendijk, 1997; and Khan, 1998), and game theory (see Geddes, 1991. 1994; Bicchieri \& Rovelli, 1995; Manion, 1996; and Bicchieri \& Duffy, 1997) analyses of the causes of political corruption. Proponents of the economic approach highlight its rigorous theorizing processes and its ability to identify 
specific causal mechanisms for the sources of political corruption. These causal mechanisms are then used to design anti-corruption programs.

Klitgaard's (1988) PAC analysis is the most widely used rational choice study for designing anti-corruption programs. PAC analyses develop their causal mechanisms through transaction analyses of the relationships between principals (patrons), agents, and clients. Klitgaard's PAC analysis begins with a principal that selects an agent to provide a service to either the principal or a client. The principal is a state's citizenry, agents are the state's governing elite, and clients are domestic or international actors desiring access to state resources. Klitgaard's PAC analysis develops causal mechanisms revealing that an agent's corrupt behavior flourishes when the agent is given monopoly power over clients, when the agent has great discretion, and when accountability of the agent to the principal is weak (Klitgaard, 1988, p. 75). His conclusions result in the following stylized equation for the causes of corruption:

Corruption $=$ Monopoly + Discretion - Accountability $($ or $C=M+D-A)$.

To lower state corruption levels, Klitgaard calls for the restructuring of the $\mathrm{C}=\mathrm{M}+\mathrm{D}-\mathrm{A}$ causal relationships. This has been the primary formula for devising modern anti-corruption programs, including the 1996 OAS Inter-American Convention Against Corruption. The need to eliminate monopolies and institute transparent and free competition in the management of state resources is a frequent topic in corruption literature. Rose-Ackerman's (1978) PAC analysis is the most sophisticated and thorough of these studies. Rose-Ackerman finds, however, that corruption can exist even in the most open and competitive political-economic systems. She also concludes that reducing 
corruption in systems with extensive corruption requires not only a political system with competition, but also an informed electorate that can hold elected officials accountable for their corrupt actions (Rose-Ackerman, 1978, p. 55). Other studies reveal how not only electoral accountability, but also administrative and judicial accountability of agents are critical to holding a governing elite accountable for corrupt behavior (see Schedler et al., 1999). As to agent discretion, Della Porta and Vannucci's (1999) study of the 1990s Italian political corruption scandals (Clean Hands investigation) reveals the importance of restricting a governing elite's ability to manage state and societal property rights, thereby reducing their opportunities to generate rents. ${ }^{3}$ In states without restrictions on governing elite discretion, these rents become the agents' corrupt payoffs. Placing limits on the governing elite's discretion to manage state and societal property rights goes to the very heart of politics in determining who gets what, when, and how (see Lasswell, 1950).

There are numerous problems with agency approaches to explaining the causes of political corruption. Moralist analyses rely too much on the normative stance that corruption is bad, and fail to develop causal mechanisms that explain corruption's causes as anything beyond bad individuals. The rational choice approach is often too reductionist (see Green \& Shapiro, 1994). Rational choice analyses tend to identify key micro-level causal mechanisms that empirically correlate with state corruption levels. However, most rational choice analyses ignore the existence of deeper institutional structures that condition agent behavior. Even Klitgaard's influential C $=M+D-A$ formula fails to recognize key factors such as types of political and economic systems, 
types of political cultures, and different paths to modernization that structuralists hypothesize as important causes of political corruption.

Structural explanations for the causes of political corruption are also referred to as the political or rotten barrel approach (see Johnston, 1982, p. 14). Structural explanations often follow a political or economic modernization approach. Modernization subcategories include the revisionist, radical, and cultural schools which all provide their own specific propositions for the most significant structural causes of political corruption. Huntington (1968), Scott (1972), and Theobald (1990) provide important contributions to the general modernization approach that sees the character of a state's political system and the nature and rate of its socioeconomic change as the major causes of political corruption. A major assumption of the modernization approach is that as states reach a developed status, their corruption levels will subside. Huntington (1968, p. 64) argues that the degree of corruption in a developing state is dependent upon: (1) the nature of the state's traditional society, and (2) the nature of the state's political and economic modernization processes. He offers that "[c]orruption is...one measure of the absence of effective political institutionalism" (Huntington, 1968, p. 59). Huntington further states:

Corruption varies inversely with political organization, and to the extent that corruption builds parties, it undermines the conditions of its own existence. Corruption is most prevalent in states which lack effective political parties, [and] in societies where the interests of the individual, the family, the clique, or the clan predominate. In a modernizing polity the weaker and less accepted the political parties, the greater the likelihood of corruption (Huntington, 1968, p. 71). 
Huntington's (1968) analysis also offers that not only poor economic performance, but also new surges in economic prosperity, can result in high levels of corruption in developing states.

Three major critiques can be levied toward the modernization approach. First, modernization analyses often focus on macro-level concepts that provide few causal mechanisms allowing the construction of anti-corruption programs. Second, due to the lack of causal mechanisms in modernization analyses, there are few empirical studies to support modernization theories of the causes of political corruption. Third, political and economic modernization has not reduced corruption levels in all developed states as their theories assume. For example, developed states such as Belgium, Italy, France, Spain, Japan, and the United States still experience significant levels of political corruption.

The structural-revisionist school follows closely with the modernization approach but takes a functional view toward explaining the causes of political corruption (see Leff, 1964; Nye, 1967; Huntington, 1968; Merton, 1968; Scott, 1972; and Friedrich, 1972). This school is labeled revisionist as their analyses develop that the effects of corruption may be good -offering that corruption can, at times, contribute to the adaptation and functioning of ineffective economic and political systems. Merton's (1968) analysis of US urban machines reveals how corruption develops from the functional need to provide urban citizens basic services where their public institutions are unable or unwilling to do so. Huntington (1968) also develops the possible good aspects of corruption in relation to its functional ability to facilitate a state's economic and political modernization. He argues that some political corruption can be good when it allows new groups to integrate 
into society, thereby helping build political organizations. Moralists condemn the revisionist views based on the normative stance that all corruption must be bad. Other critics of the revisionist school argue that these theorists, "often rely too much on anecdotal evidence, hypothetical cases, and speculative linkages between corruption and social outcomes" (Johnston, 1986, p. 985).

The structuralist-radical school attributes the causes of corruption to conditions of colonialism and neo-imperialism, dependency relationships between the developing and developed world, and global trends toward capitalism and liberal-democracy (see Frank, 1967; Dos Santos, 1970). The Caribbean governing elite populist discourse falls within the structural-radical view of the causes of corruption. There have been only a few scholarly Caribbean works that relate Caribbean corruption to structural-radical arguments (see Jacobs, 1978; Munroe, 1999b). Outside the Caribbean, Girling (1997) adopts a structural-radical view in arguing that corruption is a natural occurrence of the tensions rising between the self-interested approach of market-capitalism and the more egalitarian approach of liberal-democracy. Others of the structural-radical school follow a general Marxist paradigm in explaining corruption as a natural result of capitalism or of bad groups or classes, normally the state's governing elite and government bureaucrats (see Gould, 1980). One structural-radical corruption study offers "that corruption and underdevelopment are dialectically linked components of the same process, i.e., development at the periphery of the capitalist mode of production"(Gould, 1980, p. 7). Gould (1980) employs a structural-radical analysis in his case study of the early development of post-independent Zaire (1960-1979). He concludes that Zaire's rampant 
post-independence political corruption was the result of a situation where the state was almost completely "privatized by the bourgeois and petty bourgeois classes [the governing elites, military, and civil servants]" (Gould, 1980, p. 122). A major critique of the structural-radical school is that states adopting market-capitalist and liberaldemocratic systems generally have lower levels of political corruption than those adopting alternative statist or socialist systems.

Finally, the structural-culturalist school argues that the nature of a state's culture affects its level of political corruption. Huntington (1968, p. 71) raises the issue of culture as a cause of corruption when he states corruption is more prevalent "in societies where the interests of the individual, the family, the clique, or the clan predominate." $\mathrm{He}$ also hypothesizes that state's with less social polarization and greater senses of noblesse oblige will have less corruption (Huntington, 1968, p. 65). Heidenheimer $(1970,1989)$ addresses the cultural relativity problem that argues different cultures view corrupt acts quite differently. He shows that modern civic-cultured based social systems are less corrupt because they have a much stricter view of corrupt behavior than more traditional cultural systems (Heidenheimer, 1970; 24). Johnston (1983) finds that regions in the US with moralist political cultures are less tolerant of and more apt to ferret out corruption than regions with individualistic and traditionalistic political cultures. Putnam's (1993) study of democracy in Italy also provides insight as he finds that in more traditional areas where social capital is weak (Southern Italy) there are stronger and more developed systems of patron-clientelism that correlate with high political corruption levels. What is clear from the structural-culturalist literature is that there is little consensus regarding 
exactly which cultural factors should be used and where they fit in explaining the causes of political corruption.

The above literature review highlights the need for a comprehensive theory of the causes of political corruption. There are numerous challenges to building such a theory. First, the theory must transcend the agent-structure debate, incorporating the most important components of each. Second, it must address the sticky problem of cultural relativity. Third, the theory must include all important social factors that affect differing levels of political corruption. Finally, it must provide causal mechanisms that can be used to develop anti-corruption policy. This study's theory of the causes of political corruption developed in Chapter 2 addresses each of these challenges.

\section{Research Design}

This study investigates the domestic and international causes of political corruption in the Caribbean. The state or territory (per Table 1-1) is the unit of analysis for this study. This study's interest is in the causes of recurring patterns of either corrupt or non-corrupt behavior by a state or territory's governing elite. It is not assumed that all Caribbean states are corrupt, or even that all government officials in a systemically corrupt state are corrupt themselves. This study's interest is in explaining the recurring behavioral patterns, corrupt or not, of the governing elite in contemporary Caribbean states and territories. While this study does not focus on explaining individual Caribbean corruption scandals, it uses evidence of individual corruption scandals to support its analysis. 
The research design for this study includes the construction of a theory of the causes of political corruption, a historical survey of Caribbean political corruption, and investigations of political corruption in Jamaica and Costa Rica that advance the theory. The resultant theory is then used to evaluate the important puzzles about Caribbean political corruption.

Chapter 2 builds the theory of the causes of political corruption. The theory is built through the use of Onuf's (1989) rule-oriented constructivist approach to social science. The chapter first presents the constructivist analytic frame that combines the use of rational choice (agency) explanations for social behavior with the idea that agent choice is bounded by a surrounding institutional structure (i.e., a web of social rules). Onuf's constructivist theory of social rules is then used to link the agency and structural elements of the analytic frame and to highlight the mechanisms that cause political corruption.

Chapter 2 builds a middle-range theory of the causes of political corruption. It concentrates in the middle, between aggregate global (macro-level) and detailed narrowgauge (micro-level) concepts. There are strong statistical correlations between a state's political corruption levels and individual macro-level concepts such as a state's level of democracy, per capita gross national product, and dominant religion (e.g., Protestant states are less corrupt) (see Elliott, 1997, p. 183; Sandholtz and Koetzle, 2000, p. 45). While interesting, macro-level analyses do not reveal causal mechanisms that explain political corruption and are thus of little use in devising anti-corruption policies. There is little utility in telling a state that if it desires to lower political corruption levels that it 
must strengthen its democracy, increase its economic output, and convert its population to Protestantism.

There are also a number of micro-level concepts that strongly correlate with state political corruption levels (e.g., tax system efficiency, level of public sector wages, etc.) (see Tanzi, 1998, pp. 10-19). Micro-level analyses usually focus on only a small part of the much larger political corruption problem. This study's middle-level theory approach searches for causal mechanisms that spotlight broader areas for anti-corruption policy development. This middle-level approach investigates institutional structures affecting governing elite decision-making leading to corrupt or non-corrupt behaviors. The Chapter 2 analysis concludes with a synoptic table that delineates the range of political corruption behavior expected in Caribbean states and territories and associates them with consistent patterns of several social phenomena (institutions) that cause political corruption.

Chapter 3 begins this study's investigation of how colonialism and US interventions affect contemporary Caribbean political corruption levels. It does this by examining how Caribbean political and economic institutions evolved. As Putnam (1993, p. 182) highlights "[s]ocial context and history profoundly condition the effectiveness of institutions. Where the regional soil is fertile, the regions draw sustenance from regional traditions, but where the soil is poor, the new institutions are stunted." Chapter 3 starts its historical survey of institutional development and political corruption behavior in the Caribbean beginning with Christopher Columbus's first arrival in the region. It surveys institutional development and political corruption behavior in the 
colonial period and during the period of nineteenth and early twentieth century US interventions in the region. Chapter 3 ends its discussion in the 1940s, a major watershed period when the rules of political corruption changed significantly in the Caribbean.

Chapter 4 continues the historical investigation of Caribbean institutional development and political corruption. It looks at these issues from the 1950s to today. This last 50 plus year period of institutional development affects contemporary Caribbean political corruption levels the most. Chapter 4 includes a Caribbean-wide assessment of current political corruption levels, the dependent variable in this study.

Effective operationalization of the political corruption dependent variable hampers all corruption research. Past research reveals that it is impractical to measure objectively a state's political corruption levels. Transparency International (TI), a Berlinbased nongovernmental organization formed in 1993 to fight world corruption, offers:

An objective approach [to corruption measurement] is almost impossible. On the one hand, corruption involves concealed actions and data that are not revealed publicly. There exist objective data created by the justice system and the media. However, these data rather give an impression on how effective the media is in discovering and reporting about scandals and how independent and well trained the judiciary is in prosecuting. An efficient and incorruptible jurisdiction may bring about high numbers of convictions. Instead of acknowledging this, "objective" data would "punish" such a country with a bad score [in measuring corruption levels]. (Transparency International, 1996)

Over the past several years, however, TI has refined a method to measure corruption using respondent perceptions of state corruption levels. TI's annual Corruption Perception Index (CPI) is recognized as the single best measure of corruption currently available (see Lancaster \& Montinola, 1997). TI advertises their method as a poll of polls and compiles the CPI by combining their own Internet survey with 
corruption surveys conducted by Gallup and several commercial business risk analysis firms. For the period 1996-1999, the TI CPI was calculated using up to 10 different surveys (polls). The methodology employed by TI in compiling their annual CPI is deemed both reliable and valid (see Lancaster \& Montinola, 1997). The reliability and validity determinations are based upon the strong correlation among different corruption polls_correlation that remains strong despite the slightly different definitions of corruption used and the different sampling frames employed among the various surveys. Chapter 4 includes the TI CPI in its assessment of Caribbean-wide political corruption levels.

Chapters 5 and 6 advance this study's theory through qualitative disciplinedconfigurative case studies of political corruption in Jamaica and Costa Rica, respectively. Disciplined-configurative case studies use theoretically relevant general variables to test hypotheses within the cases selected. The results of each case study are then compared to the original theory, and not necessarily to other case studies, to advance the theory's value (see George, 1979; Eckstein, 1975). Qualitative methodology used in each case study includes library, archival, and periodical searches; semi-structured interviews; and survey data compiled by several academic and commercial research enterprises.

Jamaica and Costa Rica were selected for the case studies due to their diversity among both dependent and independent variables of interest in this study. Jamaica has a fairly high level of political corruption-typical of corruption levels found in many states in the Caribbean. Costa Rica, on the other hand, experiences one of the lowest political corruption levels in the Caribbean. Jamaica employs a parliamentary-democracy form of 
government, has generally fostered an open economic system, and its English language and mix of religions ( $56 \%$ Protestant) make it culturally similar to other former British states and current British dependent territories in the Caribbean. ${ }^{4}$ Costa Rica differs in that it is a republic with a presidential form of government, it retains a largely stateowned and highly protected economy, and its Spanish language and Roman Catholic religion ( $95 \%$ of citizens) make it culturally similar to other former Spanish states in the Caribbean. Jamaica approaches the status of a failed state- one unable to provide basic services to its citizens and characterized by extreme societal violence, soaring crime rates, and a failed formal economy. In contrast, Costa Rica bills itself as the Little Switzerland of the region and is known for its strong democracy, strong economy, and low crime and violence levels (compared to other regional states). The study of these two diverse Caribbean states highlights the most important factors that explain regional political corruption.

The Chapter 7 conclusion first uses the Jamaican and Costa Rican case studies to evaluate the utility of this study's interdisciplinary theory of the causes of political corruption. It next addresses the important questions regarding Caribbean political corruption raised earlier in this chapter. Chapter 7 then evaluates the contributions of this study in the larger context of corruption literature and outlines a further research program in political corruption.

\section{Limitations, Delimitations, Contributions}

This study is limited to an investigation of the causes of political corruption in the Caribbean. As such, it does not address all that is wrong with the developing states in the 
region — nor does it negate all that is right with these states (Johnston, 1998, p. 88). There is corruption in all social systems. The uncovering of corruption is "a symptom of weakness of the state.... it is an empirical window to deeper underlying problems" (Kaufmann, 1998, p. 147). As Scott (1972) concludes:

corruption, like violence, must be understood as a regular, repetitive, integral part of the operation of most political systems. In practice this simply means that an analysis of who in a society gets what, when, where, and how that relies exclusively upon an examination of those political acts open to public view would seldom provide an accurate picture of political reality. Recurring acts of violence and corruption are thus more successfully analyzed as normal channels of political activity than as cases of deviant pathology.... (Scott, 1972, viii).

Although the study of political corruption provides a means to uncover the reality of how political and economic systems work, political corruption must not be abused as an explanation for all a state's problems (Klitgaard, 1988, p. 64).

This study is delimited in several ways. First, the focus is upon political corruption and does not address, except anecdotally, bureaucratic-administrative or private corruption. To include these other areas of corruption would require a substantial expansion of the above research design. Second, this study focuses only on Caribbean states and territories. As noted earlier, expanding the study to all Western Hemispheric states would move the focus off the small and medium-sized Caribbean states where political corruption is far less studied than in the US, Canada, or the larger South American states that do not border the Caribbean Sea. Third, this study only advances and does not test its interdisciplinary theory of the causes of political corruption. Qualitative disciplined-configurative case studies, like those of Jamaica and Costa Rica in this study, constitute a preferred methodology for advancing new theories (see Ragin, 
1994, p. 51). Quantitative research designs, on the other hand, are the preferred method to test new theories (Ragin, 1994, p. 51). Because this study does not include a quantitative test of its resultant theory, it cannot be used to make specific inferences about the causes of political corruption in the Caribbean or in other regions. At best, this study allows broad generalizations about political corruption in the Table 1-1 Caribbean states and territories.

This study contributes to anti-corruption policy in the Caribbean, general corruption scholarship, and general theory development. First, it contributes to Caribbean anti-corruption policy development by explaining why current OAS anti-corruption efforts in the region are foundering. One of this study's significant contributions demonstrates that while technical anti-corruption measures (new laws and regulations, reformed accounting and contracting procedures, etc.) offered by the OAS and other intergovernmental and nongovernmental organizations are necessary to arrest the region's political corruption problems, they are not sufficient. Besides technical anti-corruption measures, an effective anti-corruption policy program must also address important social factors (i.e., political cultures and social trust) that are far more difficult to change.

Second, this study contributes to general corruption scholarship by developing an interdisciplinary theory of the causes of political corruption, one that combines both agency and structural approaches. While past scholarship has addressed separate agency and structural explanations for political corruption, this study is a unique attempt to combine interdisciplinary agency and structure concepts within one analytic frame, thereby highlighting political corruption's aggregate causal mechanisms. 
Finally, this study contributes to general theory development by advancing the rule-oriented constructivist approach to theory development (see Onuf, 1989). It develops a workable model for rule-oriented constructivist analysis. It then demonstrates the use of this model to develop middle-range interdisciplinary theories of social phenomena. The power of rule-oriented constructivism as a theory-building framework is responsible for this study being able to develop a comprehensive theory of the causes of political corruption.

\section{Endnotes}

1. OAS Inter-American Convention Against Corruption status, as of May 1, 2000:

a. OAS states not signing the 1986 Inter-American Convention Against Corruption: Antigua and Barbuda, Barbados, Belize, Dominica, Grenada, St. Kitts and Nevis, St. Lucia, and St. Vincent and the Grenadines. (All located in the Caribbean.)

b. OAS states signing but not ratifying the Convention: Brazil, Canada, Guatemala, Guyana, Haiti, Jamaica, Suriname, and the United States.

c. OAS states signing and ratifying the Convention: Argentina, the Bahamas, Bolivia, Chile, Colombia, Costa Rica, Dominican Republic, Ecuador, El Salvador, Honduras, Mexico, Nicaragua, Panama, Paraguay, Peru, Trinidad and Tobago, Uruguay, and Venezuela.

d. OAS states signing, ratifying, and complying with the Convention: None. Source: OAS (2000).

2. Scholars pointed out the effects of political corruption for several decades before the end of the Cold War. The international financial institutions, however, were some of the first to quantify the effects of political corruption discussed here.

3. Rent seeking refers to government elite activity aimed at increasing the payment for a resource over what the resource would command in a competitive market or other use (i.e., through regulations, payoffs, bribes, extortion, etc.) (see Krueger, 1974; Tullock, 1989).

4. During the Peoples National Party government of Prime Minister Michael Manley (1972-1980), Jamaica adopted a number of socialist economic features (state-ownership of enterprises, protected markets, etc.). Most of these socialist initiatives were reversed and Jamaica returned to a free market economy in the 1980s under the leadership of Jamaica Labor Party Prime Minister Edward Seaga. 


\section{Chapter 2}

\section{A Theory of Political Corruption}

This chapter builds an interdisciplinary theory of the causes of political corruption using Onuf s (1989) rule-oriented constructivist approach to social analysis. It first presents the rule-oriented constructivist analytic frame. Second, using the constructivist theory of social rules, differing normative and behavioral perspectives of the political corruption phenomenon are developed. Third, these normative and behavioral perspectives are included in a rational choice agency analysis that partially explains the recurring political corruption patterns expected among states. Fourth, this chapter advances the structural rule-sets (institutions) that also affect varying levels of political corruption. Finally, the constructivist agency and structural analyses are combined into a synoptic table that summarizes the relationships of the various social phenomena that cause political corruption behavior.

This chapter highlights the complexity of political corruption analysis. The first major corruption analytic issue addressed in this chapter is the problem of cultural relativity that argues how distinct cultures define and perceive political corruption quite differently. The political corruption work of Heidenheimer $(1970,1989)$ is used to overcome the cultural relativity problem in this chapter's constructivist analysis. A second major corruption analytic issue concerns the need to identify the most important social phenomena that must be included in an interdisciplinary theory of the causes of political corruption. Here Johnston's (1994) work in developing a comparative theory of political corruption is used. Johnston's work identifies the majority of important 
institutional phenomena that cause political corruption. This chapter highlights the value of the constructivist analytic frame and its ability to link several seemingly unrelated single-discipline theories, such as those of Heidenheimer and Johnston, and develop synthesized interdisciplinary theories with strong explanatory powers.

\section{The Constructivist Analytic Frame}

The rule-oriented constructivist framework developed by Onuf (1989) in his book World of Our Making provides its own ontological approach to social analysis. Ruleoriented constructivists (hereafter just constructivists) believe that reality is affected by both social and material factors and that the properties of agents and structures are both relevant to explanations of social behavior.' ${ }^{1}$ Constructivism is not a theory in itself, but provides an analytic framework that guides the development of theoretical propositions. Methodologically, Onuf's constructivism supports the application of natural science methods to social science analyses and the importance of empirically validating its theoretical explanations.

Onuf's constructivism emphasizes the complexity of social reality, the multiplicity of causal factors at work in social processes, and the constitutive power of language, including the language any agent (observer) uses to characterize social reality. He also emphasizes that theories are always partial, explanations always contestable, and propositions never fully free from normative implications. He believes that these conditions may make it necessary for scholars to tell suggestive stories and use interpretive methods - and he insists that scholars should be modest in making claims on 
behalf of their stories, theories, methods, and conclusions (N. Onuf, personal

communication, July 10, 2000).

A principal constructivist tenet is that people (agents) and society (structure) co-

constitute (construct) each other in a continuous process. Onuf explains this tenet best:

General prescriptive statements, hereafter called rules, are always implicated in this process [the co-constitution of agents and structure]. Rules make people active participants, or agents, in society, and they form agent's relations into the stable arrangements, or institutions, that give society a recognizable pattern, or structure. Any change in a society's rules redefines agents, institutions, and their relation to each other; any such change also changes the rules, including those rules agents use to effectuate or inhibit changes in societies. (Onuf, 1997b, p. 7; emphases in original.)

To constructivists, institutions are individual social rules, or sets of rules, established in consonance with material realities. Theoretical explanations emerge from the analysis of the interaction of social rules, agents, and material resources.

Constructivists analyze how these interactions cause individual behavior by providing agents with direction and incentives for action (Adler, 1997, p. 329). Social rules provide the key linkage between agency and structure and help identify the causal mechanisms in constructivist analyses.

Figure 2-1 presents a synthesized model of the constructivist analytic frame. The model consists of both internal (agency) and external (structural) worlds. The internal world constitutes the agent's decision-making (agency) processes. The external world constitutes the institutional structure (social rules and patterns of unintended consequences) that bounds the internal world of agent decision-making. Also included in the external world are material resource factors (routine and extraordinary) that affect agent information regarding expected benefits and costs leading to agent behavior. 
Another way to look at Figure 2-1 is as a complex melange of factors that define agent willingness (internal world) and opportunities (external world) that may cause the agent behavior under investigation. Figure 2-1 also displays a feedback loop that symbolizes how agent behavior affects both the institutional structure and agent decision-making processes (i.e., the constructivist process of co-constitution).

Figure 2-1. The Constructivist Analytic Frame

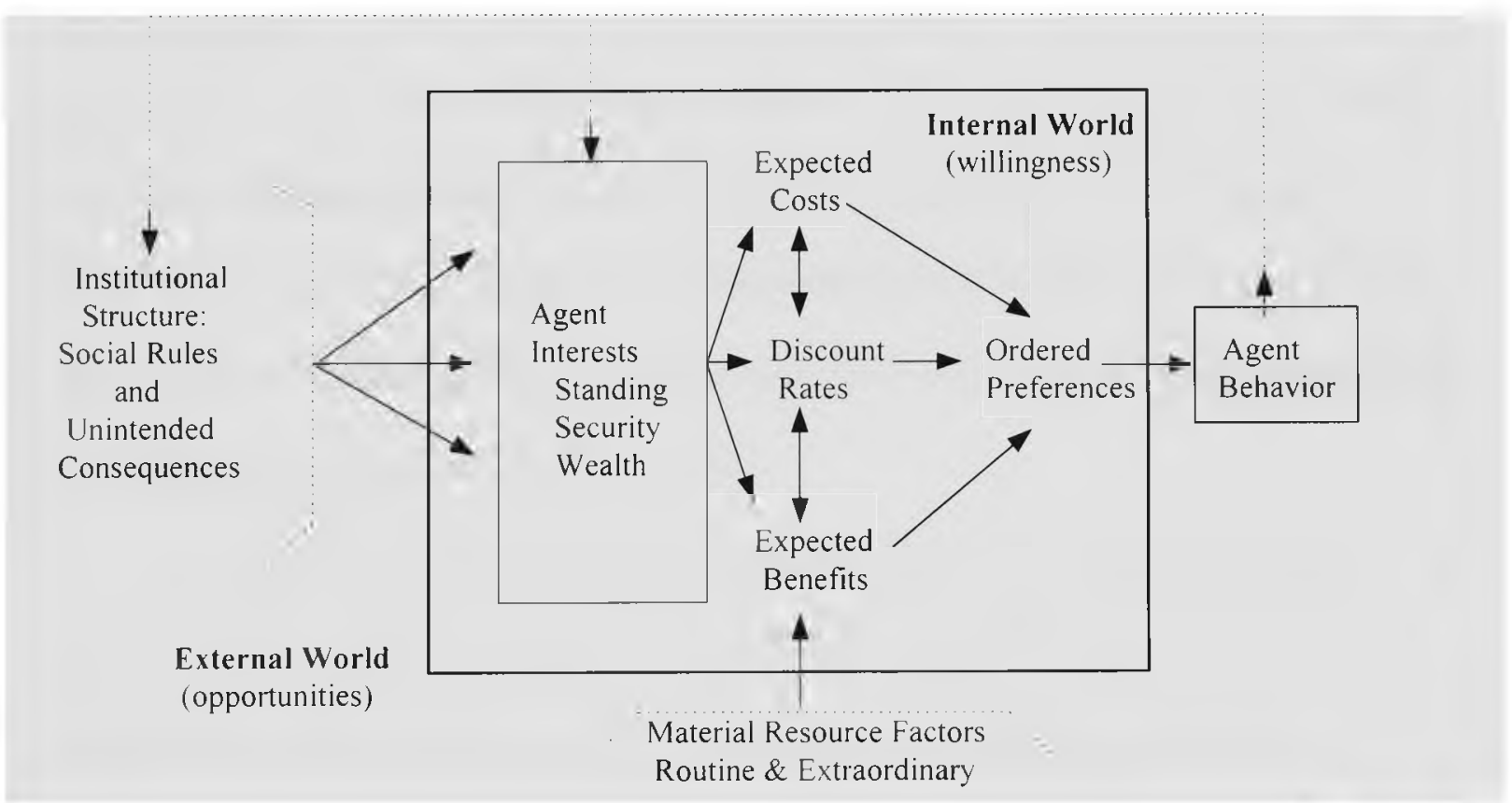

Source: Developed from Onuf (1989); Ostrom (1990); and Ostrom et al. (1994). ${ }^{2}$

The Figure 2-1 internal world displays the basic components of a rational choice decision-making process. Constructivism embraces rational choice theory and its subfield of game theory as methods for analyzing agent decision-making (see Onuf, 1989, chap. 8). Game theory assumes that agents are rational, meaning they choose the best means to gain a predetermined set of ends (Morrow, 1994, p. 17). The term agent in this study is used generically to refer to either an individual agent making decisions for 
himself/herself; a group leader with decision-making (agency) power for the entire group; or a group of individuals (e.g., governing elite) assumed to exhibit similar behaviors, i.e., act as one agent. Game theory assumes that agents are able to order their preferences based upon their evaluation of costs, benefits, and discount rates present in a decision situation. It also assumes that agent preference orderings are complete and transitive. ${ }^{3}$ Expected costs and benefits are determined by either material (money, property, etc.) or social (reputation, love, probability of arrest, probability of job loss, etc.) factors. Agent proclivity to accept risks to achieve certain goals is included in the expected cost-benefit analysis. Discount rates capture agent impatience for payoffs, i.e., do they want the benefits now or are they willing to wait? The constructivist analytic frame employs these general tenets of non-cooperative game theory to show how agent decision processes lead to a final agent behavior (see Morrow, 1994).

Social rules provide the linkages between the Figure 2-1 internal and external worlds. Onuf's constructivist theory of social rules helps establish these linkages (see Onuf, 1989, 1997a, 1997b). Table 2-1 summarizes the key components of the constructivist theory of social rules used in this study. Social rules tell people what they should do, what they must do, and what they have a right or duty to do. When agents fail to follow rules, other supporting rules bring consequences. Considering their material circumstances, agents follow or disregard rules to achieve their goals. The term institution in this study refers to patterns of stable rules. Structure is a stable pattern of rules, institutions, and their unintended consequences. 
Table 2-1. Constructivist Theory of Social Rules ${ }^{4}$

\begin{tabular}{lccc}
\hline Dominant Social Rules & Instruction & Directive & Commitment \\
Rule's Purposes & Principles, beliefs & Specificity, sanctions & Create roles \\
Rule's Function: What agents: & should do. & must do. & right/duty to do. \\
Agent Interests & Standing & Security & Wealth \\
Forms of Societal Rule & Hegemony & Hierarchy & Heteronomy \\
\hline
\end{tabular}

Source: Onuf (1989)

Constructivists offer that complex institutions, like political corruption, consist of a constantly changing mix of three different categories of social rules (see Onuf, 1989; and Table 2-1). Each of the three categories of social rules has distinct purposes and functions. ${ }^{5}$ First, instruction rules delineate the principles and beliefs that inform agents of an institution's purposes. Instruction rules tell agents what they should do. Second, directive rules provide specificity to the instruction-ruled principles and beliefs. Directive rules support instruction rules by telling agents what they must do. However, for directive rules to be effective, they must be supported by other rules (sanctions) that stipulate the consequence if an agent does not follow a particular rule. Third, commitment rules create roles for agents. Commitment rules tell agents what they have a right or duty to do. Commitment rules give some agents well-defined powers, while ensuring other agents that those powers will not be abused. How well these three categories of rules perform their assigned function depends upon their strength and formality. A rule's strength is determined by how frequently agents follow the rule. A rule's formality refers to a variety of conditions that set the rule apart and emphasize its importance. 
The three categories of rules influence an agent's principal interests in Figure 2-1 internal world decision-making situations (see Onuf, 1989, chap. 8). Onuf offers that there are three principal interests that govern all social decision-making behaviorstanding, security, and wealth (Onuf, 1989, p. 258). Every agent rational decisionmaking process includes consideration of all three of these interests, however, one interest always dominates the final behavior or decision based upon the situation's surrounding structure.

Where instruction rules dominate the decision-making situation, the agent's principal interests are his/her standing among other agents. Standing entails an agent's status or reputation among other agents and engenders feelings of esteem or envy. Where standing is the agent's principal interest, the agent compares his/her situation with that of several other agents and then orders his/her behavioral preferences so he/she can be the best among agents.

Where directive rules dominate a decision-making situation, the agent's principal interests are security. Security as an interest presents the agent with an awareness of threat (e.g., war, physical threat, job security, etc.). Where security is the agent's principal interest, the agent compares his/her situation to that of one other agent (the one presenting the threat) and then orders his/her behavioral preferences so he/she can be the winner between agents.

Where commitment rules dominate a decision-making situation, the agent's principal interests are wealth. Wealth as an interest presents the agent access to items of value, either tangible (money, land, property, health, etc.) or intangible (love, education, 
human rights, etc.). Where wealth is the agent's principal interest, the agent's

comparison is internal, meaning the agent looks within himself/herself for the desired

level of wealth. In an agent's wealth calculations, the situations of other agents are seen only as resources for or obstacles to the agent's ordering of his/her preferences to get as much as I need or want.

The three categories of rules also foster three distinct forms of rule-or methods that govern society. While all three categories of rules exist in every society, those societies with a higher proportion of instruction rules are ruled by hegemony. The concept of hegemony used here follows the analysis of Gramsci who argues that a governing class has to persuade other classes in society to accept its moral, political, and cultural values, making a society's ideology central to the characteristics of its governing system (see Gramsci, 1971). As Onuf describes:

Hegemony refers to the promulgation and manipulation of principles and instructions by which superordinate powers monopolize meaning which is then passively absorbed by the subordinate actors. These activities constitute a stable arrangement of rule because the ruled are rendered incapable of comprehending their subordinate role. They cannot formulate alternative programs of action because they are inculcated with the self-serving ideology of the rulers who monopolize the production and dissemination of statements through which meaning is constituted (Onuf, 1989, pp. 209-210).

Societies with a higher proportion of directive rules are ruled by hierarchy. Onuf offers:

Hierarchy is the paradigm of rule most closely associated with Weber because, as an arrangement of directive rules, it is instantly recognizable as bureaucracy. The relations of bureaux, or offices, form the typical pattern of super- and subordination, but always in ranks, such that each office is both subordinate to the one(s) above it and superordinate to the ones below... The visualization of this arrangement of ranks linked by directives is the familiar pyramid of organization charts (Onuf, 1989, pp. 211). 
Finally, societies with a higher proportion of commitment rules are ruled by heteronomy. The use of this term is traced to Kant who referred to heteronomy as a condition of not having autonomy (see Onuf, 1989, p. 212). Heteronomy defines a condition where rational decision-makers are never fully autonomous, and whose decisions toward particular ends are bounded both by societal rules and their material means. Commitment rules stipulate promises by some agents, promises that become the rights (i.e., promises kept) of other agents. Conditions of formal and strong commitment rules massively restrict agent autonomy.

Theories explaining social behavior are built using the Table 2-1 constructivist theory of social rules in conjunction with the Figure 2-1 constructivist analytic frame. This chapter next develops a middle-range interdisciplinary theory of the causes of political corruption using the above constructivist framework. The theory concentrates in the middle, between aggregate macro-level and detailed micro-level concepts. The objective is to isolate middle-level rule-sets (institutions) associated with the political corruption concept. From this analysis a set of coordinates (synoptic table) of social phenomena emerges that explains the recurrence of consistent patterns of political corruption behavior.

\section{A Political Corruption Agency Analysis}

Constructing the Normative Principle. The instruction-ruled principles governing political corruption can be traced to the republican thought of ancient Greece and Rome and their preoccupation with ensuring liberty and justice while resisting corruption. 
Resisting corruption meant resisting forms of government that served selfish private interests rather than the common good (Wilson, 1989, p. 1). Aristotle (384-324 BC) offers:

The true forms of government, therefore, are those in which the one, or the few, or the many, govern with a view to the common interest; but governments which rule with a view to the private interest, whether of the one, or of the few, or of the many, are perversions (Aristotle, 1943, p. 298).

Corruption was also a topic central to Machiavelli's (1469-1527 AD) discourses on virtu (civic morality) in republican government (see Machiavelli (1970); Dobel (1978); and Onuf, 1998, pp. 44-47). In analyzing Machiavelli’s works, one analyst offers:

One dimension of [Machiavelli's] political corruption is the privatization both of the average citizen and those in office. In the corrupt state, men locate their values wholly within the private sphere and they use the public sphere to promote private interests (Shumer, 1979, p. 9).

Rousseau (1712-1778 AD) also embraced the idea that government officials, selected by the people to manage society's business, must carry out their duties in a manner transcending personal interests (Rousseau, 1978, pp. 59-64). Noonan's (1984) historical treatise on bribery and corruption reveals that as the concept of official bribery developed from ancient times, it became correlated ever closer with the idea that public officials must put aside their private interests when dealing with public matters. In his treatise's conclusion Noonan offers:

The notion of fidelity in office, as old as Cicero [Roman, 106-43 BC], is inextricably bound to the concept of public interest distinct from private advantage. It is beyond debate that officials of the government are relied upon to act for the public interest distinct from private advantage (Noonan, 1984, pp. 704). 
As Western ideas of good governance evolved, a primary anti-corruption instruction rule emerged asserting the normative principle that public officials must separate their public duties from their private interests. Nevertheless, the directive and commitment rules that different societies developed to support this fundamental anticorruption instruction rule vary widely. This is referred to as the cultural relativity problem in studying political corruption-the very real problem that behavior seen as corrupt in one culture may not be seen as corrupt in another. ${ }^{6}$

The Role of Political Culture. Mexican Nobel laureate Octavio Paz once remarked "[t]he Rio Grande marks the divide 'between two distinct versions of Western civilization.' In the Anglicized north the work ethic, enterprise, the critical spirit, democracy, and capitalism prevail...in the Iberian south, hierarchy, ritualism, centralism, orthodoxy, and patrimonialism reign..." (quoted in Leiken, 1996, p. 64). Paz thus highlights some of the differences in the cultures of the Western Hemisphere.

Different cultures view political corruption in far different ways. In its most general sense, culture defines the social rules surrounding lifestyles, beliefs, customs, and values that influence a society's pursuit of its goals. Political culture, a sub-set of overall culture, defines the general process used by a society to reach its political goals (i.e., decisions about who gets what, when, and how (see Lasswell, 1950)). Classifying political cultures includes determining how a society is politically organized, both formally and informally; how political decisions are made; how political power flows within the societal organization; how both the governing elite and the mass citizenry view 
their roles in politics; and how citizens interact, both with the government and among themselves, to reach their political goals (see Diamond, 1993).

Since Almond and Verba's (1963) groundbreaking work The Civic Culture first associated culture and modernization, there have been many scholarly attempts to both classify differing political cultures and to use political culture as an independent variable explaining corruption (see Huntington, 1968; Scott, 1972; Johnston, 1983; Putnam, 1993). A synthesis of the political culture literature reveals three principal categories of political cultures-collectivist, individualistic, and egalitarian. ${ }^{7}$ Understanding the mix of social rules that constitute these three categories of political cultures is a first step in understanding the varying views of political corruption in different societies.

Collectivist (traditional) cultures generally exist in states with hegemonic forms of rule and are dominated by instruction rules. Collectivist societies are simple and segregated. Social and economic transactions in collectivist societies are organized around small groups defined by familial, kinship, tribal, ethnic, religious, class, linguistic, or other social relationships. Each group tends to have its own narrow base of interests. Paternalism is the main intra-group controlling concept in collectivist cultures, i.e., the father or group leader decides what is best for the family or group. The best interest of the group is the single most important governing rule in collectivist societies. Loyalty to the group and maintaining the traditional status quo are other important rules in collectivist cultures. With most social and economic transactions carried out within groups (intra-group), inter-group social trust in collectivist cultures is extremely weak. 
Paz's description of the Western hemisphere's Iberian south corresponds to the characteristics of collectivist cultures that exist in most Caribbean states.

Collectivist political cultures place power in the hands of a small and selfperpetuating governing elite who often inherit the right to govern through family ties or social position (Elazar, 1966, pp. 92-93). The hegemonic rule in collectivist states is often personalistic. The method of rule often relies on strong patron-client systems of informal reciprocity, where the clients (citizens or specific groups) pledge their economic and political support to patrons (governing elite) for access to government resources (see Klitgaard, 1988, pp. 69-74). Political competition in collectivist societies is primarily among the small group of self-perpetuating governing elite. Politics is considered a privilege in collectivist political cultures and those active in politics are expected to benefit personally from their efforts. Collectivist polities are centrally organized with the powerful governing elite constituting the central core of the most dominant societal group. The rule of law is weak in collectivist political cultures, focused primarily on controlling the masses and offering little accountability for the governing elite.

Individualistic cultures exist in hierarchical ruled states and are dominated by directive rules. Individualistic societies are more integrated and complex than collectivist societies. Within individualistic cultures, social and economic transactions are conducted among people from different groups. Individuals frequently shift from one group to another and have a broader range of interests. Individual self-interest is the governing rule of these cultures. The need to interact with persons from other groups in order to serve one's own self-interest results in a moderate level of social trust. Characteristics of 
individualistic cultures are found among the stronger democratic states in the Caribbean, i.e., Costa Rica and in a few of the Anglophone Caribbean states.

Individualistic political cultures view government as strictly utilitarian-to provide those functions demanded by the citizens it serves (Elazar, 1994, pp. 230-232). Individualistic political cultures see politics as a business - another means by which individuals can improve themselves socially and economically. Political competition revolves around individual attempts to gain and maintain political or economic power. Politicians in individualistic societies are more interested in public office as a means for self-interested advancement than as a chance to build a better society. Political life in individualistic political cultures is based upon systems of mutual obligation rooted in personal relationships. These systems of mutual obligation are usually harnessed through the interactions of political parties and interest groups. Citizen participation in political decision-making is conducted through networks of political parties and interest groups that attempt to influence government policy. Patron-client relationships generated by the system of political parties, interest groups, and large government bureaucracies emerge in individualistic political cultures. Individualistic political cultures are extremely legalistic. However, the rule of law, while stronger than in collectivist societies, remains focused primarily on controlling the masses and generates only limited accountability for the governing elite.

Egalitarian (civic) cultures are ruled by heteronomy and are dominated by commitment rules. Egalitarian societies are the most integrated and complex. Social and economic transactions in egalitarian cultures are conducted widely among a variety of 
differentiated groups. Individuals belong to several political, economic, and social groups and have a large array of interests. Due to the widespread horizontal interactions across differentiated groups, high levels of social trust develop in egalitarian cultures. Egalitarian cultures characterize Paz's Anglicized north and are generally found in states receiving both their population stream and political ideology from Northern Europenone of which exist in the Caribbean.

Egalitarian political cultures see politics as a public activity centered on the idea of the public good and devoted to the advancement of the public interest. The search for the common good is the controlling rule of politics. Egalitarian political cultures view politics as healthy and promote the wide-scale involvement of civil society in political decision-making. Egalitarian political officials vie for power just as those in other societies; however, their ultimate objective is not self-interested advancement but the search for the good society. Egalitarian political cultures flatly reject the notion that politics is a legitimate realm for private economic enrichment. While political parties and interest groups exist in egalitarian political cultures, their influences on political decisionmaking are weaker and they have less impact on government policy than in individualistic societies. Political competition is focused on societal issues. Egalitarian government structures are organized hierarchically, however, their bureaucracies tend to be smaller than similar sized individualistic societies and their political decision-making processes tend to be more horizontal, including both public and private groups. The rule of law is strong in egalitarian political cultures, applying equally to the masses and governing elite. 
The Behavioral Realities. Each of the above three types of political culturescollectivist, individualistic, egalitarian—generates different normative perceptions about corrupt behavior. Heidenheimer (1970, pp. 18-28) provides a useful method for understanding these differences. He classifies differing cultures' perceptions regarding political corruption along a normative continuum using three color-coded categoriesfrom white, to gray, to black. White corruption indicates that the majority of both elite and mass opinion would probably not support attempts to punish a particular governing elite behavior. Gray corruption indicates that some societal elements, either the elite or certain mass groups, may want to see a particular governing elite behavior punished, while others may not, and the majority of elite and mass opinion may well be ambiguous. Black corruption indicates that the majority of both the elite and masses would condemn a particular governing elite behavior and want it punished. Table 2-2 lists 10 types of behavior commonly associated with Western conceptualizations of political corruption and rates each in terms of its incidence and evaluation (white/gray/black) across the three classifications of political culture. The table was compiled from a content analysis of corruption literature by Heidenheimer (1970) that was updated and adapted for this study. The table highlights the cultural relativity problem in studying political corruption. 


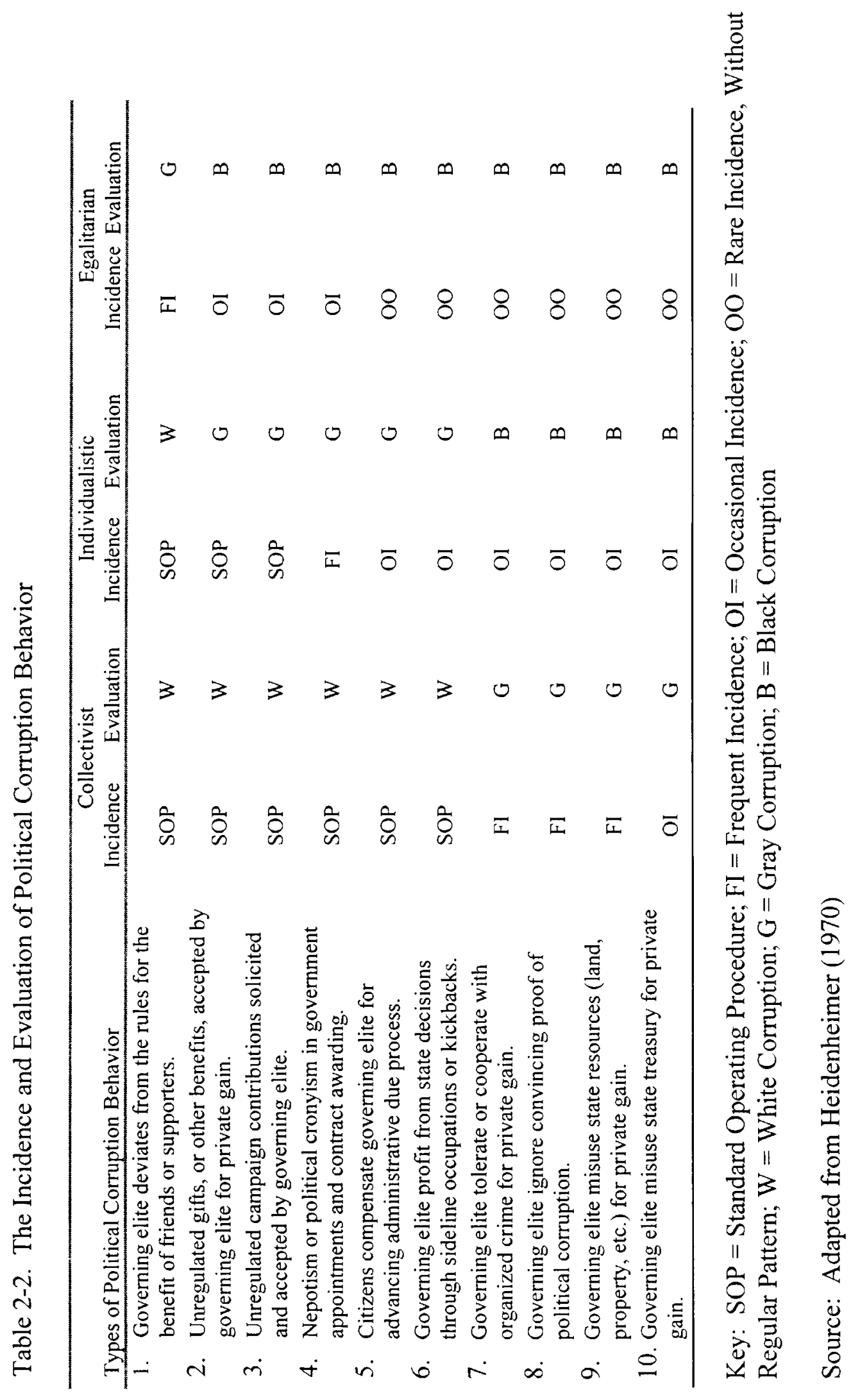


The Table 2-2 types of political corruption behavior range from minor deviations from the rules to benefit friends and supporters, to outright theft from the public treasury. The table reveals a significant variance in both the incidence and evaluation of political corruption across different political cultures. Collectivist political cultures have the most frequent incidence of the listed behaviors and the weakest (predominantly white) evaluation of the behaviors being corrupt. Egalitarian political cultures have the least frequent incidence of the listed behaviors and the strongest (predominantly black) evaluation of the behaviors being corrupt. Individualistic political cultures fall between the collectivist and egalitarian categories with moderate (predominantly gray) evaluations of the behaviors being corrupt. Another way to use Table 2-2 is as a method to evaluate the boundaries that separate a governing elite's public duties from their private interests - rated as weak (white), moderate (gray), or strong (black). The Table 2-2 results can also be used in a Figure 2-1 internal world (agency) analysis to help predict the conditions that lead to different corruption patterns. This analysis takes the form of a rational choice Political Corruption Game.

The Political Corruption Game. The objective of the Political Corruption Game is to delineate the range of a governing elite's corrupt behavior by presenting a game-theoretic analysis of the Figure 2-1 internal world agent decision-making process. The Political Corruption Game develops the range of a state's political corruption patterns as a series of game equilibriums (solutions) that identify differing levels of potential political corruption (see Calvert, 1995, pp. 58-59). The game includes an analysis of both 
governing elite and citizen behavior. As an iterated (repeat play) game, the Political Corruption Game highlights the long-term strategic advantage in resources some agents seek to gain vis-à-vis other agents-distributional effects that become institutionalized by governing elite rule-making power (Knight, 1992, p. 40). ${ }^{8}$

The Political Corruption Game includes three groups of players: the governing elite and two groups of citizens, A and B. The game assumes that the governing elite's primary goal is to remain in office, with a secondary goal to maximize their share of the state's social surplus. The social surplus is an abstract concept defining a state's political, economic, and cultural resources or products that are available for distribution among public and private entities (see Weingast, 1997, p. 247). Social surplus includes not only a state's economic product generated from private or state resources, but also basic citizen rights, e.g., human rights, free and fair elections, economic freedom, access to government services, press freedom, religious freedom, etc., that are products of the state's political and cultural systems.

The two citizen groups, $\mathrm{A}$ and $\mathrm{B}$, represent the most important groups in a state that compete for state resources. This could include a variety of political (political parties, state bureaucracies, security forces, etc.), economic (commercial sector, financial sector, etc.), or cultural (ethnic groups, religious groups, etc.) groupings. The exact combination of citizen groups competing for state resources differs among individual states. For example, in Trinidad and Tobago, the citizen groups would represent the two major ethnic groups (Afro-Caribbean and East Asian). In Haiti, the groups would represent the commercial and financial (business) elite on one hand and the poor mass 
citizenry on the other. It is assumed that the primary goal of citizen groups is to maximize their share of the social surplus. The game assumes that if the governing elite lose the support of both citizen groups, they lose office by either electoral defeat or forced removal. It is also assumed that the governing elite retain office if they maintain the support of at least one citizen group. Thus, the citizenry exert some leverage over the governing elite's hold on power.

The game assumes that the governing elite and both citizen groups have values and beliefs about the nature of political corruption (per Table 2-2). This does not assume that there is a societal consensus about political corruption. There may be differences in perceptions concerning political corruption both among and within groups of players. It is assumed that sufficient political, economic, and cultural rules (institutions) exist to provide a minimal level of social surplus. How players share in the quantities and distribution of social surplus depends upon their interactions in the Political Corruption Game.

The Political Corruption Game begins with the governing elite holding political power. The governing elite move first and have strategies to: (1) transgress against both citizen groups (A and B), (2) transgress against only one citizen group (either A or B), or (3) not transgress against either citizen group. A transgression signifies that the governing elite engage in corrupt behavior (e.g., per Table 2-2) such that the citizen groups transgressed against lose social surplus while the governing elite gain social surplus. By holding power and moving first, the governing elite have the opportunity to gain social surplus at the citizens' expense, e.g., from the full range of Table 2-2 
behaviors. When the governing elite transgress against the citizen groups, there is a resultant social surplus loss, reflecting the potential destruction of political, economic, and cultural resources due to the governing elite's corrupt behavior-an assumption consistent with recent corruption research findings that demonstrate corruption degrades a state's economic and political growth (see Mauro, 1995, 1996, 1997; Tanzi and Davoodi, 1997, 1998; Tanzi, 1998). Citizen groups A and B move second. The citizen groups move simultaneously and may either (1) acquiesce, or (2) challenge the governing elite's transgressions (corrupt behavior). Citizen groups lose social surplus if they challenge the governing elite.

The Political Corruption Game is diagrammed in Figure 2-2. Total social surplus is maximized in Figure 2-2's Subgame 4 (upper left cell) where there are no governing elite transgressions (corrupt behavior) and neither citizen group challenges, indicated by the governing elite receiving 2 units of social surplus and each citizen group receiving 8 . This acknowledges that the governing elite receive some minimal social surplus ( 2 units) from holding power. The Subgame 4 (upper left cell) payoff is Pareto-optimal for the citizen groups, as there is no other payoff position where both groups are better off. This Pareto-optimal payoff is the starting point for calculating all other Figure 2-2 payoffs. 
Figure 2-2. The Political Corruption Game

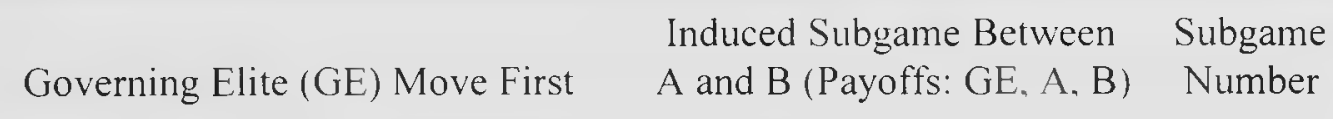

B

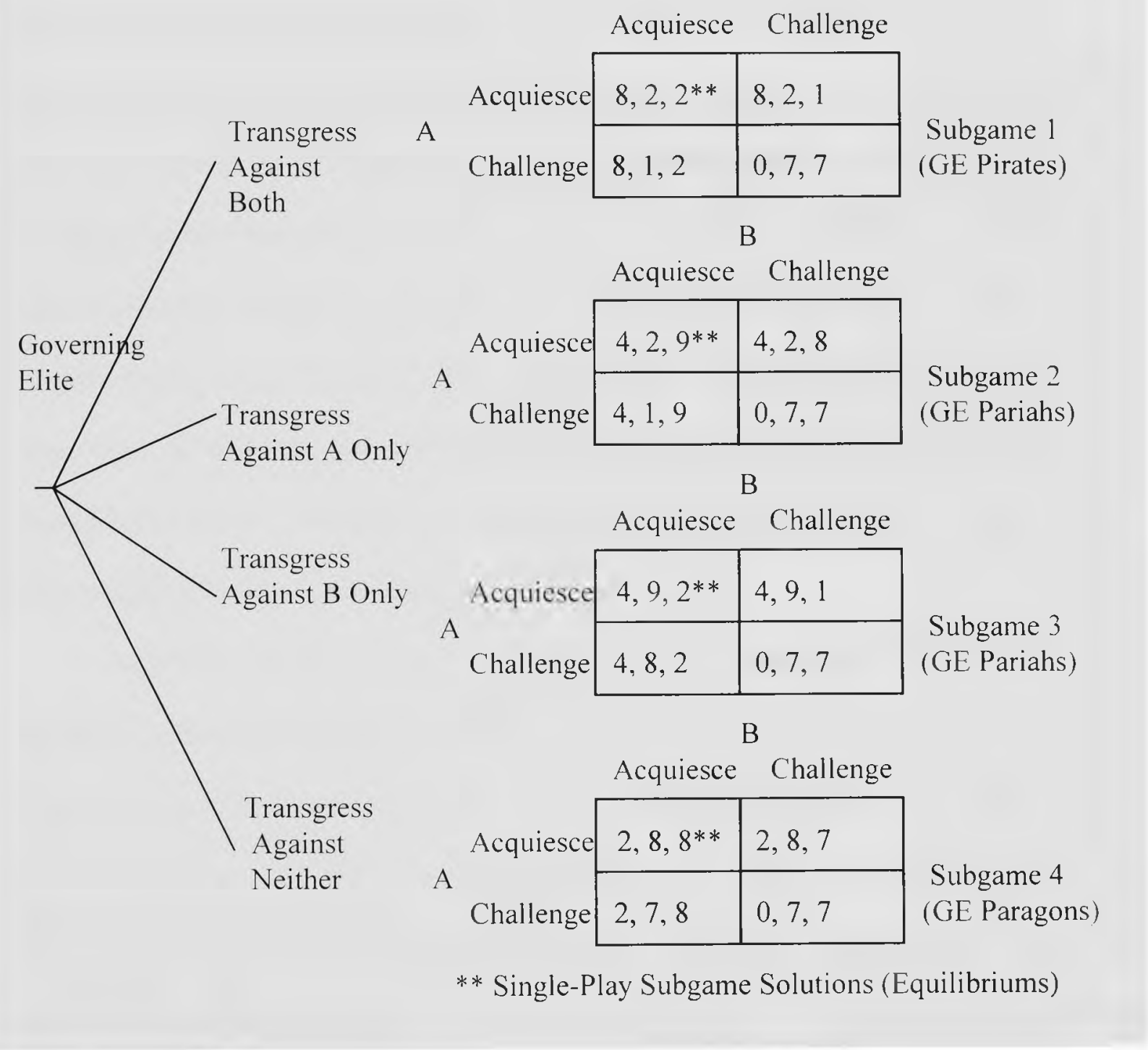

Political Corruption Game social surplus distributional consequences begin when the governing elite transgress against one or both citizen groups, and the citizen groups begin to challenge the transgressions. The governing elite lose 2 units of social surplus 
whenever both citizen groups challenge their behavior, indicating removal of the governing elite from power. The governing elite increase their social surplus payoff for each citizen group they transgress against. Corrupt behavior destroys half of all social surplus involved. When the governing elite successfully transgress against both citizen groups (Subgame 1), it costs each citizen group 6 units of social surplus ( 3 go to the governing elite and 3 are lost). When the governing elite successfully transgress against only one citizen group (Subgames $2 \& 3$ ), the other group shares some of the benefits in exchange for their support (not challenging) the governing elite. Where the governing elite successfully transgress against only one group, that group loses 6 units of social surplus, the governing elite gain 2 , the citizen group not transgressed against gains 1 , and 3 are lost. All challenges to governing elite transgressions cost the group challenging 1 unit of social surplus. The Figure 2-2 payoffs for the Political Corruption Game are determined by the strategies employed by the three players.

In the iterated (repeat play) version of the Political Corruption Game, the "folk theorem" solution scheme applies, meaning that virtually any outcome shown in the Figure 2-2 payoff matrixes can be sustained as an equilibrium (solution). On closer analysis, however, the Political Corruption Game reveals several important lessons. The structure of the game highlights that overcoming governing elite transgressions (corrupt behavior) is essentially a coordination problem among citizens. The governing elite fail in their transgressions whenever citizen groups cooperate and both challenge the governing elite's corrupt behavior. When a coordination mechanism does not exist between citizen groups and players have only the past history of citizen group moves on 
which to base their strategies, when players have a sufficiently high discount rate (i.e., they are interested more in short-term than long-term gains); and when there are opportunities for citizen groups to punish one another as this game structure allows; the following are the Pareto-optimal (best payoff) strategies for each player in an iterated game (see Weingast, 1997, p. 250):

Governing Elite: If either $\mathrm{A}$ or $\mathrm{B}$ has ever acquiesced to a transgression, the governing elite should transgress against both $\mathrm{A}$ and $\mathrm{B}$. Otherwise, if $\mathrm{A}$ and $\mathrm{B}$ have always challenged transgressions, the governing elite should not transgress against either group. (With this strategy the governing elite have the most certainty of obtaining their largest payoff ( 8 units of social surplus) while still protecting their hold on power.)

Group A: If $\mathrm{B}$ has challenged every previous transgression by the governing elite, then A should challenge if the governing elite transgress, otherwise A should acquiesce. If $\mathrm{B}$ has acquiesced to a previous transgression by the governing elite, then A should always acquiesce. (This strategy provides A its best payoff chances.)

Group B: If A has challenged every previous transgression by the governing elite, then B should challenge if the governing elite transgress, otherwise B should acquiesce. If $\mathrm{A}$ has acquiesced to a previous transgression by the governing elite, then B should always acquiesce. (This strategy provides B its best payoff chances.)

The above Pareto-optimal strategies highlight that unless a citizen group is certain that the other group will challenge a governing elite transgression, then the best citizen group strategy is to always acquiesce. Citizen group acquiescence is also always the best strategy when the governing elite are certain of the citizen group moves. In fact, when the ruling elite are confident of citizen group reactions to their first move, the single-play subgame solutions present the most likely multiple equilibriums for the overall game as shown by the solution analysis of each subgame. 
Elite Pirates and Systemic Corruption. In a single-play Political Corruption Game, Subgame 1 is similar to the classic Prisoner's Dilemma (PD) game (see Morrow 1994: 77-81). In Subgame 1, citizen groups receive higher social surplus payoffs (7 units) if they coordinate their behavior and both challenge the governing elite's transgressions. However, without a coordination mechanism-some type of binding agreement among the citizens--Subgame 1 has a dominant strategy solution where both citizen groups are better off acquiescing to the governing elite's corrupt behavior. When the governing elite are relatively certain at least one citizen group will not challenge a transgression against both groups, their optimal strategy is to transgress against both groups (i.e., engage in the most Table 2-2 corrupt behaviors). When Subgame 1 conditions exist, the governing elite most likely rule by hegemony and a collectivist political culture exists.

In a hegemonic-ruled society with a collectivist political culture, the principal interest of the governing elite is standing (reputation). With hegemonic control over their society, the interest in standing concerns the governing elite's position in relation to the governing elite in other societies. Here standing is measured primarily by the political power a governing elite wields and the tangible wealth (land, property, armed forces, etc.) it controls. Subgame 1 and Table 2-2 collectivist conditions provide the governing elite the maximum opportunities to extract wealth (social surplus) from their society. Hegemonic governing elite have only minimal worries about security (i.e., threats to their political power) as they have either ideological or coercive control over their society's masses. ${ }^{9}$ They also do not have to worry about tangible wealth accumulation—as with little or no sustained elite or mass opinion against governing elite corrupt behavior (per 
Table 2-2), the governing elite are free to extract unlimited resources from their society to support their personal quests for standing among other governing elite. Thus, in hegemonic-ruled societies with collectivist political cultures, the governing elite are most likely to act as pirates-social predators free to exploit their own societies and to pillage the resources they need to achieve or maintain standing. ${ }^{10}$ Such corruption is categorized as systemic, "a situation in which the major institutions and processes of the state [society] are routinely dominated and used by corrupt individuals and groups, and in which many people have few practical alternatives to dealing with corrupt officials" (Johnston, 1998, p. 89). ${ }^{11}$

Elite Pariahs and Institutional Corruption. In a single-play Political Corruption Game, Subgames 2 and 3 exhibit asymmetrical solutions. In each of these subgames, as a result of one group sharing in the governing elite's transgression against the other group, the citizen group not transgressed against has a dominant strategy to always acquiesce. Knowing that the group not transgressed against will always acquiesce (and will even support the governing elite in its corrupt behavior), the citizen group transgressed against will also always acquiesce to the governing elite's corrupt activity. Again, as with Subgame 1, the Subgame 2 and 3 dominate solutions can only be overcome by coordination between both citizen groups. However, because of the high social surplus payoff ( 9 units) to citizen groups not transgressed against, the Subgame 2 and 3 solutions are extremely robust. The citizen group allying with the governing elite and receiving an extra share of the social surplus in these subgames has no incentive to coordinate with the other citizen group. Therefore, constructing citizen coordination mechanisms when the 
governing elite transgress against only one group is extremely difficult. Because the Subgame 2 and 3 solutions are so robust, in the iterated Political Corruption Game these solutions are considered the game's natural equilibriums, i.e., the most likely to occur in a world of self-interested agents. Once a Subgame 2 or 3 equilibrium is reached in an iterated game, that equilibrium will persist as the citizen group not transgressed against is likely to resist building any coordination mechanism with the other citizen group. On the other hand, having established coordination with one citizen group, and knowing the other will always acquiesce, makes transgressing against only one citizen group an optimal governing elite strategy. Subgame 2 and 3 conditions are most likely in societies ruled by hierarchy and possessing individualistic political cultures.

In hierarchical-ruled societies with individualistic political cultures, the principal interest of the governing elite is security. The main elite focus is to gather sufficient political power and tangible wealth to gain or maintain their position within the society's hierarchical structure. They can usually achieve this goal by allying with one citizen group. Issues of standing are of minor importance to governing elite in individualistic societies, as they must expend their main efforts on maintaining their access to public office. With other elite and the masses less tolerant of corrupt behavior (per Table 2-2), governing elite in individualistic societies must take a strategic approach to executing their transgressions against the one citizen group, i.e., they must either avoid or successfully hide corrupt behaviors that may cause a loss of support from other elite or the one citizen group that is not transgressed against. Without such a strategic approach, the corrupt behavior of individualistic governing elite could generate a wave of adverse 
elite and mass opinion or direct action threatening their access to office. In individualistic political cultures, the governing elite are likely to become pariahs (outcasts) if their corrupt behavior is uncovered. Such individualistic corruption is categorized as institutional, indicating that it exists clandestinely within isolated sections of the society's political and economic institutions.

Elite Paragons and Incidental Corruption. In a single-play Political Corruption Game, Subgame 4 reveals both citizen groups also have a dominant strategy to always acquiesce. In this subgame, it never pays a citizen group to challenge the governing elite, since there are no governing elite transgressions. The Subgame 4 solution requires that citizens solve their coordination problems so that the governing elite are certain that a transgression against one or both groups will result in challenges by both groups. With a primary goal of remaining in office, and knowing they would face a loss of power for their transgressions (corrupt behavior), the optimal strategy for the governing elite is to not transgress against either group. Subgame 4 conditions are normally found in societies ruled by heteronomy and possessing egalitarian political cultures.

In a heteronomous-ruled and egalitarian society, the principal interest of the governing elite is both tangible (money, land, property, etc.) and intangible (education, human rights, etc.) wealth. Egalitarian governing elite worry little about either standing or security. Their principal interest is to generate wealth for the good of the entire society. In egalitarian political cultures, both elite and mass opinion are so averse to corrupt behavior (per Table 2-2) that any such behavior would threaten the governing elite's access to office. Due to the higher proportion of commitment rules in egalitarian 
cultures, the governing elite come under strong influence to honor their duties to remain non-corrupt, or face immediate removal from office fostered by a coalition of elite and mass action. In egalitarian political cultures, the governing elite are most likely to act as paragons-model rulers acting in the non-corrupt roles that society expects them to play. In a world of self-interested utility-maximizers, however, there will never be zero corruption. Thus, in egalitarian cultures political corruption should only be incidental to regular political and economic behavior.

The Figure 2-2 Political Corruption Game single-play subgame analysis reveals the four most likely solutions (equilibriums) in the overall iterated game. When faced with multiple equilibriums, game theorists turn to focal point analysis to help explain why one solution occurs in a specific case rather than another. Focal points identify factors exogenous to the game-theoretic model, e.g., factors in the Figure 2-1 external world (institutional rules, material realities, etc.), that help explain the particular game solutions. Focal points illuminate social expectations (i.e., player perceptions of other player strategies) within the social context in which the strategic game interaction occurs (Schelling, 1960, pp. 57, 59, 111-113; Knight, 1995, 102). In other words, the focal point analysis assumes that the game equilibriums (solutions) are induced by the surrounding institutional structure (Shepsle, 1989, pp. 136-138). The following political corruption structural analysis develops the focal point solution concepts that provide additional insight in explaining the range of corruption patterns expected of governing elite in differing states. 
Table 2-3 summarizes the components of the theory of the causes of political corruption developed so far in this chapter. This includes the Figure 2-1 internal world (agency) analysis and the external world structural factors dealing with political culture. Supporters of either agency or cultural explanations for political corruption could stop their analysis here, but not constructivists. Constructivist derived theories of social behavior must include not only relevant agency and cultural factors, but also other political and economic structural factors, including material resource factors. These additional structural factors, the focal point analysis still missing from the Political Corruption Game, are addressed next in this chapter.

Table 2-3. Summary of Political Corruption Agency Analysis

\begin{tabular}{lccc}
\hline Dominant Social Rules & Instruction & Directive & Commitment \\
Rule's Purposes & Principles, beliefs & Specificity, sanctions & Create roles \\
Rule's Function: What agents: & should do. & must do. & right/duty to do. \\
Forms of Societal Rule & Hegemony & Hierarchy & Heteronomy \\
Political Cultures & Collectivist & Individualistic & Egalitarian \\
Corruption Boundaries & White & Gray & Black \\
Agent Interests & Standing & Security & Wealth \\
Agent Status & Pirates & Pariahs & Paragons \\
Corruption Patterns & Systemic & Institutional & Incidental \\
\hline
\end{tabular}

\section{A Political Corruption Structural Analysis}

Constructivists define structure as stable patterns of rules, institutions, and their unintended consequences. In determining the most important structural factors that cause political corruption, the analysis is facilitated by the work of Johnston (1994) whose structural comparative theory of political corruption includes several stable social rulesets surrounding the political corruption phenomenon. Johnston (1994) argues that both societal political corruption patterns and individual political corruption scandals, across 
time and for differing political and economic systems, can be explained by analyzing only five key social rule-sets. These social rule-sets include the nature of a society's: boundaries between public office and private interests, (2) elite competition, (3) elite accountability, (4) mass participation, and (5) management of material resources. The following structural analysis adds to Johnston's work by characterizing each of his identified rule-sets by its dominant mix of social rules.

Boundaries Between Public and Private. A governing elite's separation of its public duties from its private interests, i.e., the boundaries between public and private, has been discussed in some detail in the above agency analysis. The establishment of such boundaries is the central instruction rule governing political corruption. Heidenheimer's (1970) three classifications of corruption - white (weak), gray (moderate), and black (strong) (per Table 2-2) - provide a useful method to characterize the strength of these boundaries within a society. As Table 2-2 displays, those societies with stronger boundaries between a governing elite's public duties and private interests have lower incidences of political corruption.

Evaluating a society's boundaries (rules) between public and private spheres is not necessarily easy. The inability to measure political corruption behavior has always hampered corruption scholarship. Heidenhiemer's work reveals that an initial step in measuring political corruption is to determine the types of behavior, their incidence, and their evaluation (white, gray, black). This is often difficult as both the types of political corruption behavior and their incidences are usually hidden to persons outside a society's governing elite. Evaluations of political corruption must also determine the strength and 
formality of both formal and informal anti-corruption rules. Formal rules are usually embedded in a plethora of constitutional provisions, laws, statutes, regulations, directives, standard operating procedures, etc., designed to prevent corrupt behavior by placing restrictions on a governing elite. The formal rules are usually issued as directive rules. (Specifics of these formal directive rules are discussed further in the following analyses of elite competition, elite accountability, mass participation, and material resources.)

Also of concern in evaluating a society's corruption boundaries are the informal rules that may strengthen corruption boundaries, but more likely are used to weaken formal directive rules. For example, a society may have a number of formal directive rules meant to prohibit governing elite corrupt behavior. However, if the society's informal rules designate that the sanctions assigned to these directive rules will not be enforced (an elite accountability issue), then the formal directive rules provide little support to strengthening the boundaries between public and private. Thus, it is important to investigate the existence and efficiency of both formal and informal rules when evaluating a society's boundaries between public and private spheres.

Elite Competition. A basic premise found throughout the political corruption literature, the closest thing corruption theory may have to a basic law, is that competition leads to fewer opportunities for corrupt behavior (Rose-Ackerman, 1978, p. 148). Within Johnston's (1994) rule-sets, competition is an issue in how governing elite compete for political power (discussed in this section) and in how a society's material resources are managed (discussed later). Elite competition encompasses social rules that define elite requirements for gaining or retaining their hold on power. These include rules that 
concern elite mobility issues, electoral systems, and elite consensus. While seldom issued with anti-corruption measures in mind, the rule-sets in these areas often foster unintended consequences of political corruption. Developing balanced elite competition conditions is an important factor in reducing political corruption opportunities.

Rules regulating elite mobility concern the opportunities for actual or aspiring elite to advance in the society's social system. A first elite mobility factor is the openness of the governing elite to new members. Elite competition is restricted when the governing elite is open only to individuals from certain social or economic groups. McMullan (1961, pp. 190-191) highlights the problem with a closed governing elite as he argues that when one group is put at a disadvantage in joining a governing elite, it becomes a source of corruption. This leads to a second elite mobility factor that finds when access to the governing elite is closed, and there are also few other social or economic avenues that provide elite mobility opportunities, the probability of corrupt behavior increases as elite competition is further skewed.

Huntington (1968) raised the idea that a structural imbalance in elite competition, i.e., between political and social/economic opportunities, was a cause of corruption. Huntington offers:

In most forms corruption involves an exchange of political action for economic wealth. The particular forms that will be prevalent in a society depend upon the ease of access to one as against the other. In a society with multiple opportunities for the accumulation of wealth and few positions of political power, the dominant pattern will be the use of the former to achieve the latter.... [However, when] [t] he opportunities for the accumulation of wealth through private activity are limited ....politics becomes the road to wealth, and those enterprising ambitions and talents which cannot find what they want in business may yet do so in politics. ... Corruption...results when the absence of mobility opportunities outside politics, combined with weak and inflexible political 
institutions, channels energies into politically deviant behavior. (Huntington, 1968, p. 66)

Morris's (1991) study of Mexican political corruption supports Huntington's thesis that corruption results from imbalances between political and social/economic opportunities for elite advancement. Among Mexican political and commercial entities, Morris found that when the state structure provides the principal elite mobility opportunities, the more powerful governing elite are free to extort social resources from both the business sector and the citizenry. On the other hand, he also identifies that when elite social/economic opportunities are greater, then bribery of a less powerful governing elite by commercial enterprises desiring preferential political decisions is common. Morris's study found Mexican corruption levels at their lowest when there is a balance between political and social/economic mobility opportunities. Johnston (1996a) also supports Huntington's thesis as he demonstrates that those states with the least corruption exhibit a balance between: (1) political and economic opportunities, and (2) state and society.

Governing elite longevity in office is a third elite mobility factor that affects elite competition. When a single governing elite monopolizes its hold on state power, the opportunities for corruption increase dramatically (Heywood, 1997, p. 15; Della Porta \& Meny, 1997, p. 172). This is especially true when a corrupt governing elite is able, through their directive rule making over a long period in office, to strengthen the processes (institutions) by which they extract resources legally from a society. This situation was highlighted in the iterated version of the Political Corruption Game where it could be shown that a strategic advantage in extracting resources from a state could 
become institutionalized in Subgames 1,2, and 3 by a governing elite with long-term rule-making power (also see Knight, 1992, p. 40).

A society's electoral system rules also play an important role in what a governing elite must do to gain or retain office. In most Caribbean societies, the causes of political corruption are associated closely with their electoral processes. Two important factors come into play in analyzing how a society's electoral processes affect political corruption levels. First, the voting process itself is an important factor. Governing elite greatly increase their chances of remaining in office when they alter elite competition factors by rigging elections in their favor. Such manipulation of the voting process coincides with increased corruption levels. Second, the processes governing elite use to accumulate resources for election campaigning is an important factor influencing political corruption levels.

Heywood (1997, p. 14) highlights that in democracies it costs money to run election campaigns and maintain electoral support. Weyland (1998) even argues that the need for vast resources to conduct wide-scale media campaigns is the primary cause of Latin American and Caribbean political corruption. Elite competition improves whenever the amount of resources (money, personnel, time, etc.) the governing elite need to participate in the electoral process is both minimized and balanced and the electoral process itself is fair and open. Where large amounts of resources are needed to participate in electoral processes, competition quickly becomes limited to only those elite candidates with the ability to generate resources. Political corruption increases in 
resource-driven elections as governing elite are forced into patronage networks that can generate sufficient resources to support candidates.

Political patronage or clientelistic systems are often sighted as a primary cause of political corruption (see Rose Ackerman, 1978; Klitgaard, 1988; Jain, 1998b). In its simplest form, a patron-client relationship entails transactions between individuals, groups, or combinations of both. The client normally offers a benefit or service to the patron, in exchange for which the patron offers some other benefit or service to the client (Clapham, 1982). Such transactions establish situations of reciprocity or obligation between the patron and client. Patron-client relationships are both legal and illegal. For example, representational clientelism, where citizens (clients) provide votes to a governing elite (patrons) they feel will benefit them or their society the most, is a legal patron-client transaction found in democracies. Political corruption occurs when the governing elite engage in illegal patron-client transactions that benefit the private interests of the governing elite.

Patron-clientelism is a complex social phenomenon. It involves a variety of different behaviors and a number of different actors. Actors may fill the role of patrons, clients, or agents, persons who assume an intermediary role between the patron and clients. For example, in Klitgaard's (1988) study of corruption, the patron (principal) is assumed to be the state's mass citizenry; agents, the state's governing elite; and clients, domestic or international actors desiring access to state resources. Actors may also assume dual roles. For example, Edie (1991) argues that Jamaica's governing elite are embedded in a system of dual-clientelism. She develops how the Jamaican governing 
elite act as patrons toward members of their own political parties, but are simultaneously mired in a condition of international dependency where the Jamaican governing elite act as clients to international financial concerns (international financial institutions, transnational corporations, foreign businesses, international aid organizations, etc.).

All political systems contain some patronage or clientelistic rules. For the purposes of this study, Table 2-2 helps categorize the differences in patron-client systems across political cultures. All of the types of political corruption behavior listed in Table 2-2 may involve illegal transactions between patrons and clients. This is especially true of the first five political corruption behaviors in Table 2-2 that are the subject of much of the political corruption literature regarding illegal patron-client relationships. Table 2-2 reveals that the incidences of patron-client transactions are the lowest in egalitarian political cultures. Egalitarian political cultures usually encompass representational clientelism and systems of political spoils - whereby winning political parties are able to appoint senior party loyalists to key government positions. However, even within a system of political spoils, the governing elite in egalitarian political cultures still act for the good of the entire society.

Normally, individualistic political cultures also include representational clientelism, however, their political spoils systems are much larger. Winning political parties in individualistic political cultures are able to appoint more party loyalists to an even greater number of positions within the government bureaucracy. Table 2-2 reveals that patron-client transactions are more frequent in individualistic than in egalitarian political cultures. These more frequent patron-client transactions help the governing elite 
obtain the vast resources needed to conduct media-intensive electoral campaigns and thus keep the self-interested individualistic governing elite in power.

Collectivist political cultures exhibit the most frequent patron-client transactions (see Table 2-2). Hegemonic governing elite in collectivist political cultures are able to saturate government structures with party or group loyalists. Because social institutions are weaker in collectivist political cultures, patron-client relationships may come to dominate the daily political and economic transactions in these societies. A review of the Table 2-2 types of behaviors and incidences provides a good overview of the probability of patron-client relationships in differing political cultures that affect the characteristics of a society's elite competition.

Lack of consensus among societal groups regarding what social rules should be promulgated concerning important societal issues is another important factor in evaluating elite competition. Huntington (1968) informs this analysis by offering that the absence of societal agreement, fostered by the existence of competing value systems and cultures, encourages corruption. In a study of corruption under both authoritarian and democratic systems in Chile and the Philippines, Montinola (1995) demonstrates that corruption levels decrease when competition on societal issues is unidimensionalmeaning members of the same group vote consistently on all issues. Unidimensionality, where one issue can be used to predict a group member's votes on all issues, indicates a high level of intra-elite consensus.

Montinola (1995) also argues that corruption levels increase when competition on societal issues is multidimensional-meaning members of the same group vote differently 
upon a variety of issues. Multidimensionality indicates a lack of elite consensus, thus affecting the ability of groups to construct coordination mechanisms for collective action. The ability of societal groups to foster both intra-group and inter-group consensus and cooperation is an important factor in generating the anti-corruption commitment rules discussed in following sections.

Elite competition can be characterized as constricted, oppositional, or corporatist. In societies ruled by hegemony and possessing collectivist political cultures, governing elite competition is constricted. The group of governing elite is normally closed with limited membership potential for citizens outside governing elite circles. Elite competition is limited to that among factions of the governing elite itself. Outside the society's government structure, there are usually few opportunities for citizens to advance socially or economically. Political opportunities prevail over social and economic ones. Governing elite, whether consisting of governing families or parties, normally remain in power for long periods. Constricted elite competition is also characterized by strong intra-group elite cooperation on most issues. With little or no real elite competition, directive rules concerning elite competition in collectivist societies focus only on what must be done for the elite to maintain control of the society's security apparatus, maintain ideological control of the citizenry, and/or maintain political support within the strongest factions of the governing elite.

In states ruled by hierarchy and possessing individualistic political cultures, governing elite competition is generally more unfriendly and hostile, i.e., oppositional, than that in hegemonic or egalitarian states. Elite mobility is more open as aspiring elite 
can more easily advance through party channels. Political parties tend to be voted out of office periodically. Oppositional elite competition centers on the political survival of governing elite. Resources for electoral campaigns in individualistic societies come mainly from private sources. With their hold on political power in hierarchical societies less certain than in hegemonic societies, the threat of governing elite loss of power generates the oppositional elite competition. Elite must fear being voted out of office for two primary reasons. First, loss of political power eliminates their access to the state resources that comes with public office. Second, loss of political power makes the former governing elite vulnerable to charges of corruption or other crimes from those ascending to power.

In societies ruled by heteronomy and possessing egalitarian political cultures, governing elite competition is open and balanced, thus lending itself to consensus building and not antagonistic competition. Elite competition in an atmosphere of consensus building is corporatist in nature (see Katzenstein, 1985). The governing elite are open to all societal elements. Seldom does one governing elite faction maintain power for extended periods. There is a balance between both elite and mass political, economic, and social opportunities. This balance of opportunities creates a situation where the governing elite are not threatened by a loss of power, they can always earn a living outside politics, and therefore worry little about elite competition. Corporatist elite competition focuses on societal advancement and not political survival as the chief concern of the governing elite. Directive and commitment rules concerning elite competition help ensure the balance between state and society and do not artificially 
restrict elite competition in any manner. Electoral resources in heteronomous societies are either provided by the state, or are regulated such that the competition for private resources does not affect the outcome of elections.

Elite Accountability. Onuf's constructivism offers that directive rules require the support of sanctions if agents decide not to follow the applicable rules. The analysis of anti-corruption sanctions speaks directly to elite accountability. A lack of accountability provides increasing opportunities for the elite to act corrupt. In analyzing elite accountability there are two dimensions that must be addressed: (1) answerability and, (2) enforcement (Schedler, 1999, p. 14).

Answerability concerns the obligation for public officials to keep citizens informed about their activities and to explain public decisions (Schedler, 1999, p. 14). Answerability includes public officials providing information, facts, and data on public activities, more commonly referred to as freedom of information. It requires a free media (radio, television, newspapers, magazines, etc.). The media are not only the primary purveyor of information to the public, but also act as public monitors (watchdogs) that report public activities and initiate discourses on the topics most important to society (e.g., political corruption). Answerability also requires public officials to make themselves available in public or private forums to provide information, answer citizen questions, and explain public decisions.

Enforcement, the second dimension of elite accountability, concerns the capacity of a state to impose sanctions upon officials who have violated their public duties (Schedler, 1999, p. 14). When official behavior is called into question, it must eventually 
be investigated and punished if found in violation of the rules. Sanctions (punishment) resulting from enforcement actions include those contained in the society's administrative, electoral, and criminal justice systems. Administratively, a society must have the capacity within its governmental bureaucracy to uncover corrupt behavior (by inspections, audits, whistleblowers, etc.) and then the ability to take appropriate administrative action. Administrative sanctions may include censures, fines, or removal from office. Administrative sanctions highlight the need for openness and transparency in government budgeting and contracting. Without administrative openness and transparency, corrupt behavior by the governing elite may go uncovered. (see Caiden \& Caiden, 1977; Caiden, 1978).

Corrupt governing elite may also be held accountable by the society's electoral and criminal justice systems. Electorally, when corruption is found or is a perceived problem with the governing elite, citizens must be able to remove suspected officials, i.e., throw the crooks out, during the course of regular or special elections. When an official's corrupt behavior violates criminal statutes, the society's criminal justice system must be able to investigate, bring to trial, and punish wrongdoers that are found guilty.

Evaluating elite accountability is a new topic in political research. Adapting the work of O’Donnell (1999), this study offers that there exist three distinct types of elite accountability-circular, vertical, and horizontal.

Circular accountability is characteristic of collective political cultures and symbolizes informal answerability and enforcement of societal rules within the individual's respective group. Elite accountability is the preserve of the small governing 
elite in collectivist cultures. Government bureaucracies, elections, and criminal justice systems have little or no role in circular elite accountability. For all but the most egregious offenses, elite punishment in collectivist political cultures normally entails the corrupt official's removal, often only temporarily, from the group of governing elite. Vertical accountability is characteristic of individualistic cultures and signifies that answerability and enforcement measures originate in and travel through a society's vertical bureaucracy. Offenses for which elite are held accountable would be serious and would normally be revealed by the governmental bureaucracy. Once elite offenses are made known to the public, the process for punishment would follow within the confines of the society's administrative, electoral, or criminal justice systems.

Horizontal accountability is characteristic of egalitarian cultures and indicates that answerability and enforcement originate not only within the governmental bureaucracy, but also from groups outside government. In horizontal accountability, the media and civil society assume important roles in corruption oversight and have horizontal access to all levels of the government.

Mass Participation. The recognition of the lack of mass participation as a causal factor in political corruption is an emerging segment of the anti-corruption literature (see Johnston, 1994, 1998). Two social-ruled dimensions pertain to the relationship between mass citizen participation and political corruption levels: (1) the promulgation of directive rules that allow citizens to participate in government decision-making processes, and (2) the development of commitment rules that emerge as a result of the process of mass participation. 
Many societies lack directive rules that allow their citizens the right to participate in government decision-making. As discussed above as an elite accountability issue, societies often restrict both the release of government information and the media's ability to investigate and report. Therefore, citizens often know little about government activities, which hampers their ability for real participation in government decisionmaking. Some societies place legal restrictions on citizen freedoms concerning public or private discussions; assembly and demonstration; formation of political, labor, or civic organizations; and religious worship. For example, in the Caribbean, Freedom House offers that 22 of 25 independent states restrict their citizens' civil liberties in one way or another (Karatnycky, 1999).

Freedom of civil liberties allows citizens to organize and influence government decision-making. Where mass citizen participation is permitted, citizens have the opportunity for social empowerment. Social empowerment entails "strengthening civil society in order to enhance its political and economic vitality, providing more orderly paths of access and rules of interaction between state and society, and balancing economic and political opportunities" (Johnston, 1998, p. 85). While exact methods of social empowerment differ among states, "societies will have in common...the emerging strength of the groups and interests which make up civil society - that is organizations, enterprises and informal social networks active in the realm between individuals and government" (Johnston, 1998, p. 91). Where civil society is weak, citizens become vulnerable to exploitation. Where civil society is strong, citizens are able to build coordination mechanisms across groups that are essential to ensuring elite accountability. 
An unintended consequence of the lack of mass participation or social empowerment is greater levels of political corruption.

The second social-ruled dimension of mass citizen participation concerns the emergence of societal commitment rules. A strong civil society fosters the development of commitment rules. One method of developing commitment rules, i.e., the creation of roles and establishment of rights and duties, is to strengthen instruction and directive rules. Thus, commitment rule generation becomes an unintended consequence of the strengthening of instruction and directive rules through mass participation. Before anticorruption commitment rules can emerge, a society must first possess sufficient anticorruption instruction and directive rules, including those governing the boundaries between public office and private interest, elite accountability, elite competition, mass citizen participation, and management of societal material resources (discussed later).

Fostering anti-corruption commitment rules is at the heart of building selfenforcing mechanisms that influence a governing elite to make it their duty (promise) not to behave corruptly-a situation where civil society takes this duty as their corresponding right. Where strong anti-corruption commitment rules exist, the governing elite know that if they violate their duty to not behave corruptly, civil society will automatically challenge the elite's behavior. The situation becomes self-enforcing as the governing elite honor their duties (promises) in the face of a strong civil society (see Weingast, 1997). Therefore, the ability of a state's civil society to generate anti-corruption commitment rules, i.e., strengthen its social empowerment, becomes a key horizontal accountability mechanism helping prevent political corruption. 
Not all commitment rules have positive effects upon society. Societies have different mixes of instruction, directive, and commitment rules. At times, instead of positive commitment rules leading to public goods (e.g., lower levels of corrupt behavior), commitment rules can actually foster public bads. This is the case where the roles that commitment rules create result in rights and duties that have negative social effects. For example, societies with systemic corruption patterns develop well-defined duties and rights (i.e., commitment rules) "to the point that they become actually transferable, assignable, inheritable, and saleable" (Cheung, 1996, p. 4). These institutionalized duties and rights regarding corrupt behavior result from the building of negative commitment rules that are not in the public's best interest.

Negative commitment rules can develop in situations where a society organizes informally in response to the lack of a formal system to provide public goods. In several Caribbean states, where the formal economy is unable to generate employment, or the government is unable to provide basic citizen services, societies often take it upon themselves to informally organize and foster both employment and basic citizen services. The result is the proliferation of informal economies that pay no taxes toward the public good and the fostering of criminal gangs or paramilitary military forces that provide vigilante security services to citizen groups. Accompanying these informal structures are rising societal crime and violence levels, upheavals of family structures (as more family members must work outside the home), rising social conflict, and a delegitimization of the government's authority to rule. An unintended consequence of these informal structures is the generation of their own negative commitment rules (i.e., rights and duties 
that are not in the best interest of the public). Therefore, when discussing the role of civil society in generating commitment rules, it is important to differentiate between situations leading to public goods versus those leading to public bads.

With the social empowerment of civil society able to produce both positive and negative commitment rules, another method is required to conceptualize the idea of social empowerment leading to positive commitment rules. The concept of social trust fills this requirement by representing positive social action associated with building commitment rules for the public good. An unintended consequence of the positive strengthening of civil society while building commitment rules is the growth of social trust. Social trust indicates "the expectation that arises within a community of regular, honest, and cooperative behavior, based on commonly shared norms, on the part of other members of that community" (Fukuyama, 1995, p. 26). Social trust allows groups to organize to a lower level (decentralize) and fosters spontaneous sociability - the ability of groups to work closely together (Fukuyama, 1995, p. 29). In other words, social trust is a shared willingness of both citizens and governing elite to keep commitments.

Social trust is the mechanism that allows citizens to form organizations and associations - - the foundation to building strong civil societies. Where strong social trust exists, citizens spontaneously organize into "dense and complex network[s] of voluntary organizations: churches, professional societies, charitable institutions, private schools, universities, hospitals, and ...a very strong private business sector" (Fukuyama, 1995, p. 50). Social trust can itself be seen as a public good, one that makes it possible to 
surmount societal collective action problems. The level of a society's social trust is directly correlated to its level of positive commitment rules.

Recent studies highlight the importance of building social trust. In a study of world political economy, Fukuyama (1995) demonstrates that a state's economic product is directly correlated with its level of social trust. Fukuyama reveals that states with high levels of social trust are able to build the vital organizational structures between the state structure and individual family units that are critical to economic efficiency and growth. In a study of corruption in Nicaragua, Seligson (1999) found interpersonal trust as an important variable affecting citizen perceptions of both corruption levels and the legitimacy of government. He noted "[i]ndividuals who trust each other are able to interact in civil society in a more positive fashion...."(Seligson, 1999, p. 57).

The ability to generate social trust is a function of a society's culture (Fukuyama, 1995, p. 33; Earle \& Cvetkovich, 1995, p. 10). The amount of social trust can vary in differing levels of society, ranging from the trust placed in family units, to that in government structures, to that in society as a whole. Recognizing the varying levels at which social trust exists, it can be characterized in three categories-paternalistic, pluralistic, and cosmopolitan (adapted from Earle \& Cvetkovich, 1995). The level of social trust makes an excellent proxy variable for measuring mass participation.

Paternalistic social trust is characteristic of collectivist cultures where trust is limited to only members of an individual's social group, (i.e., family, tribe, ethnic group, etc.). Where paternalistic trust dominates, there usually exists little social trust of individuals in different social groups, in the government structure, or in society as a 
whole. Pluralistic social trust is characteristic of individualistic cultures where a minimal level of trust is necessary for differing groups to work together. While self-interested behavior is the rule in individualistic cultures, most individuals see it is in their best interest to work with others. Where pluralistic social trust exists, there is moderate intragroup and inter-group trust, and a minimal level of trust in both government structures and society as a whole. Cosmopolitan social trust is characteristic of egalitarian cultures. Cosmopolitan social trust develops from widespread inter-group transactions and includes significant inter-personal communication. Where cosmopolitan social trust exists, moderate to strong intra-group and inter-group trust proliferates. Additionally, there is moderate to strong trust in government structures and in society as a whole. Cosmopolitan social trust is the result of the emergence of positive societal commitment rules.

Material Resource Factors. No constructivist analysis is complete without consideration of how material resources, both routine and extraordinary, impact upon the social behavior under investigation. Social rules turn raw materials into material resources. Material resource availability plays a major role in agent decision processes. Material resource systems help define the opportunities available for a governing elite to act corruptly. This section looks first at directive rules pertaining to routine material resource systems, or how a society's economy is structured and how state-owned resources are managed.

Beginning with the writings of Adam Smith (1723-1790 AD), David Ricardo (1772-1823 AD), and other liberal nineteenth and twentieth century economists, theorists 
argue that to achieve economic efficiency, political interests must be prohibited from subverting market forces. The subversion of market forces is often referred to as rent seeking-government elite activity aimed at increasing the payment for a resource over what the resource would command in a competitive market or in other use (i.e., through regulations, payoffs, bribes, extortion, etc.) (see Krueger, 1974; Tullock, 1989). A noninterventionist society with open and free markets is hypothesized to reduce the opportunities for governmental rent seeking or outright theft of public resources. Thus, an unintended consequence of an open and free market system is a reduction of political corruption. Building from this logic, there are three routine categories of material resource systems-patrimonial, statist, and market.

Patrimonial material resource systems are dominated by instruction rules and normally found in collectivist societies. Patrimonial material resource systems foster maximum government control by limiting which classes of citizens (normally only the governing elite) have access to material resources. In these systems the small governing elite tightly control the economy and decide, often capriciously, how state-owned resources are distributed. Patrimonial material resource systems are usually not transparent and provide unlimited opportunities for rent seeking activities. The governing elite are given the opportunity to use the national treasury and state-owned resources as if they were their own personal property, and decide what, if any, resources may be distributed for the public good. To maximize their access to societal resources, governments with patrimonial material resource systems maintain strict control over their economies, usually including high levels of protectionism of foreign trade (high tariffs, 
etc.), high personal and corporate taxes, government ownership of major enterprises (public utilities, basic foodstuff production, etc.) and infrastructure (ports, airports, railroads, etc.), strict wage and price controls, and a variety of regulations (licensing, contracting, customs procedures, etc.) that allow maximum rent seeking by government officials. One analysis of corruption in underdeveloped societies found that where extensive patrimonialism existed, "the majority of the population are more or less permanently excluded" from the benefits of state resources (Theobold, 1990, p. 91).

Statist material resource systems are dominated by directive rules and found in individualistic societies. Statist material resource systems find less government control of a state's economy and state-owned resources. Statist systems utilize a mix of patrimonial and free market mechanisms to manage their economies, while still providing the governing elite ample opportunities for rent seeking. Knowing that their opportunities to accumulate capital are dependent upon their control of the state's resources and economic processes, governing elite in statist systems strive to ensure they play key decisionmaking roles in economic and state resource management. Statist material resource economic management includes some protectionism of foreign trade, some government ownership of key enterprises and infrastructure, and a special emphasis on regulations (licensing, contracting procedures, etc.) that allow substantial rent seeking by government officials. In effect, governing elite in statist systems see the state's economy and stateowned resources as their own private business resources and regulate them in a manner providing ample opportunity for illicit capital accumulation (see Manzetti \& Blake, 1996). Theobald (1990, p. 95) found that even among developed societies, corruption 
levels soar when the state becomes so involved in economic management "that in the absence of adequate alternatives the state apparatus becomes the main vehicle of economic advancement and capital accumulation" for those in power.

Market material resource systems are dominated by commitment rules and found in egalitarian societies. Market material resource systems present the liberal ideal of free and open economies and efficient state-owned resource management. Taking their lead from the works of Smith (1937) and Ricardo (1960), market systems view the only role for the state in the economy is to provide public goods that the market is unable to provide (monetary systems, public transportation infrastructure, etc.). State ownership of enterprises is contemplated only if the enterprise has no competition and state-ownership is in the public's best interest. Market economies enjoy maximum transparency and openness. State-owned resource management is also highly efficient and transparent. Overall, the market resource system presents the fewest opportunities for rent seeking. The second dimension of material resource management concerns the input of extraordinary material resources into the Figure 2-1 internal world analysis. Extraordinary resources are any large amount of monetary or other resources that are provided outside a state's regular (routine) economic transactions. The sources of extraordinary resources may include: (1) state revenues from the discovery or development of a new industry, i.e., petroleum, mining, tourism, etc.; (2) funds from the privatization of state-owned enterprises; (3) international loans or aid, (4) large bribes to officials from foreign businesses seeking government contracts (see Lambsdorff, 1998); (5) funds from transnational organized crime activity such as drug trafficking (see 
Williams, 1994); or (6) other activities that present the governing elite with a large amount of resources outside the society's routine economic processes. The availability of extraordinary resources alters the Figure 2-1 internal world analysis. The input of extraordinary resources into the Figure 2-1 model increases both the opportunities for political corruption and the willingness of government elite to behave corruptly. While not characterized within the constructivist theory of social rules, as done with the other social phenomenon investigated above, the effects of extraordinary material resources must always be considered in analyses based upon the Figure 2-1 constructivist analytic frame.

Johnston (1986) provides an analysis that highlights the effects of extraordinary resources that are inserted into a governing elite's cost-benefit analysis. Where the stakes of the corruption are routine (i.e., situations without extraordinary resource inputs), existing political corruption patterns tend to become integrative and stable. Integrative corruption means that those involved in corrupt transactions have shared interests and the corrupt exchanges develop lasting networks. Stability indicates that agents involved in the corrupt exchanges remain the same. Political corruption with routine stakes maximizes cooperation among those involved in the corrupt exchanges, while not unnecessarily antagonizing those outside the exchanges, such that an equilibrium develops where there is little outcry to change the corrupt behavior. In situations with routine stakes, the rules that influence corrupt behavior remain stable and are extremely hard to change. 
Where the stakes of corruption become extraordinary, the resultant political corruption tends to be disintegrative and unstable. Disintegrative corruption means that those involved in the corrupt transactions have no shared interests, the corrupt exchanges are often temporary, and networks of lasting exchanges do not evolve. Unstable corruption also entails that agents involved in the corrupt activity change frequently. Political corruption with extraordinary stakes results in only temporary cooperation among those involved in the corrupt exchanges, while often antagonizing those outside the exchanges. In situations with extraordinary stakes, the political and economic rules that influence corrupt behavior become unstable.

When extraordinary stakes are present, agents display a greater willingness toward corrupt behavior because of the potential high payoffs. Increasing corrupt behavior influences changes in the Figure 2-1 institutional structure. The existence of extraordinary stakes not only increases short term corruption levels, but also tends to strengthen the instruction and directive rules that influence long term corruption levels (per the feedback loop in Figure 2-1). Additionally, by decreasing governing elite legitimacy (i.e., part of the disintegrative effect), extraordinary stakes lead to the destruction of anti-corruption commitment rules. In states with systemic or institutional corruption patterns, extraordinary stakes strengthen the rules causing corruption. In states with incidental corruption levels, extraordinary stakes destroy commitment rules and move the state toward institutional or systemic corruption levels. Thus, any one of the above six sources of extraordinary resources, if not managed within its own set of strict directive rules, can quickly raise a society's political corruption levels. 


\section{Specifying The Theory}

Table 2-4 is a synoptic table of the coordinates of political corruption. The table includes elements from the constructivist theory of social rules (Table 2-1) and the characterizations of the social phenomena addressed in the agency and structural analyses presented in this chapter. At the bottom of Table 2-4 is a hypothetical corruption index modeled on the 0 (totally corrupt) to 10 (no corruption) scale used by Transparency International (TI) to annually rate state corruption levels. ${ }^{12}$

Table 2-4. Coordinates of Political Corruption

\begin{tabular}{lccc}
\hline Dominant Social Rules & Instruction & Directive & Commitment \\
Rule's Purposes & Principles, beliefs & Specificity, sanctions & Create roles \\
Rule's Function: What agents: & should do & must do & right/duty to do \\
Forms of Societal Rule & Hegemony & Hierarchy & Heteronomy \\
Political Cultures & Collectivist & Individualistic & Egalitarian \\
Elite Competition & Constricted & Oppositional & Corporatist \\
Elite Accountability & Circular & Vertical & Horizontal \\
Mass Participation & Paternalistic & Pluralistic & Cosmopolitan \\
Material Resource Factors & Patrimonial & Statist & Market \\
Public/Private Boundaries & White & Gray & Black \\
Agent Interests & Standing & Security & Wealth \\
Agent Status & Pirates & Pariahs & Paragons \\
Corruption Patterns & Systemic & Institutional & Incidental \\
\hline \multicolumn{1}{c}{ Corruption Index: } & & & \\
& & & \\
& & &
\end{tabular}

Table 2-4 provides the basis for this study's theory of the causes of political corruption. The table is probabilistic and not deterministic. By evaluating the characteristics of the Table 2-4 social phenomenon present in a society, a vertical interpolation of those characteristics provides a probable evaluation of that society's agent status, corruption pattern, and corruption index score. Thus, the table provides a 
conceptual method to explain a society's political corruption pattern and to predict a society's rating on the annual Transparency International Corruption Perception Index.

Few societies will exhibit the exact characteristics of the social phenomenon contained in any one of Table 2-4's three right columns. Most societies will exhibit characteristics from two or more of the columns. Additionally, in accordance with the constructivist tenet that all social phenomena (institutions) are composed of different mixes of instruction, directive, and commitment rules, some societies will exhibit social phenomena characteristics somewhere between adjacent columns. For example, since the time of Alexis de Tocqueville, the US's political culture has been evaluated as a somewhat balanced mix of individualistic and egalitarian characteristics (see Ellis, 1993). Thus, horizontal interpolation between the Table 2-4 columns of social phenomena characteristics is also possible (see Chapters 5 and 6 for examples).

A number of theoretical propositions may be constructed from Table 2-4.

The three most important propositions include:

Proposition One: Societies with coordinate of political corruption factors (form of societal rule, political culture, elite competition, elite accountability, mass participation, market resource factors, boundaries between public and private) that are dominated by instruction rules, or near equal combinations of instruction and directive rules, will likely experience systemic political corruption patterns.

Proposition Two: Societies with coordinate of political corruption factors (form of societal rule, political culture, elite competition, elite accountability, mass participation, market resource factors, boundaries between public and private) that are dominated by directive rules, or near equal combinations of directive rules with either instruction or commitment rules, will likely experience institutional political corruption patterns.

Proposition Three: Societies with coordinate of political corruption factors (form of societal rule, political culture, elite competition, elite accountability, 
mass participation, market resource factors, boundaries between public and private) that are dominated by commitment rules, or near equal combinations of commitment rules and directive rules, will likely experience incidental political corruption patterns.

It is important to understand that the above propositions, and others derived from the Table 2-4 relationships, remain at the conceptual level. Table 2-4 is the result of this chapter's theoretical analysis that investigates an extremely complex social behavior (i.e., political corruption), one that has puzzled social scientists for decades, and reduces it to key social concepts that allow an understanding of the interdisciplinary causes of political corruption. While the work of Heidenheimer $(1970,1989)$ and Johnston (1994) were critical to the analysis in this chapter, it was Onuf's (1989) constructivism that highlighted the causal mechanisms (social rules) that made the development of Table 2-4 possible.

The next four chapters provide empirical support to the interdisciplinary theory of the causes of political corruption. Chapter 3 provides a historical overview of corruption during the Caribbean's colonial period. In keeping with the constructivist tenet that the world is constantly being re-constructed (re-constituted) on the rubble of the past, an understanding of contemporary Caribbean political corruption first requires an understanding of the institutional history of Caribbean states. Chapter 4 furthers this historical understanding by providing a more detailed look at contemporary Caribbean institutions and political corruption levels. While these two historical chapters provide necessary background, they do not directly advance the Table 2-4 conceptual relationships. For this, qualitative disciplined-configurative case studies of Jamaica and Costa Rica are presented in Chapters 5 and 6, respectively. This study's conclusion then 
revisits the Table 2-4 coordinates of political corruption in light of the material presented in the next four empirical chapters.

\section{Endnotes}

1. Onuf's rule-oriented version of constructivism should not be confused with several other competing versions of constructivism (see Adler, 1997). In the remainder of this study, constructivism refers to the use of the rule-oriented analytic frame initially developed in Onuf (1989).

2. The initial idea for this model of the constructivist analytic frame came from the Institutional Analysis \& Development (IAD) literature. IAD focuses upon the analysis of social behavior that is "bounded" by social institutions. The IAD framework, pioneered by Ostrom (1990) and Ostrom et al. (1994), combines the use of rational choice (agency) explanations for social behavior with the idea that agent choice is bounded by a surrounding institutional structure (i.e., social rules). The IAD framework traces its roots to classic political economy, neoclassical micro-economic theory, institutional economics, public choice theory, transaction-cost economics, and non-cooperative game theory (Ostrom et al., 1994, p. 25). The IAD framework is consistent with the new institutionalism movement among rational choice theorists that seeks to explain social outcomes through analysis of not only agent preferences and optimizing behavior, but also through the strategic context (institutional structure) within which agents must act (Shepsle, 1989, pp. 134-135). Originally designed to explain the management (or mismanagement) of common-pool resources, the IAD framework has been used to investigate a variety of political and economic issues where both agency and structure play key explanatory roles (Ostrom et al., 1994, p. 26).

3. Completeness implies that the preference order includes all likely outcomes and is reflexive, i.e., all outcomes are at least as good as themselves. For example, a preference ordering is complete, if and only if, for all pairs of outcomes $\mathrm{C}$ and $\mathrm{D}$, either $\mathrm{C}$ is at least as good as D, or D is at least as good as C, or both. Transitivity means that if one outcome (C) is at least as good as a second (D), and the second (D) is at least as good as a third (E), then the first (C) must be at least as good as the third (E). (Morrow, 1994, pp. 17-22).

4. Onuf's (1989) book World of Our Making contains a more extensive explanation of his constructivist theory of social rules. The categories shown here are only those needed to support this study's analysis.

5. Much of the growing constructivist literature refers only to two categories of rules, regulative and constitutive rules. In Onuf's (1989) constructivism, all rules are deemed to 
have both regulative and constitutive properties. To Onuf there are only three categories of rules-instruction, directive, commitment-that govern social action.

6. Cultural relativity is an often-cited problem in corruption studies. The cultural relativity argument offers that what is seen as corruption in one culture may not be seen as corruption in another. Many analysts maintain that the Western concept of corruption cannot be applied to developing states in Asia, Africa, or the Americas. Recently the cultural relativity argument has been discredited as more and more developing states adopt anti-corruption programs grounded in the normative Western concept of corruption. This is particularly true for the Caribbean where the 1994 Miami Summit of the Americas action plan and the 1996 OAS Inter-American Convention Against Corruption adopted the Western concept of corruption as the desired regional norm. This does not, however, eliminate the problem of societies perceiving corruption quite differently.

7. There have been a variety of methods used to describe differing types of political cultures. Greif (1994) uses only the collectivist and individualistic typologies. Elazar $(1966,1970,1994)$ employs the typologies of individualistic, moralistic, and traditionalistic. Ellis (1993) expands the typologies to five: individualistic, egalitarian, fatalistic, hierarchical, and hermetic. Heidenheimer (1970) offers four typologies: traditional family-kinship systems, traditional patron-client systems, modern bossfollower systems, and the civic-culture-based systems. The three typologies used in this study are a synthesis of these previous works on political culture and are in consonance with the use of threes in concepts developed within Onuf's constructivist theory of social rules.

8. The Political Corruption Game is an adaptation of Weingast's (1997) SovereignConstituency Transgression Game.

9. The constructivist concept of hegemonic rule is based upon a governing elite's ideological control of society. However, even Gramsci (1971) recognized that sometimes a balance between ideological and coercive control may be required. Coercive control, a state's legitimate threat of or actual use of force, is a very hierarchical, i.e., directiveruled, concept.

10. The idea of classifying such governing elite as pirates, pariahs, and paragons originates in enterprise theory. See Smith (1980) for an explanation of enterprise theory.

11. Alatas (1990, p. 5) also refers to this type of corruption as metastatic, a medical term symbolizing that corruption attacks the entire social system such that the infestation is total rather than localized and sporadic.

12. The annual Transparency International Corruption Perception Index is a compilation of several corruption surveys (a poll of polls). The surveys include Transparency International's Internet corruption survey, an international Gallup poll, and several 
surveys by international business research and consulting groups. The index is prepared for Transparency International by a team of researchers led by Dr. Johann Graf Lambsdorff at Goettingen University, Germany. Each state's score on the index relates solely to the results drawn from a number of surveys and reflects the perceptions of a wide variety of respondents that participated in the surveys. The scores range from 0 (totally corrupt) to 10 (no corruption) and indicate only the corruption associated with foreign business transactions in each state. Additional information on the index's preparation is available at $\mathrm{http} / / \mathrm{wwww}$.transparency.de. 


\section{Chapter 3}

\section{A History of Caribbean Political Corruption: 1492 to 1950}

Caribbean history is rife with graft and corruption. Graft and corruption permeated the political and economic institutions of the sixteenth through early twentieth century colonial Caribbean. Early twentieth century US interventions in several of the Caribbean's former Spanish and French colonies fared poorly in arresting this legacy of Caribbean corruption, despite US attempts to bring good governance to these politically and financially unstable independent states. Reviewing the record of Caribbean colonialism and US interventions is important because contemporary Caribbean political and economic institutions took root during this first 450 plus years of modern Caribbean history. This chapter reviews the role of political corruption in the development of Caribbean political and economic institutions from 1492 to 1950 . It is a first step in understanding how colonialism and US interventions may affect modern day levels of Caribbean political corruption. This chapter focuses closely on the evolution of the concept of political corruption in the Caribbean, i.e., how governing elite separated their public office duties from their private interests.

\section{Corruption Across the Spanish Main}

As early as Christopher Columbus's return from his first 1492 encounter with the New World, the Spanish crown worried about the abuse of public office in the administration of its new colonies. Under the existing fifteenth century Roman law, the Spanish crown declared itself the sole proprietor of the territories and populations of the 
New World that Columbus discovered (Borah, 1964, p. 47; Crow, 1992, p. 165). With corruption rampant among the aristocracy and merchants of fifteenth century Spain, the crown initially attempted to prevent its colonial representatives from illegally appropriating wealth rightfully belonging to the Spanish treasury.

The Spanish crown instituted a colonial revenue system based upon tariffs and taxes on colonial trade, including a Royal levy of one-fifth (el quinto) of all wealth generated from New World mining ventures (gold, silver, precious stones, etc.) (Haring 1947, pp. 256-292). The establishment of a feudal tribute on the indigenous Amerindians generated additional funds. Recognizing the potential for graft and corruption from the enormous wealth expected to flow into the Spanish treasury from the New World, the Spanish crown devised a colonial system with several key measures to thwart colonial officials from abusing their public office. Many of the these fifteenth and sixteenth century Spanish anti-corruption measures remain the core of contemporary anticorruption programs.

To prevent corruption, senior colonial officials dispatched from Spain—including viceroys, governors, audiencias (legislative courts), captain-generals, oficiales reales (treasury agents) —were subject to numerous financial and social restrictions. First, most officials were required to declare their net worth before being appointed to a colonial office (Haring, 1947, pp. 280-281). Second, during the term of their assignments (purposely limited to two, three, or five years) senior colonial officials were prohibited from personal business involvement in their colonial territory. They were forbidden to accumulate property or engage in other business that provided additional income 
(McFarlane, 1996, p. 49). As an offset for this income restriction, and as a further incentive to avoid corruption, the most senior officials were paid enormous salaries. For example, colonial viceroys were paid from $\$ 45,000$ to $\$ 65,000$ in gold annually, when Spanish soldiers in the same period received only $\$ 300$ to $\$ 600$ (Crow, 1992, pp. 165 166). ${ }^{1}$ Third, restrictions were placed on senior colonial officials' social relations. Senior colonial officials were prohibited from: marrying while in office; being godfathers; receiving personal gifts; and assisting in private celebrations, except in their official capacity (Crow, 1992, p. 166). Finally, upon completion of their assignment, senior Spanish colonial officials were subject to a residencia, an independent judicial review of their finances and personal conduct while in office.

As a further anti-corruption measure, the Spanish crown also instituted a system of checks and balances among colonial officials. While viceroys, governors, and captaingenerals performed the executive policy-making and supervisory functions in their respective geographic regions, a parallel system of Spanish courts was instituted to check the power of individual executives. Audiencias, a combination appellate court and quasilegislature, were the most senior of these courts and were collocated with the viceroys and governors. Spanish oficiales reales, those who collected and disbursed the crown's revenues, also worked autonomously from other senior colonial officials. As a further check on colonial administration, the Spanish crown dispatched a stream of colonial investigators with the high-sounding titles of pesquisadores (investigators), visitadores (visitors), and veedores (seers) (Crow, 1992, p. 167). Unfortunately, for both the crown 
and the colonies, the system of checks and balances and the personal restrictions placed on colonial officials were ineffectual at thwarting corruption.

Despite the Spanish crown's anti-corruption measures, personal venality of colonial officials became the ruling standard throughout the Spanish colonies. With thousands of miles separating the colonies from the Spanish crown in Madrid, and a poor system of communications (sailing ship) that did not improve substantially from the fifteenth to early nineteenth centuries, Spanish colonial officials experienced wide discretion in enacting and enforcing Spanish colonial rules. While there were some notably honest and effective Spanish colonial officials, it became more common for colonial officials at all levels, often acting in collusion, to engage in the theft of the Spanish crown's wealth, not to mention the brutal abuse of the Amerindians and later African slave populations.

Notwithstanding the enormous inflow of gold, silver, Amerindian tributes, tariffs, and other tax revenues into the Spanish treasury in the sixteenth century, the Spanish crown found itself nearing bankruptcy by the late sixteenth century (Borah, 1964, p. 47; Williams, 1970, p. 54). The cost of Spain's European military campaigns, the cost of maintaining the New World Empire, and the effects of widespread colonial corruption, all contributed to Spain's late sixteenth century financial straits. Desperate to find new sources of income from the New World colonies, in 1559 the Spanish crown authorized the first sale of colonial offices. Beginning with notarial offices, the sale of Spanish colonial civil offices eventually expanded and by the eighteenth century almost every 
colonial office, with the exception of viceroys and audiencias, were up for sale by the Spanish crown (Borah, 1964, p. 47).

Sale of offices, especially the sale of the positions of oficiales reales, was an outright license for Spanish colonial corruption (Haring, 1947, p. 280). Through the sale of Spanish colonial offices, the crown recognized its inability to hold colonial officials accountable, thus accepting that mid and low-level colonial officials would augment their small salaries through fraud and theft of the crown's New World resources. To increase Spanish crown revenues further, the actual number of colonial offices quickly expanded soon after offices were first placed on sale. By the seventeenth century, the Spanish crown had exchanged virtual nonintervention in colonial bureaucratic affairs for the recurring revenue generated by the sale of colonial offices and taxes on the salaries of these offices. Moreover, colonial bureaucratic efficiency plummeted and corruption accelerated soon after the sale of offices began (McFarlane, 1996, p. 51).

The report of a 1735 to 1746 visitadore to South America illustrates the extent of Spanish colonial corruption (1749 report summarized in McFarlane, 1996). In their travels around the Americas, the two man visitadore found viceroys engaging in prohibited trade activities, receiving gifts in return for favors, selling offices for private profit, and appointing family and friends to offices so that both the appointee and viceroy could profit from them. Audiencia judges were found involved in commercial enterprises and using their office to protect and advance their personal ventures. One Panamanian audiencia judge was documented openly auctioning his votes on the court to the highest bidders. The visitadore accused several corregidores, supervisors of Amerindian 
communities, of tyranny because of their abuse of Amerindian labor for personal profit, skimming of Amerindian tribute payments, and forcing of Amerindian communities to buy unneeded Spanish products at inflated prices. The visitadore also found oficiales reales involved in fraud and embezzlement of crown funds. As an explanation for the causes of corruption in the Spanish colonies the visitadore offered:

The Indies are abundant, rich and flourishing. As such, they are exposed to indolence and luxury. Far removed from the king and his high ministers and governed by people who often neglect the public interest for their own, those areas are now in a bad state because of the longevity and deep-rooted character of these ills (quoted in McFarlane, 1996, p. 44).

This visitadore report highlights the rampant corruption existing during the entire Spanish colonial period. It shows that despite early Spanish crown efforts to thwart colonial corruption, a standard of separating public office duties from personal selfinterest never took root in the Spanish controlled regions of the New World. As the nineteenth century independence movements began in the Spanish colonies, the newly independent states were saddled with a 300-year tradition of weak and corrupt governmental institutions. The Spanish Creole elite that took control of the newly independent Latin American states were not social revolutionaries (Randall \& Mount, 1998, pp. 18-19) - their primary objective in the colonial wars of independence was to overthrow the hated Spanish colonial administration (Andreski, 1966, p. 178). The only radical actions taken by the Creoles were the post-independence abolishment of slavery and the outlawing of the sale of public offices. Instead, across the region of former Spanish colonial states, the Creole upper and middle class political and economic elite came into constant conflict both among themselves and with a newly emerging military 
elite as factions sought the re-establishment of monopolistic political and economic power structures similar to those the upper and middle classes enjoyed under Spanish colonial rule. The independence of Spain's New World colonies began a two-century tradition of political turmoil, authoritarianism, and caudillo (strongman) politics that continued Latin America's legacy of rampant political corruption.

Miller (1996) offers three primary reasons why political corruption flourished in post-independence Spanish-speaking America. First, the new Latin American states were desperately short of financial resources. With their economies plagued by contraband smuggling and otherwise unable to generate sufficient tariff revenues, the new states became dependent on short-term financial support from leading domestic businessmen. Corruption prospered in the emerging clientelistic environment with domestic businessmen trading their financial assistance to authoritarian political officials in exchange for monopolies in government contracts and government resource exploitation (Miller, 1996, pp. 69-70).

Second, while the norm of separating public office duties from private interest barely existed in Spanish colonial times, there was at least minimal autonomy between colonial officials and local business elite. This autonomy completely disappeared after independence, as what colonial professional bureaucracy did exist vanished and political patronage (the filling of government positions with personal friends or political supporters) replaced the colonial period sale of offices. Patronage became the lubricant for the region's expanding system of clientelistic politics. 
Third, due to a shortage of revenues to pay regular and adequate salaries to government officials, corruption increased as officials in the newly independent states augmented their incomes through their control of government resources. This was especially true for those gaining government office through political patronage—as patronage positions often carried no salaries but did provide a license for individuals to exploit their access to government resources (Miller, 1996, pp. 69-70). Thus, political patronage and clientelistic politics became primary sources of both personal power and personal fortunes in the newly independent states of Latin America-conditions that have continued in the contemporary Spanish-speaking Caribbean..

\section{Corruption in the Colonies of Spain's European Rivals}

A Caribbean imperialist rivalry between Spain and its European antagonists of England (Britain after 1707), France, and Holland began soon after Columbus's discovery of the New World. In fact, on the return from his first voyage, Columbus was forced to evade French pirates lingering off the European coast (Williams, 1970, p. 73). Over the course of the sixteenth and seventeenth centuries, Spain's European competitors used three principal tactics in their quest to weaken Spain's monopolistic hold on the New World and to breathe new life into their own commerce. These tactics contributed to the violence and instability prevalent in the colonial Caribbean.

First, Spain's European rivals sent their own fleets or sanctioned privateers to raid Spanish shipping. These maritime operations were carried out both in European waters and in the Caribbean. The most successful fleet operations in the colonial era were the interceptions of Spain's entire treasure fleet in 1628 by Dutch Admiral Piet Heyn and 
again in 1655 and 1657 by English Admiral Robert Blake (Williams, 1970, pp. 84-85).

Privateers such as Sir Francis Drake and Sir Henry Morgan, along with many others now enshrined in the lore of privateering and piracy on the Spanish Main, also successfully harried the Spanish Caribbean shipping routes.

Second, Spain's European challengers instituted a system of contraband smuggling throughout the Caribbean as they sought to undermine Spain's economic monopoly in the region. The contraband business in precious metals, gemstones, tropical agriculture products, and European manufactured goods included trade not only among the Caribbean colonies, but also between the colonies and Europe. Williams (1970, p. 75) offers that the intensity of this contraband trade, fueled largely by the violent privateering and piracy, made the Caribbean situation in many respects a "continuation of war by other means" among the European powers.

Third, having established through maritime raids and the contraband trade that Spain was unable to adequately defend its Empire, Spain's European rivals next began to infringe on Spain's territorial monopoly in the Caribbean (Williams, 1970, p. 75). By the mid-sixteenth century, it was apparent that the Caribbean islands held little in the way of gold and silver, causing the Spanish conquistadors to migrate in the search for riches from the Caribbean to the newly found lands in New Spain (Mexico and Central America) and South America. With the exception of Spanish strongholds in the strategic ports of Havana, Santo Domingo, and San Juan, other Spanish Caribbean island possessions became sparsely populated and barely defensible. Through a combination of direct military attacks; land raids by privateers, pirates, and buccaneers; and treaty negotiations 
surrounding the settlement of European wars; the English, French, and Dutch began acquiring their own Caribbean colonies in the seventeenth century. These eventually included the smaller islands of the Lesser Antilles, the larger islands of Jamaica and Haiti (western half of Hispaniola), and the mainland areas of British Honduras (Belize), British Guiana (Guyana), Dutch Guiana (Suriname), and French Guiana.

Once Spain's European competitors gained their own Caribbean possessions, they instituted entirely different systems of empire from Spain's. While Spain's main purpose of empire was to enlarge the Spanish treasury, the primary objectives of England and France for their Caribbean colonies were as tropical agricultural producers and as monopoly markets for their own manufactured goods. The Dutch, on the other hand, organized their Caribbean colonies as strategic ports in the Dutch commercial mercantilist system, with tropical agriculture as an important but secondary objective. It is not surprising that due to differing purposes for their colonies; combined with differing European political, economic, and cultural traditions used to organize and govern their colonies, that colonial-period political corruption in the English, French, and Dutch colonies was systemically different from that found in Spain's possessions.

Political Corruption in the British West Indies. English colonial objectives and governing methods were far different from Spain's. Where the Spanish crown's system of feudal tributes, taxes from New World mining and agricultural enterprises, and the revenues from the sale of and taxes on colonial offices constituted Spain's primary revenue sources, the English crown's main interest was to stimulate English commerce. While Spain first instituted plantations to grow tropical agricultural products, the English 
perfected the use of plantation societies where English owners and overseers exploited African slave labor. Since the plantations and the commercial trade with the English colonies were private ventures, the English crown received only tariff and tax revenues from its Caribbean possessions. Although there was some variance among English colonies, their government institutions were designed to support the plantation societies and consisted of a governor and a legislative council, both appointed by the English crown, and a local assembly, elected from the colony's freeholders, a small oligarchy of white plantation owners and merchants (Parry et al., 1987, pp. 182-183).

The English colonies were governed by acts promulgated in London, constitutions developed by local assemblies, and by decree of the colonial governor. The governor was the most powerful figure in the English colonial system as all crown responsibility for colonial government rested with him. The instructions to one appointed Jamaican governor read:

He was captain-general and vice-admiral of the fleet; with the legislative assembly he was the supreme tribunal in civil matters; he had the final voice in the passing of legislation; he had to preserve good relations with the assembly and keep the machines of government working (Parry et al., 1987, p. 183).

In seventeenth century England, theft of crown property and mismanagement of government resources were already serious problems associated with the English sale of public office (see Peck, 1978). There was no professional English civil service. English public offices were briskly bought and sold and officials used Royal property as if it were their own (Peck, 1978, p. 221). Many offices were sinecures that offered good pay and little work (Peck, 1978, p. 221). Miller (1976, p. 3) highlights, “[s]eventeenth-century Englishmen believed there was nothing immoral or illegal in an official accepting-or 
even soliciting - graft and bribes. Corruption [graft], in fact, was the lubricant that greased the wheels of the nation's administrative machinery." The lack of English standards separating public office duties from private interest naturally carried over to the English colonial administration.

English colonial governors, with only their legislative councils and local assemblies as checks, used their extensive powers to reward friends, clients, and supporters. There were several areas where the governors concentrated their most nefarious self-interested activities (see Miller, 1976, chap. 2). First, English governors controlled colonial land grants. Most notable in newer and larger colonies, the governor was free to issue new parcels of land to those in the best position to reward the governor either financially or personally. Often this included the governor issuing land to himself or other family members. Second, governors controlled locally many of the rules of trade for importation and exportation in their respective colony. This included the enactment of and methods for collecting various tariffs and taxes on business ventures. As with land grants, the governors could mold these rules such that their friends, clients, or supporters-not to mention their own commercial endeavors-benefited most. Third, Caribbean piracy and buccaneering, and the continuing commercial contraband trade, required friendly governors that would allow the landing and sale of stolen and bootleg goods. Many English colonial governors grew rich from their support of this black marketeering trade (Miller, 1976, pp. 23-25). Port Royal, Jamaica, located at the mouth of the colonial capital harbor in Kingston, was just one of the pirate and buccaneer havens in collusion with the local colonial government. As evidence of the English acceptability 
of this black marketeering, Henry Morgan, one of Port Royal's most notorious pirates, was later knighted and appointed Deputy Governor of Jamaica.

In the early nineteenth century, the tradition of British colonial graft and mismanagement slowly began to change. Influenced by the ideas of the Enlightenment and the French Revolution, in 1809 a British act was passed prohibiting the sale of public office. This was followed in 1827 by an act making both the offer and acceptance of bribes by government officials illegal (Finer, 1952, p. 125). As British sovereignty in the early nineteenth century slowly shifted from the monarch to the parliament, a competitive and increasingly honest and non-corrupt British government and Home Civil Service began to emerge. Thus, the concept of separating public office duties from private interests first grew in British home-government. The same grasp for honest administration did not immediately take hold in the British Colonial Service. Instead, nineteenth century colonial governors and other officials were appointed not by sale of office but through a system of political patronage that evolved within the Colonial Office.

A watershed in British colonial government occurred with the 1833 abolition of Caribbean slavery. Wage labor replaced the forced labor of African slaves and resulted in massive social changes in the Caribbean colonies as the former slaves abandoned the plantations. During this period of rapid social change, the British colonies retained their system of government based on appointed governors, locally elected assemblies, and their ancient constitutions. The mass of former British slaves were still not allowed to vote in the nineteenth century Caribbean colonies due to previous suffrage property qualifications. However, within several decades of the abolishment of slavery, many 
industrious mulattos and freed slaves did accumulate sufficient property and wealth to become registered voters and some were even elected to local assemblies.

The inclusion of mulattos and former slaves in colonial assemblies caused two major areas of tension in colonial administration. First, the previously powerful white planter and merchant oligarchies became distressed over their gradual loss of power, with many opting to sell their Caribbean holdings and migrate back to Britain. Second, the political, economic, and social expectations of the colonial mulattos and former slaves grew along with their acquisition of more economic and legislative power. The tensions relating to such expectations came to a boil in October 1865 in Morant Bay, Jamaica, in a colonial atmosphere described by Parry et al. (1987):

In Jamaica, as in most of the West Indian islands at this period, there was almost a complete lack of candidates able and willing to devote themselves to the task of government. Total apathy towards political matters and a supreme indifference pervaded the West Indian atmosphere....[revealing] a society completely lacking in balance and stability. Violent passions, bitter animosities and complete absence of toleration overwhelmed the island[s]...(Parry et al., 1987, pp. 188-189).

The aftermath of the 1865 Morant Bay rebellion set off a series of events that affected both the type of rule and levels of corruption found in British Caribbean colonies through the end of World War II. The 1865 rebellion began as a local protest at the Morant Bay courthouse over the arrest of several locals. When the crowd failed to disperse as ordered, they were fired upon by Jamaican militia, killing seven protesters. The protest grew and rioters burned the courthouse and killed several local officials. Governor Edward J. Eyre responded with the British military, Jamaican militia, and troops of Maroons, former runaway slaves that had entered into a treaty with the 
government. Eyre eventually restored order to the area, costing 450 Jamaican deaths (354 executed by death penalty), 1,000 burned homes, and an untold number of floggings and other acts of brutality. The British investigation into the Morant Bay rebellion later cleared Eyre of charges of brutality and murder (Hart ,1998, pp. 60-87; Knight, 1990, pp. 281-283; Williams, 1970, pp. 399-402; Parry et al., 1987, pp. 187-190).

The Morant Bay uprising scared both the British Parliament and the colonial white oligarchies, convincing them that representative rule incorporating former slaves was not workable. As a result, with the exception of Barbados and Bermuda where strong local assemblies and stable social conditions prevailed, the British dissolved other existing colonial assemblies and suspended colonial constitutions, implementing Crown Colony rule across the region. ${ }^{2}$ British colonial rule in the Caribbean from 1865 until after World War II was based predominately on the Crown Colony system whereby the British colonial governor maintained absolute rule, checked only by British Colonial Office directives and the advice of an appointed local legislative council (Hart, 1998, pp. 80-87).

The British Caribbean became a neglected backwater of the British Empire during the late nineteenth and early twentieth centuries. The demand for their tropical agricultural exports waxed and waned, generating high unemployment rates that caused many inhabitants to migrate to Europe or North America. In Britain, the Home Civil Service continued to professionalize and became a model of honest bureaucracy. While the British Colonial Service never professionalized to the extent of its cousin Home Civil 
Service, over the years it did internalize a credo of efficient administration — gradually strengthening its policies separating public office duties from private interests.

As late as the 1930s, appointments to the British Colonial Service were still based on a political patronage system controlled exclusively by the Colonial Office. Colonial governors continued to be appointed from the British upper class, those with distinguished military or other public careers, or those having served long periods with the Colonial Office. Colonial administrative positions, like those in the Home Civil Service, became almost the exclusive monopoly of graduates of Cambridge and Oxford universities. By the 1930s, colonial administration had assumed the ethos of the English gentleman. Lewis (1968) submits that by the post-World War II independence movements in the British Caribbean, the British left behind a political legacy that, while not representative:

On its positive side, it was incorruptible, highly motivated, passionately conscious of duty and conduct. It was determinedly constitutionalist, although the Crown Colony system placed severe strains on constitutionalism. It cared for civil liberties....It was not even afraid to declare its own faults....(Lewis, 1968, p. 115).

As the British Caribbean colonies approached the post-World War II colonial independence movement, there developed a strong British Colonial Service standard of the separation of public office from private interest-making political corruption only a minor problem.

Haiti Becomes a Kleptocracy. While the French Caribbean colonies were smaller in number than those of the British, they were vastly more important for France's overseas commerce. In 1789, Saint Domingue (Haiti) alone generated 40 percent of French 
foreign trade as it provided half of the coffee consumed in Europe and more sugar than all the British colonies combined (Randall \& Mount, 1998, p. 16). Organizing their colonies around the plantation society model, the French ruled their Caribbean colonies through an authoritarian and militaristic government more resembling Spain's than the representative system used by England before 1865. French colonial government included a governor, intendent, law courts, and military garrison (Geggus, 1989, p. 26). The governor, usually of French noble birth or military background, was responsible for the colony's defense and the enforcement of French imperial commercial regulations. The intendent, the second senior French official in the colony, oversaw all other aspects of colonial administration (Thompson, 1997, p. 44).

Of all the European colonial powers, imperial France had the strongest tradition of the sale of public offices. In France, sale of office was legally equivalent to the buyer's right to other property-including the right to either resell the office or pass it to future generations (Swart, 1949, p. 82). As in Spanish and British colonies, graft and theft of French imperial property became widespread in French colonial administration. As the French colonies approached the nineteenth century there was no standard of separating public office duties from private interest.

French ideas of governance and its hold on Caribbean colonies changed with the 1789 French Revolution. The French Revolution provided the initial spark that ignited smoldering racial resentment in France's most populous Caribbean colony (Randall \& Mount, 1998, p. 15). Saint Domingue's 40,000 white and 26,000 free people of color favored the French Revolution's declarations of Republican values of personal liberty, 
equality, and security - but in vastly different ways. The white planters and merchants saw liberty and equality in terms of more local autonomy for them from the French court. The free people of color, including many plantation owners, small merchants, and professionals, viewed equality to mean their receipt of rights equal to the whites. Neither the whites nor the free people of color were in favor of freeing Saint Domingue's 500,000 African slaves. When the French government declared the end of Caribbean slavery in 1790, with little or no consultation with Saint Domingue's elite, the announcement unleashed a more than decade-long brutal race war in Saint Domingue, interspersed with interventions of French and Spanish troops. In 1804, the state of Haiti emerged from this violent turmoil as a coalition of the triumphant free people of color and former slaves declared full independence from France.

Wilentz (1989, p. 207) offers "[s]ince the Revolution of 1804, groupuscule [small group] allegiances, cults of personality and a reliance on spoils and revenge have characterized Haitian politics." Steeped in continual violence and widespread corruption, the nearly two centuries of Haitian independence have seen the rise of a perpetual kleptocracy. Andreski (1966, pp. 62-69) characterizes a kleptocracy as a form of government parasitism - where corruption permeates every level of government. Highlevel Haitian officials (presidents, ministers, etc.) amassed huge fortunes while in office. Mid-level public and military officials also used their access to government resources to increase their often-meager salaries. In a kleptocracy, the solicitation of bribes is also epidemic among low-level officials such as customs, immigration, and police officers. In Haiti's post-independence history, the high and mid-level kleptocrats encompassed the 
educated mulattos and military officials that made up the state's political and economic elite. The poor masses become the victims of a kleptocracy. As Andreski (1968, p. 64) submits: "[o]wing to their political power, the wealthy...keep direct taxes low and...shift the burden onto the poor by making the state rely on taxes on sale of articles of popular consumption." This partly explains why, after nearly 200 years of independence, Haiti remains steeped in poverty, consistently producing the lowest per capita income of any Caribbean state over the last two centuries. In a kleptocracy, such as Haiti, there is no standard of separating public office duties from private interests.

Dutch Commercial Corruption. The Dutch Caribbean colonies, fewest in number and smallest in land area of those of the European colonial powers, were governed through a partnership of the Dutch crown and the Dutch West India (DWI) Company. The Dutch crown sent a commander or governor from Holland to administer each colony. Like the English, the Dutch allowed a limited system of local representation in most of their colonies through a local assembly or council elected from the colony's white merchants and planters. The colonies were ruled by a combination of laws enacted by the Dutch government and those passed locally. Any laws passed in the Dutch colonies were subject to the ratification of both the DWI Company and the Dutch government (Thompson, 1997, p. 46). The DWI Company controlled the colonies' commercial trade. While sale of public office did occur in Holland, it was on a much smaller scale than sales in Spain, England, and France (Swart, 1949, p. 85). This did not mean, however, that the Dutch colonies were any less involved in graft, just that in the Dutch colonies the graft 
usually occurred with DWI Company commercial resources and not those of the Dutch crown.

Prior to the nineteenth century, graft was common in the Dutch India Companies (West and East). The men of the company "were underpaid and exposed to every temptation that was offered by a combination of a weak...organization [colonial governments], extraordinary opportunities in trade, and an almost complete absence of checks from home....'(Smith, 1971, p. 425). DWI Company officials became rich by stealing from the company. As the nineteenth century dawned, however, Dutch standards concerning graft and corruption changed similarly to what had occurred in Britain. In the nineteenth century, the DWI Company took on a lesser role in colonial management and the Dutch colonial service became more professionalized and honest.

By the mid-twentieth century the Dutch had turned over most of the colonial rule to local representatives. As in the British colonies, the nineteenth and early twentieth centuries saw the evolution of a Dutch Caribbean standard that separated public office duties from private interests.

\section{US Caribbean Interventions}

The history of Caribbean graft and corruption would be incomplete without surveying the role of the nineteenth and early twentieth century US interventions in the region. During its first century of independence (1776-1876), the US experienced its own wave of graft and corruption. Having thrown off the yoke of British colonial corruption, the US was born in the late eighteenth century in a wave of honest intent as promulgated by the US Founding Fathers in the Declaration of Independence and US Constitution. 
However, by the early nineteenth century, US electioneering and access to public offices became entangled in a system of political patronage. US graft and corruption reached its peak in the 1860s and 1870s, the so-called Gilded Age that was characterized by the licentious alliance of US business and politics (see Johnston, 1982). In the 1890s, the US Progressive Movement emerged as a counter to the wealthy and powerful US economic elite and the growing social injustices seen resulting from US industrialization. The Progressive Movement was intent on making the US political machinery more democratic by increasing its efficiency, rationality, and expertise (Gould, 1974, p. 4). An assault on graft and corruption was a major plank of the Progressive Movement platform. It was in this Progressive Era atmosphere that the US first intervened in the Caribbean.

The US's first Caribbean intervention was the 1898 Spanish-American War. The US wresting of both Cuba and Puerto Rico from Spain ended Spanish Caribbean colonialism. The US intent was to grant Cuba its independence soon after the war. However, the US distrusted the Cuban elite who were suspected of being just as prone to corruption and misgovernance as their former Spanish rulers-a suspicion proven true throughout the twentieth century. Therefore, as a condition of Cuban independence, the infamous 1901 Platt Amendment was enacted by US-Cuban treaty allowing the US the right of intervention in the event Cuban authorities failed to protect life, property, and liberty (Randall \& Mount, 1998, p. 35). The US later acted on this treaty by intervening in Cuba in 1906-1909, 1912, and 1917-1922.

The epitome of US Progressive Era presidents was Theodore "Teddy" Roosevelt (T.R.) (1901-1909). One of Roosevelt's first major encounters with Caribbean political 
corruption came with the 1903 negotiations with Colombia for the Panama Canal. In August 1903, when the Colombian Senate rejected the Hay-Herran Treaty that would authorize the US to build the Panama Canal, Roosevelt became distressed with the Colombians for two primary reasons. First, Colombian President Jose Marroquin had assured the US that the treaty would receive quick ratification after the US had assisted in negotiating an end to a bloody Colombian political civil war (1899-1902). Marroquin, in Roosevelt's view, broke Roosevelt's personal Golden Rule that a man's word was his bond (Marks, 1979, pp. 91-95).

Second, it appeared to Roosevelt that the main reason for the Colombian rejection of the Hay-Herran treaty was their attempt to increase the initial monetary indemnity (from US\$10 million to US\$20 million) they would receive from the treaty. In conversations and correspondence after the rejection of the treaty, Roosevelt, normally circumspect in his diplomatic discourse, publicly hurled a flurry of assaults toward the Colombians, characterizing them as: "backwards people," "[at] corrupt and evil purposes," "complete governmental incompetence," "road agents... who [tried] to hold-up a United States official," "a Bogota lot of jack rabbits," "the little wildcat republic," "a corrupt pithecoid [ape-like] community," and "homicidal corruptionists" (Burton, 1968, p. 125; Chessman, 1969, pp. 99-100; Cooper, 1983, p. 71; and Mowry, 1958, p. 150-151). One historian summarized US perceptions of the Colombians as:

The truth was the Americans did not feel that they were dealing with a friendly nation. They looked upon the rejection of the Hay-Herran Treaty by the Colombian Senate as what they would call a "hold-up"- a scheme to interfere, for the sake of personal profit [corruption], with a work which was to benefit all humanity (Collidge, 1908, p. 277). 
History records that Roosevelt resolved the canal crisis by dispatching US naval forces to intervene in the November 1903 Panamanian independence rebellion, assuring the Panamanian victory by keeping Colombian forces from suppressing the rebellion. Not surprisingly, only two weeks after the rebellion, the US signed a canal treaty with the newly independent Panamanian state. Roosevelt's resistance to Colombia's perceived corrupt behavior was a major factor in his decision to intervene in 1903 Panama.

The Panama Canal incident was not Roosevelt's only encounter with Caribbean political corruption. When he entered the White House in 1901, the Caribbean's independent states suffered in a general malaise of poverty, high unemployment, economic stagnation, and severe indebtedness. The Caribbean had already established a long history of debt defaults characterized by "fraud, chicanery, heavy losses for the unwary, refunding arrangements, and fresh defaults" (Kneer, 1975, p. xii). Political corruption was a major contributor to the Caribbean debt problem. By 1902, six Caribbean states-Colombia, Costa Rica, Dominican Republic, Guatemala, Honduras, and Venezuela - were in default on foreign (mainly European) loans (Kneer, 1975, p. xii). To hold their European creditors at bay, the Caribbean states conveniently called attention to the US Monroe Doctrine that proscribed the intervention of European powers in the Western Hemisphere. Roosevelt was not about to let the corrupt Caribbean governing elite hide behind the Monroe Doctrine. Faced with crises where European creditors threatened armed intervention in 1902 Venezuela and 1904 Dominican Republic, Roosevelt felt he was forced into declaring in February 1905:

Chronic wrongdoing...may in America, as elsewhere, ultimately require intervention by some civilized nation, and in the Western Hemisphere the 
adherence of the United States to the Monroe Doctrine may force the United States, however reluctantly, in flagrant cases of such wrongdoing or impotence, to the exercise of an international police power (quoted in Watson, 1976, p. 112).

This Roosevelt Corollary to the Monroe Doctrine provided the justification for his intervention for financial supervision in the Dominican Republic in 1905 and for a number of other US interventions in the Caribbean through the 1930s. These included the interventions in Cuba cited above, Haiti (1915-1934), Dominican Republic (19161924, financial supervision 1905-1941), and Nicaragua (1909-1910, 1912-1925, financial supervision 1911-1924) (Randall \& Mount, 1998, p. 6).

There are many competing explanations for the numerous US interventions in the Caribbean during the presidential term of Teddy Roosevelt, and those of presidents William H. Taft (1909-1913) and Woodrow Wilson (1913-1921), which followed in the wake of the Roosevelt Corollary to the Monroe Doctrine. Despite the early twentieth century era sometimes being dubbed one of dollar diplomacy, some historians discount that these early twentieth century US presidents acted out of concerns for US business interests (Bemis, 1943; Hill, 1965). In fact, beginning with Roosevelt, the trustbuster, these three early twentieth century US presidents were not allied closely with US big business. That US business benefited for the interventions is an unintended consequence of the US actions. On Roosevelt's relationship with US business interests, Hill (1965) offers:

Roosevelt's policy does not seem to have been influenced to any marked degree by a desire to stimulate the economic penetration of the Caribbean by American business men and American corporations.... That Roosevelt was influenced in his Caribbean policy by the economic tendencies of his day is of course beyond question, but no evidence has been found to support the thesis that either his 
measures or his actions were determined by, or were the result of, economic considerations pressed upon him by American financiers, business men, and corporations. (Hill, 1965, pp. 211-212)

Hill (1965, chap. 8) instead argues that Roosevelt's Caribbean actions were opportunistic in nature, but were guided by his devotion to the cause of US national security. Roosevelt's, and later Taft and Wilson's, national security concerns in the Caribbean focused on building and providing defense for the Panama Canal. For strictly geopolitical strategic reasons, the US could not allow a European power to intervene in a Caribbean state and attain basing rights that could threaten the canal or its approaches. Political corruption in the Caribbean's independent states contributed to the region's political and financial instability and could have lead to a European intervention. Therefore, Caribbean political corruption was a factor leading to the early twentieth century US interventions in the region.

Another explanation for President Woodrow Wilson's proclivity to intervene in the Caribbean was his tendency toward missionary diplomacy. Still primarily acting in US geopolitical strategic interests to protect the Panama Canal, the stern Presbyterian Wilson displayed a special zeal for "saving the [Caribbean] people from bad government, tyranny, and economic exploitation...." (Bemis, 1943, p. 185). Wilson aimed to institute a "politics of morality which...would inspire and uplift Caribbean governments in their presumed quest for financial respectability and an honest ballot" (Langley, 1980, p. 63). Wilson was particularly annoyed at unprincipled Caribbean politicians who "sought office for personal gain rather than for public good" (Langley, 1980, p. 63). Wilson's version of the White Man's Burden thus helped dictate US policy in the Caribbean during 
his term that included US interventions in Cuba, Haiti, Dominican Republic, and Nicaragua.

Despite their initial strong moral overtones, US interventions in the nineteenth and early twentieth century Caribbean did little to lower political corruption levels in the former Spanish and French colonies. The US standard Caribbean intervention script(1) intervene and establish political and financial stability, (2) organize and train local security forces, (3) establish an efficient state bureaucracy, (4) hold local elections, and (5) depart declaring political and moral victory — played directly into the hands of later authoritarian rulers that used their powerful US-trained security forces to seize and maintain power and extract vast rents from domestic and international actors.

\section{Changing the Caribbean Political Corruption Rules}

Determining that US moralism and idealism in the Caribbean were counterproductive to US foreign policy objectives, in 1933 President Franklin D. Roosevelt instituted the US Good Neighbor policy that repudiated both the Platt Amendment and the Roosevelt Corollary to the Monroe Doctrine, and eventually led to US formal acceptance of the principle of non-intervention in Caribbean states' internal affairs. An unintended consequence of the Good Neighbor policy was US acquiescence to Caribbean political corruption. One objective behind the US Good Neighbor policy was to keep the Caribbean and Latin American states within the US sphere of influence as war clouds formed over Europe and Asia in the 1930s. The US objective was to influence Western Hemispheric states to be anti-Nazi, anti-Fascist, or at least neutral in the looming World War. Franklin D. Roosevelt's acquiescence to authoritarian and corrupt Caribbean 
governments is clear in his reaction to Dominican Republic leader Rafael Trujillo's use of power to benefit his own private ends. When discussing the Dominican dictator's situation, Roosevelt submitted, "He may be an S.O.B., but he is our S.O.B." (quoted in Williams, 1970, p. 465). The US followed this same our S.O.B. script in the post-World War II period when it was no longer Nazism or Fascism but Communism the US feared taking hold in the Caribbean. In Roorda's (1998, p. 1) words "[t]he Good Neighbor policy demonstrated to a generation of Caribbean dictators that they were free to run their countries however they pleased, so long as they maintained common enemies with the United States: first the fascists, then the communists."

Table 3-1 provides the estimated corrupt take by some of the more notorious S.O.B.s the US condoned in both the pre- and post-World War II period.

Table 3-1. Selected Caribbean S.O.B.s

\begin{tabular}{llll}
\hline Caribbean State & Leader & $\begin{array}{l}\text { Years in } \\
\text { Power }\end{array}$ & $\begin{array}{l}\text { Estimated Take } \\
\text { (in millions US\$) }\end{array}$ \\
Cuba & Grau & $1944-48$ & 174 \\
Cuba & Prio & $1948-52$ & 20 \\
Cuba & Batista & $1952-58$ & 300 \\
Dominican Republic & Trujillo & $1930-61$ & 1,000 \\
Haiti & Duvalier(s) & $1951-86$ & 700 \\
Panama & Noriega & $1981-89$ & 772 \\
Nicaragua & Somoza(s) & $1937-79$ & 600 \\
Venezuela & Gomez & $1910-35$ & 200 \\
Venezuela & Perez Jimenez & $1952-85$ & 400 \\
\hline
\end{tabular}

Sources: Klitgaard (1988), Koster \& Sanchez (1990), Naylor (1987), Theobold (1990), Thompson (1997), Whitehead (1983).

The exact sources of the Table 3-1 corrupt takes will never be completely known; however, a large portion of each take resulted from bribes paid by foreign investors in 
individual Caribbean states. In the early twentieth century, foreign investors "insisted no company could do business in South America [or the Caribbean] without paying graft" (Braden, 1971, p. 296). A US ambassador to Cuba, with extensive business and diplomatic experience throughout Latin America, estimated that the 1930s and 1940s regional bribery "take was as high as 50 and 60 percent" on contracts and commercial transactions (Braden, 1971, p. 290). On his experiences in Cuba in the early 1940s, US Ambassador Spruille Braden wrote:

the Cuban officials had marvelous ingenuity in devising occasions for graft....I was appalled by the extent and scale of the corruption, and the apparent apathy of the public....Americans were indeed involved in it. They were doing business in Cuba, and that had always meant paying bribes and making contributions to political parties.... Indeed, Cuban big business was American, and it provided a source of graft and extortion running into many millions yearly....[For example, in one case] [t]he American Sugar Refining Co. was obliged to pay $\$ 113,000$ in graft...[in order to recover] the $\$ 226,000$ the [Cuban] government owed its mill at Jaranu. On that distribution I had the figures. Batista took $\$ 55,000$; Gen. Benitez, the Chief of Police, $\$ 25,000$; and even a very rich Senator took $\$ 11,000 \ldots$. The grafters were pitiless, sparing neither the poor, the young, the aged, or the ill (Braden, 1971, pp. 290-294).

Franklin D. Roosevelt's embrace of the our S.O.B. policy was just a precursor to the way the developed world approached the problem of political corruption from the 1930s through the end of the Cold War. During the course of world upheavals in the 1930s and 1940s, the rules concerning developed state intervention in developing states changed dramatically. With the 1945 formation of the United Nations and the subsequent collapse of colonialism, a new set of rules emerged pertaining to state sovereignty. These new rules were dispensed indiscriminately to both old and newly emerging states, including those in the Caribbean. Whereas before World War II a state had to earn its sovereignty and right to non-intervention by showing it could maintain internal stability, 
follow international norms, and provide public goods; after the war, the status of sovereignty and non-intervention were simply bestowed upon states by the international system. This new concept of sovereignty did not require any particular substantive condition in the new state, only the observance and forbearance of other members of the international community (Jackson, 1990, pp. 1, 11). Many states, including those in the Caribbean, used their new independent status of sovereignty as a shield to keep the international community from looking closely at illicit internal behaviors like political corruption. Sovereignty issues also became a favored excuse for states that lacked the political will or political capacity to comply with otherwise valid international requirements. Armed with the new rules of sovereignty and non-intervention, and combined with Cold War superpower protection in their spheres of influence, corrupt rulers, such as those in Table 3-1, felt doubly protected, by sovereignty and superpower force, as their corrupt governments depleted national treasuries and diverted state resources for their own private use. An unintended consequence of the post-World War II rules concerning sovereignty and intervention was their contribution to the nonaccountability of developing state governments that helped promote political corruption in the Caribbean.

\section{Conclusion}

From the above evidence, it is clear that the Caribbean colonial and postindependence periods through the 1940s saw significant political corruption. It is impossible to quantify the exact levels of this Caribbean colonial corruption. However, the corruption can be generally characterized. Political corruption permeated the colonial 
political and economic institutions of Spain, England (Britain), France, and the Netherlands from the beginning of the colonial period. After independence, the corruption continued unabated in the former colonies of Spain and French Haiti-perhaps even increasing. The former Spanish colonies and Haiti never established societal rules separating public office duties from private interests. After a legacy of early colonial political corruption, by the early nineteenth century new societal standards against corruption did appear in the former British and Dutch colonies. These changing rules were a direct result of the democratization of British and Dutch politics, including the professionalization of home and colonial bureaucracies. By the mid-twentieth century, political corruption was only a minor problem in the British and Dutch colonies.

The effects of US nineteenth and early twentieth century interventions on Caribbean political corruption levels are more difficult to determine. After US departure from Cuba, the Dominican Republic, Haiti, and Nicaragua, rules the US implemented separating public office from private interests were discarded and the political institutions the US left behind were used to establish dictatorships that became steeped in political corruption. Ambassador Braden's above description of conditions he found in early 1940s Cuba support this conclusion. Even in taking a counterfactual approach, i.e., analyzing the probable political corruption levels in those states if the US had never intervened, it is difficult to determine how the US interventions affected later political corruption levels. Before the US interventions these states were unstable and violent. If the US had not intervened, there is a good chance that instability and violence-along with the existing systemic corruption-would have continued as it did in other former 
Spanish colonies in the region. One undeniable conclusion from the US interventions, however, is that the dictatorships seizing power in these states after the US's departure strengthened the rules supporting political corruption behavior.

The realpolitik of Roosevelt's Good Neighbor policy institutionalized the US acceptance of corrupt authoritarian Caribbean rulers, a policy that carried over until the very end of the Cold War. The post-World War II changes in the international rules concerning sovereignty and intervention in developing states unintentionally strengthened the opportunities for developing state governing elite to be corrupt. Again, the lack of post-World War II international reaction to Caribbean political corruption activity strengthened the rules supporting the corrupt behavior.

Overall, the discussion in this chapter provides support to contemporary Caribbean governing elite arguments that the basis of present-day Caribbean political corruption can be found in their histories of colonialism and US interventions. Chapter 4, which evaluates contemporary Caribbean conditions concerning political corruption in more detail, provides further analysis of the effects of colonialism and neo-imperialism on Caribbean political corruption levels.

\section{Endnotes}

1. Crow provides these salary figures in Spanish ducats converted to US dollars. The exact conversion rate of these values to current US dollars is unknown. However, assuming the $\$ 300$ to $\$ 600$ soldier salaries would be the equivalent of US $\$ 20,000$ to US $\$ 40,000$ today, then the Spanish viceroys were paid today's equivalent of US $\$ 3,000,000$ to US $\$ 4,333,333$. Whatever the exact conversion rate, the salaries of Spanish colonial viceroys were extremely generous by sixteenth and seventeenth century standards. 
2. Trinidad and Tobago was already ruled by the Crown Colony system before the Morant Bay uprising, providing the British a governing model to follow in the rest of the region after 1865 . 


\section{Chapter 4}

\section{Contemporary Caribbean Political Corruption}

This chapter surveys Caribbean political and economic development and its association with political corruption in the last half of the twentieth century. It first looks at the different paths of post-war political and economic development that occurred across the Caribbean. It then makes a general assessment of key structural (causal) factors associated with contemporary Caribbean political corruption levels. Finally, the chapter describes some of the most prevalent types of political corruption behavior occurring in the Caribbean in the post-war period.

This chapter reviews the political and economic structures-rules, institutions, and unintended consequences-affecting contemporary Caribbean political corruption that took shape after World War II. The chapter's agency analysis looks at the Caribbean governing elite's role in post-war structural development. The analysis demonstrates that while the post-war Caribbean governing elite had numerous opportunities to establish rules to prevent corruption in their governing structures, they instead acted in their own personal best interests. This self-interested approach to development resulted in a strengthening, rather than a reform, of pre-war Caribbean structures that supported high levels of political corruption. How the Caribbean governing elite built (constituted) their state's post-war political and economic structures to serve their own private interests is an issue seldom highlighted in Caribbean political discourse. 


\section{Post-World War II Caribbean Structural Development}

Contemporary Caribbean political and economic structural conditions are largely the result of post-World War II development. During this period, the majority of regional constitutions were either written or reformed and new economic structures integrating the region into the world economy developed. The legacy of colonialism and US interventions in the region played a role in this development, as these factors helped define the social rule structure that the Caribbean governing elite inherited in the post-war period. Other significant factors in the region's development were the new post-war principles of sovereignty and non-intervention that allowed domestic governing elite to build their state's institutions with little outside interference. Thus, the essence of contemporary Caribbean political and economic structures is largely a product of development trends over the last half of the twentieth century.

Political Modernization. As with their colonial experiences, the former Spanish, British, French, and Dutch Caribbean colonies followed quite different post-World War II political modernization paths. The former Spanish Caribbean colonies experienced a string of authoritarian-dictatorial or authoritarian-democratic regimes (except Costa Rica and Puerto Rico). Many of the authoritarian-dictatorial regimes were installed by military coups that frequently cited rampant government corruption as the rational for their forcibly taking power. Most of the former British Caribbean colonies achieved independence in the post-war period and built their own unique brands of liberal- and authoritarian-democracies. The former French Caribbean colony of Haiti suffered under the authoritarian-dictatorial rule of the Duvalier dynasty from 1951 until 1986, when Jean 
Claude "Baby Doc" Duvalier fled into political exile. Since 1986, Haiti has undergone a series of internal power struggles that include several quasi-democratic starts-and-stops and a 1991 to 1994 period of authoritarian-military rule. In the post-war period, the French installed their unique brand of socialist-democracy in their former Caribbean colonies of French Guiana, Guadeloupe, and Martinique, and fully incorporated these territories into the French state as French Overseas Departments. Also during this period, the Dutch allowed their Caribbean colonies increasing self-rule, resulting in the independence of Dutch Guiana (Suriname) and the incorporation of the semi-autonomous Netherlands Antilles and Aruba into the Kingdom of the Netherlands. A review of the political development in the former Spanish and British colonies--the largest and most numerous independent states in the region-is indicative of contemporary Caribbean political conditions.

Contemporary political institutions in many of the Caribbean's former Spanish colonies are the result of a democratization wave that swept Latin America beginning in the early 1980s. During the 1960s and 1970s, many of the former Spanish colonies had been ruled, at least at times, by authoritarian-dictatorial regimes. ${ }^{1}$ During the 1980 s, many of these states broke the hold of their authoritarian-dictatorial leaders and began a process of democratization that transformed them into authoritarian-democratic regimes. An authoritarian-democratic regime is a weak representational democracy, often described as a facade democracy. In such states, elections, often not free and fair, are held to elect top political leaders. After elections, however, there is little public participation in political decision-making. Instead, important state decisions are made by 
a small group of political elite in the executive branch. This small group of political elite usually includes the state's president and his or her closest political and economic advisers. Legislatures and judiciaries play secondary, if any, roles in balancing the power of the strong executives in authoritarian-democratic states. Such states are ruled more by power than by law. One analyst characterizes authoritarian-democratic states as where "government remains a racket dominated by the powerful and the well-connected" (Payne, 1994, p. 26). It is these authoritarian-democratic regimes that carried the majority of Spanish-speaking Caribbean colonies states through the 1990s and into the twenty-first century (see D. Payne, 1992, 1993, 1994, 1995).

Understanding how authoritarian-democratic regimes arise in presidential governing systems requires a review of the rules constituting such systems. Drawn from the political philosophy of Montesquieu and Locke, presidential systems are based on the principle of separation of political power that establishes a structure of checks-andbalances among autonomous executive, legislative, and judicial branches. When the US Founding Fathers designed the first presidential system, their main concern was to limit the political power held by any one government branch, thus they chose the separation of power principle (see Peltason, 1997, pp. 24-28). Former Caribbean Spanish (less Cuba) and French colonies, plus Guyana and Suriname, are governed by different forms of the presidential system.

The emergence of authoritarian-democratic regimes resulted from conscious decisions (not unintended consequences) of Caribbean governing elite who established the rules for their presidential systems in the post-war period. The authoritarian- 
democratic structures are rooted in the region's colonial and post-independence traditions of cuadillo (strongman) or oligarchic rule. The continuation of strongman politics reveals that in the post-World War II period that many Caribbean states have not developed elite attitudes of political compromise and tolerance of opposing political views-societal rules considered vital to functioning democracies. Thus, in keeping with their traditions of strong central rule, most Caribbean states consciously adopted presidential governing systems that concentrate a state's decision-making power in the hands of only a few senior officials in the executive branch.

Caribbean governing elite facilitated the rise of authoritarian-democratic regimes by building a number of rules into their post-war constitutions that vary significantly from the original US presidential model. For example, most Caribbean presidential systems include presidential decree powers that allow Caribbean presidents to bypass their legislatures and legislate outright. They also often incorporate strong presidential veto powers and the exclusive right of the executive to initiate legislation in key policy areas, further restricting their legislature's powers. (see Shugart \& Mainwaring, 1997, pp. 41 52). Additionally, few Caribbean states with presidential systems established autonomous judiciaries with legislative review powers. Most judiciaries in Caribbean presidential systems are dependent upon their executives, relying upon the executive for their funding, appointments, promotions, and disciplinary actions. Such rules that allow Caribbean presidents to bypass their legislatures and control their judiciaries negate effective checks-and-balances on executive power, and thus foster the emergence of authoritarian decision-making processes. 
Contemporary Caribbean parliamentary governing systems have also fostered their own authoritarian-democratic structures. Contemporary political institutions in the former British Caribbean colonies can be traced to the wave of 1930s social unrest and labor riots that occurred across the British West Indies. The unrest sprang from peasant and worker frustrations with the British Crown Colony system that perpetuated high unemployment, low wages, poor working conditions, and the abject poverty that blanketed the region. The British Moyne Commission noted that the unrest was a "positive demand for the creation of new conditions that would render possible a better life" (Lewis, 1968, p. 88). The 1937-1938 Moyne Commission West Indian investigative report also found that " $[\mathrm{t}]$ he whole West Indies...are practically devoid of all multifarious institutions, official and unofficial, which characterize British life...." (Moyne Commission, 1945, pp. 94, 108). The lack of West Indian social institutions was the result of a British Crown Colony system that focused primarily on maintaining political stability in the colonies and gave little attention to economic and social development. A combination of the 1930s unrest, world de-colonization sentiment formalized in the 1945 United Nations Charter, and British colonial and post-World War II exhaustion, led to a British decision to dismantle the West Indian Crown Colony system and begin a process leading to independence for most of the West Indian colonies.

During the 1940s, the British Caribbean colonies were given universal suffrage and increasingly more responsibility in self-rule, until the British eventually approved their constitutions and granted them independence. In 1962, Jamaica and Trinidad and Tobago were the first British Caribbean colonies to gain full independence. Other British 
Caribbean colonies obtained their independence over the next three decades, with the exception of the six colonies that remain British Overseas Territories (see Table 1-1). The political institutions that evolved in the former British Caribbean colonies all imitate the British Westminster parliamentary system (see A. Payne, 1993; Emmanuel, 1993). The political parties competing for power in these Westminster-cloned systems generally trace their roots to the 1930s and 1940s West Indian labor unions. The adoption of the British Westminster structures by these newly independent small states raises a number of problems.

Westminster parliamentary systems are based on the principle of loyal opposition. The parliamentary ruling party or ruling coalition, the party or coalition with the majority of parliamentary members, selects a government consisting of the prime minister and cabinet ministers. The government is responsible for the development of a government program that must receive parliamentary approval. The non-ruling party or coalition forms an opposition that is responsible for ensuring all viewpoints on important government programs are thoroughly debated both within parliament and publicly (i.e., in the media, public forums, etc.). Once a government program has run the gauntlet of public and parliamentary debates and is passed by the parliament, both the ruling party/coalition and the opposition are bound to lend its implementation full support. Governing systems based on the principle of loyal opposition assume that a high level of tolerance for opposing views and an attitude of compromise and cooperation exist between the ruling party/coalition and the opposition. If at any time the parliament losses confidence in the government, the parliament can call for a vote of no confidence, 
requiring that a new government from the parliamentary majority be formed or that national elections be called. Power is checked in parliamentary systems through the influence of an informed citizenry on the members of parliament, parliament's oversight of government activities, parliament's ability to replace the setting government, and the opposition's readiness (with a designated shadow cabinet) to assume the reigns of government if the citizenry votes them into the majority (see Birch, 1990, pp. 130-132).

For the smaller former British Caribbean colonies, the Westminster system provides an ideal structure for the emergence of authoritarian-democratic regimes. The corruption of the Westminster system in small states is an unintended consequence of the Westminster political rules. In states with a small number of parliamentary members, prime ministers and cabinet ministers often perform a dual function of executive and legislature. In fact, in some states the prime minister and cabinet actually constitute the majority of votes in the parliament itself-thus allowing them to set parliamentary agendas, control parliamentary and public debate, and pass any legislation agreed to within their small group. The Westminster system was never intended to allow such accordance between the executive and legislature (see Birch, 1990, chap. 12). With judiciaries in Caribbean Westminster states usually subordinated to the executive, there are virtually no checks on the executive's power. The political decision-making power in small Westminster states thus unintentionally can become authoritarian-democraticresiding in the prime minister, cabinet, and a few trusted advisers. One longtime observer of British Caribbean politics refers to the Westminster system as one leading to elected dictatorships (D'Costa, 1998, p. 145). In effect, these corrupted Westminster systems 
recreate the power structures of the pre-Crown Colony British colonies by installing a powerful prime minister and cabinet, similar to the pre- 1865 colonial governors and local assemblies found in most British colonies.

Two other major problems arise in attempting to adapt the British Westminster structure to small states. First, the parliaments in small Westminster states are usually too small to offer an effective opposition to the ruling government (see Lijphart, 1993, pp. 328-332). The result is little formal public debate of government programs. The lack of a loyal opposition negates the central principle around which Westminster systems are built. Second, the Westminster first-past-the-post rules designate that the parliamentary candidate from each constituency receiving a simple majority of the popular vote represents that constituency in parliament. An unintended consequence of this rule is that parliamentary party member proportions seldom match the percentage of electoral party support as occurs in states with proportional representation. For example, it is not uncommon for an opposition party or coalition with 30 or 40 percent of the popular vote to receive only 10 or 20 percent of the parliamentary seats (see Emmanuel, 1994). This first-past-the-post problem further degrades the representational effectiveness of the Westminster system in small states.

Authoritarian-democratic systems dominate the governing structures of independent states across the Caribbean. Despite its quasi-democratic starts-and stops, Haiti remains an authoritarian-democratic system. Among independent former Spanish colonies, only Costa Rica's governing system is not authoritarian-democratic. Why Costa Rica escaped authoritarian-democratic structures is explained in Chapter 6. Among 
independent former British Caribbean colonies, only a few states (The Bahamas, Barbados, Dominica) escaped the rise of an authoritarian-democratic system. Barbados, for example, avoided the corruption of the Westminster system through a strong societal sense of consensus and public participation in politics-conditions lacking in many of the other former British colonies.

Caribbean Basin authoritarian-democratic systems foster corrupt behavior by restricting elite competition, limiting elite accountability, and negating mass participation (see discussions in Chapter 2). One of the most insidious of these effects is the restriction on elite competition that fosters animosity among elite factions. Officials other than the president or prime minister and their immediate advisers are effectively locked out of wielding real political power in authoritarian-democratic systems. Legislatures become jealous of the power held by their strong executives. Judiciaries feel compelled to support their executives at any cost. Out-of-power parties fight viciously to regain power. Citizens, seeing this internal political power imbalance and the malicious inter-party struggles, become cynical and place less legitimacy in governmental institutions. With political animosity rising in the state, it becomes more difficult to foster societal cooperation on contentious issues. The result, as Huntington (1968, p. 64) highlights, is that public agreement on important state issues is replaced by political corruption.

Economic Modernization. While Caribbean post-World War II political modernization was primarily the result of internal governing elite-controlled rule making in each state, economic modernization was driven by both external (international) and internal (domestic) causal factors. The immediate post-war decades were a time of general 
Caribbean economic boom. The standards of living in most of the region vastly improved, as there were strong international demands for the Caribbean's agricultural, mineral, and petroleum products. During the 1960s, many Caribbean states averaged commendable gross domestic product growth of 4 to 5 percent (Ramsaran, 1995, pp. 112113). Largely influenced by the United Nations-backed import-substitution economic development model, Caribbean states took actions to expand their export sectors while restricting their imports to encourage and protect nascent domestic industries. With the acquiescence of Canada, the US, Britain, and other traditional European trading partners that desired to keep the Caribbean states as part of the anti-Soviet bloc, the Caribbean states developed statist economic structures that:

encouraged governments to assume a very active role, not only as redistributors but as instigators of development through the provision of incentives and investment. The modern welfare state took root in this period. Governments saw their role not only as providing the regulatory framework but also as being involved in the production of goods and services and influencing private decisions through interventions in critical areas of the economy. Exchange rates, prices, interest rates, credit rationing, and exchange and trade controls became the major tools of economic management (Ramsaran, 1995, pp. 112114).

Dominquez (1993) labels the general economic structures that arose in the Caribbean during the post-war period as a Statist Bargain. He credits the Statist Bargain as the primary reason that democracy seemed to flourish in much of the Caribbean after World War II. The Statist Bargain entails Caribbean governing elite, in alliance with key business interests, building protectionist walls around their economies (see Dominguez, 1993, pp. 13-22). With protection against competing imports, and ample government subsidies for their operations, the Caribbean business sectors reaped large profits, while 
not having to be particularly efficient or work too hard to be competitive. In exchange for the protection of their business interests, Caribbean business elite allied with the governing elite and filled their political coffers with resources to finance large political patronage machines. The Caribbean governing elite thus found themselves with ample resources to build citizen electoral support through dispensing jobs, instituting basic education and health programs, offering other government services, and even paying cash to some citizen supporters.

From the 1960 s to 1980 s, Caribbean states were able to maintain their Statist Bargain regimes under the benevolent watch of Canada, the US, and Europe, their primary trading partners whose consumers shouldered much of the cost of the Caribbean protectionism. Programs like the 1986 Caribbean and Canada Trade Agreement (CARIBCAN), the 1983 US Caribbean Basin Initiative (CBI), and the four Lome Conventions since 1975, institutionalized the respective Canadian, US, and European acceptance of Caribbean protectionist regimes. During the Cold War, the Canadians, Europeans, and US justified their support of Caribbean protectionism as a means to keep the region within the fold of the Western anti-Soviet alliance.

Despite the robustness of the Caribbean Statist Bargain, international oil shocks in the 1970s and early 1980s caused a severe downturn in Caribbean economic prosperity. To offset the costs of the increased price of oil, to maintain social welfare programs instituted during the 1950 s and 1960 s, and for economic infrastructure and military hardware purchases, Caribbean states borrowed heavily in the international financial market in the late 1970s and early 1980s. With international banks flush in Organization 
of Petroleum Exporting Country (OPEC) funds, there were plenty of international entities ready and willing to provide loans to Caribbean states. In 1982, however, the world debt crisis put a halt to the widespread deficit financing of Caribbean state budgets as international lenders became much more discriminating. By the late $1980 \mathrm{~s}$, it also became obvious that much of the Caribbean international borrowing had gone to enrich the governing elite's personal bank accounts and not for more egalitarian purposes (see Naylor, 1987; Beaty \& Gwynne, 1993). Beaty and Gwynne (1993) allege:

the wealthy and corrupt in Latin America [including the Caribbean] managed to steal virtually every dollar lent to their countries by Western banks, creating the debt crisis of the 1980s [and later]...and others skimmed billions from their national treasuries and hid them in Swiss and Caymanian accounts free from snooping regulators...." (Beaty \& Gwynne, 1993, p. xxv).

The post-Cold War world presents the Caribbean governing elite with a new set of rules that effect their economic modernization. Developed state foreign aid has largely disappeared as the Caribbean is no longer of strategic importance in a Western-Soviet struggle over spheres of influence. International financial institutions (IFIs), i.e., World Bank, the International Monetary Fund (IMF), the US Agency for International Development, etc., are demanding transparency, accountability, and improved financial management before tendering financial assistance. As a result of the $1980 \mathrm{~s}$ world debt crisis, many commercial banks even require Caribbean states obtain IMF certification before making loans. Developed states are demanding that Caribbean states open their economies, thus undermining the Statist Bargain that was based largely on local protectionist schemes. Developed states are also pushing for corruption and good 
governance reforms. All of these new international pressures arose simultaneously with trends of decreasing regional economic growth and increasing unemployment.

Caribbean governing elite find themselves in a quandary-caught between conflicting international and domestic demands for political and economic reform. With economic prospects still dim, many states are forced to maneuver the minefield of the debt crisis by calling for IFI support. IFI insistence on reforms toward liberal (free) trade policies, increased state revenues (taxes), and decreased state budgetary outlays, undermine the populist political and statist economic structures that kept the Caribbean governing elite in power in the post-World War II period. The demand for international and domestic reforms has increased societal tensions across the Caribbean. One consequence of these tensions can be seen in Venezuela where in 1998 the mass citizenry rejected the two traditional political parties and voted in President Hugo Chavez, an exarmy officer who organized a new third-party and ran on a strong political reform and anti-corruption platform. Chavez's election has made most Caribbean governing elite uncomfortable. Caribbean governing elite are afraid that Venezuela-like third parties might force them from power as social welfare programs continue to diminish and economic growth founders. Amid this resultant political and economic turmoil, Caribbean political corruption continues to flourish.

\section{Contemporary Caribbean Institutions}

Contemporary Caribbean political and economic institutions vary widely across the region. Table 4-1 provides a set of comparative Caribbean political and economic indicators. The table includes the 1999 status of selected indicators of Caribbean 
corruption patterns, political rights, civil liberties, press freedom, income levels, trade structures, and involvement in drug trafficking and money laundering activities. While the Table 4-1 comparative indicators do not adequately measure the institutional factors that cause political corruption developed in Chapter 2, they do provide insight into the contemporary political and economic institutions existing in Caribbean states and territories. ${ }^{2}$ Included in the below discussion of the Table 4-1 indicators is qualitative information related to contemporary Caribbean institutions associated with political corruption. The Caribbean states and territories in Table 4-1 are grouped by the evaluation of their corruption patterns, discussed last in this section. 


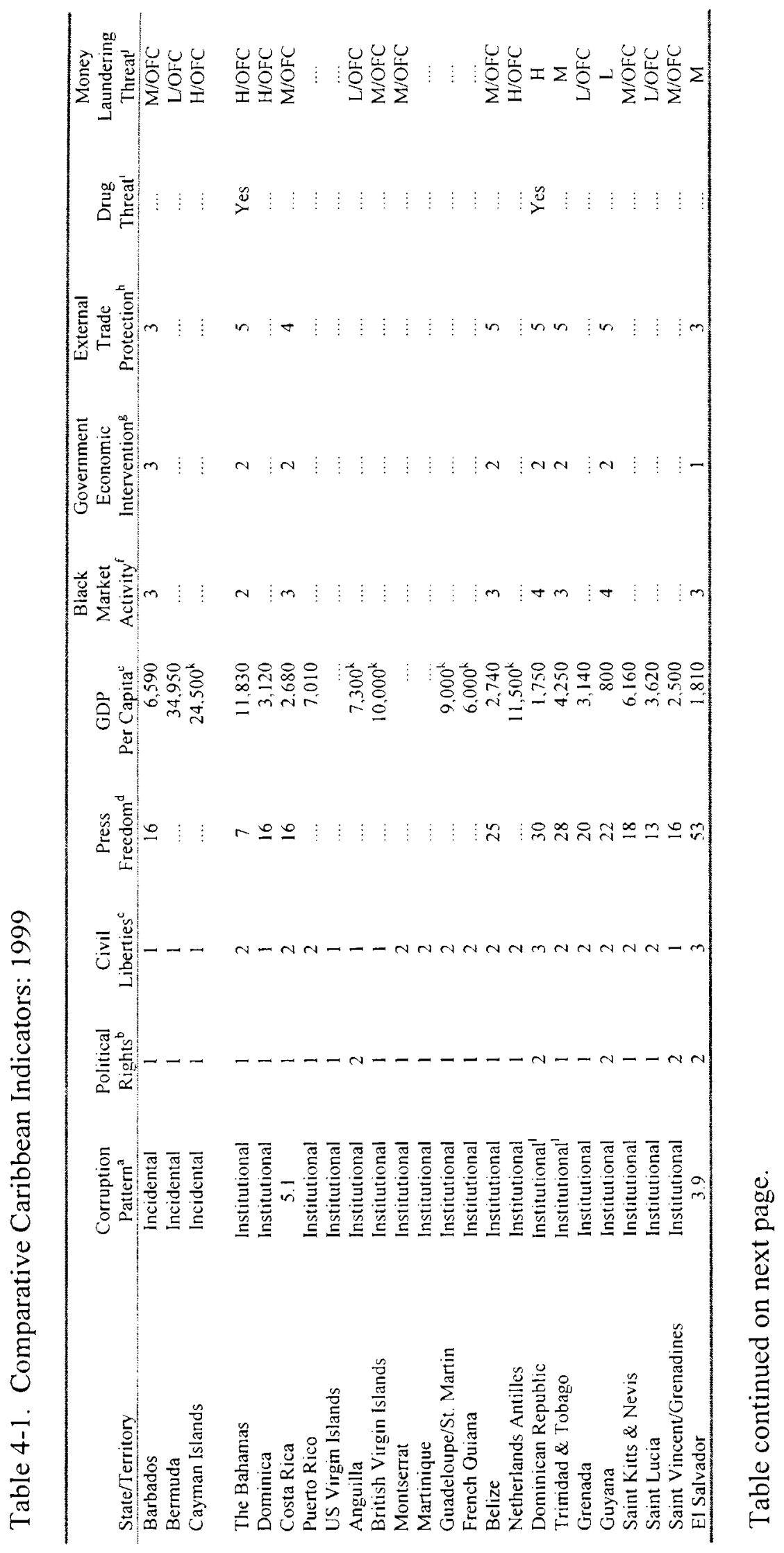




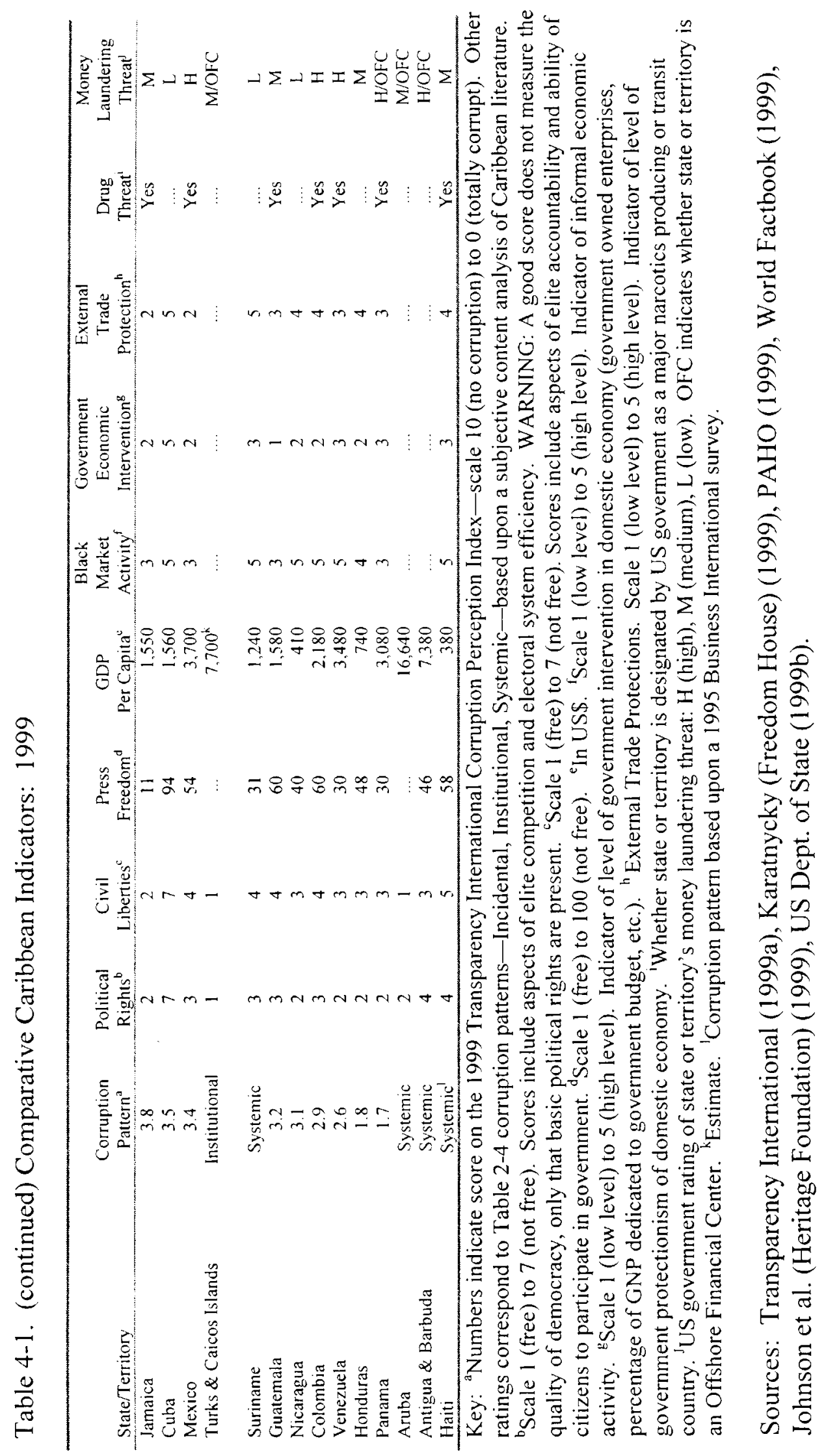


Political Structures. Table 4-1 provides Freedom House ratings of each state or territory's political rights and civil liberties. These Freedom House ratings are composite indexes that indicate whether basic political rights and civil liberties are present in a state. The political rights index includes factors relating to freedom and fairness of elections, existence of basic elite competition, and levels of self-determination for both individuals and social groups. The civil liberties index includes factors relating to freedoms of expression, press, assembly, religion, and fairness of criminal justice systems. While these Freedom House indexes do not correspond exactly with the Table 2-4 concepts of form or rule, political culture, elite competition, elite accountability, or mass participation, they do reveal that, on a macro-level, states with the highest (worst) political rights and civil liberties index scores ( 3 or greater) correspond to states with the most political corruption (systemic). ${ }^{3}$

Chapter 2 develops how the freedom and fairness of electoral systems are factors in evaluating the nature of both elite competition and elite accountability in states. In general, any state in Table 4-1 with a political rights rating of 3 or greater has problems with their elections' freedom and fairness. States in the bottom half of Table 4-1 tend to have elections tainted by charges of fraud and corruption. The Organization of American States (OAS) and Emory University's Carter Center have developed a regular industry around monitoring regional elections. Despite this international oversight, governing elite continue to have considerable influence over the electoral process in their respective states. Governing elite usually control voter registry, voting procedures, and vote counts-all areas open for abuse in the non-transparent conditions existing in many 
regional states. For example, in the 1999 national elections in Antigua and Barbuda, the ruling Antiguan Labor Party (ALP) took drastic measures to ensure their electoral victory. A document secreted from the office of Prime Minister Lester Bird titled "Winning the election is all that matters" stated:

All voters who owe utility bills "for even minimum arrears"...should be disconnected "on a large scale." Then they could be reconnected on the understanding they would vote for the ALP. Members of the party

.... [should]..."find out in each constituency the registered voters in arrears in meeting their mortgage obligations and offer to assist, but obtain an agreement that they will vote for the ALP candidate." "Rumors must be circulated in every government ministry that their jobs are only secure if they vote ALP. Serious consideration must be given to the giving away of cash money to potential voters before the day of election. I would suggest $\$ 1,500$ to $\$ 5,000 \ldots$ (quoted in Howe, 1999, p. 23).

The ALP won this election, one the OAS and Carter Center did not observe. Why did Antiguan citizens not simply take the money and, knowing the widespread ALP political corruption, vote for the opposition? One journalist offers, "The ballot in Antigua is not as secret as it should be. The Electoral Commission has been transformed into an ALP vehicle. Two party activists were planted at each polling booth checking how citizens voted" (Howe, 1999, p. 23). While such extreme measures to fix elections do not occur in every Caribbean state, as Table 4-1 implies, governing elite in many states, especially those with authoritarian-democratic regimes, are able to use similar tactics to ensure their reelections.

The financing of elections is another important factor in assessing the freedom and fairness of Caribbean elections. Geddes $(1991,1994)$ provides a compelling analysis of the financing structures in contemporary Caribbean electoral processes. Using simple game-theoretic models (agency models), Geddes (1991) investigates the relationships 
between electoral resources required to win elections and the political will of governing elite to institute electoral reform in South and Central American presidential systems. She concludes that resources obtained from political patronage networks are the single most important factor underlying the power structures in these states. Therefore, governing elite are not likely to reform patronage structures that might undermine their main source of power.

Political patronage includes both legal and illegal behaviors (see Chapter 2 discussion of patron-client systems). Representational patronage is generally legal and includes promises or provision of state resources (jobs, education and health programs, etc.) in exchange for electoral support. Illegal patronage, on the other hand, concerns resources provided by individuals or special interest groups (in expectation of special political favors) that politicians use for their own private gains-including their use to build electoral support. Illegal patronage is a behavior that is antithetical to the Western concept of good governance.

Geddes (1994, p. 42) describes the South and Central American patronage reform initiatives as a politician's dilemma. Her studies reveal that even though politicians may truly want to offer reform for illegal patronage, they face the dilemma that they cannot afford the cost of reform due to the loss of electoral resources that would threaten their hold on political power. She submits:

In order to maintain their electoral machines, politicians need to be able to "pay" their local party leaders, ward heelers, precinct workers, and campaign contributors with jobs, contracts, licenses, and other favors. What kinds of payments are common or even possible depends on political traditions, legal constraints, and the amount of state intervention in the economy among other 
things. Where state intervention has customarily been high, politicians depend heavily on the distribution of state largess to cement party loyalties (Geddes, 1994, pp. 40-41).

In a study of Westminster parliamentary systems in the Eastern Caribbean, Peters (1992) also found patronage as a major electoral factor. In analyzing Eastern Caribbean leader incentives, Peters observed that " $[t]$ he overriding objective seems to be centered on remaining in power" (Peters, 1992, p. 85). Peters describes how, immediately upon election, Eastern Caribbean politicians begin to campaign for the next election through a system of dispensing legal and illegal patronage and crusades of victimization that target both opposition politicians and supporters of the opposition party (Peters, 1992, pp. 178181). Along with their primary goal of political survival, Peters found that Caribbean political elite behavior is also motivated by a strong wealth incentive. Peters offers " $[t]$ he majority of politicians in the Caribbean rely on their position as elected officials for their sole source of income" (Peters, 1992, p. 41). He observes that because the transition back to a non-governmental role is so difficult for Caribbean politicians not reelected;

lower income nonprofessional individuals elected to [Caribbean] government will do anything necessary to remain in power as long as possible. During that period, they spend their entire term in office campaigning for the next term and try to amass as much capital [legally and illegally] as they can in order to guarantee their economic survival after they lose power. (Peters, 1992, p. 41)

Based on Geddes' $(1991,1994)$ and Peters' (1992) analyses, the reliance on illegal political patronage to fuel Caribbean elections is a characteristic of both presidential and parliamentary governing systems in the region.

Even if Caribbean elections were fair and free, there is no guarantee that electorates will hold corrupt governing elite accountable by voting them out of office. 
For example, McCann and Dominguez (1998) found that despite widespread knowledge of the Mexican ruling Institutional Revolutionary Party's (PRI) corruption, over the course of several elections from 1986 to 1995 , the electorate repeatedly voted the PRI back into power. Two principal factors explain these PRI victories. First, the PRI generated voter support through their existing extensive patronage networks. Second, with the expectation that election fraud would return the PRI to power anyway, those voters most likely to vote for the opposition failed to come to the polls (McCann \& Dominguez, 1998, pp. 498-499).

One elite competition factor not captured in Table 4-1 is the nature of elite mobility. Chapter 2 discusses how limitations on elite mobility affect the nature of elite competition. Limitations on elite mobility may take a number of forms. First, dictatorial states limit elite mobility by creating longevity in office for dictators, their handpicked successors, and their most trusted advisors. Cuba is the current best Caribbean example of a dictatorial state with limited elite mobility. President Fidel Castro has held power in Cuba for over 40 years and has designated his brother, Defense Minister Raul Castro, as his immediate successor. Real political power in Cuba is managed not within the Cuban government structure, but within the Politburo of the Cuban Communist Party, chaired by Fidel Castro and made up of his most trusted advisors. All decisions about changes within the Cuban governing elite (government or party) are made either by the Politburo or by Castro himself. Haiti under the Duvaliers (1951-1986), the Dominican Republic under Trujillo (1930-1961), and Nicaragua under the Somozas (1937-1979) are past 
examples of Caribbean states where elite mobility was restricted by dictatorial rule and accompanied by high political corruption levels.

Second, states with Westminster parliamentary systems often maintain the same individuals (or their offspring/spouses) as party presidents, and thus as candidates for prime minister, for long periods. The Bird family of Antigua and Barbuda (1950s to present), the Jagans of Guyana (a presidential system) (1960s to 1990s), the Manleys of Jamaica (1940s to 1990s), Edward Seaga of Jamaica (1970s to present), John Compton of St. Lucia (1960s to 1990s), and James Mitchell of St. Vincent and the Grenadines (1970spresent), are only a few examples of individuals or families holding the top political positions in their state or political parties for long periods (see Griffith, 1993, pp. 24-25). In many cases these individuals or families led the independence movements in the former British colonies and held political power until they became unable to serve due usually to health reasons.

Finally, states with dominate political parties precipitate restrictions on elite competition by excluding other parties from power. The Mexican PRI and Antiguan ALP are the two most glaring recent Caribbean examples of political parties that have excluded their opposition from access to their state's governing structures. The Mexican PRI maintained political control from 1929 to 2000. Antigua's ALP took power initially in that state's 1950s independence movement and has maintained control since Antigua's 1981 independence from Britain (see Henry, 1991). Although both the PRI and ALP saw the rise of competing political parties, they continued to maintain control over their 
respective governments and make all decisions about changes to the governing elite within closed party circles.

Table 4-1 includes Freedom House's rating of state press freedoms. As the table demonstrates, there are problems with press freedom in many Caribbean states. Some Caribbean states go to great lengths to control the press (see Sussman, 1999). In many states, the press is restricted outright through state-ownership or ownership by interests in alliance with the government. Some states employ systems of media and journalist licensing, special media taxes, and the withdrawal of government advertising as methods of controlling information. Some Caribbean media outlets and journalists have found their licenses revoked on short notice for reports deemed harmful to governments. Most Caribbean states also have strict defamation, slander, and libel laws-many dating to the authoritarian military rule in parts of the region prior to the 1980s. Throughout the region, the press finds itself the target of harassment and violence. Radio and television stations and newspaper offices frequently become the targets of arsonists or bombers. Almost 200 journalists were killed across the Americas during the 1990s and scores of others injured in violent attacks. The majority of these journalists were killed in Central America, Mexico, and Colombia. In an atmosphere of constant media harassment, it is not surprising that self-censorship is a major problem with press freedom in the Caribbean.

Problems of press freedom also extend to issues of freedom of information. Few states in the Caribbean have freedom of information laws. On the contrary, Caribbean states often make efforts to restrict information from their media and citizens. Most of 
the former British colonies, as part of their independence process, adopted legislation similar to the British Official Secrets Act (see Thurlow, 1995). Such legislation prohibits the release of any information not sanctioned by the government. In this case the government is defined as only the prime minister and cabinet ministers. Caribbean officials justify holding information release at such high levels as a means to ensure the executive remains responsible for the actions of their subordinate civil service. In reality, the restricted release of information is more to keep the sitting government from being embarrassed by government mismanagement and officials' illicit behaviors, especially in the period just before elections. While not as formal as Official Secrets Acts, the former Spanish colonies and Haiti also possess similar policies or structures restricting the release of government information.

An area not indicated in Table 4-1 is the enforcement aspect of elite accountability. The lack of accountability in many states due to electoral problems is discussed above. However, there also remain significant problems in administrative and criminal justice structures. Administrative mismanagement is rampant throughout the Caribbean (Jones, 1992, 1995). Similar to the lack of regional freedom of information, Caribbean government budget preparations, contracting, and accounting are often completed with little government or public oversight (Wesberry (interview), 1999). There is widespread Caribbean tax evasion. Civil services in the region are often bloated and far from professional, often the result of pressure on governing elite to provide patronage benefits (employment) to loyal party supporters. Recently, a large percentage of Caribbean homegrown technically trained experts have immigrated to developed 
states, further contributing to conditions of maladministration (Jones, 1992, p. 39). A major focus of intergovernmental and nongovernmental organizations working in the Caribbean has been to improve administrative management, professionalize civil services, and provide incentives for technical experts to remain in the region. In such conditions of administrative mismanagement, there is little chance of administrative enforcement actions holding a governing elite accountable.

In most Caribbean states, criminal justice systems lack the basic principles present in developed states (Salas \& Rico, 1993, p. 48). Governing elite are seldom held accountable in criminal justice systems that lack efficiency and openness. Courts in the region find themselves overburdened with cases due to the "upsurge in criminal activity and the growing litigiousness of the region's citizenry" (Ryan, 1998, p. 50). Moreover, as discussed previously, judicial systems lack independence as they are often dependent upon executive branches that control not only their budgets, but also the selection, promotion, and discipline of judges. Without a political base of their own outside the executive, criminal justice systems are unlikely to hold a governing elite accountable.

Another elite accountability factor that cannot be overlooked in the Caribbean is the granting of asylum to corrupt ousted elite. Caribbean governing elite know that if they are caught in corrupt acts, they can usually receive political asylum under the sovereignty umbrella of other regional states. Costa Rica is a favorite asylum haven of corrupt elite. Beginning in the 1970s, Costa Rica became an asylum for a number of fleeing elite as they followed the lead of President Jose Figueres, Sr., who philosophized "a dollar robbed or a dollar bought, is still a dollar" (Araya et al., 1982, p. 19). In 1986, 
Haiti's ousted President Jean-Claude Duvalier was granted asylum in France after plundering millions from the Haitian treasury. The US has also been the exile home of corrupt dictators such as Batista of Cuba and the Somozas of Nicaragua. The ability of a corrupt governing elite to obtain political asylum is a key contributor to the conditions of weak elite accountability in the Caribbean.

Using Table 4-1's press freedom ratings as a proxy indicator for the level of elite accountability, it is evident that states with the worst ratings (30 or greater) correspond to the states with the highest levels (systemic) of political corruption.

A final political structural factor to consider is the nature of a state's mass participation. Table 4-1 has no direct indicators of mass participation but does provide several proxy indicators. First, a state or territory's level of civil liberties is an indication of the ability of citizens to organize and participate in government. Second, Fukuyama (1995) argues that the level of social trust in a state is correlated to its level of income (GDP per capita in Table 4-1). Chapter 2 developed how social trust is a good measurement of a society's level of mass participation. Finally, the level of black market activity in a state is an indicator of both the size of its informal economy and how much citizens trust in formal political and economic institutions. Overall, it is evident form Table 4-1 that states with higher political corruption levels (systemic) have, on average, lower civil liberties scores, lower averages of personal incomes, and higher levels of black market activity.

Economic Structures. Contemporary Caribbean economic structures are just as varied as the political structures discussed above. Table 4-1 displays the wide variance in 
regional income levels (GDP per capita). The table also provides indicators for the levels of government intervention in the economy, external trade protection, and black market activities. In consonance with the Statist Bargain discussion above, most Caribbean states continue a high level of external trade protection. In keeping with international pressures for neoliberal economic reforms, Caribbean government intervention in their economies is generally lower than their external trade protection. Table 4-1 also reveals that those states with the lowest incomes also have the highest levels of black market activity -indicating that citizens are being forced into the informal economy to survive. Overall, Table 4-1 indicates that Caribbean states generally retain their statist economic structures-which Chapter 2 reveals contribute to political corruption levels.

Political Corruption Patterns. There is no single comprehensive measure of Caribbean political corruption levels. The Transparency International (TI) annual Corruption Perception Index (CPI) provides the best measure of political corruption in several Caribbean states. Table 4-1 includes the 1999 Caribbean TI CPI ratings in the corruption pattern column. The TI CPI scores are calculated by combining the scores of several international and domestic surveys. The CPI scores are a composite measure of the political and bureaucratic-administrative corruption levels as perceived by a state's mass citizenry and both domestic and international businesspersons. ${ }^{4}$ While some may dispute the exact TI CPI scores of individual states, TI considers the CPI an excellent indicator of a state's level of corruption when compared with other states (Transparency International, 1999a). 
The Table 4-1 TI CPI scores paint a rather bleak picture of Caribbean political corruption in comparison with other world regions. Even Costa Rica (5.1), the Caribbean state rated the least corrupt in the TI CPI, is below the 5.5 index threshold TI offers as the benchmark for a state that is systemically corrupt. ${ }^{5}$ In 1999 , Costa Rica ranked number 32 of the 99 states scored in the TI CPI. Point-wise, Costa Rica was well behind the world's least corrupt states of Denmark (10.0), Finland (9.8), New Zealand (9.4), and Sweden (9.4). The entire Caribbean is also well behind the contemporary CPI scores of its former colonizers-Spain (6.6), United Kingdom (8.6), France (6.6), Netherlands (9.0)-and the US (7.5). The Table 4-1 TI CPI scores place all Caribbean states rated, except Costa Rica, in the bottom-half of states worldwide. Honduras (1.8) and Panama (1.7) both place among the top 10 most corrupt states in the world. Table 4-1 reveals the substantial problem with contemporary Caribbean political corruption.

Several Caribbean states and territories are not included in the 1999 TI CPI. In Table 4-1, the other Caribbean states and territories' corruption patterns are subjectively rated as incidental, institutional, or systemic using the conceptual definitions of these terms developed in Chapter 2. These subjective ratings were developed either using other survey data or from a content analysis of Caribbean literature. ${ }^{6}$

Using a single 1995 Business International (BI) survey, three of the missing Caribbean states can be placed comparatively with those rated by Transparency International in Table 4-1 (see Mauro, 1995). The 1995 BI survey places both the Dominican Republic and Trinidad and Tobago as less corrupt than Jamaica., but more corrupt than states with TI CPI scores similar to Costa Rica. The $1995 \mathrm{BI}$ survey also 
rates Haiti as more corrupt than Panama. Some would argue, however, that it is not Haiti, but the Eastern Caribbean island state of Antigua and Barbuda that leads the region in political corruption. One author offers:

Under V. C. Bird [Vere Sr., Prime Minister 1981-1994], Antigua has become not only a sanctuary but a spawning ground for crooks and scoundrels, a place where, for the right price, one can buy everything from a diplomatic passport to a government minister, an island where all of one's schemes, no matter how illegitimate, can find official sanction. No other Caribbean nation, not even Haiti under the Duvaliers, has been plundered and mismanaged for so long in so public a fashion by a single family and with such devastating results. Members of the Bird family have long believed that because of V.C. Bird's early years [leader of the Antigua labor and independence movements], they have almost a divine right to rule Antigua....Antigua may be the last country in the Caribbean in which a head of state employs totalitarian tactics to ensure that a political dynasty is established and that one of his sons succeeds him in office. (Coram, 1993 , p. 5)

Aruba, a state whose governing elite are believed closely associated with international organized crime, also rates near the bottom of Caribbean corrupt states along with Honduras, Panama, Haiti, and Antigua and Barbuda. Aruba's corruption problems are discussed in more detail in a later section.

Based on a content analysis of Caribbean literature, Barbados, Bermuda, Cayman Islands, the Bahamas, and Dominica rate just above Costa Rica (5.1) in the Table 4-1 corruption patterns. Barbados, with the strongest regional liberal-democracy, experiences little political corruption. The Bahamas (after the 1992 ouster of Prime Minister Lyndon Pindling) and the British Overseas Territories of Bermuda and the Cayman Islands also exhibit strong democratic institutions. Dominica's reputation for probity relates to the 15-year (1980-1995) term of Prime Minister Dame Eugenia Charles who was considered a "model of both domestic virtue and geopolitical pragmatism" (Maingot, 1994c, p. 10) 
and ensured her government was not corrupt. ${ }^{7}$ Other Caribbean states and territories were rated in the Table 4-1 corruption patterns column based upon the content analysis of Caribbean literature.

The actual levels of past Caribbean political corruption will never be precisely known. At best, we can understand the corruption levels through the results of the content analyses. However, even then only some corruption behavior surfaces in the public domain. The following section looks at much of the anecdotal evidence concerning Caribbean political corruption and improves our understanding of state and territorial corruption levels measured subjectively in table 4-1.

\section{Caribbean Political Corruption Behaviors}

Caribbean political corruption encompasses a myriad of diverse governing elite behaviors (see Table 2-2). Political corruption behavior may entail outright theft of state resources or bribery, fraud, and graft associated with routine domestic or international business transactions. It may also encompass, as is being seen more frequently in the Caribbean, the misuse of extraordinary material resources resulting from governing elite assistance to international organized crime activities (drug-trafficking, arms smuggling, money laundering, etc.). The complex and often interconnected behaviors surrounding Caribbean political corruption make it a particularly dogged problem.

Theft of State Resources. The outright theft of state resources by a governing elite was common under pre-1990s authoritarian-dictatorial Caribbean rule. Along with bribes paid by foreign businesses, theft of state resources was another major source of the take 
listed in Table 3-1 for various Caribbean rulers. Scott (1972) refers to regimes with widescale theft of state resources as being predatory (similar to Table 2-4's pirate evaluation of agent status). For example, regarding Haitian dictator Francois Duvalier's (19571971) rule, Scott offers:

Government is virtually the only source of wealth in Haiti. Given the uninstitutionalized, coercive basis of the regime and the absence of any limitseither legal or traditional-predatory corruption was virtually unchecked. The annual budget, composed mostly of customs and excise taxes, was the dictator's personal purse to dispose of as he saw fit. Loyal retainers and family members were given personal gifts, the Tonton Macoute [Duvalier's secret police force] was rewarded for it missions of intimidation and death, personal fortunes were created, and so forth (Scott, 1972, p. 85).

Most cases of governing elite theft of state resources never surface due to the lack of investigative journalism and the ineffectual administrative and criminal justice systems throughout the Caribbean. However, when cases do surface, they are often surrounded by political overtones (Maingot, 1994a, p. 64). Such political victimization was the case in the 1993 Venezuelan Congressional impeachment and later conviction of President Carlos Andres Perez for misusing a secret US\$17 million Venezuelan government fund to pay for campaign debts and a lavish 1989 inauguration. More commonly, the theft of state resources is part of a complex scheme involving multiple persons and including connections to domestic and/or international businesses. Venezuela, Mexico, and Colombia provide examples of the complexity surrounding predatory Caribbean political corruption.

Venezuela is an example of a complex predatory system of political corruption. During the first three decades after World War II, Venezuelan political corruption was supported by the political rents acquired from manipulation of the state's massive oil 
industry. However, the 1980s world debt crisis, along with 1980s sagging oil revenues, decreased the Venezuelan state resources available for rent extraction and forced the governing elite to find other methods to support their predatory ways. In 1983, the Venezuelan government decided to abandon fixed convertibility on foreign exchange and adopt a differential exchange system. The decision was justified publicly as a means to reduce capital flight, cut imports, restrain inflation, reactivate the economy, and protect jobs and wages (Beroes, 1990, cited in Little \& Herrera, 1996, pp. 269-270). But in actuality, it became a license for the governing elite to steal government revenues and resulted in the Venezuelan state's direct loss of US\$11 billion in hard currency during the mid-1980s. With the Venezuelan government unable to adequately regulate their new differential exchange rate system, a massive system of fraud and misappropriation of assets began that included most of the state's import sector, numerous state and foreign businesses, the political parties, senior government officials, and even the Venezuelan Central Bank (Little \& Herrera, 1996, p 270). Later known as the Recadi scandal, the massive political corruption surrounding the differential exchange rate system:

was an instrument used by public officials, businessmen, and politicians to traffic in influence, grant and receive privileges and economic advantages, evade laws, and enrich themselves, individually and as groups to the detriment of the national interest... (Beroes, 1990, quoted in Little \& Herrera, 1996, pp. 269-270).

Only one importer (a Chinese national) in the Recadi case was ever tried and convicted of fraud for the massive loss of Venezuelan state revenues (Little \& Herrera, 1996, p. 270). The Recadi case is an excellent example of the lack of governing elite accountability in authoritarian-democratic systems. 
Mexico presents a second example of an entrenched governing elite that fashioned a complex predatory system to extract political rents through the exploitation of state resources. From 1929 to 2000, Mexico's ruling PRI asserted almost unchallenged control over Mexican politics and the economy. The PRI combined the use of the stick and the carrot, coercive and allocative political corruption, to perpetuate the 71 -year continuous control of Mexican politics (Knight, 1996, pp. 227-231). Described as fostering an authoritarian-corporatist (form of authoritarian-democratic) governing regime (Morris, 1991, p. 24), the PRI cultivated tremendous corruption throughout the Mexican governmental system.

Countless cases of bribery, extortion, fraud, kickbacks, nepotism, and unexplained wealth routinely attend the upper echelons of the [Mexican] government....The early 1980s unleashed a rash of public investigations and scandals centering on such once-powerful figures as the head of the huge state owned oil monopoly PEMEX (Mexican Petroleum), leaders of national trade unions, state governors, and even former presidents. Besides bringing lucrative employment opportunities for many members of his family, for instance, it has been estimated that President Jose Lopez Portillo (1976-82) skimmed from $\$ 1$ to $\$ 3$ billion [US\$]. General estimates of the sums pilfered in the major cases exposed in the early 1980 s approach $\$ 20$ billion [US\$], enough, according to one report, to have paid the interest on the huge Mexican debt for 1983, 1984, and the first five months of 1985. (Morris, 1991, pp. xvi-xvii)

With such entrenched Mexican political corruption, it was not surprising that when in 1996 over US $\$ 120$ million of unexplained funds were found in the accounts of Raul Salinas, brother and political confidant of former Mexican President Carlos Salinas (1988-1994), that the revelation barely raised eyebrows in Mexico (Bamrud, 1996, pp. 38-39). Mexican citizens take political corruption for granted, viewing the US\$120 million in Salinas's accounts as mere petty cash and knowing that these sums are no 
doubt dwarfed by amounts in other still hidden Salinas accounts (Bamrud, 1996, pp. 3839).

Colombia provides a third example of complex predatory political corruption spawned by an authoritarian-democratic system. In 1958, Colombia's two largest political parties entered into a formal elite pact (the National Front) agreeing that the parties would share political power. The National Front ended political conflict over the spoils from Colombia's enormously profitable coffee business and the future income from emerging mining and petroleum industries. Although presented as a solution to Colombia's massive political violence of the 1950 s, and as a Colombian return to civilian rule after the 1953 to 1957 period of military rule, the National Front was effectively a governing elite agreement to end political competition over the control of state resources, allowing monopolistic control to alternate between the two principal political parties. On the political corruption the National Front engendered, one writer comments:

In every country of the world there is patronage, but in Colombia this practice has been taken to the extreme on account of the Frente Nacional [National Front]. It has reached a stage in which policy consists of distributing the fruits of power, appointments, licenses, contracts, scholarships. This has degraded political life in Colombia. Indeed, there is no debate on programmes and ideas. This means the relationship between the government and the congress has been reduced to deciding what to give to whom. (Cepeda, 1998, p. 78)

The Colombian National Front officially ended in 1978, however, some of its unintended consequences were the continuation of a legacy of a predatory governing elite, widespread patronage, entrenched systemic corruption, and extreme political violence. In 1991, a Bogota editorial declared that the corruption "problem is so huge that no one knows what to do about it" (Semana, 1991). The same editorial cited that in early-1991, 
29 parliamentarians, 48 judges and magistrates, 65 directors of public municipal corporations [city managers], 68 directors of decentralized institutes [parastatals], 72 military officials, 88 national police officials, and 1,261 customs officials, were under investigation for corruption by the Colombian attorney general (Semana, 1991). In a Colombia already saturated with political corruption, it is little wonder that drug-related corruption (discussed below) took such rapid and firm root in the 1980s and 1990s.

The above three examples-Venezuela, Mexico, and Colombia-include the three largest and most populous Caribbean states with the largest regional economies. These three states, all ruled by versions of authoritarian-democratic regimes, are among the Caribbean's most corrupt (see Table 4-1) — providing an indication of the types of corrupt behavior occurring in authoritarian-democratic regimes across the region.

Foreign Business Bribery. One objective of the Western Hemispheric heads of state and government at the 1994 Miami Summit of the Americas was to cast blame for their domestic corruption problems on foreign businesses bribing government officials across the region (Feinberg, 1997, pp. 90-91). In 1994, only the US possessed a law, the Foreign Corrupt Practices Act (FCPA), prohibiting its national businesses from bribing foreign officials. Since 1994, the United Nations, the Organization for Economic Cooperation and Development (OECD), and the OAS have all addressed the need to criminalize foreign business bribery. Several OECD and OAS members have now passed laws similar to the US FCPA. However, these international and domestic actions have not stopped the bribery of government officials by foreign businesses. 
In 1999, based on a survey of senior domestic business and financial officials in 14 emerging market states, TI published its first Bribe Payers Index (BPI) (Transparency International, 1999a). Similar to the TI CPI, the BPI rates a state's businesses' propensity to bribe foreign officials in negotiating government contracts along a scale of 10 (no bribery) to 0 (very high level of bribery). Several prominent Caribbean investors, including China (3.1), Italy (3.7), Japan (5.1), France (5.2) and Spain (5.3), show moderate to high propensities to bribe foreign government officials. The Caribbean's main investors, including Canada (8.1), Netherlands (7.4), United Kingdom (7.2), and the US (6.2 despite the FCPA), exhibit lower propensities to bribe foreign officials. While the exact level of foreign business bribery occurring in Caribbean states will never be known, it is a significant factor in Caribbean political corruption behavior.

Like most political corruption behaviors, the details of foreign businesses bribing Caribbean government officials seldom reach public attention. But some do. Just prior to the 1977 US FCPA enactment, it was revealed that United Brands, a US fruit company, had paid the president of Honduras US $\$ 2.5$ million to reduce a proposed tax upon banana exports. The resultant scandal ended with the Honduran president being overthrown in a military coup and the Chairman of United Brands committing suicide (Maingot, 1994a, p. $60)$.

In 1986, Vere Bird, Jr., an Antiguan cabinet minister and the son of Antigua and Barbuda's Prime Minister Vere Bird, Sr., was involved in a foreign business bribery case—one with a new wrinkle. Vere, Jr., Minister of Aviation, notified the Antiguan parliament that he had arranged for a French consulting firm to handle all arrangements 
for resurfacing the deteriorated runways at Antigua's Vere Bird, Sr., International Airport. It was later found that Vere, Jr., embezzled US\$4 million out of the US\$11 million allotted by the Antiguan government for the resurfacing contract. The investigation of this scandal revealed that the principal stockholder in the French consulting firm was Vere, Jr. Thus, Vere, Jr., the foreign businessman, effectively bribed himself, the Antiguan Minister of Aviation, in order to siphon money from the airport contract. Even though the official inquiry into this scandal recommended Vere, Jr., be dismissed from public office, Vere, Sr., chose not to remove his eldest son from government (Coram, 1993, pp. 132-139). There are no doubt thousands of bribery transactions annually in the Caribbean involving foreign businesses and government officials—some as direct as the above United Brands example and others buried in the complexity of international contracting and finance as displayed in the above Antiguan airport scandal.

A further example of the corrupting influence of foreign businesses, and the welcoming of such behavior by Caribbean governments, surrounds the case of Robert Vesco, a fugitive US financier. Vesco fled the US in 1972 after stealing over US\$200 million from a European mutual fund. Vesco was able to buy himself temporary protection in Costa Rica through a combination of local investments in support of influential politicians (bribes) and his provision of international financial advice to Costa Rican President Jose Figueres, Sr. (Sunol, 1974). In 1978, a new Costa Rican president, facing increasing US pressure for Vesco's extradition, terminated Vesco's Costa Rican asylum. Vesco then took his investments and advice to the Bahamas and later Antigua, until they also pulled out his welcome mat. Finally, in the 1980 s, Vesco relocated to 
Cuba where he lived until 1996 when Fidel Castro's government charged him with fraud and awarded him a 13-year sentence in a Cuban prison (Eaton, 1999). In the cases of Costa Rica, the Bahamas, and Antigua, Vesco was welcomed with open arms as long as he paid-off the right government officials and as long as US pressure for his extradition was controllable. In Cuba, while Vesco's investments and international financial expertise were initially appreciated, he was given asylum as an annoyance to the US. However, Vesco's later trial and conviction shows that even Fidel Castro's government has limits for tolerating foreign business corruption.

Cuba provides a unique case to examine political corruption cultivated by foreign businesses. Since 1959, Cuba has been ruled by a Communist Party elite that maintains its hold on power through a combination of communist ideology and control of the state's security apparatus. Until the early 1990s, Cuba was closed to foreign investment. As Cuba began to loosen control of its state-owned economy in the 1990s and allow outside foreign investors, especially from Spanish tourist hotel conglomerates, a raft of political corruption scandals came to light (Tamayo, 1999). The Cuban scandals reveal an entrenched Communist Party political elite grasping to retain its hold on power while at the same time personally benefiting from the expansion of foreign investments in the Cuban tourist, mining, and agricultural industries. One author cites "[c]orruption is so pervasive in Cuba that few are arrested for stealing from the state. If the government was serious about cracking down on corruption. It would have to put the whole island behind bars..." (Oppenheimer, 1992, p. 417). It is clear from the foreign businesses taking part 
in the TI surveys (Cuba is rated 3.5 on the TI CPI) that political corruption has taken a strong hold on Cuba's socialist-run state.

Drug-Related Corruption. Bursting onto the Caribbean scene in the 1970 s, political corruption associated with the international drug trade has had a deleterious effect upon the region (see Lee, 1985). Drug corruption first began in the drug producing state of Colombia and then spread like wildfire along the Caribbean routes used by the Colombian drug cartels to transport their illegal products to markets in North America and Europe. Political corruption is also a major factor in fostering the ancillary drug trade activities of arms smuggling and money laundering. While drugs (marijuana, cocaine, heroin, amphetamines) may be the product in demand, political corruption provides the fuel that keeps the production, transportation, marketing, and financial components of the illicit business running smooth.

Thoumi (1995) argues that low risk to drug traffickers led to Colombia's comparative advantage in becoming the production and control center of the Latin American drug trade. Factors contributing to this low risk condition include: (1) a weakened state with guerrillas fighting the armed forces for control of large geographic areas, (2) high levels of societal violence traditionally used to settle conflicts, (3) an established contraband [black market] trade, (4) a unique Colombian brand of capitalism fostering expectations of high short-term profits, and (5) geographically isolated areas that allowed the traffickers to initially bribe only a few local officials to ensure protection (Thoumi, 1995, pp. 172-176). Following the Colombian drug cartels' efforts to maintain 
this low risk advantage provides a road map to the drug-related political corruption that spread throughout Colombia and the Caribbean beginning in the late 1970s.

In the early to mid-1970s, when marijuana was Colombia's main drug export, the above low risk factors were sufficient to ensure the drug trade prospered. As the Colombian drug trade grew, especially its expansion in the late 1970s into the more profitable cocaine exports, the traffickers could no longer just bribe local officials, but also had to bribe those on the national level to ensure their continued low risk advantage. "In 1978, for instance, [Colombian] President Alfonso Lopez Michelson was told by top US drug enforcement officials that some thirty high-level officials, including two cabinet ministers and five federal judges, had been corrupted by the drug traffickers" (Nadelmann, 1993, p. 279). Lopez Michelson took no action on this report, confirming that the traffickers retained their low risk advantage.

As Colombian cocaine, amphetamines, and later heroin, flooded the North American and European markets in the 1980s and 1990s, "the traffickers grew even more powerful, investing in the legitimate economy, buying protection from all branches and levels of government, and bribing, intimidating, and killing those who challenged them" (Nadelmann, 1993, p. 279). By the mid-1990s, drug corruption had reached the very top of the Colombian political structure. In 1996, President Ernesto Samper was charged with financing his election campaign with US\$6 million donated by the Cali Drug Cartel. Samper's later absolution on all charges by the corruption-tainted Colombian Chamber of Deputies revealed the continued low risk advantage held by the Colombian drug traffickers. 
Outside Colombia, Caribbean drug-related corruption can be correlated with the Colombian trafficker's access to low risk drug transportation routes. In the early to mid1970s, the Colombian marijuana crop was largely delivered by aircraft or boat direct from the Colombian Guajira region to North America with little need for support in other Caribbean states. This changed in the late 1970s to mid-1980s when cocaine became the primary Colombian drug export and the preferred (low risk) method of transport was by boat or small aircraft to the Bahamas where the drugs were loaded into small fast boats (40-60 knots capable) for the final run into South Florida. This is the era when the Medellin Cartel, specifically Carlos Lehder, bribed the Bahamian government of Prime Minister Lyndon Pindling to obtain virtual unrestricted use of Bahamian air space and territory (see Gugliotta \& Leen, 1989). Pindling, later investigated for his dealings with Lehder, was never charged with illegal acts despite having no explanation for US\$2.5US\$3.5 million of deposits in his personal accounts. A Bahamian commission of inquiry, however, did lead to a string of indictments against Pindling's political and personal colleagues for drug-related corruption (Wilson, 1992).

By the late 1980s, when US and Bahamian law enforcement had shutdown much of the fast boat drug traffic into South Florida and Lehder resided in a US federal prison, the traffickers needed new low risk transportation routes. Here, the Colombian Cartels diversified. The emerging Colombian Cali Cartel and the more established Medellin Cartel began shipments around and through the Central American isthmus to Mexico where the drugs were later smuggled across the US-Mexican border. The Medellin and Colombian North Coast cartels also established transportation networks through the 
Eastern Caribbean with the objective of moving the drugs into Puerto Rico (and then onto the US) or to Western Europe. This diversification lead to the spread of drug corruption across the Central American peninsula, into Mexico, and throughout the Eastern Caribbean.

Panamanian dictator General Manuel Noriega is the most infamous of the Central American leaders embroiled in drug-related corruption. As early as the 1970s, Noriega, then head of Panamanian military intelligence, was suspected of drug trafficking involvement. In the 1980s, after Noriega rose to head the Panamanian military (after General Omar Torrijos' mysterious death in a plane crash), new evidence emerged that this former CIA asset had become deeply involved in the drug trade. One report estimates Noriega pocketed more than US\$350 million in the 1980 s for allowing Peruvian and Colombian traffickers the unrestricted use of Panama as a drug transshipment point, money laundering site, and protective safe-haven (Koster \& Sanchez 1990, p. 298). With US collusion, Noriega was part of a 1980s scheme where arms were flown into Costa Rica destined for the Nicaraguan Contras and then drugs flown back to the US for the drug cartels in the same airplanes (Scott \& Marshall, 1991). In 1988, Noriega was indicted on drug-trafficking charges in a US federal court. In 1989, a US military invasion of Panama ousted Noriega who was later arrested, tried, and convicted of drug-trafficking charges.

Mexico, with its own marijuana and heroin production dating back to the $1960 \mathrm{~s}$, also possesses a complex history of drug-related corruption. In 1970s and 1980s Mexico:

federal, state, and local police alternately competed and cooperated with one another and with assorted prosecutors, judges, military units, political officials, 
and agents of the security services in extracting bribes from drug traffickers, actively participating in drug trafficking operations, and cracking down on drug trafficking. Even though top-level officials, in Mexico City reportedly exercised substantial influence over career, policy, and operational decisions with implications for drug enforcement and drug-related corruption, substantial power was exercised more or less independently by regional commanders and political bosses (Nadelmann, 1993, p. 277).

The Mexican drug-related corruption reached the very top of the Mexican government in the late 1980 s and 1990s. At least part of the US $\$ 120$ million in unexplained funds found in the foreign bank accounts of Raul Salinas in 1996 were payoffs from Mexican drug-traffickers to President Carlos Salinas for his involvement in the drug trade. In 1997, the Mexican drug czar, General Jose de Jesus Gutierrez Rebollo, the person responsible for overseeing all of Mexico's anti-drug programs, was arrested on charges of drug trafficking, bribery, and illicit enrichment. Gutierrez's arrest resulted from his close association with at least one of Mexico's own major drug cartels. In 1999, the head of the US Drug Enforcement Administration testified, "Corruption in Mexican law enforcement was the worst he has seen in his 39-year law enforcement career. Continuing reports of corruption and the rapidly growing power and influence of the major organized criminal groups in Mexico cause us great concern...." (Miami Herald 1999, p. 10A).

The virus of drug-related corruption also emerged as the Colombian cartels moved their drug transportation routes to the Eastern Caribbean in the late 1980s. In 1988, St. Lucia's Police Commissioner, Cuthbert Phillips, was dismissed due to allegations of drug-related corruption and inefficiency in the Royal St. Lucia Police Force (Griffith, 1997, p. 160). In 1992, Trinidad and Tobago's assistant police commissioner 
publicly alleged that a drug-trafficking cartel was operating within the police force (Griffith, 1997, p. 162). The subsequent investigation of this allegation found evidence of close relationships between drug-traffickers and all levels of the Trinidadian police, including the police commissioner.

In November 1994, a prison riot broke out in St. Kitts over the release of two drug-murder suspects. In October 1994, Vincent Morris, the son of the St. Kitts-Nevis Deputy Prime Minister, and his fiancée were found murdered in the trunk of a burned-out car. Two weeks later, the police superintendent investigating these murders was gunned down and killed on his way to work. In November, Deputy Prime Minister Morris's two other sons, suspects in all three murders, were arrested with 121 pounds of cocaine. At arraignment, the two Morris brothers were immediately granted bail, no doubt due to their father's powerful political connections. The release of the two murder and drugtrafficking suspects caused a violent public protest and prison riot in St. Kitts. The prison riot destroyed the St. Kitts-Nevis's central prison and allowed over 150 prisoners to escape. The Eastern Caribbean Regional Security Force, based in Barbados, was called on to help the St. Kitts police restore order and recapture the escaped prisoners. The following summer, Deputy Prime Minister Morris's People's Action Movement party was voted out of power (Griffith, 1997, pp. 169-170). This St. Kitts example demonstrates the severe effects drug-related corruption can have on the political stability of small Eastern Caribbean states.

Seeing the vulnerability of the small Caribbean states to drug-related corruption, the ultimate fear of US policy-makers was "that one day traffickers might take full control 
of a country by putting a majority of elected officials, including the president [or prime minister] directly on the payroll" (US Dept. of State, 1997, p. 6). Under Noriega, Panama came close to being a corrupted narco-state in the late 1980s. However, the one state to actually achieve this notoriety was the Caribbean island of Aruba. One writer argues that Aruba became "[t]he world's first independent mafia state in 1993" (Sterling, 1994, p. 21). She reports how in the late 1980 s, the Cuntrera brothers Sicilian mafia family bought "everything of importance on the island: hotels, casinos, tourism, building land, construction, banks, police, customs, the justice minister, the prime minister, and the governing and opposition parties" (Sterling, 1994, p. 21). In 1987, the Cuntrera brothers allied with the Colombian drug cartels and offered Aruba as a safe haven for mafia/cartel vacations, money-laundering, and as a transshipment point both for drugs headed to North America and Southern Europe and for commercial contraband goods illegally smuggled along the Caribbean coasts of South America and Panama. The global drug and commercial merchandise that the combined Sicilian mafia and Colombian cartels peddle is estimated at US\$300 billion annually (Sterling, 1994, p. 22).

In 1992, Venezuela, under US and Italian pressure, captured the Cuntrera brothers and deported them to Italy. However, the structure of Aruba's narco-state was left behind to serve as the "headquarters of the first international joint venture [mafia and cartel] in organized crime" (Sterling, 1994, p. 22). Aruba presents political corruption in its purest form-the principal fuel that sustains an entire state. But in the Aruban case, a classic anecdotal example for corruption revisionists, the political corruption helped ignite booming tourist, international banking, and commercial maritime and air shipping 
industries, improving the island's standard of living as it boosted the Aruban per capita gross national product to US $\$ 16,640$, the highest in the Caribbean after Bermuda (PAHO, 1999).

Arms Smuggling Corruption. Drugs themselves are not the only commodity that drugrelated corruption supports in the Caribbean. Drug-related arms smuggling is also a serious regional problem. A drug-related arms smuggling case became the most notorious incident of political corruption in Antigua, another state many believe is close to a full-fledged narco-state.

In the 1989 arms smuggling scandal, Vere C. Bird, Jr., still an Antiguan minister despite the 1985 airport scandal, facilitated an illegal transshipment of 10 tons of Israeli arms to members of the Colombian Medellin drug-cartel (see Blom-Cooper, 1990; Thorndike, 1991; Coram, 1993). The arms were invoiced from Israel to the Antigua and Barbuda Defense Force, but upon their arrival in Antigua were immediately redirected to Colombia. Colombian security forces found a large cache of the arms during a December 1989 assault that killed Medellin Cartel henchman Jose Rodriguez Gacha. Colombia's investigation found that some of the guns from this shipment had also been used in the 1989 assassination of Colombian presidential candidate Luis Carlos Galan (Maingot, 1994c, p. 155).

A Colombian diplomatic protest to Antigua over the arms discovery lead to an official inquiry of the incident by British jurist Louis Blom-Cooper, who uncovered collusion between Vere, Jr., and several Israeli arms merchants. He recommended that, for his role in this scandal, Vere, Jr., should never again hold public office. Additionally, 
Blom-Cooper recommended that Lieutenant Colonel Clyde S. Walker, head of the Antigua-Barbuda Defense Force, be dismissed from the service and also never hold public office again. Prime Minister Vere Bird, Sr., reluctantly removed Vere, Jr., and Walker from government service, however, by the late 1990s both had returned to prominent positions as special advisors to the new Antiguan Prime Minister Lester Bird, Vere, Jr.'s, younger brother.

Another Caribbean arms smuggling case illustrates the complex international connections associated with this drug-related activity. In January 1989 , US $\$ 8$ million in arms were found in a shipping container in the port of Kingston, Jamaica. The arms were of West German manufacture and were bound for an unknown guerrilla group in Colombia. Colombian guerrilla groups are known for providing protection to drug growing and processing areas. The arms were shipped from Portugal on a Panamanian registered freighter. A Panamanian company that had previously been linked to illegal arms shipments, cocaine smuggling, and drug-related money laundering owned the freighter. The joint Jamaican, British, US, and Colombian investigation of this incident deemed it "an international network of traffickers and terrorists" (Maingot, 1994c, p. 152).

Money Laundering Corruption. A second drug-related criminal endeavor closely associated with political corruption is money laundering. "Money laundering generally involves a series of multiple [financial] transactions used to disguise the source of financial assets so that those assets may be used without compromising the criminals who are seeking to use the funds. Through money laundering, the criminal tries to transform 
the monetary proceeds derived from illicit activities into funds with an apparently legal source" (US Dept. of State, 1999b). The world drug-trade is estimated to generate US\$500 billion in illegal cash transactions annually (Payne, 1996). There is an enormous demand by drug traffickers to turn this illegal cash into financial instruments that appear clean. There is also a huge demand by Caribbean governing elite to both clean the proceeds from their corrupt behavior and to move their ill-gotten assets to offshore financial centers inaccessible to state auditors or investigators. The ability of a state's governing elite to extract political rents from their support of money laundering or other questionable financial activities, whether drug-related or from other illegal behaviors, has become a lucrative source of Caribbean political corruption.

Money laundering is a profitable business across the Caribbean. While some money laundering schemes are uncovered by domestic and international investigations, the majority goes undiscovered and unprosecuted. The largest international financial scandal ever, a US\$20 billion fraud that lead to the 1991 collapse of the Bank of Credit and Commerce International $(\mathrm{BCCI})$, involved $\mathrm{BCCI}$ branches in 62 states, with the BCCI branch in the Cayman Islands a principal player (see Truell \& Gurwin, 1992). Investigations of the BCCI scandal found Manuel Noriega and the Colombian Medellin Cartel as BCCI clients. BCCI, not a bank in the conventional sense of the word, was an international financial entity involved in money laundering, drug trafficking, political bribes, untraceable cash transactions, weapons trafficking, and the financing of terrorists worldwide. Senior officials in the US government knew of BCCl's illicit activities beginning in the early 1980 s, however, US officials found it convenient to keep BCCI 
open to facilitate its own clandestine intelligence operations, including the Iran-Contra arms smuggling. The scariest part about the BCCI scandal is that the bank's officials were following most international financial rules—rules that have changed little since BCCI's 1991 collapse (Beaty \& Gwynne, 1993).

A governing elite's ability to engage in money laundering is determined by two principal factors. First, to be a money laundering threat requires a state to have a welldeveloped international financial sector. For example, Nicaragua, although rated in Table 4-1 as a systemically corrupt Caribbean states, presents a low money laundering threat because of its poorly developed international financial sector. Second, the attitude of the governing elite toward money laundering and other questionable financial business (Internet gambling, economic citizenship, etc.) helps determine a state's corrupt behavior. The Caribbean has become famous for its governing elite's promotion of Offshore Financial Centers (OFC) that facilitates money laundering and other financial crimes. The US Department of State describes OFCs:

An OFC is a jurisdiction where an intentional effort has been made to attract foreign business by deliberate government policies such as the enactment of tax and other fiscal incentives, "business friendly" regulatory/supervisory regimes and secrecy enforced by law. It is the OFC's legal framework that makes it unique. Common to most developing and mature OFCs is a legal framework that to varying degrees facilitates the maintenance of secrecy, the minimization or mitigation of tax and supervisory burdens, and freedom from common regulatory constraints, such as exchange controls and disclosure requirements. When viewed as a financial services concept, an OFC is any jurisdiction that enables banks, trust companies, company incorporators, other financial intermediaries and financial advisors resident in that jurisdiction to provide products and services to non-residents in their home countries. In many cases the same services are not available to their own residents. These jurisdictions are often sovereign states but not necessarily so. They may be a free zone within a city.... They may also be political subdivisions within a sovereign state.... The relationship between offshore and onshore jurisdictions is complex, but for the 
most part offshore financial centers tailor their products and services to residents of other jurisdictions. Through a practice known as nicheing, OFCs regularly modify their legislation, developing new financial vehicles and services to attract business from their target markets (US Dept. of State, 1999b).

Table 4-1 lists those Caribbean states where the governing elite have sponsored OFCs and the money laundering threat level each state presents based on the analysis of the US Department of State. The Table 4-1 money laundering threat ratings must be qualified. Some states, even though possessing strong OFCs and being a high threat for money laundering activity, still do not condone illegal behavior outright. For example, the Cayman Islands are in compliance with nearly every international convention against money laundering, but remain an OFC with a high threat for money laundering due to the estimated US\$5-US\$10 billion dollars that get lost in the US\$ hundreds of billions the island's financial sector processes each year. When evidence of money laundering does surface, Cayman officials gladly cooperate with international investigators in uncovering its sources (US Dept. of State, 1999b).

Barbados presents another unique international banking case. Although an OFC of moderate threat for money laundering activities, Barbados's OFC is known for its open and transparent offshore financial services. Barbados's OFC regulations insist financial entities know the identity of their clients and were written to attract clients who want disclosure (Maingot, 1995, p. 18). Several of the other Caribbean OFCs; Antigua and Barbuda, Aruba, and Panama; are largely in the international finance business for both the legal and illicit gains it brings their respective governing elite. The willingness of governing elite in these states to support OFCs correlates closely with the high levels of political corruption in these states. 


\section{Conclusion}

This chapter reveals the diversity in contemporary Caribbean political and economic institutions and their general association with regional political corruption levels. The chapter highlights that Caribbean states with authoritarian-democratic political systems suffer the region's worst political corruption problems. The rise of authoritarian-democratic systems was both a conscious effort and unintended consequence of Caribbean political development paths. In contemporary Caribbean presidential systems, the governing elite drew upon their states' histories of colonial and early post-independence strongman and oligarchic rule to build (constitute) governing systems that placed political decision-making power in the hands of a small political elite. In contemporary Caribbean Westminster parliamentary systems, governing elite took advantage of the inappropriateness of the Westminster system for small states lacking strong societal values of tolerance and civic cooperation, and also built governing systems centered on only a few powerful decision-makers. In both the presidential and Westminster parliamentary cases, the governing elite played the lead role in manipulating their state's political and economic development for their own self-interests-and not necessarily the best interests of their larger citizenry.

While this chapter neither tests nor advances this study's theory of the causes of political corruption, it does demonstrate that certain Caribbean indicators-political rights, civil liberties, press freedom, and economic structures-are associated with high political corruption levels (as Table 2-4 predicts). It also reveals anecdotal evidence of the most prevalent types of political corruption behaviors that have become public 
knowledge in the region. Next, Chapters 5 and 6 advance this study's theory through closer investigations of the agency issues, institutional structures, and political corruption behavior in Jamaica and Costa Rica, respectively.

\section{Endnotes}

1. States with authoritarian-dictatorial governments during all or some portions of the period from 1960 to 1980 included El Salvador, Guatemala, Honduras, Nicaragua, Panama, Venezuela, and Cuba.

2. Table 4-1 cannot be used to establish statistical correlations of the causes of Caribbean political corruption. The concepts (variables) hypothesized in Table 2-4 to cause political corruption are neither operationalized nor adequately measured in Table 4-1. At best, Table 4-1 can be used to establish general trends in the relationships between the indicators shown and corresponding levels of political corruption.

3. This finding is statistically significant when computed for all world states rate by Transparency International in their annual Corruption Perception Index.

4. The methodology for the 1999 Transparency International Corruption Perception Index can be found in Dr. Johann Graf Lambsdorff, The Transparency International Corruption Perception Index 1999-Framework Document October 1999, available at http: Uwww.transparency.de.

5. The Transparency International definition of systemically corrupt states is the equivalent of states designated institutionally or systemically corrupt as developed in Chapter 2 of this study.

6. The content analysis was developed using Griffith (1993, 1997), Nadelmann (1993), Maingot (1993, 1994a, 1994b, 1994c, 1995), Collier (1998); reviews of the periodicals Caribbean Insight (1995-1999) and Central American Report (1996-1999); and database searches of Info-LatinoAmerica (1988-2000). The ratings correspond to the TI CPI as follows: Incidental (6.7 to 10), Institutional (3.4 to 6.6), and Systemic (0 to 3.3).

7. With Prime Minister Charles's retirement in 1995, political corruption in Dominica is beginning to resemble that in other small Eastern Caribbean states (St. Lucia, etc.). Dominica has become a regional leader in offering economic citizenship to the nationals of other states and is working toward becoming a major offshore financial center. 


\section{Chapter 5}

\section{Jamaica: Westminster Corrupted}

Jamaica possesses some of the Caribbean's most breathtaking vistas. The third largest Caribbean island after Cuba and Hispaniola, Jamaica boasts steep wooded mountains, green fertile lowland fields, and white sandy beaches, all surrounded by the deep blue Caribbean Sea. A closer look behind this natural beauty, however, reveals a Jamaica with one of the Caribbean's most entrenched authoritarian-democratic governing systems. Since its 1962 independence from the British, Jamaica's governing elite have manipulated their Westminster parliamentary structures to place government decisionmaking in the hands of a small group of powerful political elite. The competition to attain Jamaican political power has degenerated into open, and often violent, warfare between the state's two principal political parties. Not surprisingly, the Jamaican governing elite's exploitation of political power has spawned serious problems with political corruption.

Transparency International (TI) assigns Jamaica a 1999 rating of 3.8 on their scale ranging from 0 (totally corrupt) to 10 (no corruption) (see Table 4-1). Placing this Jamaican TI rating on the corruption index in Table 2-4 (the coordinates of political corruption) leads to the following hypothesis that is tested in this disciplinedconfigurative case study of Jamaica:

Hypothesis: Jamaica's coordinates of political corruption causal factors (form of societal rule, political culture, elite competition, elite accountability, mass participation, market resource factors, boundaries between public and private) are dominated by instruction rules, or near equal combinations of instruction 
and directive rules, resulting in political corruption patterns between systemic and institutional.

This chapter investigates the above hypothesis using the framework of this study's theory of the causes of political corruption. It first provides a historical survey of institutional development in Jamaica. Second, it assesses the nature of contemporary Jamaican political corruption patterns, including determining the boundaries Jamaicans have established between their public duties and private interests. Third, it investigates contemporary structural factors that cause Jamaican political corruption. Finally, the chapter summarizes the interdisciplinary causes of Jamaican political corruption. This chapter demonstrates that the main cause of political corruption in Jamaica is a selfinterested governing elite who have manipulated their state's political and economic development to serve their own personal interests.

\section{Historical Setting}

Jamaica takes its name from its original inhabitants, the Arawak Indians, who called the island Xaymaca - the land of wood and water. Columbus arrived in Jamaica in 1494. The Spanish first settled the island in 1509 and took quick advantage of Jamaica's natural harbors to use the island as a supply base for Spanish expeditions exploring the Caribbean, Mexico, Central America, and South America. The island's original Arawak inhabitants were subjugated and eventually died out in Spanish attempts to establish plantation (encomienda) based agriculture. African slaves were then imported to replace the decimated Indian work force. Lacking precious metal deposits, the Spanish gave Jamaica little priority among its New World colonies, resulting in the growth of neither 
large nor well-fortified Spanish settlements. Capturing Jamaica in 1655, in the face of little Spanish resistance, was an easy task for the British forces under the command of Vice Admiral William Penn (Hillman \& D’Agostino, 1992, pp. 30-32).

Soon after Penn's victory, the British fortified Jamaica and expanded its plantation-based economy. During the eighteenth century, Jamaica's strong agriculturalexport sector and its role as a regional market for the slave trade made it the crown jewel of Britain's Caribbean colonies. Jamaica's version of slave-based plantation agriculture was particularly onerous, one reliant on terror as the principal means to keep slaves in line. While some plantation owners lived in Jamaica, many of Jamaica's plantations were absentee landlord operations, i.e., owned by entrepreneurs living in Britain and run by local overseers who brutalized the African slaves. Between 1690 and $1820,800,000$ African slaves were imported by the British to work Jamaica's prosperous plantations producing rum and sugar for European markets. Despite the large number of slaves imported by 1820 , only 340,000 slaves then populated the island (Trager, 1994).

The lower than expected number of slaves in 1820 was due not only to Jamaica's role as a slave market for other British Caribbean and North American colonies, but also due to a combination of other factors (Hillman \& D'Agostino, 1992, p. 33). First, the number of male African slaves imported far outnumbered the females (Trager, 1994). Second, at least one-third of all slaves died soon after their arrival in Jamaica, many from suicide (Trager, 1994). Third, as a result of primitive health and medical conditions, only half of the babies born to Jamaican slave mothers survived. Finally, Jamaican slavery, like that in other Caribbean colonies, promoted humiliations, mutilations, and killings as 
common methods for slave discipline. For example, British authorities and plantation owners reacted to an 1831 slave rebellion led by Samuel Sharp, one where no whites were killed, by flogging and hanging hundreds of slaves who joined in Sharp's refusal to work without adequate compensation (Trager, 1994; Randall \& Mount, 1998, pp. 21-22).

The end of slavery brought significant changes to Jamaica. The British ended the slave trade in the British Empire in 1807 and abolished slavery in Jamaica in 1834. All former Jamaican slaves were finally declared free in 1838 . Under the system of wage labor that took slavery's place, Jamaican sugar production fell from a high of 70,000 tons in 1821 to only $20,000-25,000$ tons annually by the early 1840 s (Trager, 1994). Many of the former slaves preferred to live on subsistence agriculture rather than return to arduous plantation work for the meager wages their former brutal masters offered. After the 1830 s, both the production of and European demand for Jamaican tropical agricultural products declined. Jamaica, once one of Britain's most prized overseas colonies, became a forgotten backwater of the British Empire until just before the outbreak of World War II (see Lewis, 1968, chap. 7; Hillman \& D'Agostino, 1992, pp. 33-35).

During its three centuries of British colonial rule, Jamaica epitomized what Knight (1990, p. 76) defines as an exploitation society — conditions where a minority of Europeans dominated a majority of non-Europeans in a socioeconomic complex designed to produce export commodities for the European market. In an exploitation society, the Europeans never ceased to behave like transients and continued to base their society and politics on those of the metropolis (Knight, 1990, p. 75). Additionally:

exploitation societies lacked a common, unifying, institutional basis beyond the plantations and other economic enterprises. They were innovative only for self- 
preservation. Not only were such societies divided, they tended to be divisive.... The elites lacked cohesion and self-confidence. However long the elite remained physically in situ, they were psychologically transients, with myopic confusion of social order and productive efficiency. The most enduring and sometimes the most interesting features of such societies were created by the lower orders, who were often told what they could not do but rarely told what they ought to do. (Knight, 1990, p. 86)

Jamaica's three centuries as a British exploitation colony resulted in an everincreasing level of societal frustration and political apathy among the masses. After a short period of British military rule (1655 to 1661), a semi-representational colonial governing system was installed in Jamaica (Hillman \& D'Agostino, 1992, p. 32). A governor and ruling council (upper legislative house) were appointed by the British king. A local assembly, elected from the white plantocracy (rich planters) and mercantile interests, made up a lower legislative house. This colonial governing structure changed little between 1661 and 1865 when societal frustrations flared in the Morant Bay rebellion (see Chapter 3).

After the 1834 abolition of Jamaican slavery, the white plantocracy and mercantilists continued to rule as they had since 1661-in the moneyed elite's best interests while giving little attention to the needs of the black masses. Just before the 1865 rebellion in Morant Bay, mulatto and black entrepreneurs began to gain political power as they attained the requisite financial resources to qualify as both voters and candidates for the Jamaican local assembly. The possibility of sharing power with the successful mulattos and blacks was unnerving to Jamaica's white elite. The white elite concluded from the Morant Bay rebellion that a government that included former slaves was unworkable. Thus, in the name of self-preservation (as could expected in an 
exploitation society), Jamaica's white plantocracy and mercantilists overwhelmingly supported the abolition of Jamaica's locally elected assembly and the institution of British Crown Colony rule. To Jamaica's white elite, non-representative British rule was a better choice than a shared local government with the successful mulattos and black ex-slaves (see Lewis, 1968, chap. 6; Hillman \& D'Agostino, 1992, pp. 33-35; Randall \& Mount, 1998, pp. 47-48).

The British Crown Colony system in Jamaica allowed no local representation beyond an unofficial council from the moneyed plantocracy and mercantilists that acted as informal advisers to the British appointed governor. With local political activities discouraged, the Crown Colony system focused on establishing bureaucratic efficiency, maintaining societal order, and providing basic government services (education, health, water, roads, etc.). In British liberal-democratic tradition, the Crown Colony system left Jamaica's economic development to market forces (i.e., the plantocracy and mercantilists). As the 1945 Moyne Commission investigation in the West Indies confirmed, the Crown Colony system gave little attention to building the political, economic, and social institutions found in modern states (Moyne Commission, 1945).

Jamaican societal frustrations continued to simmer under British Crown Colony rule well into the twentieth century. These frustrations peaked in 1937 and 1938 as evidenced by a series of labor riots that signaled the beginning of Jamaica's quest for selfgovernment. The 1930s worldwide economic depression and a growing sense of Jamaican nationalism helped spark the Jamaican independence movement. The 1930s depression caused a serious slump in foreign demand for Jamaica's tropical agricultural 
products-making a bad internal economic situation even worse. During this same period, the Jamaican masses were moved by calls from Marcus Garvey and others toward a new sense of Jamaican racial pride and nationalism. Frustrations over Jamaica's economic and political malaise, continuing widespread poverty, worker grievances against management, the lack of political or economic institutions as avenues for expressing their frustrations (e.g., no labor unions), and a rising sense of nationalism, all combined to ignite a series of protests and riots in the late 1930s (see Lewis, 1969, chap. 7).

Two charismatic leaders who eventually lead Jamaica to its 1962 independence emerged from the 1930s unrest. First, Alexander Bustamante, the 1938 founder of the Bustamante Industrial Trade Union (BITU) and the Jamaican Labor Party (JLP) (in 1942), captured the attention of the Jamaican working masses, especially the rural poor, and became their hero in the fight against British colonialism. Second, Bustamante's cousin, Norman Manley, a Rhodes scholar and Jamaican barrister, who in 1938 founded the People's National Party (PNP) that later allied with the new National Workers' Union (NWU), became the darling of the Jamaican middle class and intelligentsia as the new spokesman for Garvey's earlier appeals for Jamaican nationalism and political independence (see Lewis, 1968, chap. 7). The competition that arose between Bustamante's JLP/BITU and Manley's PNP/NWU carried Jamaica through its transition to independence and remains the basis for present day Jamaican politics.

British colonial and post-World War II fatigue, and the strong decolonization sentiment in the newly formed United Nations, influenced Britain to start its Caribbean 
colonies on a road to independence. The British granted Jamaica universal suffrage in 1944, along with a new constitution that allowed Jamaicans to regain the initial trappings of representative government for the first time since 1865 . Over the next 18 years, Britain implemented further incremental steps in Jamaican self-government until full independence was granted in 1962 (see Munroe, 1969). The pre-independence period was facilitated by a period of Jamaican economic growth that lasted from the 1940 s until the late 1960s. This economic expansion was precipitated by the development of the bauxite-alumina and tourist industries and a strong world demand for Jamaica's traditional tropical agricultural products (sugar, coffee, bananas, etc.). Between 1950 and 1968, the Jamaican economy grew at the average annual rate of 6.7 percent (Worrell, 987, p. 3).

Jamaican colonial experience with political corruption was typical of other British Caribbean colonies. The seventeenth and early eighteenth centuries saw widespread corruption surrounding Jamaica's role as a pirate and smuggling haven (Marx, 1992). In the later eighteenth and nineteenth centuries, especially after the abolishment of slavery, corruption ensued from the elite's (colonial officials, plantocracy and mercantilists) selfinterested quest for wealth and power at the expense of the black masses. However, by the mid-twentieth century, the professionalized British Colonial Office had reduced corruption to only a minor problem (Lewis, 1968, p.115). Jamaica began its first years as a sovereign state with a Jamaican-born civil service that inherited strong values of honesty and probity from its former British colonizers (Munroe, 1994, pp. 189-191; Mills, 1997, p. 24; Cargill (interview), 1999). The two principal political leaders, 
Bustamante and Manley, had reputations of strong British democratic values-especially the need for consensus politics-and were considered upstanding politicians with the interests of the Jamaican people as their central concerns (Cargill (interview), 1999). The rule of law was strong in the early days of Jamaican state formation, as revealed in the pre-independence 1950s where several elected Jamaican parliament members were prosecuted and jailed for corruption (Chang, 1999).

By the 1970 s, the pre-independence and early post-independence Jamaican conditions of honest and non-corrupt government changed. After barely 10 years of independence, the Jamaican civil service became largely politicized, with most of the formerly incorruptible Jamaican-born civil servants retired or replaced (see Mills, 1997, pp. 13-20); Bustamante and Manley had both stepped-down from national leadership; and the rule of law, especially surrounding the Jamaican governing elite's accountability, was severely weakened. A Jamaican journalist describes the emergence of the corrupt Jamaican state:

Since independence in 1962, Jamaica has undergone a most far-reaching change in its attitude toward corruption in government. It has moved from having isolated cases to acceptance of corruption as the norm. In the mid-1970s, Jamaica's two major political parties [JLP and PNP] became fully aware of the deficiency in accountability that existed in our democratic framework. This realization flowed out of the 1976 State of Emergency, which led to the institutionalization of what I call "Politocracy"--the corruption of power and government institutions for political ends. In that year, the relatively efficient bureaucracy left behind by the British became totally fragmented. The legislature, judiciary and administration became victims of corruption by politics. (Buck, 1989, p. 21)

Two key events helped solidify the rules surrounding the lack of Jamaican elite accountability and the rancorous JLP-PNP political competition that arose in the 1970s. 
First, in a 1972 act of political revenge, a newly installed PNP government commissioned an inquiry into the handling of government contracts and work permits during the previous JLP government (1962-1972). The Da Costa Commission of Inquiry found widespread disregard for proper government financial planning, including extreme mismanagement and political influence surrounding the award of government contracts, approval of work permits, and sale of state-owned land during the JLP's reign (Da Costa, 1973). While the Da Costa Commission's final report detailed the illegal behavior of several JLP officials, its final recommendations called for no legal actions against any individual. The report only encouraged the ruling PNP to strengthen government contracting procedures. No action was ever taken on the $\mathrm{Da}$ Costa report, indicating the PNP lacked the political will to either prosecute JLP officials or limit the system of political influence over government resource management that had become a lucrative source of funds for both the ruling party and individual government officials. The ruling PNP saw no need to change the rules of the political game under which they were then benefiting.

Second, in 1976 the PNP government declared a nationwide State of Emergency. After their 1972 election, and in the face of strong JLP opposition, the PNP set about dismantling Jamaica's open market economy and installing a socialist economy based on government ownership of key modes of production and increased government planning and regulation of the entire economy. The JLP-PNP policy disagreements eventually turned violent with factions from both parties engaging in open armed warfare in the poorer neighborhoods of Kingston. The resulting crisis reached a peak on June 19, 1976, 
when PNP Prime Minister Michael Manley, son of PNP founder Norman Manley, declared a constitutional-based State of Emergency that suspended many civil and human rights. Manley justified his declaration as a means to stop the rising tide of politically engendered gang violence and to restore public stability (Gunst, 1995, p. 18). However, the PNP's actions went beyond restoring public safety and included the imprisoning of numerous JLP officials and supporters. In the introduction to a book about the State of Emergency, Stone (1989) describes the mid-1970s Jamaican political context:

Democracy in Jamaica was in a crisis in the 1970s as the two major political parties, the Jamaica Labor Party and the People's National Party, confronted each other from sharply opposed ideological positions. [The PNP was socialdemocratic, the JLP more liberal-conservative.] Political violence intensified to unprecedented levels and the contest for power assumed a winner-take-all situation that shattered the very foundation of the inter-party consensus, which had been built up during the 1950s and 1960s. For the first time in the history of party competition in the country, the governing PNP took it upon itself to use the full power of a State of Emergency to paralyze the campaign efforts of the opposition by locking up the key members of its leadership and by publicly accusing the party of consorting with enemy forces and of plotting subversion (Stone, 1989, p. i).

Manley lifted the State of Emergency on June 4, 1977, after the PNP won the 1976 national elections. The PNP's control over the Jamaican media allowed them to mount a propaganda campaign that convinced most voters there was truth to the PNP allegations against the JLP, and therefore, the State of Emergency was justified. Over 600 JLP officials and supporters were detained or jailed during the one-year State of Emergency. Later it was revealed that there was little basis for the PNP accusations, but not one PNP official, or member of the Jamaican police or defense force, who enthusiastically enforced the PNP's emergency orders, was ever held accountable for the misuse of political power that occurred during the State of Emergency (Charles, 1989). 
The only accountability the PNP experienced was its later loss to the JLP in the 1980 national elections. The 1976-1977 State of Emergency, especially the lack of accountability for its PNP leaders, helped solidify the rules for the acrimonious and often violent JLP-PNP political competition that still haunts Jamaican politics.

After the widespread expansion of the Jamaican economy in the 1950s and 1960s, it began to contract significantly in the 1970 s and 1980 s. The 1972 to 1980 ruling PNP socialist programs saw the state take a leading role in economic planning, including state ownership of many sectors of the economy. This restructuring of the economy occurred during the period of the 1970 s world oil crisis and general recession. Jamaica was particularly hard hit by the world oil crisis, as it possesses no petroleum or coal resources and is totally reliant on imports for its energy needs. Additionally, Jamaica's move toward a socialist economy angered the US, leading the US to undermine Jamaica's receipt of vital investment capital from international financial institutions (IFIs) (World Bank, IMF, etc.).

When the JLP recaptured the government in 1980 , it commenced a reversal of the PNP socialist economic programs. While maintaining a firm hold on Jamaican economic planning to maximize rent seeking, the JLP began to privatize state economic holdings and shift to a more open market economy. JLP Prime Minister Edward Seaga became a favorite of US President Reagan as the US reversed its 1970s stance and insured Seaga's government received preferential treatment from the IFIs. Despite the JLP's efforts at revitalizing the Jamaican economy, GDP growth remained weak, reaching only a peak of 4.2 percent in the 1980 to 1988 period of JLP government (Gayle, 1996, p. B397). After 
the PNP regained power in 1989, GDP peaked at close to 7 percent growth and then plummeted dramatically, leveling off at around 1 percent growth from 1991 to 1996 and dropping to negative growth from 1997 through 1999 (Political Risk Services, 1998b; World Fact Book, 1999).

During the 1980s and early 1990s, the political war between the JLP and PNP continued. Hundreds of politically motivated murders occurred each year, with the numbers peaking in election years (see Headley, 1996). In 1997, when the PNP won an unprecedented third consecutive election over the JLP, the political violence seemed to recede for the first time in the three decade JLP-PNP political war. This chapter now turns to assessing contemporary political corruption levels and institutions that developed over these last three decades of Jamaican political and economic turmoil.

\section{Assessing Contemporary Jamaican Political Corruption}

TI's 1998 and 1999 corruption perception index (CPI) scale ratings of Jamaica at 3.8 (on a scale of 0 to 10 ) drew mixed reactions in Jamaica. Those in Jamaica's ruling PNP government took the low ratings as personal affronts, immediately questioning the competency of TI to publish such ratings while simultaneously heralding recent PNPinitiated anti-corruption measures (Campbell, 1998). Those in the opposition JLP and new third party, the New Democratic Movement (NDM), saw the ratings as a means to discredit the ruling PNP and offered that the TI ratings were too high, i.e., that the Jamaican PNP governing elite were even more corrupt than TI offered (Campbell, 1998). Trevor MacMillan, a former Jamaican police commissioner and head of the Jamaican TI chapter, justified the Jamaican ratings when he stated, "I think it reflects what most 
people in Jamaica believe. The fact is there is a major corruption problem in Jamaica" (Campbell, 1998).

In a 1999 poll of Jamaican citizens, 49 percent thought corruption was the greatest threat to Jamaican democracy. In the same poll, seventy-seven percent felt that there was more corruption in Jamaica now than there was 10 years ago (Chang, 1999; Daily Gleaner, 1999). A 1995 survey of Jamaican citizens found that 64 percent thought most or all Jamaican politicians were corrupt (Rodrigues, 1996, p. 110). Thus, the consensus, both inside and outside Jamaica, is that political corruption presents a significant problem.

Table 5-1, developed from a content analysis, characterizes the current incidence and evaluation of Jamaica's political corruption problems. ${ }^{1}$ Table 5-1's results correlate closely with the 1999 TI 3.8 CPI rating of Jamaica. The content analysis of Jamaican political corruption reveals a governing elite that regularly abuses its power to benefit themselves, their friends, and their supporters. The single greatest source of Jamaican political corruption is associated with the Table 5-1 behaviors related to political influence peddling - where the governing elite use their positions to intervene in government contracting and the delivery of government services with the expectation of private gain. Jamaican jurist Barnett (1999) summarizes the political corruption problems as:

The partisan type of corruption, which manifests itself in the award of contracts and the employment of persons on the basis of their political affiliations to the governing party, are generally accepted as part of the political system. Financial contributions and the political support of political parties often come from persons who expect most favored treatment in the distribution of the scarce benefits dispensed by the government. In many areas of public administration it 
is well known that gifts to public officials are the only means of obtaining expedition in the handling of the citizen's application to government departments. An even more unsavory corollary is that failure to pay may result in retardation of the processing of one's matter. (Barnett, 1999, pp. 10-11)

Table 5-1. The Incidence and Evaluation of Jamaican Political Corruption Behavior

\begin{tabular}{|c|c|c|}
\hline \multirow{3}{*}{$\begin{array}{l}\text { Types of Political Corruption Behavior } \\
\text { 1. Governing elite deviate from the rules for } \\
\text { the benefit of friends or supporters. } \\
\text { 2. Large gifts, or other benefits, accepted by } \\
\text { governing elite for private gain. }\end{array}$} & Incidence & Evaluation \\
\hline & SOP & W \\
\hline & SOP & W \\
\hline $\begin{array}{l}\text { 3. Unregulated campaign contributions } \\
\text { solicited and accepted by governing elite. }\end{array}$ & SOP & W \\
\hline $\begin{array}{l}\text { 4. Nepotism or political cronyism in govern- } \\
\text { ment appointments and contract awarding. }\end{array}$ & SOP & W \\
\hline $\begin{array}{l}\text { 5. Governing elite profit from state decisions } \\
\text { through sideline occupations or kickbacks. }\end{array}$ & SOP & W \\
\hline $\begin{array}{l}\text { 6. Citizens compensate governing elite for } \\
\text { advancing administrative due process. }\end{array}$ & SOP & W \\
\hline $\begin{array}{l}\text { 7. Governing elite tolerate or cooperate with } \\
\text { organized crime for private gain. }\end{array}$ & FI & G \\
\hline $\begin{array}{l}\text { 8. Governing elite ignore convincing proof of } \\
\text { political corruption. }\end{array}$ & SOP & G \\
\hline $\begin{array}{l}\text { 9. Governing elite misuse state resources } \\
\text { (land, property, etc.) for private gain. }\end{array}$ & SOP & G \\
\hline $\begin{array}{l}\text { 10. Governing elite misuse state treasury for } \\
\text { private gain. }\end{array}$ & $\mathrm{OO}$ & B \\
\hline
\end{tabular}

Key: $\mathrm{SOP}=$ Standard Operating Procedure; $\mathrm{FI}=$ Frequent Incidence;

$\mathrm{OI}=$ Occasional Incidence; $\mathrm{OO}=$ Rare Incidence, Without Regular Pattern

$\mathrm{W}=$ White Corruption Boundaries, $\mathrm{G}=$ Gray Corruption Boundaries;

$\mathrm{B}=$ Black Corruption Boundaries.

Source: Content Analysis (see Endnote 1).

Table 5-1 reveals that Jamaican political corruption is not only pervasive, but also widely accepted by the Jamaican elite and masses (predominantly white boundaries). This corrupt behavior persists in present day Jamaica in spite of a number of anticorruption laws and regulations-rules the Jamaican governing elite regularly violate 
with impunity (Cargill (interview), 1999). For example, to prevent conflicts of interest, the 1962 Jamaican Constitution prohibits members of parliament from owning or having financial interests in businesses that obtain government contracts-unless a parliamentary waiver is granted (Aub \& Aub, 1994). Despite this prohibition, at least one-third (20) of Jamaica's elected parliamentarians are associated with business interests holding government contracts - all having received parliamentary waivers (Aub \& Aub (interviews), 1999a, 1999b; Cargill (interview), 1999).

The centerpiece of Jamaican anti-corruption statutes, the Corruption Prevention Act of 1931, dates to the British colonial period. Although the Corruption Prevention Act encompasses a plethora of activities considered corrupt, and applies to all public servants except Parliament, there have been no prosecutions of senior public servants under the act in Jamaica's almost four decades of independence.

Jamaican parliamentarians fall under the anti-corruption provisions of the 1973 Parliamentary Integrity of Members Act. This act establishes a commission to investigate the assets, liabilities, and income of members of parliament, those both elected to the Jamaican House of Representatives and appointed to the Jamaican Senate. Again, like the Corruption Prevention Act, the requirements of the Integrity of Members Act are regularly ignored, including parliamentarian's failure to submit annual declarations of assets to the Integrity Commission (Cargill (interview), 1999). There are also a number of Jamaican anti-corruption statutes surrounding the misuse of public finds, electoral fraud, illegal government contracting, and government financial irregularities (see Barnett, 1999). However, like other anti-corruption measures, the governing elite also 
regularly ignores these. In surveying the problem of Jamaican elite accountability, Stone (1980, p. 101) confirms "the official rules of the game are violated with impunity by political bosses...." This allows the Jamaican governing elite to act as near predators (pirates in accordance with Table 2-4) as they are free to enrich themselves and fill ruling party coffers in the execution of their public duties.

\section{Explaining Jamaican Political Corruption}

There are several competing explanations for Jamaica's political corruption problems. Most take structural approaches. Barnett (1999) takes the structural approach when he blames corruption on various deficiencies with the Jamaican criminal justice system that present the governing elite no risk of prosecution. Others explain Jamaica's corruption problems as a result of the governing elite's manipulation of the Westminster parliamentary system for their own private interests (see Jacobs, 1978; Mills, 1997; Munroe, 1999b). Stone (1980) and Edie (1991) further the structural arguments by relating Jamaica's political corruption problems to the strong clientelistic system that developed after 1962.

This chapter reveals that while all of the above explanations for Jamaica's political corruption problems have merit, the overall causes for the problems are more complex. Taking advantage of the weaknesses of the Westminster system in small states, Jamaica's governing elite have constructed an authoritarian-democratic governing structure. Predictably, this governing structure is accompanied by restrictions on institutions concerning elite competition, elite accountability, and mass participation. This authoritarian-democratic structure, combined with a self-interested governing elite 
that built and perpetuate this structure, led to Jamaica's severe political corruption problems.

Form of Rule. Jamaica's form of rule is a mix of hegemonic and hierarchical conditions (see Chapter 2). It is partly hegemonic because of the paternalistic relations that exist between the governing elite and mass citizenry. At the same time, it is also partly hierarchical because of the threats of or actual use of coercion that are used by the governing elite to maintain political control and public stability (coercion is a directiveruled condition). The nature of this partly hegemonic, partly hierarchic, form of rule are evident in the below description of Jamaica's formal and informal ruling structures.

During Jamaica's 1944 to 1962 transition to independence, the rising governing class seemed oblivious to the inappropriateness of the Westminster system as a Jamaican democratic model (Munroe, 1969, p. 302). The core of the Jamaican Westminster system is a 60 member House of Representatives elected from individual geographic constituencies. The political party (or coalition) with the majority of the 60 elected Members of Parliament (MPs) forms the Jamaican government and becomes the ruling party/coalition. ${ }^{2}$ The ruling party selects one elected MP as the Prime Minister (PM) or head of government. Since independence, the PM has always been the president of the ruling party. The PM and Opposition Leader, the MP who heads the non-ruling party or coalition, recommend the 21 persons to be appointed to the Jamaican Senate (13 by the ruling party or coalition, 8 by the opposition) by the largely ceremonial Governor General. The PM also selects approximately 30 of the ruling party or coalition MPs or 
Senators as cabinet or state ministers, constituting the senior decision-makers in the executive branch of government.

The Jamaican Westminster system places extraordinary power in the hands of the PM (see Munroe, 1999b, p. 52). The source of this political power is the PM's control of ministerial appointments, as the Jamaican government ministers, checked only by the PM, possess the dominant say in how state resources are managed and distributed in their respective areas of responsibility. The vast majority of Jamaican public policies, including all budget decisions, originate within the ministries. As is traditional in Westminster parliamentary systems, the process of government policy formulation is closed, with the final decisions of the ministers presented as a consensus of the entire government (PM and ministers). This principle of collective responsibility for the government's programs is typical of Westminster governments. Thus, the Jamaican public, and even MPs that are not ministers, are not privy to the ministerial debates leading to final policy formulation. The PM, if he/she sees fit, can rule dictatorially over the entire public policy process as each minister serves only at the continuing pleasure of the PM. This forces a strong unidimensionality on Jamaican governmental policymaking -at least as presented to observers outside the ruling circle of ministers.

As discussed in Chapter 4, the Westminster key governing principle of loyal opposition often does not work in small states such as Jamaica. The principle of loyal opposition calls for the opposition MPs to oppose draft government policy and thereby ensure a complete and adequate public debate of all policy issues (Birch, 1990, pp. 130132). The opposition MPs are joined in the opposition process by the backbenchers of 
the ruling party. Backbenchers are MPs of the ruling party or coalition that do not hold ministerial appointments. Backbenchers in Westminster states are free to support either the government or opposition, but it is partly their responsibility to ensure all policy matters are thoroughly debated. However, in states with a small number of MPs, like Jamaica, the process whereby loyal opposition to government policy occurs can quickly break down.

The undermining of the loyal opposition principle is best illustrated by looking at Jamaica's current parliamentary structure of 51 PNP MPs and 9 JLP MPs. Almost 30 of Jamaica's current PNP MPs are ministers, and constitute a group that not only runs the executive branch of government, but also holds a near majority vote in the legislature. Approximately 20 PNP MPs remain as backbenchers. Because these PNP backbenchers have realistic chances of someday becoming government ministers themselves, they always support draft public policy presented by the cabinet (Cargill (interview), 1999). This can be contrasted to Great Britain, where the vast majority of backbenchers will never become ministers and are free to challenge their own party's government policy and thus assist the opposition. Jamaican backbenchers always back their party's government policies as they have no desire to upset the PM or other senior party leaders and damage their future chances for ministerial appointments.

Even with only 9 MPs, the opposition JLP can, and does, oppose government policy. Although the JLP is heard in Parliament and their opposition does foster media coverage of key policy debates, in reality the overwhelming majority the PNP holds in parliamentary votes ensures that governmental policy as presented by the PM and 
ministers always prevails. In the past, the Jamaican Parliament has seen more evenly balanced numbers of MPs between the PNP and JLP. Nevertheless, because of strict Jamaican party discipline the ruling party always prevails in government policy votes (Cargill (interview), 1999).

Under the Westminster principle of loyal opposition, once a parliamentary vote is taken, all sides are suppose to accept the results and lend their full support to the policy's implementation. This is not the case in Jamaica where what is best for Jamaica and its citizens is subordinate to both MP self-interests and what is good for their respective parties. Long after Jamaican legislation is approved, the opposition continues to assail and undermine government programs. This results in a highly fractured parliamentary atmosphere. However, no matter how rancorous parliamentary debate may become over a government policy, there is virtually no chance-because of the strict party disciplinethat the opposition can muster a majority of MPs for a parliamentary vote of no confidence that would replace the government or require new national elections. With no effective legislative check on the strong executive, and no judicial review of acts passed by the legislature, the PM, who controls the entire Jamaican public policy process, holds enormous personal political power. In Jamaica, these Westminster manipulations led to the rise of an authoritarian-democratic system.

Political Culture. Jamaican authoritarian-democratic rule is supported by a political culture with a mix of collectivist and individualistic characteristics. Its collectivist component is anchored in citizen loyalties to the two traditional political parties (JLP and PNP). Its individualistic component deals with both how the political parties are 
informally organized and how coercion and violence are used to maintain the structures within and between parties.

When acting as the ruling party, both the JLP and PNP have manipulated the disbursal of state resources to gain electoral advantage. Over time, Jamaica evolved into a strong clientelistic political system relying on extreme political patronage (see Stone, 1980; Edie, 1991). Locally christened a tribalistic governing system, the Jamaican system is unique in the Caribbean for the rancor and political violence it spawns between JLP and PNP party loyalists (National Committee on Political Tribalism, 1997). To understand the influence tribalism exerts over Jamaican politics, requires an examination of the inner-workings of Jamaica's political parties, the collectivist groups that help shape Jamaica's political culture.

The leader of a Jamaican political party is the chief of his/her political tribe. The party leader's power emanates from his/her control over party appointments, including not only his/her influence over those who fill high party offices but also over which party members will run for Parliament from which constituencies, and which MPs will become ministers for the ruling party. ${ }^{3}$ Therefore, as with other Westminster systems in small states, the careers of aspiring politicians are substantially in the hands of their party leader. The strength of the party leader is shown in the case of Edward Seaga, JLP leader since 1974. Seaga was first elected a JLP MP in 1962. He was the Jamaican PM from 1980 to 1989 . In 1989,1993 , and 1997 , the JLP, headed by Seaga, lost decisively in national elections to the PNP. Today, Seaga remains the JLP leader and the Opposition Leader in the Jamaican House of Representatives. In what democratic state would a party 
leader that led his/her party to three consecutive crushing defeats still be in power? Probably nowhere.

Under the Jamaican political party leaders, MPs become the vanguards for distributing political patronage, i.e., the dispensing of state resources to loyal political supporters. Constituencies with an MP elected from the ruling party receive much greater levels of state resources (schools, health clinics, parks, youth programs, etc.) than those with opposition MPs. Additionally, within individual constituencies, voters who support the ruling party receive more individual state resources (state contracts, jobs, housing, scholarships, personal loans, etc.) than supporters of the opposition party (National Committee on Political Tribalism, 1997). The system of representative political patronage, where the ruling party provides state resources in exchange for electoral support, underpins the entire Jamaican political system.

Which ruling party is in power makes a significant difference in the quality of life of individual Jamaican citizens. Individuals supporting the ruling party expect to share in state largess, while these same benefits are denied supporters of the opposition party. As MPs have little time, especially MPs in ministerial positions, to manage the distribution of state resources to their party's constituents, the MPs rely on informal systems of political dons in each constituency to direct the distribution of political patronage.

Notwithstanding both party and governmental (state and local) bureaucracies, the real power structure of the Jamaican political tribes follows the patronage resource distribution flow from the party leader (paternal tribal chief), to the senior party officials (MPs), to the political dons, to party supporters. This structure is diagrammed in Figure 
5-1. Extreme citizen loyalty to individual parties and political dons generates the bitter competition for limited state resources between the JLP and PNP tribes. This has resulted in a system of violent garrison politics. Ten of the sixty Jamaican electoral constituencies are designated garrisons, areas so highly controlled by one party's loyalists (9 PNP controlled, 1 JLP controlled) that just entering one as a member of the opposite party can get a person killed.

Figure 5-1. The Structure of Jamaican Clientelistic Power

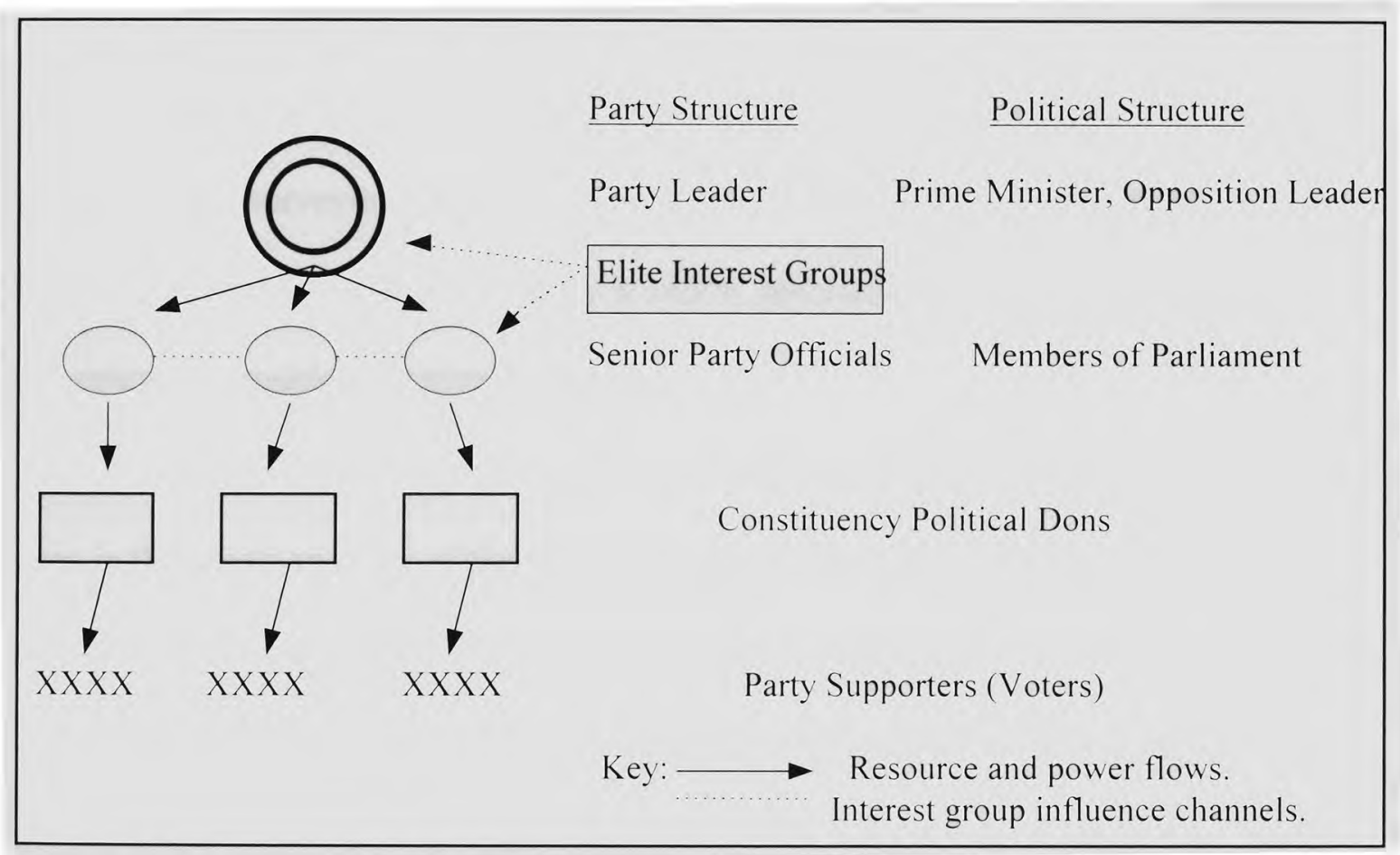

Adapted from Stone (1980, p. 104)

Organized around the two major political parties, Jamaica has two distinct partypolitical structures similar to Figure 5-1, one for the JLP and one for the PNP. Those lower in the party-political structures always look to those higher for resources and solutions to problems, while persons at all levels of the Figure 5-1 structure tend to act 
either in the best interests of their respective party or in their own self-interests. Between JLP and PNP party structures there are relatively few transactions. Those between-party transactions that do occur are usually acrimonious and often include threats or acts of coercion and violence. Thus, in Jamaica there are actually two separate political societies, one JLP and one PNP, with a mix of collectivist and individualistic characteristics.

Elite Competition. Jamaica's collectivist-individualistic political culture is associated with a mixed constricted-oppositional elite competition. The Figure 5-1 clientelistic system constricts competition within political parties, while exacerbating it between the parties. When surveying the nature of Jamaica's elite competition with regard to openness of party structures, longevity in office, and electoral processes, its mixed constricted-oppositional nature is apparent.

Access to Jamaican political party leadership positions is severely restricted. As seen in the above example of the JLP's Edward Seaga, party leadership positions often remain in the hands of the same person for decades. This is because politics provides one of the only routes for social and economic advancement among Jamaica's middle class professionals. Jamaica's economy, discussed further below, is weak and presents only limited opportunities for new entrepreneurs. Jamaica's main economic enterprises remain in the hands of an extremely small and well-entrenched upper class. Therefore, for educated, middle class, professional Jamaicans to advance socially and economically, they have two principal options. First, they can immigrate to the Canada, Great Britain, or the US-which has resulted in a massive brain drain from the island over the past 30 
years. Second, they can gain access to state resources through a career in politics (either within the party or government). Politics thus becomes a full-time profession for those choosing the second option-resulting in the severely restricted access to senior party positions.

Longevity in office for the entire Jamaican governing elite, and not just for individual party officials, is a hidden factor that also constricts Jamaican elite competition. Since Jamaica's 1962 independence, the JLP and PNP have alternated as the ruling party, each serving a series of two consecutive terms to then be replaced as ruling party by the other. (This rotation was broken when the PNP won a third consecutive term in 1997.) Since 1980, despite differences in party campaign platforms, there have been only minor differences in the policy implementation of the two parties. By the 1980s, when the PNP's experiment in socializing the Jamaican economy was recognized as a failure, the policy differences between the JLP and PNP became matters of degree and not substance (see Payne, 1993). With the PNP originally offering a socialdemocratic ideology, and the JLP more liberal-conservative beliefs, both converged into populist parties by the late 1980s (see Stone, 1992). Both parties now offer similar populist social welfare programs (aimed at their political supporters), while also implementing similar economic policies as they wrestle with international pressures on Jamaica's weak and dependent economy.

Throughout the post-independence period, as seen in the PNP inaction over the 1973 Da Costa Commission inquiry, both parties worked to strengthen Jamaica's clientelistic system (Figure 5-1), i.e., fortify the rules of how ruling parties could extract 
political rents and dispense them for political patronage purposes. Thus, since the early 1980s, it has mattered little which political party was in office, as both parties' economic and social policies and their support to the clientelistic structure have remained stable.

Also contributing to a mixed constricted-oppositional elite competition is the Jamaican electoral process, one fraught with widespread irregularities. Manipulation of voter lists, irregularities at polling stations, and fraudulent vote counts are just a few of the seemingly constant problems prohibiting free and fair elections in Jamaica. Political parties are behind the electoral failures and the parties share equally in their occurrence. Ruling parties look for every advantage in the timing of calling national elections, obstructing voter registrations in opposition garrisons and constituencies, manipulating final voter lists, and even making sure voter lists never arrive at some polling stations. Even more troubling is the control political dons maintain over polling locations. Constituency political dons are known to interfere in elections by orchestrating threats to polling station officials, threats to voters to keep them from voting, and ballot box stuffing to ensure their candidates win (Electoral Advisory Committee, 1994).

In the 1997 Jamaican national elections, a nongovernmental organization, Citizens Action For Free and Fair Elections (CAFFE), emerged to provide independent oversight of elections. However, even with 2,000 CAFFE volunteer election observers deployed across the island, plus the observation of teams from the US-based Carter Center, many of the past electoral irregularities continued. As a result, CAFFE would not declare the 1997 elections free and fair. It only reported that there were major improvements in 
electoral freedom and fairness and that the will of the Jamaican people (to retain the PNP as ruling party) was expressed (CAFFE, 1998, p. 7).

How Jamaican political campaigns are funded also constricts elite competition. There are no public funds allocated for national political campaigns. There are also no limitations on where or how parties or candidates can receive campaign funding (Golding (interview), 1999). The funds come from two primary sources. First, upper class economic elite and the few existing interest groups (trade unions, etc.) contribute both to political parties and individual candidates in the hopes of gaining influence over governmental policies and access to state-owned resources from the ruling party (i.e., through the elite interest group influence channels in Figure 5-1). Elite interest groups are the primary funding sources for the opposition party.

Second, the ruling party has access, through its ability to conduct political influence peddling, to significant funds obtained from the manipulation of state contracting and state-owned resource management. As seen earlier, governing elite behaviors surrounding the manipulation of the awarding and financing of state contracts is the single most frequent source of political corruption in Jamaica. The funds received from these illicit acts are then made available to the ruling party and its candidates for national campaigns. These funds are converted to votes through campaign advertising, candidate stumping, and dispersal of funds to voters as either benefits (housing, etc.) or direct cash payments (Golding (interview), 1999). The prevalence of a votes-for-cash atmosphere is seen in how MPs are expected to freely disburse moderate sums (US\$20 to 
US\$200) of cash to individual political supporters whenever they visit their constituencies (Chuck (interview), 1999; Golding (interview), 1999).

Elite Accountability. The lack of elite accountability is a serious problem contributing to Jamaican political corruption. Despite a string of post-independence corruption scandals, not one Jamaican senior public official has been prosecuted for a corruption offense since 1962. Jamaica's circular (intra-elite) system of elite accountability experiences problems with both answerability and enforcement (see Chapter 2).

Jamaican elite answerability problems start with the fact that the state has no freedom of information regulations. Jamaica closely follows the Westminster parliamentary system's "cult of secrecy and confidentiality in government" (Mills, 1997, p. 34). Like most other Westminster systems, Jamaica uses a combination of the constitutional collective responsibility doctrine and an Official Secrets Act to control government information. Under the collective responsibility doctrine, all government officials (ministers and civil servants) take an oath that keeps government policy-making processes closed and non-transparent (Aub \& Aub, 1994). A Jamaican government agency can only release information to the public cleared by the minister responsible for that agency. The separate Official Secrets Acts, as originally adopted in Great Britain, was meant to foster governmental consensus in Westminster governments, ensure ministers were held responsible for the bureaucracies in their respective agencies, and prevent information vital to national security from being erroneously released (Thurlow, 1995). Jamaica, as other small Caribbean Westminster systems, uses their Official Secrets Act well beyond the limits intended by the British. In Jamaica, the Official 
Secrets Act becomes a tool of authoritarian-democratic rule as it shields the government from releasing even the most basic state information. ${ }^{4}$

The case of Jamaica's Financial Sector Adjustment Company (FINSAC) provides a good example of how government secrecy laws are abused. A mid to late 1990s decline in the Jamaican banking sector and a number of business bankruptcies caused the loss of investor and business confidence in the Jamaican financial sector. In answer to this problem, the PNP government commissioned FINSAC to use state funds to either take over or subsidize private banks and businesses to avert total financial system chaos. Approximately US $\$ 2.5$ billion in state funds were used in the late 1990 s to compensate for the mismanagement in the Jamaican banking and business sectors. To put this amount in perspective, it is almost half of Jamaica's annual Gross Domestic Product (US\$5.8 billion, 1997), double one year's government budget expenditures (US\$1.6 billion, 1997), and two-thirds the size of Jamaica's total foreign debt (US\$3.2 billion, 1997) (Political Risk Services, 1998b). The FINSAC bailouts were not only for bankers, a source of traditional PNP support, but also for PNP supportive businesses and numerous high level PNP party and government officials.

In 1999, on learning of the large amounts of FINSAC liabilities, there was a media outcry for transparency and accountability as to exactly which bankers, businesses, and politicians were being dispersed what amounts of state funds. One 1999 poll revealed that 80 percent of Jamaican citizens thought the names of politicians receiving FINSAC bailouts should be made public (Jamaica Observer, 1999b). FINSAC's reply to the media argued that it was a financial institution similar to a bank and therefore came under 
strict Jamaican banking secrecy laws-thus avoiding any transparency or accountability for its use of state funds. The PNP government supported this FINSAC stance (one the media also assailed) - no doubt because it would be politically embarrassing if the list of PNP officials and supporters saved by FINSAC was published. ${ }^{5}$

A positive note for Jamaican answerability is the state's recent embrace of media freedom. Prior to the 1990s, the Jamaican Broadcast Corporation (JBC) (television only) was owned by the state and subject to ruling party politicization-as seen in its abuse by the PNP during the 1976-1977 State of Emergency (Bennett, 1994). In the 1990s, as part of continuing efforts to open the Jamaican economy, the ruling PNP privatized the JBC. Jamaican newspapers and radios have historically been privately owned and regularly report on government policy issues and criticize government behavior. Foreign television and radio broadcasts are also readily available in Jamaica by satellite or short wave and are not regulated. Overall, Freedom House gives Jamaica a score of 11 (scale 0-100, 0 being most free) on press freedom, ranking it as one of the freest states in the entire world (Sussman, 1999). Despite this veneer of press freedom, there is significant selfcensorship in the Jamaican media (Cargill (interview), 1999).

Jamaica has strict libel and defamation laws (see Barnett, 1977, pp. 408-409). Whenever media reports include anything the least bit controversial about an individual in the governing elite, the media outlet is immediately slapped with a libel lawsuit, whether the allegations are true or not. Within the Jamaican criminal justice system, once the libel lawsuit is filed, no further media reporting on the person (by any media source) is allowed until the lawsuit runs its course (which can take years) (Aub, 2000). This 
effectively eliminates serious attempts at investigative reporting in Jamaica. The media's lack of courage to challenge libel lawsuits limits its role to sniping at the margins of governmental problems. Thus, the media never becomes a serious threat to the governing elite in governmental policy matters or elite misbehavior such as political corruption (Cargill (interview), 1999).

Another problem relating to Jamaican answerability is that MPs are not readily available to their constituents to explain government policy. To address this problem, a 1991 report (The Stone Report) recommended "[t]he establishment of regular nonpartisan public meetings between MPs and constituents to allow MPs to give public account of their stewardship and to keep voters informed in constituency plans and developments" (Stone Committee, 1991, p. 3). A few MPs do hold public meetings in their constituencies and frequently meet with constituents. Other MPs only make themselves available in their Kingston offices to constituents from their own party. Still other MPs never set foot in their constituencies until just before national elections and allow political dons to dispense the bulk of their patronage resources. The 1991 Stone Committee reported that overall "the allocation of the MP's time to constituency representational work falls far short of what is needed to adequately serve the needs of constituencies" (Stone Committee, 1991, p. 15).

Enforcement is also a major problem for Jamaican elite accountability. On paper, Jamaica has a robust administrative system with an Ombudsman, an Auditor-General, and a Contractor-General who are tasked to uncover government waste and fraud associated with political corruption. As seen with other Jamaican regulations and laws, 
there is no accountability of the governing elite, even when administrative investigations reveal strong evidence of political corruption. A 1999 report (Orane Report) highlighted the "lack of accountability throughout the public sector including the top echelons of the public sector and the political directorate. Much of the waste and inefficiency occur because there is no culture of economy and/or efficiency" (Orane, 1999). This same inefficiency and lack of accountability surrounds government action on the reports of Jamaica's Ombudsmen, Auditor-General, and Contractor-General. For example, the Contractor-General submits an annual report to Parliament detailing his/her findings into the administration of government contracts. Often these reports disclose discrepancies in individual contracts. However, no follow-up investigations are ever commissioned. In 1998, the outgoing Contractor-General, frustrated at the continued lack of parliamentary follow-up on his reports, included in his annual report:

The great disappointment has been that after seven years [as ContractorGeneral] it has not been possible to persuade Parliament to which I report to undertake an examination of the Annual Reports which are made in accordance with the Contractor-General Act. This means no one has been asked to account for actions criticised in the Reports.... If there is no change in how the Annual Reports are handled then the money spent for the operation of the office will continue to be regarded as not being likely to lead to significant improvement in the sector. (Contractor-General, 1998, p. 2).

A review of several years of Auditor-General and Contractor-General reports reveals numerous allegations of improper contracting and questionable disposal of stateowned property. Even more telling of the lack of elite accountability portrayed in these reports are the refusal of government agencies to provide the necessary documents or cooperation that the auditors need to complete their inquiries. For example, the ministries of National Security and Justice, Education, Health, and Public Utilities and Transport 
were all several years in arrears in providing documents to the Auditor-General, even after many formal requests for the documents (Auditor-General, 1997, 1998). Likewise, the Contractor-General repeatedly reported that the government's Urban Development Corporation continually disregarded Jamaican contracting regulations (ContractorGeneral, 1997, 1998). The lack of parliamentary attention and follow-up to these administrative reports clearly reveals the flagrant disregard Jamaica's governing elite have for any form of administrative accountability.

In general, Jamaican politicians cannot be voted out of office as an elite enforcement tool. The only real choice Jamaican voters have is to elect the prime minister, as they know the head of the ruling party will become prime minister. Jamaican voters have no say in who (only which party) represents their constituency, as the party selects MP candidates. There is unarguably deep citizen dissatisfaction with the lack of public input to Jamaican politics. In a 1995 poll, 64.5 percent of respondents reported the Jamaican political system did not work well and needed changes (Rodrigues, 1996, p. 75). In the 1997 national elections, only 66 percent of those registered voted (33 percent of all those eligible) - the lowest voting percentages in any contested Jamaican election since 1962 (CAFFE, 1998).

In the Jamaican tribalist system, the primary governmental performance criteria that influences the largely illiterate and poverty stricken masses is which political party can deliver the most patronage benefits. This helps explain why, even though the mismanaged Jamaican economy has been severely retracting for most of the 1990 s, the PNP maintains voter support. The PNP has a highly developed patronage delivery system 
including control of the 9 PNP garrisons. Since its 1989 defeat, the JLP has fractured internally and does not appear capable of outperforming the PNP's patronage distribution. The inability to deliver patronage benefits also explains why Jamaica's emerging third political party, the National Democratic Movement (NDM), has been unable to break the JLP and PNP hold on parliamentary seats.

Disgruntled Jamaican middle class professionals and intelligentsia that are calling for an array of constitutional, justice, and corruption reforms primarily support the new NDM. The NDM lost decisively to the JLP and PNP in the 1997 elections because it has no history of patronage distribution to the masses. Even the NDM party leader, Bruce Golding, a former popular JLP MP who had won his constituency over a number of years, lost to a new JLP candidate largely because of the JLP's history (i.e., Golding's) for delivering patronage to the constituency's citizens. While the NDM continues to gain support in Jamaica, until the patronage-supported Jamaican political culture changes, the JLP and PNP will continue to capture mass citizen support and maintain power with little accountability.

The final area of elite accountability enforcement to consider is the Jamaican criminal justice system. As in many developing states with limited resources and authoritarian-democratic governments, the Jamaican criminal justice system has serious problems with case backlogs, witness intimidation, jury tampering, prison overcrowding, and worst of all, increasing politicization in favor of the governing elite (JIS, 1994; Chuck (interview), 1999). On the bright side, most Jamaican judges have reputations for honesty and are considered one of the most trusted elements in the Jamaican government 
system (Cargill (interview), 1999). However, Jamaican judges are becoming more politicized, meaning they are being increasingly influenced by the governing elite (Aub \& Aub (interviews), 1999a, 1999b). A general reputation for honesty also applies to the office of the Jamaican Director of Public Prosecutions (DPP). The DPP prosecutes all cases for the Jamaican state. The DPP is also the source for most judicial appointments. Unfortunately for Jamaican citizens, while the judges and prosecutors are not generally corrupt, the same is not true of the Jamaican police.

The Jamaican police force (Constabulary Force) is reportedly the most corrupt and least trusted state institution in all Jamaica (Chuck (interview), 1999; Cargill (interview), 1999). The Jamaican police are so highly politicized that, in effect, they become the enforcement arm of the ruling party as was seen in the 1976-1977 State of Emergency (Harriott, 1997). The police are extremely violent - with approximately one-quarter of all Jamaicans killed by gunshot each year being victims of police shootings (Chevigny, 1995, p. 212). ${ }^{6}$ Through the Minister of National Security and Justice, the ruling party directs the police to do its bidding, ranging from the control of anti-government protesters to the targeting of opposition party members. The police receive their corrupt largess from a combination of ruling party patronage, their alliance with powerful drug dons (discussed later), and extortion of the mass citizenry.

As in most developing states, the Jamaican police are organized and outfitted to control the masses, but not to investigate or control the governing elite. The DPP has no investigative arm of its own and relies on the police for all investigative support. Police investigations that implicate ruling party officials are stonewalled or conveniently lost. 
Additionally, the police have neither the trained personnel nor technical abilities to conduct complex political corruption investigations. Barnett (1999) argues that the lack of a professional criminal investigation capability is a primary reason for Jamaica's corruption problems.

Despite the corrupt behavior of the Jamaican police, they remain protected by the governing elite. For example, in 1991 the PNP government commissioned a group of senior British police officials to review the work of the Jamaican police. The resultant Hirst Report was so critical of the Jamaican police that the Ministry of National Security and Justice never released it publicly (Chevigny, 1995, p. 204). Jamaican governing elite have little fear of being held accountable by the Jamaican criminal justice system, as charges of political corruption, even if made by someone outside the police or government, will never be investigated and presented to the DPP for action.

Elite accountability in Jamaica is strongly circular, i.e., there is no accountability of the governing elite outside of their own circles. This can be seen in the 1989 Shell Oil scandal. Shell Oil, whose Jamaican operations chief, Howard Hamilton, was a member of the PNP National Executive Committee, sought to begin the import of unleaded gasoline. In gaining approval for the imports, PNP Minister of Finance, Percival J. Patterson, waived all import duties on the gasoline for Shell. In January 1992, when Patterson's actions in relation to Shell's gasoline imports were made public, the political and media outcry resulted in Patterson's resignation as Deputy Prime Minister, although he continued to hold his parliamentary seat. An official inquiry was never begun and public accountability of the Shell Oil scandal was never provided (Cargill (interview), 
1999). In March 1992, PM Michael Manley resigned due to health reasons and Patterson, the newly elected PNP President, ascended to the PM position where he later received strong public mandates to continue as PM in the 1993 and 1997 national elections. In consonance with constricted elite accountability patterns, Patterson avoided severe administrative, electoral, and criminal accountability for his behavior in the Shell Oil scandal. ${ }^{7}$ He was instead sanctioned by the PNP governing elite through the loss of his Deputy Prime Minister appointment. Then, only two months later, he was forgiven by both the PNP leadership and Jamaican masses and returned as the head of Jamaica's government. This is a classic case of circular accountability within a governing elite.

Mass Participation. There is little mass participation in the Jamaican Westminster system. Every four to five years Jamaican citizens are allowed to vote in national elections within their constituencies for their choice of a ruling party (disguised as a vote for an MP). The effectiveness of these national elections is often in question, as discussed above. Other than national elections, Jamaican citizens have virtually no input to the public policy process as a result of Jamaica's authoritarian-democratic governing structure. Mass participation in public policy is strongly paternalistic as the vast majority of the Jamaican masses wait for the government to solve their problems and tell them what is in their best interests. In a moment of rare candor, in a May 1999 speech, PM Patterson highlighted this paternalistic situation when he urged Jamaicans to become more involved in nation building and not wait for the government to provide every single job and solve every single problem (Jamaica Observer, 1999a). 
There are few avenues to follow for Jamaican citizens that do want a public policy input. Stone's (1980, p. 223) analysis of Jamaican politics reveals that the main influence on public policy from outside the government is confined to elite interest groups (see Figure 5-1). The clientelistic structure of the political party system is optimized for distributing patronage downward to the masses, not for allowing substantive public policy input from the masses to flow upwards. The sources of patronage resources, the economic elite and party officials that run the state bureaucracy, have generally open access to government officials and exert at least some influence on the public policy process. Stone $(1980$, p. 76$)$, however, argues that the political power of the economic elite, i.e., the private business sector, diminished considerably in the 1970 s as the state became more and more involved in economic planning and policy-making. With only limited middle and upper class influence, the principal public policy-making power resides in the closed-circle of government ministers.

Outside of the Jamaican political party system, citizens must rely on trade unions, churches, miscellaneous social organizations, or as is more commonly seen, radio talk shows and street protests, to make their political inputs known to the governing elite. Trade unions are the most visible component of Jamaican civil society (Hillman \& D'Agostino, 1992, p. 133). Trade unions represent 16 percent of Jamaica's formal work force. This does not include the thousands of informal workers that exist within Jamaica's enormous informal economy. (As much as 78 percent of all Jamaican economic transactions occur within an enormous informal sector that runs the gamut from the ever-present unlicensed street vendors (higglers) to an immense illegal drug trade 
(Bennett, 1995, p. 235).) Eighty percent of workers who do belong to trade unions belong to the BITU and NWU that are allied closely with the JLP and PNP, respectively. Any influence the BITU and NWU may have on public policy-making is a component of Jamaica's Figure 5-1 clientelistic system. Since the early 1990s, a growing trend is for new trade unions to emerge outside the political party structure such as the University and Allied Worker's Union (UAWU). Despite this trend in independent union growth, a Jamaican labor leader offers that Jamaican trade unions have become "a less significant factor in civil society" (Munroe, 1999b, p. 82).

Jamaican churches play only a peripheral role in addressing the state's most critical political and social problems. Jamaica's historical churches, the Anglicans, Roman Catholics, and Methodists, traditionally ally with the state's socio-economic elite and are generally supportive of the status quo. Over the past 50 years, however, there has been significant growth in fundamentalist denominations such as the Church of God and Seventh Day Adventists. Taking an anti-socialist, anti-statist, and pro-market stance, the fundamentalist sects generally align on the side of the JLP, against the PNP supportive center-left leaning historical churches. In the 1990s, both the historical and fundamentalist churches have been relatively silent on Jamaica's vast societal problems (Munroe, 1999b, p. 87). The two exceptions to this silence are the church opposition to casino gambling and the Roman Catholic Church's interests in electoral reform, which helped, spark the 1997 formation of CAFFE (Munroe, 1999b, p. 88).

The political role of other social organizations in Jamaica is questionable. On one hand, membership in and the number of nongovernmental social groups with limited 
political purposes, such as neighborhood watches, police youth clubs, $4 \mathrm{H}$ clubs, soccer clubs, music clubs, etc., have been on the rise in the 1990s. On the other hand, there is a consensus that overall civil society political activism and volunteerism is on the decline (see Robotham, 1998). A World Bank study offered, "that social unity has always existed within the [Jamaican] communities, but its level has decreased over the years, influenced by the political warring of the 1980s" (World Bank, 1999, p. 32).

One encouraging trend from the 1990s is the emergence of several organizations focused specifically on Jamaican political reform. These include CAFFE, Citizens for a Civil Society, Impact Jamaica, Jamaicans for Justice, and the Jamaican chapter of Transparency International. Members of these new organizations are predominantly middle class and mainly include professionals and members of the intelligentsia. These organizations are lobbying for reforms to Jamaica's constitutional, justice, and electoral systems, and for the implementation of good governance and anti-corruption measures. Through a combination of public meetings, protests, and media campaigns, these groups have been effective at raising societal awareness about these issues.

These emerging civil society groups are hampered by two key factors. First, being predominantly middle class (from the affluent uptown neighborhoods of northern Kingston), these groups have only begun to built bridges to Jamaica's majority lower classes (from the poor downtown neighborhoods of central and southern Kingston and most rural areas) whose support is held by the JLP and PNP through the clientelistic patronage-based political structures. Second, in the post-1970s Jamaican tradition of politicizing every societal issue, the ruling PNP attacks these groups in the media as no 
more than fronts for the emerging NDM political party. The PNP attacks hinder these groups from building bridges to the lower classes as they submerge important societal issues in acrimonious political debate that frames issues as a political PNP versus NDM conflict. The final effectiveness of these groups in influencing Jamaican public policymaking and governmental reform depends upon their abilities to keep important reform issues in front of the Jamaican public and recruit support from the lower classes.

With limited trade union, church, and formal social organizations to act as representational vehicles, the Jamaican public resorts to radio talk shows and street protests to air their public policy concerns. Radio talk shows have become a vital part of Jamaican civil society (Munroe, 1999b, p. 94). Radio talk shows are a favorite of many lower class Jamaicans. The talk shows allow citizens to call in and discuss a wide array of Jamaican societal issues. Some believe that radio talk shows have become replacements for the Jamaican Parliament's lack of a loyal opposition, as at least on the airwaves all pending public policy decisions are thoroughly debated (Aub \& Aub (interviews), 1999a, 1999b; Perkins (interview), 1999). One talk show host reported that since most of his listeners have limited education, he sees his role to help Jamaican citizens build critical thinking skills so that they would not just blindly accept the ideological drivel that the traditional political parties present as their party platforms (Perkins (interview), 1999).

With limited channels of organized civil society to present their complaints, the most common method for Jamaican citizens to send messages to the governing elite is through street protests. The reliance on street protests traces its roots to the 1930s labor 
riots that started Jamaica on its road to independence. Street protests remain a frequent occurrence in Jamaica, spawned by everything from unpopular government policies to local government's inability to provide basic citizen service (water, roads, etc.). In a 1995 poll, respondents indicated they believed protest action was the most effective means of sending a message to the Jamaican government, winning handily over other choices such as contacting their MP, a ministry, or the media (Rodrigues, 1996, p. 83). Rodrigues (1996, p. 83) concludes that there is "occurring a shift within society away from faith in and reliance on state and political actors."

The downside of Jamaican street protests is that they can quickly become violent. For example, in April 1999 the ruling PNP government announced a 50 percent hike in gasoline taxes. The announcement led to three days of island-wide protests by thousands of citizens. With no parliamentary or public debate on the pending gas tax increase, PM Patterson thought he could get away with its implementation without facing the wrath of the people. He was wrong. The final costs of these gas riots were six people dead, dozens injured, and 150 arrested, along with an estimated US\$350 million in damage and lost production. In response, the PNP government did partially rollback the gas tax. These particular riots were unique in two ways. First, they were the most costly of any previous post-independence riots, both in terms of deaths and value of damages. Second, they included not only lower class protesters, but also many middle class citizens who for the first time were seen protesting in middle and upper class (uptown) neighborhoods.

The level of social trust is a primary indicator of the nature of mass participation in a state. Jamaica has a deep problem with its levels of societal trust that runs from little 
trust in government to individual disdain for other citizens. One study of Jamaican political culture found:

Surveys and other research data indicate that by and large people neither trust politicians nor each other. Social commentators lament the atomistic society that they see being created and the fragmentation and decay of the communitarian culture that existed in the past....the lack of a strong internal community trust and cooperation precludes community solutions to problems (Rodrigues, 1996, pp. 179-180).

Rodrigues's (1996) study found only 13 percent of survey respondents trusted the Jamaican government to place the interests of the people above those of political parties (Rodrigues, 1996, p. 108). Similarly, he found only 5.8 percent of respondents felt MPs could be trusted to serve the interests of the people most of the time (Rodrigues, 1996, p. 111). Similar societal mistrust surrounds the Jamaican police who are seen by citizens as ineffective, unresponsive, and uncaring (Moser \& Holland, 1997, pp. 8-9). One report found that residents were angered at what they saw as the divide-and-rule tactics of the JLP and PNP which undermined attempts at community cohesion within constituencies (Moser \& Holland, 1997, p. 8).

There is also a deep distrust between Jamaican trade unions and management (see Carter, 1997). Throughout Jamaica, workers see management as untrustworthy and believe that enterprises universally conceal their true profits in order to justify paying workers low wages (Rodrigues, 1996, p. 180). Trade unions respond to this distrust by presenting management a constant threat of strikes.

There is also a deep distrust among individual Jamaican citizens. Interpersonal violence in Jamaican society is so widespread that it pervades everyday life (Moser \& Holland, 1997, p. 16). Much of the worst violence (murders, etc.) takes place in the 
garrison constituencies or lower class neighborhoods and is related to either JLP-PNP political conflicts or Jamaica's serious problem with the drug trade. The violence also includes widespread women-on-women conflicts over petty jealousies (fights over hair styles, clothes, etc.) and those locally dubbed matey wars (fights over men) and pickney wars (fights between mothers sparked by their children) (Moser \& Holland, 1997, p. 17). Tenant wars, fights over the use of common spaces in multi-household buildings, are another common form of interpersonal violence. These fights are often worsened by what is often described as grudgefulness-Jamaican societal tendencies toward revenge and resentment at the good fortune of others. One author characterized Jamaican interpersonal relations as one of crab antics, the desire to "behave like crabs in a barrel who are constantly trying to climb on each other's backs, and in the process only succeed in pulling down the nearest to the exit, in order to achieve the ultimate goal of getting out of the barrel" (Wilson, 1973, p. 58ff). In an atmosphere of extreme societal distrust, it is easy to see how the Jamaican masses take a paternalistic view toward the governing elite--the one source of resources and security for most citizens.

Material Resource Factors. Material resource factors, i.e., how the Jamaican governing elite direct and manage their societal resources, is a key element in assessing a society's potential for political corruption. This not only includes routine resource factors related to how the economy and state-owned resources are managed, but also extraordinary resource factors that may become available to the governing elite. As discussed in Chapter 2, how a state manages societal resources helps define the opportunities a governing elite have for corrupt behavior. 
Today's Jamaican economy is not well diversified, relying on four principal industries, and is highly dependent on world markets for its economic livelihood. Tourism is the most important industry and is the largest source of foreign exchange. However, in the latter 1990s tourism stagnated because of rising crime levels in Jamaica and the lack of investment in tourist infrastructure. The second most important industry, and the second largest source of foreign exchange, is the production of bauxite and alumina. Jamaica is the third largest producer of bauxite ore in the world, after Australia and Guinea. The 1980s and 1990s decline in world bauxite ore prices, plus uncertainty over poor productivity and conflictive Jamaican labor-management relations, decreased the demand for Jamaican bauxite ore and impeded investment in this vital industry. The third major Jamaican industry encompasses the export of tropical agriculture products (sugar cane, bananas, coffee, and citrus), which during the 1990s had a mixed performance, based on shifting US and European demand. The fourth key sector of Jamaican industry is textile production. An outgrowth of the US 1980s Caribbean Basin Initiative $(\mathrm{CBI})$, the textile industry has been severely damaged by the North American Free Trade Agreement (NAFTA) that devastated the Caribbean textile industry as manufacturers relocated to Mexico. Therefore, several factors, including the effect of crime on tourism, foreign investors that are suspect of Jamaican labor-management relations, NAFTA, the lack of financial stability (see previous FINSAC discussion), and declining world markets for its traditional export commodities, all contributed to the stagnation of the Jamaican economy during the 1990s (Political Risk Services, 1998b). 
In assessing Jamaican economic management, the Heritage Foundation rates Jamaica's economic openness at 2.7 (mostly free) on a scale of 1 (free) to 5 (not free) (Johnson et al., 1999, p. 231). This places Jamaica solidly among a number of Caribbean states that, while recently opening their economies, remain largely statist. On the positive side, the Heritage Foundation gives Jamaica scores of 2 (on a scale of 1 (low) to 5 (high)) for its low levels of external trade protection and government intervention in the economy-both the result of neoliberal economic reforms begun in the 1980s by the JLP. The Heritage Foundation reports:

Jamaica seldom uses free-market approaches to economic policy. During the 1970 s and 1980s, the government was the primary player in the economy, and it did not encourage entrepreneurship.... Until recently, a high level of protectionism and government intervention characterized Jamaica's economy. The government has opened the economy to foreign investment in the past several years...and has reduced both taxes and tariffs. (Johnson et al., 1999, p. 231).

Jamaican state-owned resources appear to suffer greater government mismanagement than does the overall economy. As discussed previously, Jamaican government Auditor-General and Contractor-General annual reports are replete with examples of how state-owned resources are regularly mismanaged. Everything from the issuance of professional licenses to the sale of state-owned lands smacks of the intervention of the ruling party elite. The situation of the 1990 s government Urban Development Corporation (UDC) provides a good example. Dr. Vincent Lawrence, a major construction contractor and childhood friend of PM Patterson, heads the UDC. The UDC regularly takes control of state-owned land for lease, resale, or development. The negotiations for the lease, sale, or construction on state-owned lands, like other 
government business, are conducted behind closed doors with no public input. Lawrence has been implicated numerous times in incidents where the UDC let contracts to businesses he owned or in which he held partnership (Aub, 1993). Numerous UDC land leases and sales were also suspected of directly benefiting key members of the PNP. On several occasions, the Contractor-General questioned the UDC's inappropriate, if not illegal, actions in his annual reports, only to have no follow-up by the PNP-controlled Parliament (Contractor-General, 1997, 1998). This one example is typical of how stateowned resources are mismanaged in Jamaica. Thus, while the overall economy may be statist, state-owned resources are managed patrimonially (see Chapter 2).

During the 1990s, extraordinary sources of government resources primarily originated from the privatization of state-owned entities and Jamaica's large drug trade. Privatization efforts from 1981 to 1997 included the sale of 70 state-owned enterprises that raised US\$284 million (Political Risk Services, 1998b, p. A-8). In accordance with Jamaican government secrecy, there has been no public accounting for the receipt and distribution of these funds.

The second major source of extraordinary resources, funding from the drug trade, is an extremely complex issue. No senior political officials and only one recent judge have ever been indicted for collusion with the drug lords. Munroe (1999b, chap. 4) argues that senior politicians are not directly associated with the drug trade because, in part, it takes place in the lower levels of the state's clientelistic political structure (see Figure 5-1). In fact, MPs benefit greatly from the drug trade, although they never have to dirty their own hands by dealing with the powerful drug dons in person. The connection 
between Jamaican politics and drugs occurs among the drug dons, constituency political dons, and the Jamaican police.

Drug dons that control Jamaican drug gangs enjoy great power and high social status among many sectors of Jamaican lower classes (see Gunst, 1995; Headley, 1996). The Jamaican drug trade includes the production of Jamaican-grown marijuana (ganga) crops and the shipment of not only ganga but also cocaine and other drugs originating in South America to illegal markets in the US and Europe (see Khan-Melnyk, 1994). Jamaica also has a high level of domestic drug use. Involvement in the lucrative illegal drug trade is seen as a quick way out of the rampant poverty in Jamaica's urban slums and rural areas. Stone (1994, p. 154) offers that "[t]he drug industry, starting with ganga and developing into hard drugs, has corrupted large sections of society with a kind of "get rich quick" mentality and has made living by means of illegality a normal mode of operation in Jamaica."

At the local level, the Jamaican drug dons help insure the security of their illegal business by hiring their own heavily armed security forces and bribing local police, or both. However, just buying off the police is not enough. They must also buy off the political structure to: (1) keep additional state law enforcement resources from being applied to their territory, and (2) to pacify political dons who often have their own organic security forces separate from the police. The resulting alliance of drug dons and political dons, especially in the highly armed garrison communities, provides the political system a lucrative source of patronage benefits (see Munroe, 1999b). The political dons act as gobetweens. Political dons disburse resources obtained from the drug dons as part of the 
normal political patronage system. It matters little where the patronage benefits originate, as long as the political party gains citizen voting support from its disbursal. These activities are all carried out clandestinely. MPs remain free to display public outrage at the drug trade, while, at the same time, the powerful drug dons help cultivate MP political support among the masses behind the scenes. Thus, the extraordinary resources provided by the drug trade are often a key component of Jamaica's paternalistic politics.

The rise of Jamaica's drug dons is an unintended consequence of the political war that erupted between the JLP and PNP in the 1970s. Jamaican drug gangs, referred to as posses, are the remnants of political-based gangs originally recruited to fight for the JLP and PNP in the 1970s constituency power struggles (Gunst, 1995). In the 1980s, many of the posse members, under threat of death from other posses or the Jamaican police, immigrated to Canada, the US, and Great Britain-coinciding with the wave of crack cocaine crack problems in those states. The Jamaican posses proceeded to capture much of the crack production and distribution business in these developed states while simultaneously strengthening their ties with Jamaican-based posses. The result was the establishment of posse networks where cocaine and ganga were smuggled from Jamaica to Canada, the US, and Great Britain, in return for arms and money shipped back to Jamaica (Headley, 1996, pp. 3-5). During the 1990s, many of the posse members were deported back to Jamaica from Canada, the US, and Great Britain, only to strengthen their hold on the local Jamaican drug trade. Many feel that the power of the Jamaican drug dons-measured by their monetary and property resources, tendencies toward violence, and territorial control-has created a second parallel system of informal government in 
Jamaica (Aub, 2000). Currently the liaison between the drug dons (posse leaders) and political dons present the greatest source of extraordinary resources fueling the entrenchment of the Jamaican political corruption structure.

\section{Findings}

Table 5-2 summarizes the above discussion of the contemporary causes of Jamaican political corruption. The institutional structure causing Jamaican political corruption patterns is directly related to its authoritarian-democratic governing system.

This system has spawned a form of rule that manifests mixed hegemonic and hierarchical characteristics, a mixed collectivist-individualistic political culture, and a mix of constricted and oppositional factors in its elite competition. Jamaica displays little elite accountability outside of political party circles (circular characteristics) and has an extremely low level (paternalistic characteristics) of mass participation. Jamaica's most positive structural factor concerning political corruption is its statist material resource system relating to its low levels of protectionism in its external trade and low level of government intervention in its domestic economy. As Table 5-1 displays, Jamaica maintains a predominantly white evaluation in its societal boundaries established between public office and private interests. These conditions lead to the prediction of Jamaican political corruption patterns occurring in the area between systemic and institutionalcorresponding to the TI 1999 rating of 3.8. Thus, this chapter's hypothesis is supported by the above analysis and demonstrates that Jamaica's institutions associated with the causes of political corruption are constructed primarily of instruction or directive rules, or combinations of both. 
Table 5-2. Coordinates of Jamaican Political Corruption

\begin{tabular}{|c|c|c|c|}
\hline Dominant Social Rules & Instruction & Directive & Commitment \\
\hline Forms of Societal Rule & Hegemony & Hierarchy & Heteronomy \\
\hline Political Cultures & Collectivist & $\square$ Individualistic & Egalitarian \\
\hline Elite Competition & Constricted & Oppositional & Corporatist \\
\hline Elite Accountability & Circular & Vertical & Horizontal \\
\hline Mass Participation & Paternalistic & Pluralistic & Cosmopolitan \\
\hline Material Resource Factors & Patrimonial & Statist & Market \\
\hline Public/Private Boundaries & White & Gray & Black \\
\hline Corruption Patterns & Systemic & Institutional & Incidental \\
\hline \multirow[t]{2}{*}{ Corruption Index: } & & & \\
\hline & & $\mathrm{JM}(3.8)$ & 10 \\
\hline
\end{tabular}

This chapter provides background information as to why Jamaica came to exhibit an authoritarian-democratic governing system leading to the Table 5-2 institutional structure. The British left the newly independent Jamaica with strong boundaries between public office and private interests as was manifest in the honest values of the native-born Jamaican civil service, the Corruption Prevention Act of 1931, and a strong rule of law. However, the British also left Jamaica with the easily corruptible Westminster governing framework, including a scarcity of mature political, economic, and social institutions needed to make the Westminster system work properly. It took the Jamaican governing elite less than a decade to determine that they could manipulate the Westminster system toward their own private ends, resulting in the rise of the an authoritarian-democratic governing system supported by a strong clientelistic system (see Figure 5-1).

With the Jamaican economy limited in size, even during the economic boom of the 1950s-1960s, the Jamaican governing elite could not have constructed the Table 5-2 
institutional structure without some external resource assistance. During the early to mid1970s, this resource assistance came from the international banking community in the way of loans and from the US in economic and social aid programs. During the late1970s, the international loans and aid largely dried up as the US resisted PNP PM Michael Manley's attempts at installing a socialist economy in Jamaica. With the JLP's return to power in 1980, and PM Edward Seaga's becoming a favorite of US President Ronald Reagan, the US ensured that Jamaica received an abundance of international assistance- fueling the solidification of the corrupt Jamaican state. The Jamaican privatization efforts during the 1980s and 1990s were another source of extraordinary resources that contributed to the governing elite's largess. Finally, in the post-Cold War period, with little international financial support and privatization opportunities declining, Jamaica's governing elite turned to the international drug trade to provide the resources needed to maintain their patronage-based political systems. With few other sources of extraordinary resources readily apparent, the Jamaican governing elite may have to rely on the drug dons for their patronage-support for some time to come.

Although this chapter's discussion and Table 5-2 focus primarily on structural causes of Jamaica's political corruption, we cannot forget that the main responsibility for contemporary Jamaica's high levels of political corruption lies with a self-interested Jamaican governing elite who capitalized on opportunities to exploit the Jamaican masses. The Jamaican governing elite constructed the Table 5-2 institutional structure. Instead of strengthening the Westminster structure they inherited from the British, as was their early option, the governing elite molded it to their own corrupt purposes-i.e., to 
gain power and wealth. Instead of using the extraordinary resources from international sources for the benefit all the Jamaican masses, the governing elite used them to strengthen their clientelistic power structures and foster violent competition between JLP and PNP supporters. While it may be easy for Jamaica's governing elite to blame their corruption on colonialism, US interventions, and neoliberal reforms, the real cause of the corruption problems was the conscious decisions of Jamaica's governing elite to manipulate their state's political and economic development toward their own private interests.

\section{Endnotes}

1. The content analysis included Panton (1994), Rodrigues (1996), Mills (1997), and Munroe (1999b); author interviews with Jamaican journalists, politicians, and academics (see references); reviews of the annual reports of the Jamaican Auditor-General (1997, 1998) and Contractor-General (1997, 1998); reading of Caribbean Insight (1995-1999), the Daily Gleaner on-line (1998-1999), and Jamaica Observer on-line (1998-1999), and data base searches of Info-LatinoAmerica (1988-2000). There was a high correlation among all these sources concerning the nature of Jamaican political corruption.

2. Although the employment of a parliamentary coalition is possible, there has never been coalition government in Jamaica.

3. Party members are allowed to hold both party and government positions. MPs are not required to live in their constituencies. There are no primaries for citizens to select constituency candidates.

4. For example, because their negotiations are carried on by government officials behind closed doors, the Jamaican public is not told what prices the state receives for its bauxite or coffee exports (Aub \& Aub (interview), 1999b).

5. The opposition JLP did not join in the outcry over FINSAC transparency and accountability as several senior JLP officials, including party leader Edward Seaga, were also suspected of having been bailed out by FINSAC (Cargill (interview), 1999).

6. The Jamaican police's brutal attitude has been influenced by a Suppression of Crime Act dating from the 1970s, which was in force for over two decades (now repealed). This 
act applied to all the areas around the capital city of Kingston and suspended many legal guarantees (i.e., illegal search, privacy of the home, need for warrants, etc.). A whole generation of police officers were recruited and trained in the climate of this act. The violence this act encouraged in the police still prevails, despite the act's repeal.

Numerous reports, including the Hirst Report by British police advisers, have criticized the brutal attitude of the Jamaican police, but no reforms have been implemented (Aub \& Aub (interview), 1999b).

7. This was not the first time P.J. Patterson escaped responsibility for his behavior as a Jamaican minister. In 1975, then PNP Minister of Industry and Tourism Patterson negotiated a deal to sell 50,000 tons of sugar to Iran. Later it was revealed that two US corporations were acting as middlemen in the deal whereby Jamaica sold them the sugar for US $\$ 330$ per ton and it was then sold to Iran for US $\$ 1,040$ per ton (a US $\$ 35.5$ million profit for the US middlemen) (Cargill, 1987). Despite a media call for accountability in the Iran Sugar Deal, none was ever given. 


\section{Chapter 6}

\section{Costa Rica: Democracy Manipulated}

Costa Rica prides itself on being the Little Switzerland of the Western

Hemisphere. Costa Rica is exceptional among Caribbean states in terms of its admirable levels of development (see Table 1-1). Most remarkable, however, is that while surrounded by instability and authoritarian rulers in other Central American states for the past 200 years, Costa Rica managed to build a stable representational democracy. In light of its propitious development and strong democracy, it should be expected that Costa Rica experiences relatively low levels of political corruption. This is true to a certain extent. On the one hand, compared to other Caribbean developing states, Costa Rica possesses one of the lowest corruption ratings in the entire region (see Table 4-1). On the other hand, Costa Rica's corruption ratings are much worse than those of Switzerland or other strong democracies.

Transparency International (TI) assigns Costa Rica a 1999 corruption perception index rating of 5.1 on their scale ranging from 0 (totally corrupt) to 10 (no corruption) (see Table 4-1). Placing this Costa Rican TI rating on the corruption index in Table 2-4 (the coordinates of political corruption) leads to the following hypothesis that is tested in this disciplined-configurative case study of Costa Rica:

Hypothesis: Costa Rica's coordinates of political corruption causal factors (form of societal rule, political culture, elite competition, elite accountability, mass participation, market resource factors, boundaries between public and private) are dominated by directive rules, or near equal combinations of directive rules with either instruction or commitment rules, resulting in institutional political corruption patterns. 
This chapter investigates the above hypothesis using the framework of my interdisciplinary theory of the causes of political corruption developed in Chapter 2. It first provides a historical survey of institutional development in Costa Rica. Second, it assesses the nature of contemporary Costa Rican political corruption patterns, including determining the boundaries Costa Ricans have established between their public duties and private interests. Third, it investigates contemporary institutional factors that cause Costa Rican political corruption. Finally, the chapter summarizes the interdisciplinary causes of Costa Rican political corruption. This chapter demonstrates that the main cause of political corruption in Costa Rica is a self-interested governing elite that, while largely concerned for the greater good of the Costa Rican populace, have manipulated their state's political and economic development to serve their own personal interests.

\section{Historical Setting}

Costa Rica's modern history began with Columbus's arrival in 1502.

Impressed with the gold decorations worn by the local Indians, Columbus christened the area the rich coast. Despite initial Spanish interest, it took until the 1560s for the first permanent Spanish settlement to be established. Exploration and settlement of Costa Rica assumed a low priority once the Spaniards determined the gold Columbus found came from either inconsequential local deposits or from pre-Columbian Indian trade networks that linked Costa Rica's Indians to those further north and south on today's Central American isthmus. The Spaniards also discovered that there were few Costa Rican Indians to exploit as laborers in mining and agricultural ventures. Spanish settlement was also delayed by the presence of Costa Rica's dense coastal jungles, 
debilitating tropical diseases, rugged mountains, and pockets of Indian resistance that obstructed the Spaniards' exploration of the region. In 1561, Spanish conquistadors finally established permanent settlements in Costa Rica's fertile and salubrious central highland valleys where the vast majority of Costa Rican citizens reside today (see Wilson, 1998, chap. 2; Biesanz et al., 1999, chap. 2).

The low priority the Spaniards gave Costa Rica between Columbus's arrival and initial settlement continued throughout the Spanish colonial period. Costa Rica was the tail-end, literally and figuratively, of the Spanish Guatemalan captaincy-general encompassing today's Southern Mexico, Guatemala, Belize, El Salvador, Honduras, Nicaragua, and Costa Rica. With the northern sections of the captaincy-general containing more precious metal deposits and greater numbers of exploitable Indian laborers, Spanish conquistadors of higher noble rank flocked to the areas that constitute present-day Guatemala and El Salvador. These Spaniards eventually established the captaincy-general's audiencia in today's Guatemala City (Haring, 1947, p. 76). The more southern and resource poor Costa Rica was settled by Spanish conquistadors of lower noble rank. Even the church officials and commoners who made their way to Costa Rica tended to be of lower rank or status than those who settled Spanish lands further north. Costa Rica became the Cinderella province of the Guatemalan captaincy-general-one that was taxed, scolded, ignored, and kept miserably poor (Biesanz et al., 1999, p. 17). Hoping to find some means to exploit Costa Rica's natural resources, Spaniards migrating to Costa Rica were forced instead to establish a settler society. Knight (1990, pp. 66-87) defines a settler society as one where the Europeans' primary activities were to 
recreate the institutions and relationships of the metropolis, unlike the exploitation societies in the rest of the Guatemalan captaincy-general that were primarily interested in profiting from the resources and peoples of the region. Caribbean history reveals that settler colonies only prospered under climatic conditions similar to Europe, like those in Costa Rica's central highlands (Knight, 1990, p. 76). The leaders of settler societies sought to recreate the social arrangements of the metropolis-in Costa Rica's case the Spanish system of nobles and commoners.

Settler societies were pragmatic and adapted freely to their conditions, no matter how much some settlers might deplore such actions (Knight, 1990, p. 86). In Costa Rica, a noble-commoner duality of status and power arose - one based upon birth and the size of land holdings and not upon differences in wealth or standards of living. During most of the sixteenth through eighteenth centuries, the standard of living of Costa Rican nobles was similar to that of the general populace, as both noble and commoner alike were forced to work the land simply to survive (Wilson, 1998, p. 11). In 1719, the local governor of Costa Rica complained in writing to the Spanish crown about the miserable local conditions as even "he had to undergo the humility of tilling the land to feed his family" (Stone, 1990, p. 17). Many trace the roots of modern Costa Rican institutions to the harsh conditions faced by those who built the settler society.

Costa Ricans take pride in explaining their state's present-day political, economic, and cultural exceptionalism as the result of societal values that emerged from a culture of rural democracy that took root in the colonial period. Rural democracy is said to result from the mix of individualistic and egalitarian values that sprang from Costa Rica's small 
farmer society. Unlike in the northern parts of the Guatemalan captaincy-general dominated by large noble-owned haciendas, colonial Costa Rica displayed a patchwork of small isolated farms worked by Spanish and creole commoners. The idealized history of rural democracy, today part of the Costa Rican psyche, can be seen in a passage from a school text widely used in Costa Rica:

[Each farm was] a small world in which the family was born and raised far from other farms. Their simple life, without ambitions and desires, gave the inhabitants a rude, mistrustful, very individualistic character. They were without exception peasants who had to till the soil for their food: as a result Costa Rica became a rural democracy. Unlike other Spanish colonies, Costa Rica had no social classes or castes, no despotic functionaries who looked down on others, no powerful creoles owning land and slaves and hating the Spaniards, no oppressed mestizo class resentful of the maltreatment and scorn of the creoles. (Monge, 1976, p. 192; quoted in Biesanz et al., 1999, p. 19)

Modern scholars studying Costa Rica have shown rural democracy to be more myth than reality (see Stone, 1990; Booth, 1998; Wilson, 1998). Colonial and postindependence Costa Rica was far from a classless, stable, and democratic society. Like most myths, however, there is some truth to it. Colonial Costa Rica experienced few of the societal tensions that arose in other Caribbean colonies. The encomienda system of abusing Indian labor lasted only briefly in the early years of the Costa Rican colony, with at most a few hundred Indians employed by Spanish masters (Biesanz et al., 1999, p. 18). There was also little exploitation of African slaves. At its peak, no more than 200 African slaves were ever present in colonial Costa Rica (Biesanz et al., 1999, 18). With few Indians and Africans to intermarry with the Spanish settlers, the colonial Costa Rican populace remained more racially homogeneous (white) than most other Spanish colonies. 
Contrary to the rural democracy thesis, there were class differences among Costa Rica's settlers. Nobles descending from the Spanish conquistadors claimed the largest tracts of land and constituted an upper class. With the few middle class professionals present in the colony, i.e., merchants, doctors, etc., the upper class, along with Spanish colonial officials, formed a governing elite that wielded political power. The large mass of small farmers had no say in colonial government, just as the commoner had no say in the governance of Spain. Unlike in most other Spanish colonies, major rifts did not arise between the Costa Rican governing class and lower class small farmers. The fight for daily survival, engaged in equally by all Costa Rican classes, drew the population together, fostering societal values of cooperation and brotherhood (Wilson, 1998, p. 12). This is seen even today where Costa Ricans affectionately refer to themselves and other countrymen as part of one large family of hermanitos (little brothers), locally shortened to Ticos.

Societal cooperation that developed during the colonial period was a boon to the start-up of Costa Rica's nineteenth century coffee industry. From its earliest days as a colony, the Costa Rican upper class searched for a profitable export crop that would generate wealth similar to that flowing into the northern parts of the Guatemalan captaincy-general from their exploitative mining and agricultural ventures. Cattle ranching and cacao exports brought limited prosperity to a few large Costa Rican landowners, but it was not until coffee was developed as an export product that Costa Rica found its first consistent source of wealth. 
Coffee trees were introduced into Costa Rica as early as 1740 , but were seen as more of a novelty as most Costa Ricans drank mainly cacao and sugar drinks (Booth, 1998, p. 36). By the 1820s, spurred by increasing European demands for coffee, Costa Rica developed coffee into a full-fledged export industry. The Costa Rican central highlands provide the perfect climate and fertile volcanic soil for growing high quality coffee. The Costa Rican economic and social structure that supported the emerging coffee industry grew from the colonial Tico relationships. Costa Rica's small farmers could easily grow and pick their own coffee, but needed money to finance their crops, mills to remove the coffee bean husks, and the means to transport the coffee to Costa Rica's Pacific Coast seaports. The large landowners, on the other hand, needed workers to help tend and pick their larger coffee crops.

A mutual dependence, if not partnership, arose among the small and large early nineteenth century landowners. ${ }^{1}$ The large landowners financed the small farmers' crops, built coffee mills (beneficios), provided the mules and wagons to transport the crops, and, from their position as the governing elite, employed the Costa Rican state to provide the roads and port infrastructures needed to facilitate the coffee industry. The small farmers provided the large landowners both excess labor and the crops from their own coffee harvests, which together ensured the quantity of coffee the large landowners needed to make their coffee businesses profitable. The new wealth the coffee industry provided the Costa Rican upper class cafetaleros changed the landscape of Costa Rican politics and economics. 
Costa Rica obtained its independence from Spain in 1821, almost simultaneously with the emergence of the coffee industry. Being the tail end of the Guatemalan captaincy-general, and having played virtually no role in the revolutionary struggle, it took Costa Rica almost a month to even learn of its freedom from Spain. Over the next two decades, Costa Rica was little more than a spectator as various northern creole caudillos fought among themselves to gain power and unite the former Guatemalan captaincy-general as the Central American Federation (CAF). Costa Rica abandoned the CAF in 1838 and became an autonomous state. During these first two decades of independence under the $\mathrm{CAF}$, the upper class cafetaleros became increasingly wealthy and assumed total political, economic, and military control over Costa Rica (see Stone, 1990). Infighting among the cafetaleros led to over a century of political instability in Costa Rica, far from the democratic and peaceful times that the rural democracy thesis offers.

During the later nineteenth and early twentieth centuries, similar to other Central American states, Costa Rica was engulfed in a wave of political instability. Costa Rica's governing elite, like those in other former Spanish colonies, adopted a republican form of government with a presidential system similar to that of the United States. However, there was little agreement as to who should rule Costa Rica. Elections were regularly held, but only males from the propertied upper and middle classes were allowed to vote, limiting suffrage to only 2-3 percent of the Costa Rican populace. Palace political intrigue and political and military coups became constant elements of the Costa Rican political landscape--the result of cafetalero disputes over who should brandish political 
power. Political parties that first formed in the late nineteenth century were based on personalistic cliques that supported one powerful cafetalero over another. Costa Rica dates its true democracy to the 1889 elections where, for the first time since its 1821 independence, a winning opposition presidential candidate was allowed to peacefully take office (Wilson, 1998, p. 22). Even this milestone did not end the cafetalero struggle for political power, as military coups remained a constant part of Costa Rican politics through the 1920s.

Despite the sense of Tico brotherhood among the populace, neither colonial nor post-independence Costa Rica escaped the scourge of political corruption. Costa Rica was designated a gobernacion (province) of the Guatemalan captaincy-general in 1542 and along with it came a Spanish governor and other colonial officials, many who had purchased their crown positions. With little Costa Rican economic activity beyond subsistence farming, Spanish colonial officials' main source of income was to either dip into the provincial treasury or to exploit Crown property (land grants, etc.). Local colonial alderman (regidores) were initially elected from the Costa Rican populace, but by the seventeenth century "patronage and graft [was so widespread]...[that] local officials came to be appointed rather than elected, and the office of regidor usually went to the highest bidder" (Creedman, 1991, p. 234).

In the post-independence period, the sense of Tico brotherhood between the cafetaleros and small coffee farmers only went so far. Commercial houses that were owned by the politically and economically powerful cafetaleros financed the small farmers' coffee crops and commonly practiced usury—borrowing money from foreign 
bankers and then loaning it to the small farmers at much higher interest rates (Wilson, 1998, p. 25). The post-independence personalistic governments that arose from the cafetalero political power struggles were also wracked with graft and patronage. Thus, Costa Rica was not spared the political corruption rampant in other Spanish colonies or in other regional caudillo-governed post-independence states.

The cafetaleros, direct descendants of the original Spanish conquistadors, wielded political control over Costa Rica's government for the first 125 years after independence (see Stone, 1990). As the coffee industry expanded in the early 1820s, Costa Rica's population was predominantly rural and totaled only 60,000 to 65,000 settlers. In the early years of the coffee boom, the interests of the upper class cafetaleros, small middle class (especially the merchants and coffee exporters), and lower class small farmers all coincided - to strive for maximum exploitation of the coffee crop to generate wealth. Soon, Costa Rica, the poor colonial Cinderella province, rose to become the wealthiest independent state in Central America. The governing cafetaleros effectively co-opted the lower class by paying the small farmers a fair price for their coffee harvests and excess labor and by instituting a national system of free education for all Costa Rican citizens. They did not, however, develop social programs--health, housing, etc.--and did little to protect workers' rights. Over the course of the nineteenth and early twentieth centuries, Costa Rica's increasing wealth, combined with the ignoring of social programs and workers' rights by the governing elite, led to widening class distinctions and growing societal tensions (see Vega, 1990). 
In the late 1800 s and early 1900 s, Costa Rican societal tensions grew-the unintended consequences of cafetalero efforts to improve Costa Rican society and the coffee industry. First, improving levels of education sparked societal tensions. The compulsory post-independence primary education programs instituted by the cafetaleros created a "citizenry ever more politically aware and desirous of participating in elections" (Vega, 1990, p. 204). The base of middle class professionals also expanded as children of the governing elite, fresh from their time in European or US universities, brought a liberal approach to solving the problems of rapid modernization and urbanization taking place in Costa Rica (Vega, 1990, p. 204). The desire for mass participation and the push for liberal reforms soon conflicted with the interests of the more conservative cafetaleros. Second, the late nineteenth century completion of the Atlantic Railroad created a miniexploitation society along Costa Rica's Caribbean Coast. With the mini-exploitation society came societal tensions common to other Caribbean developing states.

Prior to the 1870 s, coffee could only be shipped to Europe from Costa Rica's Pacific Coast seaports, requiring a five to six month voyage around Cape Horn at the southern tip of South America before reaching Europe or the US East Coast. In the 1870 s, the government began a project to build an Atlantic Railroad that would connect the Costa Rican central highlands with the Atlantic Coast port of Limon. This railroad would cut three months off the shipping time from Costa Rica to its European and US markets. Unable to make significant progress on the railroad, in 1883 the Costa Rican government hired US railroad engineer Minor Keith to complete the project that traversed both the steep cliffs of the central mountain range and the malaria infested tropical 
jungles of Costa Rica's Atlantic Coast. With few available Costa Rican laborers, Keith imported Chinese, Italian, and West Indian laborers to build the Atlantic Railroad. To defray the railroad costs, the government awarded Keith long-term leases to 800,000 acres along the railroad's coastal right of way. Keith later used this coastal land grant to establish Costa Rica's banana industry. Under the control of the Boston-based United Fruit Company, bananas soon became Costa Rica's second most important export crop after coffee (Biesanz et al., 1999, p. 24).

With the banana industry came increasing societal pressures. First, to finance the railroad, the Costa Rican government went deep into debt with British and other foreign bankers. Paying this debt placed major constraints on Costa Rican government budgets. Second, many of the Chinese and West Indian railroad laborers remained in Costa Rica, and many more West Indians, mainly from Jamaica, were brought in to work in the new banana industry. Costa Rican labor from the central highlands showed little interest in working on the tropical banana plantations. This created a separate labor market, one not built on a sense of Tico brotherhood as in the coffee industry, but one where the US industrial giant United Fruit exploited immigrant laborers. Having been co-opted by the ruling cafetaleros, Costa Rica's small farm coffee growers never presented an organized labor threat. This was not the case with the banana laborers. Worker grievances began with the railroad project and banana industry and became a source of societal tension that eventually led to a 1934 strike by the Communist Party led union, Bloc of Workers and Peasants-the first major labor disorder in Costa Rican history (Biesanz et al., 1999, p. 
28). This strike signaled the demise of the cafetalero monopoly on Costa Rican political power.

The cafetaleros did not completely relinquish their grip on Costa Rican political power continued until the mid-1900s when rising political, labor, and social tensions led to the 1948 Civil War. In 1940, Rafael Calderon, hand-picked by the cafetaleros to succeed President Leon Cortes (1936-1940), was elected Costa Rica's president. President Calderon (1940-1944) soon turned on the coffee oligarchy and began a series of liberal social and economic reforms that "reoriented the state as an instrument of the working and middle groups " (Rosenberg, 1981, p. 279). Allying with the Catholic Church and the Communist Party, Calderon introduced reforms that included a social security program, an eight-hour workday, a minimum wage, and workers' rights to organize (Wilson, 1998, p. 31). Calderon's enlightened elite approach to social legislation was consistent with his view that enacting social reform was the best method to prevent later societal conflict (Wilson, 1998, p. 31). Calderon's social and economic reforms continued throughout the presidency of his successor Teodoro Picado (19441948), considered a puppet of Calderon who was prevented by the Costa Rican Constitution from succeeding himself. In 1948, Calderon ran again for the presidency and lost to moderate-conservative candidate Otilio Ulate, a respected newspaper publisher. Calderon's loss provided the spark that set off Costa Rica's Civil War. Costa Rican scholars still debate the exact causes of the 1948 Civil War. Soon after Ulate's election victory over Calderon, the Costa Rican Congress, dominated by Calderon supporters, cited election disparities and voted to annul the election results, the 
equivalent of a political coup. Jose "Pepe" Figueres, a social democrat who had been exiled from Costa Rica for speaking out against Calderon in 1942, raised an army and declared war on the Calderon-Picado led government. Different factions fought in the war for different reasons (Biesanz et al., 1999, p. 32). Calderon-Picado supporters thought they were fighting for continued social reforms that were best accomplished by returning Calderon to power. Figueres and Ulate supporters thought they were fighting against government corruption and communism. In the end, the disorganized and poorly trained Costa Rican military were no match for Figueres's volunteer force, and, after six weeks of fighting and nearly 2,000 deaths, a peace treaty was signed.

The Civil War shook the foundation of a Costa Rican society that prided itself on values of consensus, tolerance, and non-violence. Two important political ramifications came from the war. First, the historical cafetalero hold on Costa Rican political power ended as the middle class assumed a larger role in Costa Rican politics. Second, the new Costa Rican governing elite, led ostensibly by Figueres, was forced to regroup and devise a governing structure that could regulate elite conflict and prevent another bloody Civil War.

The elite pact emerging from the Costa Rican Civil War established the political structure that remains in place today. At the end of the war, Figueres was installed as the head (president) of a ruling junta. He immediately called national elections to pick a Constituent Assembly to write a new Costa Rican Constitution. Three-quarters of the elected Constituent Assembly members turned out to be moderate-conservative supporters of Ulate. The Assembly rejected a draft constitution presented by Figueres 
and his social democratic supporters. Instead, they used Costa Rica's 1871 Constitution, combined it with social reforms instituted under Presidents Calderon and Picado, and then added several reforms of their own.

The Constituent Assembly maintained the four-year terms for elected officials and the prohibition on the immediate re-election of presidents or diputados (legislators). They provided for a strong governmental balance of power. The new constitution formalized many of Calderon and Picado's social and economic reforms. The assembly also initiated universal suffrage for those over 20 years old-women had been denied the vote before 1949. (A later amendment lowered the voting age to 18 years.) They formalized the autonomous Supreme Electoral Tribunal (TSE) that organizes and directs all elections, another Calderon-Picado initiative. The assembly instituted a professional civil service to replace the corrupt patronage system used to fill government positions. They also created, following the Uruguayan government model, autonomous government institutions to resolve Costa Rica's technical, economic, and social problems (Vega, 1990, p. 208). Most significantly, the assembly disbanded the Costa Rican armed forces-forever removing a historical source of instability from the Costa Rican political scene. Costa Rica became the only state in Central America without a standing military. After the 1949 ratification of the new Constitution, Figueres's ruling junta returned the presidency to the previously elected Ulate to serve a four-year term (1949-1953).

From the beginning of the 1950 s to the mid-1970s, Costa Rica experienced a period of peace and prosperity. The 1949 Constitution provided a commendable blueprint for sharing political power. Figueres, founder of the new National Liberation 
Party (PLN), replaced Ulate as elected president in 1953. Then in 1958, the PLN opposition party, Union Nacional, won the national elections and took office without incident, revealing both the TSE's effectiveness and the PLN's (Figueres's) commitment to democratic processes. Since 1958, there have been regular peaceful turnovers of power between the PLN and its opposition. Economically, strong world market demands for Costa Rica's coffee and banana crops and the emergence of a tourism industry fueled economic prosperity. Costa Rica's economy grew at a phenomenal rate during the 1950 s to mid-1970s-including a more than doubling (from US\$400 to US\$900-in 1970 prices) of per capita gross domestic product (Wilson, 1998, p. 82).

Using the proceeds of their economic boom, successive Costa Rican governments (both PLN and opposition) worked to install and strengthen an extensive social democratic system. The Costa Rican state played the major role in economic planning as it upgraded economic infrastructure (roads, ports, etc.,) and, through the autonomous institutions, assumed ownership of most state services (electricity, telephone, etc.) and many basic commodities (food, alcohol, cement, etc.). Costa Rica implemented an import-substitution industrialization model that protected domestic producers. Most importantly for working and lower class standards of living, Costa Rica developed into a strong benefactor (welfare) state that improved education and health services, subsidized basic commodities and housing, and kept real wages on the rise. The legacy of Tico brotherhood, the 1949 elite constitutional pact, and the rise of the benefactor state, resulted in a Costa Rica that today leads most of the Caribbean in political, economic, and 
social statistics (see Table 1-1). Propitious Costa Rican development did not, however, prevent the emergence of moderate levels of political corruption.

\section{Assessing Contemporary Costa Rican Political Corruption}

TI's 1999 corruption perception index (CPI) rating of Costa Rica at 5.1 (on a scale of 0 to 10) drew local reactions far different from those in other Caribbean states. The immediate reaction of most regional states with far worse TI CPI ratings than Costa Rica's was to attack TI's credibility. In Costa Rica a more cosmopolitan reaction occurred. First, the head of TI's Costa Rican chapter was asked in the press to explain the methodology of the ratings and their general meanings. Second, government officials, including those that head government watchdog agencies, responded that the TI CPI rating "coincided closely with the perception of Costa Rican citizens" and "provided evidence to the international community of the [Costa Rican] national problem with corruption" (Villalobos, 1999c, p. 5A). Costa Ricans generally agree that there is both a serious problem with political corruption and a need to address the problem.

Costa Rican citizens are candid about their corruption problems. In a 1989 survey that asked whether "corruption penetrates all the powers [executive, legislative, judicial] of the Republic," 64 percent responded yes. When the same survey question was asked in 1993, 72 percent responded yes, an indication that citizens perceived corruption as increasing (Proyecto Estado de la Nacion, 1996, p. 152). This was reconfirmed in 1997, when Costa Ricans were asked whether there was more corruption now than 10 years ago and 85.7 percent responded yes (Barometro Centroamericano, 1997). In a 1997 survey, Costa Ricans who said their country was not democratic gave the existence of corruption 
as the principal reason (Rodriguez et al., 1998, p. 297). In the last two decades of Costa Rican public opinion polls by CID-Gallup, corruption became a factor mentioned as a Costa Rican societal problem only in the 1990s (CID-Gallup, 1980-1999). This new corruption awareness largely grew in the aftermath of severe economic recessions that racked Costa Rica in the 1980s and out of renewed post-Cold War international interest in corruption. During the 1990 s, public opinion polls consistently placed corruption among Costa Rican society's four or five most serious problems, along with the cost of living, drug trafficking, crime and violence, and loss of societal values (CID-Gallup, 1980-1999).

Political corruption is far from a recent Costa Rican problem. Charges of corruption were one of the reasons that Figueres gave for declaring war on the government in 1948. During Presidents Calderon (1940-1944) and Picado's (1944-1948) administrations, their enemies created an image of government officials "as depraved self-seekers who sought public office manly to enrich themselves at the expense of the nation" (Bell, 1971, p. 63). While corruption was not the equal of other major issues leading to the Civil War, it was of sufficient importance that it helped lower the public's confidence in government (Bell, 1971, p. 62).

Corruption did not end with the Civil War. Stone (1990, pp. 125-129) documents a continual string of political corruption affairs beginning in 1958 and continuing into the 1980s that involved the top echelons of the Costa Rican government. This included, among several other affairs, the suspicious personal relationship between President Figueres and US fugitive financier Robert Vesco in the early 1970s and a reported theft of 
US\$10 million from the National Emergency Fund during the administration of President Luis Monge (1982-1986).

The administration of President Jose Maria Figueres (1994-1998), Pepe Figueres's son, was also marred by a string of corruption affairs (Latin America Institute, 1997). In summarizing the problems of corruption that surfaced in the 1980s and continued into the 1990s, Stone (1990) concludes:

These incidents have shaken national society to its bones and lead to questioning the legitimacy of the political system. Costa Rica has known corruption in the past....Today, however, illegal activity is so frequent that in spite of the huge quantities of money involved, the ruling class and the populace take it for granted....Giving and receiving bribes becomes increasingly a way of getting around cumbersome requirements. Members of the ruling class set examples for other social categories and promote corruption. (Stone, 1990, pp. $127-128)$

Table 6-1, developed from a content analysis, characterizes the current incidence and evaluation of Costa Rica's political corruption problems. ${ }^{2}$ Table 6-1 correlates closely with the 1999 TI CPI 5.1 rating of Costa Rica. The content analysis of Costa Rican political corruption reveals a governing elite that regularly engages in acts of political corruption, however, they do so in a strategic manner so as to avoid having members of the elite and/or masses (predominantly gray evaluation) condemn their behavior if it becomes public knowledge.

The content analysis reveals that not all Costa Rican government institutions are corrupt. Those dealing with state-owned resources or handling public moneys-e.g., Ministry of Public Works and Transport, Costa Rican customs, and autonomous institutions administering public housing, social security, and pension funds-are steeped in corruption. Government institutions that do not handle large amounts of state-owned 
resources or public moneys, such as the Ministry of Foreign Affairs, experience very little if any corruption.

Table 6-1. The Incidence and Evaluation of Costa Rican Political Corruption Behavior

\begin{tabular}{|c|c|c|}
\hline Types of Political Corruption Behavior & Incidence & Evaluation \\
\hline $\begin{array}{l}\text { 1. Governing elite deviate from the rules for } \\
\text { the benefit of friends or supporters. }\end{array}$ & SOP & W \\
\hline $\begin{array}{l}\text { 2. Large gifts, or other benefits, accepted by } \\
\text { governing elite for private gain. }\end{array}$ & SOP & W \\
\hline $\begin{array}{l}\text { 3. Unregulated campaign contributions } \\
\text { solicited and accepted by governing elite. }\end{array}$ & SOP & W \\
\hline $\begin{array}{l}\text { 4. Nepotism or political cronyism in govern- } \\
\text { ment appointments and contract awarding. }\end{array}$ & FI & G \\
\hline $\begin{array}{l}\text { 5. Governing elite profit from state decisions } \\
\text { through sideline occupations or kickbacks. }\end{array}$ & FI & G \\
\hline $\begin{array}{l}\text { 6. Citizens compensate governing elite for } \\
\text { advancing administrative due process. }\end{array}$ & OI & G \\
\hline $\begin{array}{l}\text { 7. Governing elite tolerate or cooperate with } \\
\text { organized crime for private gain. }\end{array}$ & OI & G \\
\hline $\begin{array}{l}\text { 8. Governing elite ignore convincing proof of } \\
\text { political corruption. }\end{array}$ & OI & G \\
\hline $\begin{array}{l}\text { 9. Governing elite misuse state resources } \\
\text { (land, property, etc.) for private gain. }\end{array}$ & OI & B \\
\hline $\begin{array}{l}\text { 10. Governing elite misuse state treasury for } \\
\text { private gain. }\end{array}$ & $\mathrm{OO}$ & B \\
\hline
\end{tabular}

Key: $\mathrm{SOP}=$ Standard Operating Procedure; FI $=$ Frequent Incidence;

$\mathrm{OI}=$ Occasional Incidence; $\mathrm{OO}=$ Rare Incidence, Without Regular Pattern .

$\mathrm{W}=$ White Corruption Boundaries, $\mathrm{G}=$ Gray Corruption Boundaries;

$\mathrm{B}=$ Black Corruption Boundaries.

Source: Content Analysis (see Endnote 2).

As described by several knowledgeable Costa Rican citizens, Costa Rican elite

and masses take corruption as a part of everyday life and overlook corrupt behavior that

involves one-on-one informal contract exchanges (bribes, speed money, etc.) between government officials and private citizens. On the other hand, the Costa Rican elite and masses are not tolerant of corruption when the corrupt behavior: (1) affects the ability of a 
government institution to function properly, or (2) results in the accumulation of excess wealth with no visible contract or reasonable explanation (Carazo (interview), 1999; Hidalgo (interview), 1999; Vargas (interview), 1999). Thus, the Costa Rican governing elite must conceal their corrupt behaviors so as not to breach the threshold that will energize elite or mass condemnation.

The Table 6-1 behaviors persist in present day Costa Rica in spite of a number of anti-corruption laws and regulations. Costa Rica's 1949 Constitution mandates that the president, government ministers, and managers of government funds, must declare their assets annually. The Costa Rican penal code also lists a variety of corruption offenses which public employees may be charged with, including the abuse of authority, receipt of bribes, illicit enrichment, and aggravated or judicial corruption. The penal code offense of illicit enrichment, however, was declared unconstitutional in 1995 because, as written, it places the burden of proof on the defendant and not the state (Umana, 1995). A 1998 independent review of Costa Rica's anti-corruption measures found that while there were established standards of official conduct, asset disclosure rules, and anti-corruption oversight bodies, Costa Rica was missing: (1) a resolution to the constitutional problem surrounding illicit enrichment, (2) rules mandating the denouncement of subordinates caught in illegal acts by superiors, (3) a system of witness immunity to facilitate corruption prosecutions, and (4) rules prohibiting nepotism and political cronyism (University of Texas at Austin, 1998). Also in 1998, to re-emphasize the standards of conduct for executive branch officials, President Miguel Rodriguez issued a directive 
further prohibiting conflicts of interest and other measures that could be construed as corrupt (Rodriguez Echeverria, 1998).

Despite the formal structure of rules mandating that Costa Rican officials separate their public business from their private interests, political corruption continues as a serious societal problem. Costa Rica's governing elite continue to selectively enrich themselves through their access to public resources. La Nacion columnist Julio Rodriguez captured the essence of the corruption problem when he wrote:

There it [corruption] is, serpentine, encrusted in the convolutions of public administration and the private sector. Its power is colossal. It mobilizes dormant desires, stalled procedures, productive projects. It is the lubricant of the system, to the point where the honorable citizen, if he does not play the game, loses out (Rodriquez, 1993, as quoted in Biesanz et al., 1999, p. 83).

\section{Explaining Costa Rican Political Corruption}

There are only a handful of studies addressing the causes of Costa Rican political corruption. ${ }^{3}$ Those authors speculating on its causes usually point to the 1970 s as the beginning of Costa Rica's contemporary problems with political corruption. Those taking a moralist position see Costa Rica's corruption problems as starting with the third administration of President Pepe Figueres (1970-1974) whose supporters began a systematic pillage of state resources and fostered Costa Rica's reputation as a safe-haven for international criminals such as financier Robert Vesco (see Sunol, 1974, 1977; Araya et al., 1982). Others see corruption as a result of the loss of Costa Rican societal values (Comision Nacional de Rescate y Formacion de Valores, 1992). Still others trace contemporary corruption problems to the rise of the Costa Rican entrepreneurial state 
and the emergence of societal values of self-interested consumerism (see Araya et al., 1982; Corrales, 1999).

The Costa Rican entrepreneurial state solidified in the 1970s. During the 1950s and 1960s, Costa Rica established an increasing number of autonomous institutions (AIs) that heightened state intervention in the economy and expanded social programs as part of the benefactor state (Wilson, 1998, pp. 99-103). This effort to involve the state in Costa Rican economic and social affairs was lead by social democratic PLN governments (1953-1958, 1962-1966, 1970-1974, 1974-1978) and continued by the more conservative PLN-opposition governments (1958-1962, 1966-1970, 1978-1982). With the burgeoning number and size of AIs, came attempts to centralize their control in the Costa Rican executive (Wilson, 1998, p. 102). The result was a bloated government bureaucracy with an executive branch having near monopoly control of Costa Rican economic and social welfare programs—the perfect environment for widespread rent seeking (see Corrales, 1999). Costa Rican citizens raised little resistance to the increasing level of state economic involvement and control as they were delighted by the state's stable democracy, booming economy, and increasing standards of living. By the mid to late 1970s, however, the rise of Costa Rica's entrepreneurial state led to increasing levels of political corruption. One Costa Rican scholar laments:

In Costa Rica, in the 1970 s, $\ldots$ we see the ultimate mix: politics, paternalism, centralism, consumerism, and dependent business. The result has been corruption that affects our entire political apparatus. Many [PLN supporters] did not intend for this situation to happen...the ideology that guided the country so well for years went up in smoke and was carried away by the wind (Araya, 1991, p. 56; author's translation). 
The causes of Costa Rica's political corruption are more complex than just the rise of the entrepreneurial state. Beginning in the 1970s, the monopolistic hold the Costa Rican state held over economic and social programs contributed to increased levels of political corruption. Just as important, however, was the lack of elite accountability that emerged from the political structures that trace their roots to the 1949 Constitution. What arose in Costa Rica after 1949 was an opportunistic governing elite-controlled political and economic system that was maximized for rent seeking. This chapter now investigates this rent seeking structure.

Form of Rule. On paper, and to a lesser extent in operation, the Costa Rican government structure presents one of the best-developed presidential systems in the world. It allows for strong democratic checks and balances, not only among the three traditional branches (powers in Costa Rican parlance) of democratic government—executive, legislature, judiciary-but also with the autonomous Supreme Electoral Tribunal (TSE) that is considered a fourth branch of government. The governmental system has a mix of hierarchical and heteronomous characteristics (see Chapter 2). The government structure is partly hierarchical because of its extreme legalistic nature. It is also partly heteronomous because the roles and responsibilities of each branch of government are clear and respected by not only other branches of government but also by the Costa Rican population. The government structure accepts the legitimacy of opposition views and reaches most major decisions through a consensus process. Popular support for the Costa Rican government structure is among the strongest of all regional states (see Rodriguez et 
al., 1998). To understand the roles and duties established in the Costa Rican governing system requires a description of the evolution of its core institutions.

One goal of the 1949 Constitutional Constituent Assembly was to restrict the power of the executive. Costa Rican political values include a strong societal distrust for the concentration of power in one person or branch of government. Such concentrations of power were believed responsible for the instability in Costa Rican politics from 1821 to the 1948 Civil War. The 1949 Constituent Assembly kept the 1871 Constitution's prohibition against presidents succeeding themselves-but they could run for future terms. (A subsequent 1969 constitutional amendment limited presidents to a single term.) Presidents are elected every four years in national elections. Presidents select their own cabinets, without legislative approval, and maintain oversight of the almost 200 AIs. Costa Rican presidents oversee each of the AIs through their appointment of the AI executive president and the majority (four) of AI directors (three directors are selected by the second largest party in the legislature--or the first largest if the president is not from the largest legislative party). The AI executive president and directors report directly to the president.

The Costa Rican executive can submit legislation for consideration and can veto acts passed by the legislature, except the annual budget act that only requires the legislature's approval. Like many other Latin American presidential systems, the president can bypass the legislature and issue executive decrees (legislate by decree). Unlike many other Latin American presidential systems, the president cannot issue decrees unilaterally, but must do so in conjunction with the minister responsible for the 
issue area the decree addresses. Costa Rican presidents are very resolute about using the decree power to avoid charges of abuse of power from the legislature, media, or public (Solis (interview), 1999b).

The 1949 Costa Rican Constitution designates the legislature (Congress) as the supreme power in the land. The legislature is unicameral and consists of 57 diputados (legislators) elected from seven geographic districts simultaneously with the president. Legislators cannot succeed themselves, but can be elected for multiple terms as long as they sit out four years between terms. The legislature can impeach the president, but only censure government ministers. The legislature also has no disciplinary power over sitting Supreme Court or lower court judges.

The judicial branch consists of the Supreme Court and lesser courts. The autonomous judicial system has a Constitutional mandate to receive six percent of the annual government budget. Twenty-two Supreme Court justices are elected by the legislature for eight-year terms (with an all but automatic re-election to a second term). The Supreme Court elects judges to the lesser courts. The Supreme Court has disciplinary power over its own and lower court judges. The Supreme Court apportions its work among four sections (Salas) with individual justices rotating among the Salas. Sala IV provides judicial constitutional review. Since 1949, Costa Rica has had the power of judicial constitutional review. However, starting with its creation in 1989 , the separate Sala IV Constitutional Court has become a more active player in the Costa Rican governmental system of checks and balances. Differing from most presidential systems with judicial review, Costa Rica's Sala IV is a regular part of the legislative process, 
ruling on the constitutionality of legislative projects and presidential decrees while they are still in the drafting and staffing stages. Sala IV also rules on thousands of citizen complaints brought before it each year. In its short existence, Sala IV has become one of the most respected Costa Rican government institutions.

The autonomous Supreme Electoral Tribunal (TSE) consists of three magistrates and six alternates appointed by the Supreme Court. The TSE is responsible for Costa Rica's reputation of having some of the most free and fair elections in the entire hemisphere. The TSE oversees the political parties and the course of electoral campaigns, including the allocation of state campaign funds authorized for political parties. The TSE provides judicial review and interpretation of all electoral legislation. It also directs and manages the entire quadrennial national election process, including the counting of votes and verification of election results. The TSE also acts as the state's official recorder, registering births, deaths, marriages, and divorces. At birth, every Costa Rican citizen is assigned a single identification number (cedula) that follows them through their entire lives, e.g., bank account number, social security number, voter registration number, passport number, etc., all in one. On turning 18 years of age, all Costa Rican citizens are automatically registered to vote.

The Costa Rican governing system works well to control the abuse of power, but is not without its problems. First, despite restrictions on executive power, the system remains strongly presidential—due mainly to the president's control over the large executive bureaucracy, including the AIs (Urcuyo, 1999, pp. 168-170). Due to their inability to gain legislative subject matter expertise, because of a combination of their 
short terms in office and small personal and committee staffs, legislators are often at the mercy of the executive branch bureaucracy for drafting legislation, especially highly technical legislation. This results in over half of all proposed legislation being submitted by the executive (Proyecto de la Nacion, 1999, p. 250).

A second problem with the Costa Rican governing system concerns the weak political party discipline the Costa Rican system fosters. Even when a president's political party has a majority in the legislature, there is no guarantee that the president's legislative agenda will be successful. This is an unintended consequence of the rules that do not allow either presidents or legislators to succeed themselves. Instead of supporting a lame duck president, who can do them few future political favors, legislators of the president's political party regularly ally with the candidate they believe will be successful as their party's next presidential candidate. The incentive for legislators to abandon their party's setting president concerns the fact that if the next presidential candidate is elected, he/she will be in a position to appoint the then ex-legislator to a ministerial or AI position-thus continuing their career in Costa Rican politics. This often causes the best interests of the Costa Rican people to get lost in the process of legislators maneuvering for what is best for their future political careers. The weak party discipline this situation promotes means that on every major legislative issue the executive branch must work to muster the needed legislative votes. This often stresses even the Tico capacity for consensus and cooperation. It also makes the legislative process slow and laborious, especially if a controversial issue is being addressed. Despite these flaws, the Costa 
Rican presidential system contains strong checks and balances against the abuse of political power.

Political Culture. Costa Rica's political culture is strongly individualistic. Costa Rican citizens tend to be conservative, cautious, and formalistic. Most of all, they are very individualistic in their outlook toward not only political affairs but also life in general. Costa Ricans greatly value individual liberty (Biesanz et al., 1999, p. 9). While generally averse to forming associations and collectives, Costa Ricans recognize the value of political and economic participation to advance their self-interests. Costa Rica consistently posts some of the highest voter turnouts in the region. Costa Ricans also tend to be extremely legalistic; constantly passing laws, creating institutions, and holding meetings to solve problems - if not concretely then at least symbolically (Biesanz et al., 1999, p. 10). In explaining or justifying their behavior, Costa Ricans invariably tie their actions to a legal document of one form or another. Large sections of books containing legal codes and government regulations are found in even the smallest bookstores in the capital city of San Jose. Costa Ricans are constantly trying to work the government system, both formally through the hierarchy of state bureaucracy and informally through the influence of personal contacts in high places, to advance their political, economic, and social self-interests (Solis (interview), 1999b).

One paradox in Costa Rica's individualistic political culture is their reliance on the state. Despite their individualistic natures, Costa Rican citizens have developed a dependent relationship with the Costa Rican benefactor state. Costa Ricans rely on the state for almost everything from employment; to direct benefits such as health care, 
education, and pensions; to government subsides on food and gasoline; to basic services such as housing, electricity, and telephones. The state provides employment in two primary ways. First, the swollen state bureaucracy, especially the AIs, provides one-tenth of all employment. As most of these jobs are part of a professional civil service, citizens are not subjected to the political patronage of a ruling party (the president's party) to ensure their government employment. Political patronage (spoils) does, however, play a role in the staffing of the 9,500 person national police (substantially replaced with each change in the ruling government party) and in some jobs requiring state licenses, e.g., taxis, etc., where the influence of an elected or appointed government position is important in securing license approval. Second, because of the state's dominate role in economic planning, Costa Rican citizens rely on the state to establish economic conditions that lead to employment opportunities. As a taxi driver told the author "Ticos will vote for whichever party they think will provide them work."

Costa Ricans place extremely high trust in their democratic state institutions. Contrary to the situation in many developing states, Costa Ricans expect their formal state institutions to work (Vargas (interview), 1999). This helps explain why there is both mass and governing elite condemnation of political corruption behaviors (per Table 6-1) that affect the functioning of state institutions. It also helps explain the extremely high utilization of and high trust in state watchdog agencies, including the Contralaria General (state comptroller), Defensoria (ombudsman), and the Supreme Court Sala IV, that are responsible for overseeing state institutions. The strong confidence Costa Ricans 
place in their democratic institutions does not, however, extend to their political parties or to individual government officials.

As the result of the decline in the standard of living during the 1980s and 1990s, Costa Rican citizens are generally frustrated with their politicians. The oil shocks of the late 1970s and early 1980s, combined with the world debt crisis of the 1980s, arrested the almost three decade Costa Rican economic boom which began in the 1950s. During the 1950s to 1970s, Costa Rican governments borrowed heavily to fuel the rise of their benefactor state. Borrowing, combined with the economic boom after the 1948 Civil War, resulted in an ever-expanding pie of Costa Rican material resources. The cost of oil after the mid-1970s (Costa Rica has no domestic oil production), restrictions on developing state loans after the 1980s world debt crisis, and the dwindling of US economic aid programs after the end of the Cold War (especially after the end of Central American conflicts outside Costa Rica), all combined to shrink the Costa Rican material pie (Vargas (interview), 1999). The result was a flattening of economic growth in the 1980s and 1990s and a scaling back in the amount of social benefits the benefactor state could provide individual citizens-thus lowering overall standards of living.

Remembering the good times of the 1950s to early 1970s, Costa Rican citizens became frustrated at the inability of the current political parties and politicians to provide the same standards of living. This frustration is seen in citizen opinion surveys. In a 1997 poll, 59.1 percent of respondents indicated that the Costa Rican political parties provided little or no representation of citizen interests and aspirations. The same poll found high percentages of either little or no citizen confidence in government personnel, 
including civil servants (67.4 percent), judges (53.9 percent), and legislators (71.4 percent) (Rodriguez et al., 1998, p. 307). The polls also show that citizen confidence in the government has decreased steadily over the course of the 1990s (Rodriguez et al., 1998; CID-Gallup, 1980-1999). This lack of citizen confidence in government is consistent with the Costa Rican political culture steeped in individualistic self-interest.

Elite Competition. Costa Rican elite competition presents a mix of constricted and oppositional characteristics (per Chapter 2). The constriction results from the fact that, in spite of the facade of Costa Rica's two major competitive political parties and several smaller ones, there is really only one Costa Rican governing elite. The majority of elite members from all parties grow up in the same neighborhoods, attend the same schools and universities, belong to the same social clubs, and marry within the same small circle of elite families (Solis (interview), 1999b). Despite efforts to establish a difference in ideologies between the liberal PLN and its major rival the conservative Social Christian Unity Party (PUSC), both parties are populist, centrist, and, due to the consensus nature of Costa Rican politics, tend to follow the same general policy agendas when in office. Political competition, while presenting an illusion of vigor, is restricted to a relatively small circle of governing elite and becomes no more than a friendly game between friends with little real competition over ideas or issues occurring.

The existence of the small circle of Costa Rican governing elite can be seen in President Oscar Arias's (1986-1990) 1976 doctoral thesis, Who Governs in Costa Rica. Arias investigated which social classes actually held Costa Rican government positions. He found that "in the majority, formal leaders belonged, since 1948, to the upper class 
when they entered the executive or legislative branches for the first time" (Arias, 1976, p. 241; author's translation). Surprisingly, even with the 1948 Civil War ending the cafetalero grip on Costa Rican political power, Arias determined that the percentages of upper and middle class legislators did not substantially change from the 1920s through 1970s. He further discovered the Costa Rican executive has always been the province of the upper class, with only limited middle class participation. The Costa Rican legislature, on the other hand, was much more open to the middle class, but remained closed to the lower classes (Arias, 1976, p. 242). Stone (1990) took Arias's study a step further and revealed that a substantial number of Costa Rican executives and legislators are descendants of Costa Rica's original conquistadors. Overall, the governing elite in Costa Rica consists of a few thousand closely linked individuals from the upper and middle classes.

Within the small governing elite, there is substantial political openness that fuels the oppositional characteristics of Costa Rica's elite competition. The 1969 Constitutional amendment preventing presidents from running for a second term helps ensure that one or two powerful individuals do not dominate Costa Rican politics. From the 1950 s to early 1970 s, Pepe Figueres and his small circle of PLN confidants were the power behind Costa Rican politics. Even after stepping down from the presidency in 1958, Figueres remained a powerful PLN official and behind-the-scenes power broker through the 1960s and leading up to his second full term as president (1970-1974) (the 1969 amendment prohibiting presidential re-elections did not apply to this election). Today, once a Costa Rican president's term is over, he returns to the private sector, 
accepts a role as an informal senior statesman, and has only a peripheral presence in national politics. An ex-president's immediate advisors either return to the private sector or assume other party or governmental positions. This results in continual rotation of party and government leadership among the governing elite. ${ }^{4}$

Other factors also lead to an environment of openness in the small Costa Rican governing elite circles. First, individuals are prohibited from holding both party and government positions, resulting in a larger number of governing elite positions being available and providing flexibility for those frequently changing between party and government positions. Second, because of Costa Rica's moderately strong economy, there is sufficient employment for younger members of the upper and middle classes not desiring government careers. In Costa Rica, education is seen as a path to economic and social betterment (Proyecto Estado de la Nacion, 1996, p. 53), and the economy is generally able to absorb the student output from Costa Rican universities. For young professionals of the upper and middle classes desiring a political career, there are entrylevel opportunities within the party structures or within the large Costa Rican civil service. However, for the lower class, even those obtaining university degrees, becoming a member of the small governing class is extremely difficult.

Costa Rican electoral processes, both in the selection of legislative candidates and funding of elections, also constrict elite competition, if only slightly. The tight TSE control of national elections removes any doubt about their freedom or fairness. Internal elections of the major parties are a different story. PLN and PUSC presidential candidates are selected through a system of primaries and national conventions (see 
Lehoucq, 1997, chap. 2). There is considerable rank-and-file participation by registered party members in the selection of presidential candidates (Booth, 1998, p. 73). In electing legislators, however, Costa Rica employs a closed-list proportional representation system. The major political parties utilize a system of primaries and conventions to select legislative candidates. However, the process of determining a candidate's exact position on the closed-list of party candidates, and thus their chances of being elected, is often manipulated by party insiders--restricting the public's real say in selecting their representatives (Booth, 1998, p. 73). The same is true of parties outside the PLN and PUSC, where insiders in party executive councils substantially determine both their presidential and legislative candidates (Booth, 1998, p. 73).

How Costa Rican elections are funded adds to the constricted elite competition. Costa Rican elections are funded by a combination of state and private resources, a system that is open to political corruption. To reduce the impact of wealthy candidates or parties on the electoral process, Costa Rica allots two percent of the national budget in election years to support electoral campaigns. Any party receiving at least five percent of the presidential votes in a national election may receive a share of the national election funds in the next election. Since 1949, only the PLN and its major opposition party, now the PUSC, have garnered sufficient votes to receive the national election funds. The national election funds fall far short of supporting a major party's overall presidential and legislative campaigns. Additional funds are required from private sources. There are no restrictions on either the receipt of private campaign funds or the total amount a party can spend on running a campaign. The lack of regulation and lack of transparency in the 
administration of private campaign funding results in a system of political patronage within the governing elite.

The need for private campaign funding begins with the presidential precandidates, those vying for their respective party's presidential nomination. Some precandidates start their campaigns as much as four years in advance of national elections and must use either personal funds or private contributions to support their campaigns leading up to their respective party's national convention. It is often beneficial for interest groups to contribute to pre-candidates as they frequently control large voting blocs of setting legislators. The need for private campaign funding increases after the party national conventions as Costa Rican election campaigns have come more and more to resemble US elections where vast amounts of resources are spent on extensive media campaigns that include significant radio and television advertising.

Costa Rican politicians rely on interest groups, both legal and illegal, to provide the private campaign funding. Legal interest groups supplying campaign support encompass wealthy business owners, powerful business associations, and labor organizations that provide funds in expectation of favorable post-election considerations from winning candidates. As contribution sources and amounts are never published, some interest groups support both major parties. Because of the open nature of the Costa Rican political system, there are numerous entry points for interest groups to funnel campaign support. Funds may be given directly to a presidential candidate (or precandidate), to candidates for the 57 legislative seats, or to the party itself. Funds may also be funneled to either candidates or parties through party members holding ministerial or 
AI director positions. There is also a growing perception in Costa Rica that both major parties receive campaign-funding support from illegal drug traffickers (discussed in detail later). In return for campaign funding, contributors, both legal and illegal, expect favorable treatment by the winning candidates or party. The result is a system of patronage that occurs largely within governing elite circles. The closed and nontransparent nature of both legal and illegal campaign funding makes it all but impossible to determine the exact amounts and sources of the private contributions.

Elite Accountability. The lack of elite accountability is a major cause of Costa Rica's political corruption problems. Elite accountability displays a mix of vertical (within the government hierarchy) and circular (intra-elite) characteristics. On paper, Costa Rica meets almost all the answerability and enforcement measures expected of a system with vertical elite accountability (see Chapter 2). On closer inspection, however, it can be seen that these accountability measures apply only to the Costa Rican masses, and not to the governing elite.

Costa Rica's answerability problems begin with the lack of freedom of information regulations and the absence of investigative journalism. Information on Costa Rica's government is generally available, even with the lack of freedom of information rules. Most government entities, including AIs, publish annual operating reports that include detailed budget summaries. A United Nations and Costa Rican government sponsored development program, Proyecto de la Nacion, gathers government and other open-source political, economic, and social data on Costa Rica and issues an annual report on the state of Costa Rican development. While government reports can 
easily be altered to disguise corrupt behaviors, there is a general attitude that the public not be denied information on their government entities. One journalist reports few problems gathering data on the Costa Rican government. When there are problems in getting data, she explains it is either (1) due to someone trying to hide something that is wrong, or (2) due to the administrative disorganization common in government agencies (Pratt (interview), 1999).

When the government is trying to hide something from the public, there is no limit to the tactics it will use. For example, in 1996 the media questioned the use of Civil Aviation Funds to purchase Israeli-made arms for the Costa Rican police. To stop further journalist investigation and avoid accountability, President Jose Maria Figueres declared the arms purchase a national security matter and therefore closed to all further reporting and open discussion (Latin America Institute, 1997). The lack of freedom of information laws, plus the government's ability to manipulate information that is released, hinders elite answerability. This is also the case with Costa Rican press freedom.

Freedom House rates Costa Rica as a 16 (scale 0 to 100,0 being freest) in press freedom (Sussman, 1999). This rating is one of the best in the Caribbean, surpassed only by a few of the small Anglophone Caribbean island states, and far better than the ratings of other former Spanish colonies in the region. Costa Rica's written press, radio, and television are all privately owned and free to criticize public figures (Sussman, 1999). Despite the appearance of press freedom, several government measures are regularly used to dampen press reporting and restrict investigative reporting. First, reporters have no right to keep their sources secret (Biesanz et al., 1999, p. 84). If named in a libel suit, 
journalists are forced to identify their sources in court. Second, government agencies are known to cancel their advertising when they disagree with a media outlet's reporting. The loss of government advertising revenues, a principal funding source for many small media outlets, becomes a significant factor in editors deciding what to report (Biesanz et al., 1999, p. 83). Third, restrictive libel laws dampen the full exercise of press freedom (US Depart. of State, 1999a). Libel suits against media outlets that report misbehavior of individuals in the governing elite are common. Fourth, the media is prohibited from printing the names of persons or entities under investigation for crimes (Biesanz et al., 1999, p. 84). Fifth, a 1996 right to response law provides persons criticized in the media the right to respond with equal attention and equal length in the same media (US Depart. of State, 1999a). Finally, media owners and senior staff are often part of the governing elite and come under considerable pressure form their peers to control the reporting of information harmful to other members of the governing elite (Biesanz et al., 1999, pp. 8384). This last point is the real core of the problem with Costa Rican elite accountability that leads to political corruption: members of the Costa Rican governing elite, whether elected officials, part of the government bureaucracy, sitting judges, or members of the media, are all averse to condemning other governing elite members for misconduct. This is especially evident in matters of enforcement surrounding elite accountability.

Costa Rica does have a good system of electoral enforcement. Citizens can punish dishonest politicians at the voting polls. Because the major parties differ only slightly in their ideologies or issue stances, Costa Rican presidential campaigns often become personal popularity contests between the PLN and PUSC candidates. Thus, 
candidate values, including their perceived honesty, become major factors in presidential elections. This might appear less important in legislator elections, where party leaders determine a candidate's place on the closed-lists and voters are only allowed to vote for their preferred legislative party and not individual candidates. Although the party leaders have a major say in developing the closed-lists, the process of legislative primaries, including party consultations with community leaders, ensures all candidates placed on the closed-lists are acceptable to their constituencies. The major parties will not promote a legislative candidate who has questionable honesty as it may cause voters to vote for another legislative party. Thus, elections are one area where enforcement works. That is not the case with Costa Rican administrative and criminal justice enforcement.

Administratively, Costa Rica possesses what appears to be a model system. The 1949 Constitution established the office of Contraloria, a government watchdog office that reports directly to the Costa Rican legislature. The Contraloria periodically inspects and audits all government agencies, including the AIs. It also conducts special investigations either requested by individual legislators or initiated by the Contraloria itself (Contraloria, 1994; Hidalgo (interview), 1999). Most government entities also have their own small contraloria staffs for internal investigations and to respond to public complaints. In the face of rising interest in government agency performance and the need for additional government oversight, in 1989 the Supreme Court Sala IV Constitutional Court was formed, followed in 1993 by the Defensoria (ombudsman), an office where private citizens can file their complaints against government agencies or individual government officials. Along with the establishment of these new agencies, Costa Rica 
began a coordinated public information campaign to teach citizens their rights and to inform them how to use the various public watchdog agencies (see Blanco, 1997; Salazar et al., 1999). This public information program, combined with the performance of the public watchdogs, have made the Contraloria, Sala IV, and Defensoria the most respected government entities in public opinion polls (Rodriguez et al, 1998; CID-Gallup, 1980-1999).

Despite the public respect given the Costa Rican public watchdogs, they do very little to address political corruption. First, the Defensoria, in full operation only since 1995, receives few public complaints about political corruption. Even though the Defensoria declared public corruption one of its primary focuses in its 1997 annual report, there has been no public rush on the Defensoria offices to renounce acts of public corruption (Esquival (interview), 1999). Even with public opinion polls that see corruption as a major societal problem, Costa Ricans appear averse to publicly reporting corrupt acts to the authorities. This problem is amplified by the government system's overall aversion to holding the governing elite accountable.

Once the Defensoria investigates a complaint, it can either go directly to the government agency involved for corrective action, or in more serious cases, it can refer the complaint to the Contraloria or criminal justice system. Defensoria referrals and recommendations for corrective action are only advisory. The Defensoria has no power to force follow-up action (Defensoria, 1994). The Contraloria falls under different political constraints. The Contralaria is forced to balance its recurring inspections and audits with the action it takes on complaints referred by the Defensoria or individual 
legislators. This is especially difficult when individual legislators, in a sense of political vindictiveness, report every rumor they hear about opposition party members and demand Contraloria investigations (Hidalgo (interview), 1999). When the Contraloria does find grounds for criminal prosecution, it refers the case to the Costa Rican criminal justice system, which has its own set of political constraints.

A 1980s US Agency for International Development study of the Costa Rican criminal justice system found it lacking in several areas (see Rico et al., 1988). Because of the patronage-based re-staffing of the Costa Rican police each time a president from a different party takes office, the rating given the police force was far from professional. Once a case entered the Costa Rican criminal justice system, resource constraints continually delayed the case's final resolution, sometimes for years. The delay in case resolutions strained the already overcrowded prison system with defendants awaiting trial. The rich were perceived to manipulate the system through their ability to afford the most expensive lawyers and to bring political pressure on judges. As a result, in the 1980s, the public, defense attorneys, prosecutors perceived the Costa Rican criminal justice system, and even judges, as one wracked with corruption (Rico et al., 1988, p. 195).

During the 1990s, major emphasis was placed on professionalizing the Costa Rican criminal justice system (see Proyecto de la Nacion, 1995-1999). The investigative arm of the police, the Office of Criminal Investigations (OIJ), is now professionalized and does not change personnel after presidential elections. Court proceedings are now computerized and delays in case adjudication have been reduced substantially. Legal 
ethics are stressed and the overall perception of judicial corruption lowered. However, at least two areas that degrade the Costa Rican criminal justice system did not change. First, neither the police nor the courts developed the technical expertise to prosecute complex corruption cases. Second, the rich are still able to avoid prosecution through their abilities to afford the most expensive lawyers and to place political pressure on judges. A review of two recent political corruption cases demonstrates the lack of elite enforcement within the Costa Rican criminal justice system.

In 1998, just after PUSC President Miguel Rodriguez took office, it was discovered that from January 1998 to May 1998, the Costa Rican Family Assistance and Disaster Relief Fund (FODESAF) had been illegally investing state funds in a private brokerage firm. Of the US $\$ 61.3$ million illegally invested, state auditors were unable to account for US $\$ 4.8$ million which was believed to have been siphoned-off by either the fund's managers or the private brokerage firm (Pratt, 1999). It took over a year for this case to come to trial. Before trial, the FODESAF treasurer confessed to the illegal investments and agreed to repay a portion of the losses (amount unknown). The majority shareholder in the private brokerage firm involved in the illegal investments was found guilty at trial and sentenced to 16 years in prison.

The lack of elite accountability in the FODESAF case concerns several issues. First, the majority of the lost US $\$ 4.8$ million was never found and the end of the trial terminated the search for these government funds (Villalobos, 1999b). Second, the convicted majority shareholder of the private brokerage firm denies any wrongdoing and paints herself as a scapegoat for FODESAF or other government officials who pocketed 
the US\$4.8 million (Villalobos, 1999b). Third, the FODESAF director and sub-director, members of the governing elite who both signed off on the illegal investments, were found not guilty at trial—basing their defenses on the fact their administrative role in the investments was minor and that they placed too much trust in the FODESAF treasurer (Villalobos, 1999b). Fourth, only two weeks after the FODESAF trial ended, the PLN ethics committee exonerated the former PLN Labor minister, the Vice-President, and President Jose Maria Figueres, who were directly responsible for FODESAF operations (Villalobos, 1999a). This was just one of several corruption scandals involving the illegal use of government funds that arose during Jose Maria Figueres's (1994-1998) PLN administration. The PUSC are, however, not without their own corruption scandals.

In June 1994, President Figueres's PLN Council of Government, with the approval of the legislature, closed the Banco Anglo Costarrincense (BAC), Costa Rica's oldest state-run bank (see Wild, 1998). The resultant investigation found that over US\$100 million had been lost due to mismanagement and theft of the bank's investment portfolios. Although the investigation revealed that $\mathrm{BAC}$ had been poorly managed since the 1980s, the most significant losses occurred during the PUSC administration of President Rafael Calderon, Jr. (1990-1994), son of former President Rafael Calderon, Sr. (1940-1944), and were associated with loses from the purchase of risky Venezuelan and Brazilian bonds meant to reduce Costa Rica's foreign debt.

The BAC closure severely rocked the confidence of Costa Rican citizens in their state-run financial institutions. It took over five years for the BAC case to come to trialmainly due to the government's inability to investigate the complex case and determine 
exactly what crimes had been committed (Webster (interview), 1999). During the fiveyear delay, BAC's ex-president died in a plane crash and two Chilean businessmen involved in the BAC investments skipped bail and escaped to their home country. Avoiding the implication of any senior members of President Calderon's economic team, only the BAC's ex-general manager and six directors stood trial for the US\$100 million loss (Segnini, 1999). (The case is ongoing at this writing as the defendants base their defense on the principle that it was not a crime to make bad investments.) Additionally, the investigation revealed BAC's possible involvement in political influence peddling as it uncovered large outstanding unsecured loans to many of the influential governing elite, including several former and setting legislators (Segura \& Solis, 1999).

FODESAF and BAC are just two of several major political corruption affairs that surfaced in Costa Rica in the 1990s. Government reactions to these scandals, including the role of the criminal justice system, followed a disturbing trend. First, the missing government funds were seldom if ever recovered. Second, efforts were made to shield the governing elite from accountability for the losses. In the FODESAF case, a private investment broker and the FODESAF treasurer were punished but members of the governing elite were exonerated. In the $\mathrm{BAC}$ case, only the general manager and directors stood trial, while members of the governing elite, some owing hundreds of thousands of dollars in outstanding loans, were not called to task. Further evidence of the governing elite avoiding accountability over corruption issues can be seen in presidential and legislative campaigns. Although the FODESAF and BAC affairs were the topics of frequent media reports, neither became an issue in the 1998 national elections. Costa 
Rican governing elite have thus created a system that largely protects them from accountability, no matter to which political party they belong.

Mass Participation. Costa Rica has developed a system of mass participation that is strongly pluralist (see Chapter 2 ). An astonishing 70 to 80 percent ( 71 percent in 1998) of eligible Costa Rican citizens regularly vote in national elections, providing an indication of the importance that citizens place on political participation (Rodriguez et al., 1998 , p. 300). Groups from a variety of societal interests have regular and open access to the Costa Rican government hierarchy. Citizens and interest groups with complaints about government services or performance have easy access to the contralorias in government ministries and AIs. Additionally, they may go outside these direct channels to file complaints with either the Defensoria or the Sala IV Constitutional Court. Costa Rican citizens and interest groups also have easy access to Costa Rican legislators who spend a significant amount of their time interacting with constituents both in their San Jose capital offices and in public and private meetings in Costa Rica's seven provinces.

This system of open access to the Costa Rican government hierarchy dates back to the early nineteenth century and is rooted in the ideology of rural democracy. The Costa Rican governing elite have always felt a strong responsibility for the well being of the lower classes-the sense of Tico brotherhood (Wilson, 1998, p. 162). At the same time, however, the Costa Rican governing elite have always been afraid that the citizens would organize to an extent that would challenge the governing elite's hold on power (Wilson, 1998, p. 136). The fear of an organized citizenry helps explain the nineteenth century cooptation of small farmers by the cafetaleros, the 1940s social reforms by Presidents 
Calderon and Picado, and the late twentieth century rise of the benefactor state, all welfare-related actions designed to limit organized mass citizen participation. It also explains why, although Costa Rica has the largest number of nongovernmental organizations (NGOs) of any Central American state, strong interest groups that might challenge the governing elite's power still do not exist.

Costa Rica hosts 304 NGOs, almost a third more than Honduras (210) which has the next highest number of NGOs in Central America (Arias Foundation, 2000). These NGOs represent a variety of societal interests. None of the Costa Rican NGOs are particularly large and they also tend not to coordinate among themselves. Instead, like individual Costa Rican citizens, they work one-on-one with elements of the Costa Rican government hierarchy to advance their group's private interests.

Absent in Costa Rica are the powerful military, student, trade union, worker, and church interest groups found in some Caribbean states (see Wilson, 1998, pp. 66-75). Costa Rica lacks a military, and the non-professional police, with most officers acquiring their jobs through political patronage, are neither organized nor a threat to their governing elite patrons. University students tend to be more self-interested than activist and normally remain on the campuses. Trade unions and worker organizations, having been co-opted by the benefactor state, are also weak, representing only 15 percent of all Costa Rican workers. With few human rights and poverty problems, the Catholic Church, to which 85 percent of the Costa Rican people belong, has no incentive and little money to pursue an activist role. Thus, Costa Rica's governing elite have been successful at accommodating individual citizen and small interest group (NGO) access to government 
decision-makers, while keeping traditional powerful interest groups weak. The Costa Rican governing elite's success in fostering this version of mass participation can also be seen in the levels of Costa Rican societal trust.

As discussed earlier, Costa Ricans place high levels of trust in their government institutions. They also tend to trust their immediate neighbors and fellow Ticos. A 1997 poll found that 47 percent of Costa Rican's felt their neighbors would approve of them personally (CID-Gallup, 1980-1999). Also as discussed earlier, Costa Ricans do not trust individuals in the government or the major political parties to act in the citizenry's best interests. This distrust of government officials was made clear in a series of protests that occurred in March 2000 regarding the reorganization of the Costa Rican Electricity Institute (ICE).

The March 2000 ICE protests were a watershed in both mass participation and societal perceptions of political corruption in Costa Rica. Small-scale strikes and isolated peaceful street protests have been a regular part of Costa Rican politics for the last 20 years. Despite the frequency of such protest action, a 1997 poll found that 90.5 percent of Costa Ricans were against protest actions that blocked streets and damaged buildings and vehicles (Rodriguez et al., 1998, p. 299). This societal attitude did not seem to matter in March and April 2000, as thousands of Costa Ricans took to the streets over a two-week period to protest the Costa Rican legislature's passage of a bill to reorganize ICE. ICE, a wholly state-owned AI, maintains a monopoly hold on Costa Rican electric and telecommunications services. In March 2000, the Costa Rican legislature voted to 
separate the electric and telecommunications services into separate AIs and to allow private investment in each of the new AIs (up to 49 percent of each project's value).

The ICE legislation precipitated the largest street protests in post-Civil War Costa Rican history. The protests spread across the state and involved several NGOs and thousands of individual citizens. The protests saw the uniting of many previously uncoordinated NGOs and interest groups. Each interest group had its own self-interested reasons for protesting. ICE worker unions protested because the reorganization threatened many of their jobs. Environmental groups protested because the new law allowed new power generation projects in sensitive environmental areas. Individual citizens protested because the reorganization would raise the price of electricity and telephone service. Even university students came off the campuses for the first time to protest the perceived social injustices in the ICE reorganization.

Costa Rican commentators noted that while individual groups had their own reasons for protesting, the protests went beyond the issue of ICE reorganization (see Herrera, 2000). Many commentators felt that NGOs and individuals were coming together, for the first time in Costa Rican history, to protest legislation they perceived as benefiting the minority governing elite at the expense of the majority population. Newspapers documented that several Costa Rican legislators already held interests in companies that were set to profit from the ICE reorganization (Espinoza, 2000). Mass participation in the ICE protests was thus a watershed awakening of societal concerns-a possible first step in changes to the accepted boundaries between public office and private interests as seen by the Costa Rican masses. 
Material Resource Factors. Costa Rica exhibits a mixed patrimonial and statist material resource system (see Chapter 2). It is partly patrimonial because citizens look to the state for their material support. It is also partly statist because it maintains moderately strong protectionist measures for external trade and significant government intervention in the domestic economy. The economic shock that rocked Costa Rica in the early 1980s began a slow process of changing the import-substitution and protectionist economic policies adopted in the building of Costa Rica's social democratic benefactor state. In spite of pressure from international financial institutions for Costa Rica to open its economy and accept free trade and other neoliberal measures, actual reform has been extremely slow. As the owner of extensive Costa Rican economic enterprises, the Costa Rican government retains a strong hand in economic planning. As the above ICE protests demonstrate, the Costa Rican populace has little desire for this mix of patrimonial and statist economic structures to change.

By the beginning of the twenty-first century, the Costa Rican economy had diversified from its previous dependence on coffee and banana exports (see Political Risk Services, 1998a). The tourism industry, despite suffering from a lack of infrastructure, had become the main source of foreign exchange. Along with tourism, the cut flower business and textile and light manufacturing industries now account for over two thirds of export earnings. In the late 1990 s, computer chip manufacturing by the Intel Corporation quickly became a significant portion of Costa Rica's exports, a venture Costa Rica hopes is an initial step toward an expanded high-technology sector that can take advantage of Costa Rica's educated work force. Traditional agricultural products, including coffee, 
bananas, and beef, remain important to the Costa Rican economy but do not hold the prominent place they did prior to the 1990s.

The Heritage Foundation rates Costa Rica as 2.80 (scale 1 to 5,1 being freest) on its index of economic freedom (Johnson et al., 1999). Since the mid-1980s, Costa Rica has been slowly moving to open its economy by lowering tariff and tax rates, reducing the state role in banking, and reducing government intervention in the economy. Despite external pressures to adopt neoliberal reforms, Costa Rica retains a high level of trade protectionism and is a difficult market for new businesses to penetrate (Johnson et al., 1999).

Costa Rica's internal economy has been slow to reform. Corrales (1999) describes how the Costa Rican internal economy is permeated with state intervention, state monopoly ownership of significant economic sectors, bloated bureaucratic procedures, and wide discretion of public officials involved in economic regulation. The result is an opportune system for governing elite rent seeking-a system that evolved during the social democratic reforms of the 1950s and 1960s and one that now supports the majority of Costa Rican middle class citizens through either direct or indirect employment. Costa Rica presents a perfect example of a system where the economic and political elite formed an alliance (Statist Bargain-see Chapter 4) where both directly benefit from the significant role of the state in the economy. The governing elite forged this alliance at the same time they co-opted the lower classes through the expanded welfare benefits of the Costa Rican benefactor state. 
Over the past two decades, extraordinary material resources (see Chapter 2) have entered the Costa Rican political corruption equation via three principal methods, through: (1) funds from privatization of government owned enterprises, (2) international financial institution loans and international aid, and (3) drug trafficking. The amounts of extraordinary resources are minimal from privatization efforts. In 1988, a government owned aluminum plant was privatized, followed by fertilizer, cement, and sugar plants in 1994 and 1995 (Corrales, 1999). However, none of the largest state-owned monopoly enterprises, including electricity, telecommunications, petroleum refinement, insurance, airports, or seaports have been privatized. The reasons for not privatizing these larger state-owned enterprises are three-fold. First, non-ruling parties want to avoid the privatization of the largest state-owned enterprises to prevent the ruling party access to funds which may be turned into electoral support in the next national elections. For example, if ICE were privatized, an extraordinary influx of several hundred million dollars would allow the PUSC ruling party to pay off part of Costa Rica's external debt, providing more funding for state infrastructure and social welfare programs that could then result in more PUSC support in the next election (Solis (interview), 1999b). Second, by privatizing large state-owned enterprises, the governing elite reduce their opportunity structures for obtaining rents from state-owned monopoly industries. Rents obtained from Costa Rica's extensive system of parastatal enterprises (the AIs) are the source of much of the governing elite's corrupt gains. Third, the Costa Rican populace, dependent on the outputs of the benefactor state, is against privatization. In a 1999 poll by CIDGallup, the largest percentage of respondents was for the continuation of state-owned 
monopolies in the enterprises of insurance ( 46 percent for, 41 percent against), electricity and telecommunications ( 57 percent for, 33 percent against), and petroleum refining (47 percent for, 40 percent against) (CID-Gallup, 1980-1999). Thus, privatization is only a minor factor in assessing extraordinary resource effects upon Costa Rican political corruption.

International financial institutions, including the International Monetary Fund, World Bank, and US Agency for International Development, are a second source of extraordinary resources. This was particularly true from 1983 to 1987, when the US provided aid in the amount of US $\$ 175$ million to US $\$ 225$ million annually. This US aid was critical to Costa Rica's survival of the 1980 s recessions. The aid was provided as an incentive for Costa Rica to renounce the communist-led Sandinista regime in Nicaragua and for Costa Rica's support of US efforts to aid the Nicaraguan contras. With the end of the Nicaraguan war and the overall end of the Cold War, Costa Rican external aid, especially from the US, plummeted to its current annual levels of less than US\$25 million annually. Like privatization efforts, these current levels of IFI aid are a minor factor in assessing extraordinary resource effects on Costa Rican political corruption. However, this was not so during the 1980s, when the huge amounts of US aid corresponded with the increasing concern over Costa Rican political corruption levels.

The 1980s also saw the establishment of Costa Rica as a drug trafficking transit country for cocaine shipments headed from Colombia to the US (see Weir, 1994). The Costa Rican cocaine connections first began with the Nicaraguan Contra factions operating along Costa Rica's northern border. These connections developed around the 
relationship between the Panamanian dictator and convicted drug trafficker, Manuel Noriega, and the Costa Rican-based Contra factions, who flew arms and cocaine from Panama to airstrips in northern Costa Rica--the arms meant for the Contras and the cocaine for further transshipment to the US (Scott \& Marshall, 1991). This cocaine trafficking could not have continued without the support of the Costa Rican police and high government officials. Scott and Marshall (1991) summarize the US involvement in the cocaine smuggling:

The US government did not invent this Contra-drug symbiosis, which...indeed reflects much older realities of political power in Latin America. But there are documentary indications that, as far back as 1983, Washington used or at least condoned many or all of these different Contra drug connections to maintain Contra support operations. At a minimum, the US Government and the CIA were well aware of the drug problems. (Scott \& Marshall, 1991, p. 106).

The Costa Rican drug trafficking connections continued after the Contra war ended with the help of the newly emerging relationships between the Colombian and Mexican drug cartels. Contacts between the Mexican traffickers and Costa Rican officials are believed to have first begun during the PUSC presidency of Rafael Calderon, Jr., (1990-1994) (Carazo (interview), 1999). During Calderon's presidency, several Mexican investors became prominent in Costa Rican economic enterprises. One major Mexican investor, Hank Gonzalez, is a known drug trafficker and money launderer in Mexico (Matute \& Solorzano, 1999). The Mexican cartels use Costa Rica as a transshipment point for drugs bound from Colombia to Mexico (and eventually destined for the US), as a safe-haven for meetings between Colombian and Mexican cartel members, and as a quiet vacation spot and refuge when Mexican or US law enforcement pressure cartel operations. 
During Calderon's administration (1990-1994), rumors emerged that politicians from both the PLN and PUSC were being supported by drug money (see Weir, 1994). In 1997, with his pre-presidential campaign short on cash, current President Miguel Rodriguez was a guest, along with other PUSC officials, at Hank Gonzalez's home in Mexico. During the public outcry that arose over this visit, then candidate Rodriquez denied that he knew of Gonzales drug-tainted background and that the visit was only social in nature. In August 1998, a Costa Rican court handed down a guilty verdict against former legislator Leonel Villalobos for his participation in international trafficking of cocaine to the United States and sentenced him to twelve years in prison (US Depart. of State, 1999b). The Villalobos case is the only confirmed evidence of the linkage between senior Costa Rican government officials and drug trafficking. However, the perception that the linkages exist is strong. When asked in 1990 by CID-Gallup what was the biggest problem with drug trafficking, 40 percent of Costa Rican respondents (the largest percentage) answered that it was the cause of official corruption (CID-Gallup, 1980-1999).

\section{Findings}

Table 6-2 summarizes the above discussion of the contemporary causes of Costa Rican political corruption. Costa Rica's mix of a hierarchical and heteronomous form of rule and its individualistic political culture create a democratic structure that includes pluralistic (moderate) levels of mass participation. Coinciding with this democratic structure is an elite competition characterized by a mix of constricted and oppositional conditions - a situation that may largely be an unintended consequence of the small size 
of the Costa Rican governing elite. The Costa Rican governing elite also constructed a mixed circular (intra-elite) and vertical (within the government hierarchy) system of elite accountability, which, when combined with the mixed patrimonial-statist material resource factors, allows the governing elite significant opportunities for corrupt behavior (per Table 6-1). With gray (moderately strong) boundaries established between public office and private interests, the Costa Rican governing elite must hide their corrupt behavior so that they do not energize elite or mass condemnation of their actions.

The above conditions lead to a Costa Rican political corruption pattern in the institutional area-corresponding with the TI 1999 rating of 5.1. Thus, this chapter's hypothesis is supported by the above analysis and demonstrates that Costa Rica's institutions associated with the causes of political corruption (per Table 2-4) are constructed primarily of directive rules, or near equal combinations of directive rules with either instruction or commitment rules.

Table 6-2. Coordinates of Costa Rican Political Corruption

\begin{tabular}{|c|c|c|c|}
\hline Dominant Social Rules & Instruction & Directive & Commitment \\
\hline Forms of Societal Rule & Hegemony & Hierarchy $\square$ & Heteronomy \\
\hline Political Cultures & Collectivist & Individualistic & Egalitarian \\
\hline Elite Competition & Constricted & Oppositional & Corporatist \\
\hline Elite Accountability & Circular & Vertical & Horizontal \\
\hline Mass Participation & Paternalistic & Pluralistic & Cosmopolitan \\
\hline Material Resource System & Patrimonial & Statist & Market \\
\hline Public/Private Boundaries & White & Gray & Black \\
\hline Corruption Patterns & Systemic & Institutional & Incidental \\
\hline \multirow[t]{3}{*}{ Corruption Index: } & & 1 & \\
\hline & & 1 & 7 \\
\hline & 0 & CR $(5.1)$ & 10 \\
\hline
\end{tabular}


This chapter demonstrates how Costa Rica came to exhibit a paradox of a strong democratic system coinciding with elite accountability and material resource conditions that allow significant rent seeking. The Costa Rican colonial experience, whether one accepts the rural democracy thesis or not, established the foundation for the contemporary democratic system. However, it was the 1948 Civil War, and the political and economic development occurring in its aftermath that most affected contemporary Costa Rican institutions. The Civil War wrested political power from the upper class cafetaleros and placed it in the hands of a growing middle class. With the middle class only able to peripherally tap Costa Rica's traditional coffee and banana wealth, they had to find another system of wealth generation-i.e., they used their new political power to manipulate their democracy and construct the entrepreneurial state composed largely of the network of parastatal AIs. In building their entrepreneurial state, whether out of a sense of Tico brotherhood or the need to co-opt the lower class for electoral support, the new middle class governing elite simultaneously constructed the benefactor (welfare) state.

The Costa Rican governing elite could not have constructed the causal structure in Table 6-2 without some external assistance. This first came in the 1950s and 1960s where Costa Rica borrowed heavily on the international market to finance the construction of both the entrepreneurial and benefactor states. This international financing was also a major source of the benefits received from political corruption behavior. With international financing dwindling after the 1982 world debt crisis, US economic aid during the 1983-1987 period (in return for the Costa Rican anti-Sandinista 
stance) allowed the Costa Rican governing elite to keep their economy and political spoils system running through the 1980s. With US economic aid gone in the post-Cold War 1990s, the Costa Rican governing elite found themselves in a quandary. With a good international credit history, some financing was available from international sources. However, to finance large media-intensive electoral campaigns, the perception of many in Costa Rica is that the governing elite turned to international drug traffickers for support.

Thus, in the post-1948 period, the Costa Rican governing elite constructed a system with two dimensions that result in moderate levels of political corruption. First, they developed institutions that present a minimal amount of elite accountability and maximum access to state-owned resources (via the parastatal AIs), which increase opportunities for political corruption. Second, they hid this opportunity structure for political corruption behind the trappings of a strong democracy. The overall result is a serpentine institutional corruption pattern whereby the governing elite are relatively free to adopt corrupt behaviors, provided they do not cross the threshold that energizes elite and mass condemnation. It is the Costa Rican governing elite that constructed these structures. Thus, it is the Costa Rican elite's manipulation of their democratic structures, and not aspects of the international system, that cause Costa Rica's problems with political corruption.

\section{Endnotes}

1. Some argue that it was not a system of mutual dependence that arose but a case of the large landowners paying off the small farmers and peasants to work on the larger coffee farms. This co-optation of the working and lower classes by the governing elite remains a characteristic of present-day Costa Rica. 
2. The rough content analysis included a literature review, primarily of the Costa Rican press (La Nacion 1998-1999; Tico Times 1998-1999) on political corruption in Costa Rica; author interviews with Costa Rican journalists, politicians, government officials, and academics (see reference list); reviews of the annual reports of the Proyecto Estado de la Nacion $(1995,1996,1997,1998,1999)$ and the Defensoria $(1998,1999)$; the general descriptions of Costa Rican political corruption found in Stone (1990), Biesanz et al. (1999), and Corrales (1999), and data base searches of Info-LatinoAmerica (19882000). There was a high correlation among all these sources concerning the nature of Costa Rican political corruption.

3. Costa Rican scholars have been relatively quiet on the subject of political corruption. This is understandable for two reasons. First, the major universities are government financed and scholarly corruption studies are likely to offend powerful government officials. Second, Ticos by nature are not confrontational and tend to shy away from such acrimonious subjects.

4. Even ex-President and Noble Peace Prize winner Oscar Arias (1986-1990), although highly popular with the Costa Rican populace, plays only a minor player in national politics. In 2000, Arias began a movement to rescind the Constitutional amendment baring the reelection of presidents, arguing that Costa Rican democracy had matured to the point that this check on power was no longer needed. 


\section{Chapter 7}

\section{Conclusion}

This study investigates the complex problem of political corruption in the states and territories of the Caribbean. It argues that we cannot understand the many puzzles about political corruption unless we first have a comprehensive theory of its causes. This study develops an interdisciplinary theory of the causes of political corruption. It then presents a historical survey of Caribbean political corruption and a review of contemporary Caribbean institutional factors theorized to contribute to a state's political corruption problems. Finally, the theory is advanced through qualitative disciplinedconfigurative case studies of political corruption in Jamaica and Costa Rica. The study demonstrates how international factors such as colonialism, neo-imperialism, transnational corporations, foreign businesses, drug trafficking, etc., contribute to the region's political corruption problems. The study concludes, however, that there are more significant domestic factors that cause today's high levels of Caribbean political corruption. Specifically, the major cause of political corruption is Caribbean governing elite who manipulate their society's political and economic institutional development and provide themselves the opportunities to plunder state resources for their own benefit at the expense of their citizenry.

This chapter presents the findings from this study's analysis of Caribbean political corruption. First, it assesses the interdisciplinary theory of the causes of political corruption in light of the Jamaican and Costa Rican case studies. Second, it answers the research questions concerning Caribbean political corruption that were raised in 
Chapter 1. Third, it presents a discussion of the study's location within the larger context of corruption scholarship. Finally, it summarizes the study's key contributions and limitations, and provides an outline for an expanded research program in political corruption.

\section{Assessing the Theory}

Table 7-1 (reprinted from Table 2-4) provides the basis for this study's interdisciplinary theory of the causes of political corruption. Table 7-1's coordinates of political corruption were developed using Onuf's (1989) constructivist analytic frame (Figure 2-1) and theory of social rules (Table 2-1) to link several competing agency and structural explanations for the causes of political corruption. In developing Table 7-1, this study's constructivist analysis demonstrated how agency and structural factors are both important in revealing the causal mechanisms associated with political corruption. Chapter 2's Political Corruption Game analysis demonstrates how a governing elite's behavior (i.e., agent status and corruption patterns) are partially explained through a rational choice (agency) model that includes the causal factors of form of societal rule, political culture, boundaries between public and private, and agent interests. Chapter 2's structural analysis then develops how differing corruption patterns are further explained through the additional causal factors of elite competition, elite accountability, mass participation, and material resource factors. Table 7-1 displays the key agency and structural factors that cause political corruption and characterizes each as to its dominant category of social rules (instruction, directive, or commitment). 
Table 7-1. Coordinates of Political Corruption (reprinted from Table 2-4)

\begin{tabular}{lccc}
\hline Dominant Social Rules & Instruction & Directive & Commitment \\
Rule's Purposes & Principles, beliefs & Specificity, sanctions & Create roles \\
Rule's Function: What agents: & should do & must do & right/duty to do \\
Forms of Societal Rule & Hegemony & Hierarchy & Heteronomy \\
Political Cultures & Collectivist & Individualistic & Egalitarian \\
Elite Competition & Constricted & Oppositional & Corporatist \\
Elite Accountability & Circular & Vertical & Horizontal \\
Mass Participation & Paternalistic & Pluralistic & Cosmopolitan \\
Material Resource Factors & Patrimonial & Statist & Market \\
Public/Private Boundaries & White & Gray & Black \\
Agent Interests & Standing & Security & Wealth \\
Agent Status & Pirates & Pariahs & Paragons \\
Corruption Patterns & Systemic & Institutional & Incidental \\
\hline \multicolumn{1}{c}{ Corruption Index: } & & & \\
\cline { 2 - 2 } & & & 10
\end{tabular}

Table 7-1 is probabilistic and not deterministic. By investigating the characteristics of the Table 7-1 causal factors (form of societal rule, political culture, elite competition, elite accountability, mass participation, material resource factors, and boundaries between public and private), and using vertical and horizontal interpolation, an analyst can estimate the probable conditions of agent status and corruption patterns in the society. Thus, by investigating a society's social-ruled make-up-as is done in the Jamaican and Costa Rican case studies--Table 7-1 provides a vehicle to explain and predict a state's overall corruption levels along the corruption index situated below the table.

The Jamaican and Costa Rican case studies advance the theory of the causes of political corruption derived from Table 7-1 by demonstrating how the structural (socialruled) conditions in these two states closely correlate with the Transparency International 
Corruption Perception Index (TI CPI) rating of each state. The Jamaican case study

supports a hypothesis derived from the theory's first major proposition:

Proposition One: Societies with coordinate of political corruption causal factors (form of societal rule, political culture, elite competition, elite accountability, mass participation, market resource factors, boundaries between public and private) that are dominated by instruction rules, or near equal combinations of instruction and directive rules, will likely experience systemic political corruption patterns ( 3.8 on the TI CPI in Jamaica's case).

The Costa Rican case study supports a hypothesis derived from the theory's second major proposition:

Proposition Two: Societies with coordinate of political corruption causal factors (form of societal rule, political culture, elite competition, elite accountability, mass participation, market resource factors, boundaries between public and private) that are dominated by directive rules, or near equal combinations of directive rules with either instruction or commitment rules, will likely experience institutional political corruption patterns (5.1 on the TI CPI in Costa Rica's case).

This study does not test a hypothesis derived from the theory's third major proposition:

Proposition Three: Societies with coordinate of political corruption causal factors (form of societal rule, political culture, elite competition, elite accountability, mass participation, market resource factors, boundaries between public and private) that are dominated by commitment rules, or near equal combinations of commitment rules and directive rules, will likely experience incidental political corruption patterns.

With only two empirical case studies of this study's theory, and with the lack of hypotheses tests from the theory's third major proposition, we are somewhat limited in our ability to make inferences about the causes of political corruption in states other than Jamaica and Costa Rica. At best, we can make only broad generalizations about how the theory applies to other Caribbean states and territories. Jamaica presents an authoritariandemocratic governing system characterized by a mixed hegemonic-hierarchical form of 
rule. While the social rule mix differs in societies, the structural characteristics related to political corruption found in Jamaica are likely similar to those in other Caribbean states with authoritarian-democratic systems (roughly the bottom two-thirds of the states and territories listed in Table 4-1). Costa Rica, on the other hand, presents a non-authoritarian democratic governing system characterized by a mixed hierarchical-heteronomous form of rule. Again, while social rule mixes differ, the structural characteristics related to political corruption found in Costa Rica are likely similar to those found in the stronger democratic Caribbean states (roughly the top one-third of the states and territories listed in Table 4-1). In the remainder of this chapter, it is assumed that Table 7-1 can be generalized to all states and territories in the Caribbean.

Not contained in the Table 7-1 coordinates of political corruption, but a key factor found in this study's theoretical and case study analyses, is the important domestic agency role of a society's governing elite in constructing its structural characteristics. A key constructivist tenet is that agents (people) create institutions (structure). Additionally, constructivism offers that the social rules that make up institutions are constantly changing. These constructivist tenets were particularly evident in the case studies of Jamaica and Costa Rica, where, in both cases, the governing elite constructed structures that resulted in increased levels of political corruption. Just after its 1962 independence - with generally honest political leaders and a British-trained civil service embracing moderate to strong boundaries between public duties and private dutiesJamaica experienced political corruption levels between the institutional and incidental corruption patterns in Table 7-1 (likely 6.5 to 7.5 on the corruption index). However, as 
Chapter 5 reveals, over the next 30 years the Jamaican governing elite corrupted the British-provided Westminster system and built an institutional structure resulting in today's systemic corruption patterns. Costa Rica experienced its lowest levels of political corruption in the 1950s, the period just after its 1948 Civil War when the government was implementing a new constitution containing several anti-corruption measures. However, as Chapter 6 reveals, by the 1970s, the Costa Rican governing elite had molded the institutional structures surrounding their entrepreneurial state, thus manipulating their democratic structures so as to allow them substantial opportunities for influence peddling and rent seeking. Therefore, although Table 7-1 appears to emphasize the importance of structural factors as the causes of political corruption, we must not forget the key agency role of a society's governing elite in building these structures. This study concludes that this domestic role of the governing elite is the major cause of today's Caribbean political corruption problems.

A significant contribution of this study's theory is its ability to deal with the cultural relativity problem in political corruption studies. This study takes Heidenheimer's $(1970,1989)$ linkage of differing political cultures to varying boundaries between public duties and private interests (see Table 2-2), and situates them among the larger Table 7-1 structural factors that cause political corruption. Societies with collectivist political cultures and white (weak) boundaries between public and private have significantly different views of political corruption than societies with egalitarian political cultures and black (strong) boundaries. However, the fact that most of the world's states, including all those in the Caribbean, have signed international or regional 
agreements accepting Western (black) boundaries as an international or regional standard, allows us to make normative assessments about societal corruption patterns. It is recognized, as Heidenheimer highlights, that societies with collectivist political cultures may not condemn their governing elite's corrupt behavior. However, the international community-using Western (black) standards—-will still assess collectivist societies with white (weak) boundaries between public and private as having systemic corruption patterns.

A major challenge to this study's theory development was to include all the relevant variables (agency and structural causal factors) that contribute to differing political corruption levels. Johnston's (1994) comparative theory of political corruption was of significant help in this endeavor as he identified elite competition, elite accountability, mass participation, material resource factors, and boundaries between public and private as key causal variables. This study builds on Johnston's analysis by expanding the conceptualization of these variables and by placing them into the larger Table 7-1 structure of the causes of political corruption. The use of the constructivist analytic frame allowed the linkage of Heidenheimer and Johnston's works, along with the works of numerous other corruption theorists, resulting in the Table 7-1 coordinates that include the major causes of political corruption. The constructivist analytic frame also allowed the identification of specific causal mechanisms, i.e., the social rules that explain the political corruption phenomenon.

A measure of this study's usefulness concerns how well it develops causal mechanisms that can contribute to anti-corruption policy development. The real test is 
whether this study's theory improves upon the policy relevance of Klitgaard's (1988) stylized formula $(C=M+D-A)$ that is used worldwide as the framework for developing anti-corruption programs like the 1996 Organization of American States (OAS) Inter-American Convention Against Corruption. This study contributes to anticorruption policy development in two primary ways.

First, this study's analysis reveals that to reduce political corruption a society must change its Table 7-1 social-ruled structure. Specifically, constructing commitment rules is the key causal mechanism leading to incidental corruption patterns. This finding is in consonance with the theory's third major proposition reprinted above. To reduce political corruption, a society must build commitment rules in the key areas of form of societal rule, political culture, elite competition, elite accountability, mass participation, market resource factors, and boundaries between public and private. Table 7-2 summarizes the middle-level structural (causal) factors developed in Chapter 2 that must be the target of anti-corruption commitment rule development. 
Table 7-2. Summary of Political Corruption Structural Factors

\begin{tabular}{|c|c|}
\hline $\begin{array}{l}\text { Structural Factors for Anti-Corruption } \\
\text { Commitment Rule Development }\end{array}$ & $\begin{array}{l}\text { Ideal Commitment-Ruled } \\
\text { Anti-Corruption Conditions }\end{array}$ \\
\hline Form of Societal Rule & Heteronomy \\
\hline Political Culture & Egalitarian \\
\hline $\begin{array}{l}\text { Elite Competition } \\
\text { Elite Mobility } \\
\text { Electoral Freedom and Fairness } \\
\text { Election Finance Sources } \\
\text { Elite Consensus } \\
\end{array}$ & Corporatist \\
\hline $\begin{array}{l}\text { Elite Accountability } \\
\text { Answerability Factors: } \\
\text { Freedom of the Press } \\
\text { Freedom of Information } \\
\text { Public Access to Governing Elite } \\
\text { Enforcement Factors: } \\
\text { Administrative Transparency/Efficiency } \\
\text { Election Efficiency (Can We Throw the Crooks Out?) } \\
\text { Criminal Justice System Efficiency } \\
\text { Sovereignty/Political Asylum } \\
\end{array}$ & Horizontal \\
\hline $\begin{array}{l}\text { Mass Participation } \\
\text { Civil Liberties/Human Rights Status } \\
\text { Civil Society Organization/Strength } \\
\text { Levels of Social Trust }\end{array}$ & Cosmopolitan \\
\hline $\begin{array}{l}\text { Material Resource Factors } \\
\text { Routine Factors: } \\
\text { External Trade/Economic Management } \\
\text { Domestic Economic/Business Management } \\
\text { State-Owned Resource Management } \\
\text { Extraordinary Factors: } \\
\text { International Aid/Finance } \\
\text { Neoliberal Reform (privatizations, etc.) } \\
\text { Organized Crime (drug traffickers, etc.) } \\
\end{array}$ & Market \\
\hline $\begin{array}{l}\text { Boundaries Between Public and Private } \\
\text { Anti-Corruption Laws and Regulations (focused on the Table 2-2 } \\
\text { governing elite political corruption behaviors) } \\
\text { Elite and Mass Citizenry Views of Corruption }\end{array}$ & Black (Strong) \\
\hline
\end{tabular}

Building anti-corruption commitment rules in the Table 7-2 structural factors is the key to reducing political corruption, but doing so presents significant challenges. ${ }^{1}$

While commitment rules creating roles and establishing rights and duties can be

legislated or implemented by regulation, more often commitment rules are built over time through the formal and informal interactions of agents (elite and masses) who see that, 
once established, the intended roles, rights, and duties will be honored. A first step in building stable commitment rules is usually to implement a strong system of directive rules and their corresponding sanctions. To reduce political corruption, this means establishing directive rules and their associated sanctions in the key Table 7-2 areas. Strengthening anti-corruption directive rules, i.e., increasing the frequency a governing elite follows the directive rules, allows a society to build stable anti-corruption duties and rights that constitute commitment rules. Within a robust directive-ruled structure, anticorruption commitment rules will not only develop and become stronger, but will also increase in formality, i.e., they will assume a status and importance of their own. This process of building commitment rules takes time and is far from easy.

To construct effective anti-corruption commitment rules, a society must first have the political will and political capacity to establish a full range of anti-corruption directive rules and their associated sanctions. Political will concerns the society's (elite and/or citizenry's) acceptance of the Western (black) standards of boundaries between public and private and their willingness to take action to change conditions not congruent with these Western (black) standards. Political capacity concerns the ability of a society to follow through on their political will and fully implement a comprehensive array of anticorruption directive rules, including the enforcement of directive-ruled sanctions when members of the governing elite do not follow these rules. Additionally, over time, a society must evolve to where the incentive for the governing elite to follow the anticorruption directive rules is not just based on the threat of directive-ruled sanctions, but where following the rules becomes the moral commitment (duty) of the governing elite. 
Simultaneously, over time, a society's citizenry assumes it is their right to be represented by an honest governing elite. The difficulty in building commitment rules explains why this process takes significant time.

Second, this study contributes to anti-corruption policy development by highlighting that the process of building anti-corruption commitment rules has both technical and social aspects. Technical aspects include the implementation and enforcement of anti-corruption directive rules and their corresponding sanctions. Intergovernmental organizations (IGOs) and nongovernmental organizations (NGOs) have focused the bulk of their anti-corruption efforts in technical areas. In developing states, IGOs and NGOs have made major efforts to establish anti-corruption legislation; initiate transparency in government budgeting, accounting, and contract administration; reform state criminal justice systems; advance freedom of the press and freedom of information; and strengthen other aspects of the Table 7-2 structural factors associated with elite competition, elite accountability, and boundaries between public and private. The 1996 OAS Inter-American Convention Against Corruption is constructed largely of such technical anti-corruption measures. This study's theory of the causes of political corruption reveals that technical anti-corruption measures are necessary to reduce political corruption levels, however, they are not sufficient. Also needed are social measures that address issues of social trust-primarily those pertaining to improving the levels of a society's mass participation.

Mass participation leading to high levels of social trust includes citizen freedom to organize into a number of political, economic, and social interest groups; to foster 
frequent horizontal communications among societal groups and the government; and to generate an atmosphere of social trust among individual citizens, their state institutions, and the ruling government. While a government cannot legislate social trust, it can establish a societal framework (i.e., in accordance with Table 7-2's structure) that allows social trust to emerge. By not including social measures that build social trust in anticorruption programs, policy makers undermine efforts to build anti-corruption commitment rules. The need to include social measures in anti-corruption programs is a major finding of this study and helps explain why IGO and NGO anti-corruption programs that do not address social measures have experienced only limited success.

While not in the Caribbean, Singapore and Hong Kong present two cases that appear to contradict the above finding that successful anti-corruption programs must include both technical and social anti-corruption measures. Singapore and Hong Kong, both small city-states with a history of British colonialism, emerged from World War II with serious corruption problems. By different routes, both generated the political will and political capacity to address their corruption problems. In Singapore, it was enlightened despotism, i.e., leaders ascending to power in the late 1950 s and early 1960 s that were committed to honest government who sparked their anti-corruption efforts (Girling, 1997, p. 170). In Hong Kong, it was a 1973 corruption scandal surrounding the police superintendent that coalesced societal anti-corruption support (Johnston, 1999, p. 221). In both Singapore and Hong Kong, autonomous government anti-corruption agencies took the lead in implementing and enforcing a wide array of anti-corruption directive rules and their associated sanctions. By the $1990 \mathrm{~s}$, the construction of stable 
anti-corruption directive-ruled and commitment-ruled institutions led to Singapore and Hong Kong being rated two of the least corrupt states in the annual Transparency International Corruption Perception Indexes. ${ }^{2}$

With both Singapore and Hong Kong exhibiting authoritarian governing structures--structures that normally engender little social trust - they appear to contradict the need for anti-corruption social measures. However, looking deeper at the conditions surrounding Singapore and Hong Kong's corruption reforms, it can be seen that social measures played a major role in their successes. Despite their authoritarian governing structures, both Singapore and Hong Kong exhibit political cultures with individualistic (self-interested) and egalitarian (public good) values that led both to accept the Western (black) standards for boundaries between public and private interests. Both states developed strong political (authoritarian) and economic institutional structures with stable and well-defined duties and rights for both the governing elite and masses. Both states also developed strong market economies resulting in high per capita income levels (Weder \& Brunetti, 1999). Both states also included programs for public participation in the development and enforcement of anti-corruption rules. These conditions combined to provide a framework that produced moderate to high levels of social trust in both Singapore and Hong Kong. Thus, both states adopted not only the technical measures but also the social measures required for their anti-corruption programs to be successful.

Singapore and Hong Kong went beyond Klitgaard's (1988) stylized formula (C = $\mathrm{M}+\mathrm{D}-\mathrm{A}$ ) in arresting their corruption problems. They both adopted comprehensive anti-corruption programs that took into account most of the technical and social measures 
developed in this study's theory. This study's theory includes the monopoly (M), discretion (D), and accountability (A), components of Klitgaard's formula in its Table 7-2 structure. Additionally, it addresses causal factors associated with forms of societal rule, political culture, elite competition, and mass participation that Klitgaard's work excludes. The major difference between this study's theory and Klitgaard's, however, is that his theory addresses only technical measures associated with the causes of political corruption. By identifying the social measures that must be included in anti-corruption programs, this study's theory is potentially more policy relevant than Klitgaard's.

\section{Answering the Political Corruption Questions}

A first test of this study's policy relevance is to use the theory of the causes of political corruption and this study's analysis to answer several questions concerning Caribbean political corruption that were raised in Chapter 1. Are the causes of Caribbean political corruption primarily international as many Caribbean leaders argue? Do neoliberal economic and good governance reforms increase opportunities for Caribbean political corruption? Are there deeper domestic or international factors that cause political corruption? What contributes to the lack of political will and/or political capacity that undermines Caribbean interest in anti-corruption reforms? These questions capture the main contemporary issues in Caribbean corruption reform.

Are the Causes Primarily International? This study's theoretical and historical analyses demonstrate that a variety of past and present international factors contribute to contemporary Caribbean political corruption problems. To review briefly the key points 
presented in Chapters 3 and 4, the period of European colonialism helped established the foundation for many contemporary Caribbean institutions. The legacy of caudillo or strongman rule in the former Spanish colonies and Haiti, and the British oligarchic local assembly and one-man (governor) Crown Colony governing systems, remains evident in the contemporary authoritarian-democratic governing systems in many Caribbean states. Despite almost 200 years of independence in some of the former Spanish colonies and Haiti, the region has not been able to overcome these authoritarian governing tendencies that are usually accompanied by weak political institutions and high levels of political corruption. Nineteenth and early twentieth century US interventions in Cuba, the Dominican Republic, Haiti, and Nicaragua did little to lessen those states' corruption problems. Despite US intentions to restore stability and implement government efficiency in those states, the US actions played directly into the hands of later authoritarian rulers that used the US-provided security forces and bureaucratic structures to seize power and misuse state resources for their private interests.

The US interventions were only the first US contribution to contemporary Caribbean political corruption problems. Franklin D. Roosevelt's S.O.B. policy, "He may be an S.O.B., but he is our S.O.B," ensured corrupt Caribbean rulers that after the 1930s the US would not intervene in regional states as long as they remained anti-Fascist (and later anti-Communist). By the 1940s, new international rules concerning sovereignty and non-intervention strengthened Roosevelt's S.O.B. policy as they kept the international community from looking closely at illicit internal behaviors in Caribbean states. The new rules concerning sovereignty and non-intervention were reinforced by the 
Western and Soviet Cold War competition for spheres of influence that further allowed political corruption activity in Caribbean states to be ignored in the name of larger political objectives.

Additionally, many of the resources supporting post-World War II Caribbean political corruption came from international sources. This includes routine material resources associated with transnational corporations and foreign businesses that regularly bribe Caribbean government officials to obtain preferences in government contracts and access to foreign markets. It includes extraordinary material resources provided by international banks and international aid organizations, much of which were tied to a state's Cold War allegiance in the Western and Soviet competition. It also includes the extraordinary material resources now being provided to some Caribbean governing elite to help facilitate the international drug trade and its associated activities of arms smuggling and money laundering.

From a populist Caribbean viewpoint, this study supports Caribbean leaders' accusations that the international community not only provided the basis for contemporary Caribbean corrupt institutions (i.e., facilitated the corrupt institutional (rule) development) but also largely funded the corruption through their transnational corporations, foreign businesses, international loans, or international aid. However, as seen in the evidence provided by the Jamaican and Costa Rican case studies, these international factors, while contributing to contemporary Caribbean political corruption problems, are overshadowed by a more significant domestic cause-i.e., the region's selfindulgent governing elite who manipulate their society's political and economic 
institutional development to plunder state resources for their own benefit at the expense of their citizenry.

Do Neoliberal and Good Governance Reforms Cause Corruption? This study offers that instituting market material resource systems should lessen a society's political corruption levels. In the Caribbean, instituting market systems includes the adoption of neoliberal economic reforms which include measures to privatize state-owned enterprises, remove external trade barriers, open a state's economy to international competition, increase foreign direct investment, allow the entry of multinational corporations, and institute a plethora of other reforms focused on reducing the state's role in the economy and increasing the overall economic output. Despite such actions, most Caribbean neoliberal reforms have been accompanied by increased political corruption.

The issue of privatization, the total or partial sale of state-owned enterprises to private entities, provides a good example to explain why Caribbean neoliberal reforms have generated increased political corruption. This study presents privatization activities as a source of extraordinary resources. This is due to the large dollar values in most privatizations. In most developing states, privatization processes are carried out in institutional structures that are already corrupt-i.e., where new directive rules are usually not issued to manage the privatization process. According to Johnston's (1986) costbenefit analysis presented in Chapter 2, the effects of placing large amounts of extraordinary resources into an already corrupt governing system are disintegrative and tend to make the system unstable. In such situations, a governing elite displays a greater willingness toward corrupt behavior because of the potential high payoffs from the 
misuse of the extraordinary resources. In states with existing systemic or institutional corruption patterns, extraordinary stakes from privatization processes tend to strengthen the existing instruction and directive rules causing political corruption while also destroying any anti-corruption commitment rules that may have existed. Therefore, this study's theory offers that it is not neoliberal reforms, like privatization efforts, that cause increasing Caribbean political corruption, but the fact the neoliberal reforms are being carried out in already corrupt systems.

The problem with good governance reforms is related. All reforms, whether neoliberal economic reforms or good governance reforms, change existing social-ruled structures. Reforms are usually accompanied by the issuance of new instruction and directive rules. Reforms may also include the destruction of old commitment rules, however weak, that established societal duties and rights. Rule changes, of whatever form, are contentious issues in most societies. Until new commitment rules emerge from the reform process, political animosity between competing groups may arise and it may become difficult to foster societal cooperation. Where public disagreement on important issues occurs, it can quickly be replaced by political corruption (see Huntington, 1968, p. 64). Therefore, this study's theory would explain that it is normal, on a short-term basis, to see political corruption problems worsen after neoliberal economic or good governance reforms.

The utility of establishing a new directive-ruled structure to accompany neoliberal economic reforms can be seen in Panama's attempts to privatize its state-owned telephone company. In 1996, Panama, which experiences serious problems with systemic 
corruption (see Table 4-1), decided to sell 49 percent of its state-owned telephone company, Intel S.A. In the Intel S.A. privatization process the Panamanian government desired to eliminate corruption accusations by creating a special Privatization Board to manage the sale. The Intel S.A. privatization process included outside (nongovernmental) technical and commercial advisers and close monitoring by the Panama chapter of Transparency International which wrote weekly newspaper bulletins explaining the status of the process to the public. In the end, it was deemed by all parties that the Intel S.A. privatization process was fair and transparent and no claims of corruption emerged (Transparency International, 1999b). The use of autonomous privatization agencies established within strict directive-ruled frameworks, as was done in the Panamanian Intel S.A. privatization, is not normal in the Caribbean.

\section{Are There Deeper Domestic and International Causal Factors? This study reveals} the complex domestic and international factors associated with the causes of Caribbean political corruption. Tables 7-1 and 7-2 delineate the complex array of domestic and international factors that contribute to a society's levels of political corruption. While accepting the role of the key international factors discussed above in causing Caribbean political corruption, this study concludes that they are far from the most important cause. Again it is important to point out that this study's analysis finds that the major cause of Caribbean political corruption is domestic governing elite who manipulate their society's political and economic development to plunder state resources for their own benefit at the expense of their citizenry. The Jamaican and Costa Rican case studies both support this conclusion. 
At key times in the post-World War II period, Caribbean governing elite faced opportunities to either strengthen non-corrupt institutions or to reform corrupt institutions and provide for more transparent and honest government. In Jamaica, this opportunity arose in the period just after their 1962 independence when the governing elite could have strengthened, rather than corrupted, the Westminster system. In Costa Rica, this opportunity was after the 1948 Civil War, but instead the governing elite manipulated their new democratic structures for their own self-interested purposes. Other Caribbean states and territories had similar opportunities to reform their governing systems. However, like Jamaica and Costa Rica, Chapter 4's analysis supports the argument that Caribbean governing elite normally chose to manipulate the construction of their political and economic institutions for their own self-interest. The main responsibility of Caribbean governing elite in causing their political corruption problems is a topic seldom discussed in international anti-corruption forums.

Why the Lack of Caribbean Corruption Reform? Caribbean states have been unable to muster the political will or political capacity to implement anti-corruption reforms, including ratification of and compliance with the 1996 OAS Inter-American Convention Against Corruption. This lack of compliance is largely explained by elite competition factors concerning the threat anti-corruption reforms present to the Caribbean's selfinterested governing elite. Geddes $(1991,1994)$ and Peters (1992) found that the primary motivation of Caribbean politicians was staying in office (see Chapter 4). The implementation of corruption reforms would significantly undermine the processes (e.g., 
political patronage and other corrupt behavior) that Caribbean governing elite use to collect the resources they need to support their electoral campaigns.

This study's theory predicts that Caribbean governing elite will not support corruption reform programs because such reforms undermine their power base by changing the methods by which the elite gather resources to gain or retain office. Caribbean leaders are usually quick to embrace anti-corruption platforms in international forums, where the issue of their immediate standing (reputation) among other regional or international leaders is their primary interest. However, when faced with the domestic political realities of implementing the anti-corruption measures, their reform willingness quickly wanes. Their motivation to implement corruption reforms subsides because in domestic issues their primary interest is not standing, as in international forums, but security, i.e., ensuring their job security-their ability to gain and retain political power.

The lack of political will to implement real corruption reforms does not keep the Caribbean governing elite from taking weaker anti-corruption actions. For example, in 1999, the Jamaican cabinet attempted to force a Corruption Bill through the Parliament. The Jamaican cabinet justified the bill as one needed to comply with the 1996 OAS InterAmerican Convention Against Corruption. In actuality, the bill did little to comply with the elements of the 1996 OAS Convention, but instead focused on controlling corruption among mid- and low-level employees in the Jamaican government bureaucracy (see Munroe, 1999a). The bill also caused a media and public outcry when it attempted to restrict press reporting on government corruption cases. Thus, the Jamaican Corruption Bill did not restrict the governing elite's opportunities for corrupt behavior, but did 
attempt to limit the press's ability to investigate and report such behavior. ${ }^{3}$ Similar cosmetic attempts to comply with the 1996 OAS Convention may be expected from other Caribbean states with authoritarian-democratic systems that see real corruption reform measures as threats to their power structures. Even non-authoritarian democratic states in the Caribbean, like Costa Rica, will likely be slow in complying with the 1996 OAS Convention as to do so would place significant restraints on governing elite behavior.

\section{Situating the Study Within a Larger Context}

The interdisciplinary theory of the causes of political corruption developed in this study might seem to fit best in the no longer fashionable modernization school. As a society's institutions progress from the left to the right of Table 7-1, it is assumed that a modernization process takes place. This study's results differ from other modernization school approaches in two significant areas. First, this study goes beyond the limited macro-level conceptual development of most modernization analyses and identifies the middle-level causal mechanisms (social rules) that allow the design of anti-corruption programs. Second, while this study supports the tenet that political and economic modernization generally results in less political corruption, it also highlights the mechanisms that limit certain societies from reaching the Table 7-1 ideal of incidental corruption patterns.

This study develops that modernization processes related to a society's political corruption levels are far from linear and may even be somewhat disconnected from other political, economic, and cultural modernization processes underway in the society. ${ }^{4}$

While most analysts would agree that both Jamaica and Costa Rica underwent political 
and economic modernization in the last half of the twentieth century, their case studies reveal that during the same period both state's political corruption levels actually increased-a move from the right to the left on Table 7-1's corruption index indicating a de-modernization process occurred. Why Caribbean states have been unable to reduce political corruption levels, and are unable to modernize further than they have, can be largely understood by looking closer at a state's political culture--thus also situating this study among the structuralist-culturalist corruption literature (see Chapter 1).

This study highlights the importance of political culture in explaining differing levels of political corruption. Reforming a state's political culture is an area seldom addressed in domestic or international forums. One reason for political culture's neglect as an explanatory variable is that there is little agreement as to how political culture fits into social science causal models. Some scholars do use political culture as a principal independent variable to explain social behavior in developing states (see Huntington, 1968; Scott, 1972; Putnam, 1993). Others question the usefulness of political culture as an explanatory variable or cluster of variables. For example, Johnson (1997a, 1997b) offers that culture should not be used as an explanatory variable but be seen as a hiddenhand-like mechanism that helps govern the outcome of rational choice models.

Within the constructivist framework employed in this study, political culture is included as another sub-set of rules - a sub-set that is closely associated with a society's form of rule and which influences the rules developed in other Table 7-1 agency and structural factors. This study defines political culture as the general process used by a society to reach its political goals (i.e., decisions about who gets what, when, and how, 
(see Lasswell, 1950)). Categorizing the rule-sets in specific political cultures requires an investigation of how a society is politically organized, both formally and informally; how political decisions are made; how political power flows within the societal organization; how both the governing elite and the citizenry view their roles in politics; and how citizens interact, both with the government and among themselves, to reach their political goals (see Diamond, 1993).

Booth and Seligson (1993) raise the argument that Latin America may not be a place for political modernization because the local cultures are so antithetical to liberaldemocratic values. The analysis in this study supports this somewhat controversial argument. Most Latin American and Caribbean states exhibit collectivist or mixed collectivist-individualistic political cultures. Collectivist political cultures are organized around social groups and are extremely paternalistic-always looking to the group leader for resources or solutions to problems. In collectivist cultures, the good of the group prevails over the good of individuals or the greater society. Collectivist political cultures can act like an anchor that keeps societies from developing the directive and commitment rules needed in market-oriented and liberal-democratic states. This study in fact demonstrates how collectivist and mixed collectivist-individualistic political cultures are associated with hegemonic or mixed hegemonic-hierarchical forms of rule and provide conditions for spawning authoritarian-democratic and not liberal-democratic governing systems. In most of Latin America and the Caribbean the success of implementing neoliberal market and liberal-democratic reforms is thus directly related to the success of transforming a state's collectivist political culture. Changing the social rules of a 
collectivist political cultures, some steeped in hundreds of years of strongman or oligarchic rule, is not an easy task.

Political culture has a similar anchoring effect on implementing corruption reforms. As long as Caribbean states exhibit collectivist political cultures, they are unlikely to develop strong institutions with effective anti-corruption directive and commitment rules. Without effective anti-corruption directive and commitment rules, it is unlikely that Caribbean corruption reform will ever be successful.

\section{Key Contributions, Limitations, and Directions for Future Research}

This study has made several key contributions. First, this study's findings have significant relevance for policy makers working to reduce Caribbean political corruption. Tables 7-1 and 7-2 identify the many complex factors that must be considered in developing anti-corruption policy. This study's theory, summarized in these tables, has the potential to answer a broad array of questions about political corruption. Second, this study's ability to develop a comprehensive interdisciplinary theory of the causes of political corruption, one that includes both important agency and structural factors, is a useful contribution to overall corruption scholarship. Third, this study demonstrates the utility of Onuf's (1989) constructivist analytic frame for building social theory. While many scholars contribute concepts to the theory of the causes of political corruption built in this study, it was Onuf's constructivism that allowed the linkage of these concepts from several different academic disciplines and theoretical approaches.

Like most other modernization approaches to political corruption, this study's contribution is limited by its lack of empirical support. This study is just the initial step 
in a larger research program in political corruption. In order to make more general inferences about the causes of political corruption and to uncover more puzzles about the political corruption phenomenon, a next step is to conduct additional qualitative disciplined-configurative case studies of political corruption in Caribbean states and territories. Barbados is the leading candidate for a next case study as it is the Caribbean state with the best conditions to study society's with incidental corruption patterns (see Table 4-1), thus allowing a first test of hypotheses resulting from this study's third major proposition. After several additional qualitative disciplined-configurative case studies, comparative methodology could be employed among the case studies to uncover additional insights about the causes of political corruption in the Caribbean (see Ragin, 1987, 2000). Additionally, a quantitative (statistical) test is required of all Caribbean states and territories to reveal the true impact of Table 7-1 structural factors on variances in corruption patterns.

A quantitative test of this study's theory requires greater precision in the measurement of the Table 7-1 structural factors (variables). A first challenge is to develop a better measurement for political corruption. While the Transparency International Corruption Perception Index is an accepted comparative measure of corruption, it includes only corruption related to a state's foreign business transactions. The Transparency International ratings also do not contain all Caribbean states and territories (see Table 4-1). Table 2-2 provides the framework for developing an index of political corruption based upon the incidence and evaluation of the full range of political corruption behaviors found in a society. 
Other structural factors in Table 7-1 must also be operationalized and measured. Good measures must be developed for the range of behaviors associated with each factor in the table. Some of these measures may constitute only nominal measurements, e.g., form of rule. Others may be measured on an interval continuum, e.g., an index of the level of elite accountability. Others may require the employment of proxy variables. For example, Chapter 2 develops how a society's level of social trust is a good proxy variable for its level of mass participation. Only through a valid quantitative test of this study's theory of the causes of political corruption can we determine the weighted effects of each Table 7-1 factor on a society's level of political corruption. This then allows revisions to the theory and provides for even more informed policy guidance to Caribbean anticorruption programs.

Finally, this study's theory of the causes of political corruption requires extension to other societies. This study's unit of analysis was the Caribbean state or territory. It is likely, however, that this study's theory is equally applicable to the investigation of political corruption in other Caribbean polities (cities, provinces, etc.) that have an identifiable governing elite (50-100 persons minimum). Because of similar historical experiences and political, economic, and cultural institutions, the theory should be easily adaptable to investigating the causes of political corruption in all Western Hemispheric polities. Moreover, because of the diverse Caribbean structures used in developing this study's theory, it should be useable, with only minor modifications, to the study of political corruption throughout the world. 
This study demonstrates the extreme complexity encountered in analyzing political corruption. It develops a comprehensive theory of the causes of Caribbean political corruption. It then uses the theory to answer the most important contemporary questions about political corruption in the region. The expanded research program in political corruption described above is required to give the theory, and the answers to contemporary and future questions about political corruption, more precision and policy relevance. A vigorous focus on Caribbean political corruption would hopefully help to improve the lives of citizens across the region. As this study reveals, however, the success of future Caribbean anti-corruption programs is dependent on including social measures to improve mass participation and foster social trust-areas largely ignored by past policy-makers. Political corruption can be arrested, but as this study demonstrates, it requires a combination of political will and political capacity that have so far eluded most Caribbean states and territories.

\section{Endnotes}

1. Onuf (1989) does not provide a discussion on how to build commitment rules. The process for developing commitment rules provided in this chapter was developed after numerous discussions with Dr. Onuf on the subject.

2. 1999 Transparency International Corruption Perception Index ratings: Singapore -9.1 and Hong Kong -7.7 , on a scale of 1 (totally corrupt) to 10 (no corruption). Singapore and Hong Kong were also selected as examples as these polities experienced the most success with anti-corruption programs over the last half of the twentieth century.

3. Media and public outcry over the proposed Corruption Bill forced its tabling by the Jamaican Parliament in late 1999. By mid-2000 the bill had not been reintroduced.

4. This study does not assume that the Table 7-1 structural factors move in unison from the right to left in the modernization process. In fact, as the Jamaican and Costa Rican case studies reveal, each individual Table 7-1 structural factor develops its own specific 
institutional (social-ruled) characteristics. However, as this study also demonstrates, the Table 7-1 structural factors are influenced and limited by other structural factors, including the society's form of rule and political culture. 


\section{List of References}

\section{Interviews}

Arevalo, O. (1999). Attorney and Vice-Director of the Costa Rican National Commission for the Improvement of the Administration of Justice (CONAMAJ), San Jose, CR, October 28, 1999.

Aub, B. \& Aub, M. (1999a). Members of Jamaicans for Justice and the Jamaica Chapter of Transparency International, Plantation, FL, June 11, 1999. Ms. B. Aub is also a freelance journalist and former columnist for the Daily Gleaner. Dr. M. Aub is also a Mathematics Professor at the University of the West Indies-Mona.

Aub, B. \& Aub, M. (1999b). Kingston, JM, November 19, 1999.

Boxill, I. (1999). Sociology Professor at the University of the West Indies-Mona, Mona, JM, November 12, 1999.

Carazo, M. (1999). Private Attorney and President of the Costa Rican Chapter of Transparency International, San Jose, CR, October 28, 1999. Mr. Carazo is also a former Deputy in the Costa Rican Congress.

Cargill, M. (1999). Longtime Jamaican journalist and columnist for the Daily Gleaner, Kingston, JM, November 10, 1999.

Chevarria, M. (1999). US Drug Enforcement Administration Agent, US Embassy, San Jose, CR, October 27, 1999.

Chuck, D. (1999). Private Attorney and Member of the Jamaican House of Representatives from the Jamaican Labor Party (JLP), Kingston, JM, November, 15, 1999. Mr. Chuck is also the JLP Shadow Minister for National Security and Justice.

Denton, C. (1999). Director of CID-Gallup, San Jose, CR, October 25, 1999.

Esquivel Faerron, M. (1999). Deputy Director of La Defensoria de los Habitantes (Ombudsman), San Jose, CR, October 27, 1999.

Golding, B. (1999). President of the Jamaican National Democratic Movement, Kingston, JM, November 10, 1999. Mr. Golding is also a former Vice-President of the Jamaica Labor Party (JLP) and a former JLP member of the Jamaican House of Representatives. 
Guitierrez Espeleta, E. (1999). Director of the Observatory of Development, University of Costa Rica, San Jose, CR, October 26, 1999.

Hidalgo Cuadra, R. (1999). Vice-Director, Directorate of Judicial Matters, ControllerGeneral of the Republic of Costa Rica, San Jose, CR, October 28, 1999.

Munroe, T. (1999). Political Science Professor at the University of the West Indies-Mona, Mona, JM, November 17, 1999. Dr. Munroe is also an Independent Senator, Jamaican Senate and President of the University and Allied Workers' Union.

Perkins, W. "Mutty." (1999). Host of talk radio show Perkins On-Line, Kingston, JM, November 15, 1999.

Pratt, C. (1999). Political and Social Reporter at the Tico Times, San Jose, CR, October 22, 1999.

Reape, J. (1999.). US Drug Enforcement Administration Country Attaché, US Embassy, Kingston, JM, November 15, 1999.

Solis, L. (1999a). Senior Research Fellow (Visiting), Latin American And Caribbean Center, Florida International University, Miami, FL, April 14, 1999.

Solis, L. (1999b). Political Science Professor at the University of Costa Rica and Director of the Foreign Service Foundation for Peace and Democracy (FUNPADEM), San Jose, CR, October 18-29, 1999.

Vargas Cullel, J. (1999). Political Science Professor and Political Consultant Proyecto Estado de la Nacion, San Jose, CR, October 26, 1999.

Vega Miranda, H. (1999). Private Attorney and President of the Costa Rican National Commission for the Rescue and Formation of Moral, Civic, and Religious Values, San Jose, CR, October 22, 1999.

Webster, G. (1999). Political Officer, US Embassy, San Jose, CR, October 27, 1999. Mr. Webster is also the former US Consul General in Costa Rica.

Wesberry, J. (1999). Certified Public Accountant and Director of the US Agency for International Development's Proyecto Respondabilidad/Anti-Corrupcion, Casals and Associates, Crystal City, VA, February 15, 1999.

Zoido-Lobaton, P. (1999). World Bank Institute for Governance, Regulation, and Finance, Washington DC, February 22, 1999. 


\section{Newspapers and Periodicals}

Caribbean Insight. (1995-1999).

Central America Report. (1996-1999). Internet edition available at: http://www.worldcom.nl/CAR/.

Daily Gleaner (Jamaica). (1998-1999). Internet edition available at: http://www.gojamaica.com.

Jamaica Observer. (1998-1999). Internet edition available at: http://www.jamaicaobserver.com.

La Nacion (Costa Rica). (1998-1999). Internet edition available at: http://nacion.co.cr.

Tico Times (Costa Rica). (1998-1999). Internet edition available at: http://ticotimes.co.cr.

\section{Articles, Books, and Other Materials}

Adler, E. (1997). Seizing the Middle Ground: Constructivism in World Politics. European Journal of International Relations, 3(3), 319-363.

Alatas, S. H. (1990). Corruption: Its Nature, Causes and Functions. Aldershot, UK: Gower Publishing Company Limited.

Almond, G. A., \& Verba, S. (1963). The Civic Culture. Boston, MA: Little, Brown and Company.

Andreski, S. (1966). Parasitism and Subversion, The Case of Latin America. New York, NY: Pantheon Books.

Araya Calvo, J., Chen Shean, J., Quiros Ramirez, M., Sibaya Castro, P., \& Zuniga M., S. E. (1982). Corrupcion Politica. San Jose, CR: Universidad de Costa Rica, Escuela de Estudios Generales.

Araya, R. (1991). Vino Nuevo en Odres Nuevos. San Jose, CR: Editorial Universidad Estatal a Distancia (Open University).

Arias Foundation. (2000). Ceiba. San Jose, CR: Arias Foundation.

Arias Sanchez, O. (1976). Quien Gobierna en Costa Rica? Un estudio de liderazgo formal en Costa Rica. Ciudad Universataria "Rodrigo Facio," Costa Rica: Editorial Universitaria Centroamericana. 
Aristotle. (1943). Politics. In L. R. Loomis (Ed.), One Man in the Universe. New York, NY: Walter J. Black.

Aub, B. (1993, May 17). Our own, our native land. Daily Gleaner, pp. 6, 35.

Aub, B. (2000). Covering Corruption in Jamaica. Presentation before the eighteenth annual Journalists and Editors Workshop on Latin America \& the Caribbean, Florida International University, Latin American and Caribbean Center, Miami, Fl, May 5, 2000.

Aub, M. \& Aub, B. (Eds.). (1994). The Layperson's Version of the 1962 Constitution of Jamaica. Kingston, JM: Martin Aub and Beth Aub.

Auditor-General. (1997). Report of the Auditor General on the Appropriation and Other Accounts of Jamaica, for the financial year ended 31 March 1996. Kingston, JM: Auditor General's Department.

Auditor-General. (1998). Report of the Auditor General on the Appropriation and Other Accounts of Jamaica, for the fincancial year ended 31 March 1997. Kingston, JM: Auditor General's Department.

Bamrud, J. (1996). The Other Face of Business in Latin America. Latin Trade (September), 34-41.

Barnett, L. (1999). Proscribing Corruption Under Jamaican Law, A Legal Roadmap. In Carter Center (Ed.), Combating Corruption in Jamaica, A Citizen's Guide (pp. 830). Kinston, JM: Sangster's Bookstores Ltd.

Barnett, L. (1977). The Constitutional Law of Jamaica. Oxford, UK: Oxford University Press.

Barometro Centroamericano 1997. (1997). Barometro Centroamericano 1997. San Jose, CR: Programa Regional de Gobernabilidad/PNID, Observador del Desarrollo.

Beaty, J., \& Gwynne, S. (1993). The Outlaw Bank; A Wild Ride into the Secret Heart of $B C C I$. New York, NY: Random House, Inc.

Bell, J. P. (1971). Crisis in Costa Rica, The 1948 Revolution. Austin, TX: The Institute of Latin American Studies, University of Texas Press.

Bemis, S. F. (1943). The Latin American Policy of the United States. New York, NY: Harcourt, Brace \& World, Inc. 
Bennett, K. M. (1995). Economic Decline and the Growth of the Informal Sector: The Guyana and Jamaica Experience. Journal of International Development, 7(2), 229-242.

Bennett, W. (1994). Questions of Identity, Democracy and Broadcasting - The Case of Jamaica. Caribbean Quarterly, 40(2)(June), 23-32.

Beroes, A. (1990). Recadi, la Gran Estafa. Quoted in W. Little \& A. Herrera, (1996), Political Corruption in Venezuela, in W. Little \& E. Posada-Carbo (Eds.), Political Corruption in Europe and Latin America (pp. 267-285). New York, NY: St. Martin's Press, Inc.

Bicchieri, C., \& Duffy, J. (1997). Corruption Cycles. In P. Heywood (Ed.), Political Corruption (pp. 61-79). Oxford, UK: Blackwell Publishers.

Bicchieri, C., \& Rovelli, C. (1995). Evolution and Revolution, The Dynamics of Corruption. Rationality and Society, 7(2), 201-224.

Biesanz, M. H., Biesanz, R., \& Biesanz, K. Z. (1999). The Ticos, Cultural and Social Change in Costa Rica. Boulder, CO: Lynne Rienner Publishers.

Birch, A. H. (1990). The British System of Government. London, UK: Unwin Hyman.

Blanco Odio, A. (1997). Derechos e Intereses de los Habitantes . San Jose, CR: Comision Nacional para el Mejoramiento de la Administracion de Justicia (CONAMAJ).

Blom-Cooper, L. (1990). Guns for Antigua, Report of the Commission of Inquiry into the circumstances surrounding the shipment of arms from Israel to Antigua and transshipment on 24 April 1989 en route to Colombia.

Bollens, J. C., \& Schmandt, H. J. (1979). Political Corruption; Power, Money, and Sex. Pacific Palisades, CA: Palisades Publishers.

Booth, J. A. (1998). Costa Rica, Quest for Democracy. Boulder, CO: Westview Press.

Booth, J. A., \& Seligson, M. A. (1993). Paths to Democracy and the Political Culture of Costa Rica, Mexico, and Nicaragua. In L. Diamond (Ed.), Political Culture and Democracy in Developing Countries (pp. 99-130). Boulder, CO: Lynne Rienner Publishers.

Borah, W. W. (1964). Spanish Colonial Theory and Practice. In G. H. Nadel \& P. Curtis (Eds.), Imperialism and Colonialism (pp. 38-47). London, UK: The Macmillan Company. 
Bottomore, T. B. (1964). Elites and Society. Harmondsworth, UK: Penguin Books Inc.

Braden, S. (1971). Diplomats and Demagogues. New Rochelle, NY: Arlington House.

Buck, B. (1989). A Caribbean Journalist's Opinions on Combating Corruption in Government. In US Agency for International Development (Ed.), First InterAmerican Conference on the Problems of Fraud and Corruption in Government (p. 21). Washington DC: USAID.

Burton, D. H. (1968). Theodore Roosevelt: Confident Imperialist. Philadelphia, PA: University of Pennsylvania Press.

CAFFE (Citizen Action For Free and Fair Elections). (1998). The 1997 General Elections in Jamaica: The Establishment of CAFFE and its Role in the Electoral Process. Kingston, JM: CAFFE.

Caiden, G. (1978). Administrative Reform: A Prospectus. International Review of Administrative Sciences, 44, 106-120.

Caiden, G. E., \& Caiden, N. J. (1977). Administrative Corruption. Public Administration Review, 37(3), 301-309.

Calvert, R. L. (1995). Rational Actors, Equilibrium, and Social Institutions. In J. Knight \& I. Sened (Eds.), Explaining Social Institutions (pp. 57-93). Ann Arbor, MI: The University of Michigan Press.

Campbell, H. (1998, October 2). Jamaica: Failing Grade on Corruption Test Draws Mixed Reaction. Inter Press Service (in Lexis/Nexis).

Cargill, M. (1987). Morris Cargill, A Selection of his Writings in the Gleaner 1952-1985. Kingston, JM: Tropical Publishers Ltd.

Carter, K. L. (1997). Why Workers Won't Work-The Worker in a Developing Economy: A Case Study of Jamaica. London, UK: Macmillan.

Cepeda, F. (1998). The Culture of Patronage. In UNDP (Ed.), Governance \& Democratic Development in Latin America \& The Caribbean ( p. 78). New York, NY: United Nations Development Programme.

Chang, K. O. B. (1999, June 28). Corruption and consensual sex. Jamaica Observer (Internet edition).

Charles, P. (1989). The Politics of Power. Kingston, JM: Kingston Publishers Limited and Associates. 
Chessman, G. W. (1969). Theodore Roosevelt and the Politics of Power. Boston, MA: Little, Brown and Company.

Cheung, S. N. S. (1996). A Simplistic General Equilibrium Theory of Corruption. Contemporary Economic Policy, XIV(3)(July), 1-5.

Chevigny, P. (1995). Edge of the Knife, Police Violence in the Americas. New York, NY: The New Press.

CID-Gallup. (1980-1999). Public Opinion Polls. San Jose, CR: CID-Gallup.

Clapham, C. (1982). Clientelism and the state. In C. Clapham (Ed.), Private Patronage and Public Power (pp. 1-35). New York, NY: St. Martin's Press.

Collidge, A. (1908). The United States as a World Power. New York, NY: The Macmillan Company.

Collier, M. W. (1998). Political Corruption in the Eastern Caribbean: A Comparative Analysis. Paper presented at the Caribbean Studies Association, Twenty-Third Annual Conference, St. Johns, Antigua, May 25-31, 1998.

Comision Nacional de Rescate y Formacion de Valores. (1992, November 25-27). Exposiciones Congreso, Deberes y Responsabilidades en la Administracion Publica, San Jose, CR: Comision Nacional de Rescate y Formacion de Valores.

Contractor-General. (1997). The Tenth Annual Report of the Contractor-General. Kingston, JM: Office of the Contractor-General.

Contractor-General. (1998). The Eleventh Annual Report of the Contractor-General. Kingston, JM: Office of the Contractor-General.

Contraloria General de la Republica. (1994). Ley Organica de la Contraloria General de la Republica . San Jose, CR: Contraloria General de la Republica, Direccion General de Planificacion Interna y Evaluacion de Sistemas.

Cooper, J. M. (1983). The Warrior and the Priest, Woodrow Wilson and Theodore Roosevelt. Cambridge, MA: The Belknap Press of Harvard University Press.

Coram, R. (1993). Caribbean Time Bomb; The United States' Complicity in the Corruption of Antigua. New York, NY: William Morrow and Company, Inc. 
Corrales Quesada, J. (1999). The Role and Size of the State and Incentives for Corruption in the Context of Globalization. Paper delivered at the United Nations Ad Hoc Expert Group Meeting on "Economic Governance Within the Context of Globalization: Conceptual and Policy Issues, September 27-29, 1999.

Creedman, T. S. (1991). Historical Dictionary of Costa Rica. (2nd ed.). Metuchen, NJ: Scarecrow.

Crow, J. A. (1992). The Epic of Latin America. (4th ed.). Berkeley, CA: University of California Press.

Da Costa, H. L. (1973). Report of the Commission of Enquiry into the Award of Contracts, the Grant of Work Permits and Licenses and Other Matters. Kingston, JM.

Daily Gleaner. (1999, May 3). Corruption worse now. Daily Gleaner (Internet edition).

D'Costa, D. (Ed.). (1998). Public Disturbances, Morris Cargill--a collection of writings 1986-1996. Kingston, JA: The Mill Press.

Defensoria de los Habitantes. (1994). Ley y Reglamento de la Defensoria de los Habitantes de la Republica. San Jose, CR: La Defensoria de los Habitantes.

Defensoria de los Habitantes. (1998). Informe de labores 1997. San Jose, CR: La Defensoria de los Habitantes.

Defensoria de los Habitantes. (1999). Informe de labores 1998. San Jose, CR: La Defensoria de los Habitantes.

Della Porta, D., \& Meny, Y. (1997). Democracy and corruption: towards a comparative analysis. In D. Della Porta \& Y. Meny (Eds.), Democracy and Corruption in Europe (pp. 166-180). London, UK: Pinter.

Della Porta, D., \& Vannucci, A. (1999). Corrupt Exchanges. New York, NY: Aldine de Gruyter.

Dessler, D. (1989). What's at Stake in the Agent Structure Debate? International Organization, 43(3)(Summer), 443.

Diamond, L. (1993). Introduction: Political Culture and Democracy. In L. Diamond (Ed.), Political Culture and Democracy in Developing Countries (pp. 1-27). Boulder, CO: Lynne Rienner Publishers. 
Dobel, J. P. (1978). The Corruption of a State. The American Political Science Review, $72,958-873$.

Dominguez, J. I. (1993). The Caribbean Question: Why Has Liberal Democracy (Suprisingly) Flourished. In J. I. Dominguez, R. A. Pastor, \& R. D. Worrell (Eds.), Democracy in the Caribbean: Political, Economic, and Social Perspectives (pp. 1-28). Baltimore, MD: The Johns Hopkins University Press.

Dos Santos, T. (1970). The Structure of Dependency. American Economic Review, 60(May), 231-236.

Earle, T. C., \& Cvetkovich, G. T. (1995). Social Trust, Toward a Cosmopolitan Society. Westport, CT: Praeger.

Eaton, L. (1999, July 11). Steal a Bundle. Get Out of Town. Now Try to Call It Home. The New York Times, sec. 4, p.1.

Eckstein, H. (1975). Case Study and Theory in Political Science. In F. Greenstein \& N. Polsby (Eds.), Handbook of Political Science (pp. 79-137). Reading, MA: Addison-Wesley.

Edie, C. J. (1991). Democracy by Default, Dependency and Clientelism in Jamaica. Boulder, CO: Lynne Rienner Publishers.

Elazar, D. J. (1966). American Federalism: A View from the States. New York, NY: Thomas Y. Crowell Company.

Elazar, D. J. (1970). Cities of the Prairie; The Metropolitan Frontier and American Politics. New York, NY: Basic Books, Inc.

Elazar, D. J. (1994). The American Mosaic. Boulder, CO: Westview Press.

Electoral Advisory Committee. (1994). Electoral Advisory Report on Electoral Reform. Kingston, JM.

Elliott, K. A. (1996). Implementing the Summit of the Americas: Combating Corruption. Coral Gables, FL: North-South Center, University of Miami.

Elliott, K. A. (1997). Corruption as an International Policy Problem: Overview and Recommendations. In K. A. Elliott (Ed.), Corruption and the Global Economy (pp. 175-233). Washington DC: Institute for International Economics.

Ellis, R. J. (1993). American Political Cultures. New York, NY: Oxford University Press. 
Emmanuel, P. (1994). Parties and Electoral Competition in the Anglophone Caribbean, 1944-1991: Challenges to Democratic Theory. In C. J. Edie (Ed.), Democracy in the Caribbean, Myths and Realities (pp. 251-275). Westport, CT: Praeger.

Emmanuel, P. (1993). Governance and Democracy in the Commonwealth Caribbean: An Introduction. Cave Hill, Barbados: University of the West Indies.

Espinoza, M. (2000, March 31). Combo Protests Continue. Tico Times (Internet edition).

Feinberg, R. E. (1997). Summitry in the Americas, A Progress Report. Washington DC: Institute for International Economics.

Finer, S. E. (1952). Patronage and the Public Service: Jeffersonian Democracy and the British Tradition. Public Administration, 30, 333-353. Reprinted in A. J. Heidenheimer, (Ed.), (1970), Political Corruption, Readings in Comparative Analysis (pp. 106-125). New Brunswick, NJ: Transaction Books.

Frank, A. G. (1967). Capitalism and Underdevelopment in Latin America. New York, NY: Monthly Review Press.

Friedrich, C. J. (1972). The Pathology of Politics; Violence, Betrayal, Corruption, Secrecy, and Propaganda. New York, NY: Harper and Row.

Fukuyama, F. (1995). Trust, The Social Virtues and the Creation of Prosperity. New York, NY: The Free Press.

Gayle, D. J. (1996). Jamaica. In J. M. Malloy \& E. A. Gamarra (Eds.), Latin America and Caribbean Contemporary Record, Vol. VIII (1988-1999) (pp. B397-B403). New York, NY: Holmes \& Meier.

Geddes, B. (1991). A Game Theoretic Model of Reform in Latin American Democracies. American Political Science Review, 85(2)(June), 371-392.

Geddes, B. (1994). Politician's Dilemma, Building State Capacity in Latin America. Berkeley, CA: University of California Press.

Geggus, D. (1989). The Haitian Revolution. In F. W. Knight \& C. A. Palmer (Eds.), The Modern Caribbean (pp. 21-50). Chapel Hill, NC: The University of North Carolina Press.

George, A. (1979). Case Studies and Theory Development: The Method of Structured Focused Development. In P. G. Lauren (Ed.), Diplomacy (pp. 43-68). New York, NY: Free Press. 
Gillespie, K., \& Okruhlik, G. (1991). The Political Dimensions of Corruption Cleanups, A Framework for Analysis. Comparative Politics, 24(1)(October), 77-95.

Girling, J. (1997). Corruption, Capitalism and Democracy. London, UK: Routledge.

Gould, D. J. (1980). Bureaucratic Corruption and Underdevelopment in the Third World; The Case of Zaire. New York, NY: Pergamon Press.

Gould, H. D. (1998). What Is at Stake in the Agent-Structure Debate? In V. Kubalkova, N. Onuf, \& P. Kowert (Eds.), International Relations in a Constructed World (pp. 79-98). Armonk, NY: M.E. Sharpe.

Gould, L. L. (1974). Introduction, The Progressive Era. In L. L. Gould (Ed.), The Progressive Era (pp. 1-10). Syracuse, NY: Syracuse University Press.

Gramsci, A. (1971). Selections From the Prison Notebooks. New York, NY: International Publishers.

Green, D. P., \& Shapiro, I. (1994). Pathologies of Rational Choice Theory. New Haven, CT: Yale University Press.

Greif, A. (1994). Cultural Beliefs and the Organization of Society: A Historical and Theoretical Reflection on Collectivist and Individualist Societies. Journal of Political Economy, 102(5), 912-950.

Griffith, I. L. (1993). The Quest for Security in the Caribbean; Problems and Promises in Subordinate States. Armonk, NY: M. E. Sharpe, Inc.

Griffith, I. L. (1997). Drugs and Security in the Caribbean, Sovereignty Under Siege. University Park, PA: Pennsylvania State University Press.

Groenendijk, N. (1997). A principal-agent model of corruption. Crime, Law \& Social Change, 27, 207-229.

Gugliotta, G., \& Leen, J. (1989). Kings of Cocaine; Inside the Medellin Cartel - An Astonishing True Story of Murder, Money, and International Corruption. New York, NY: Simon and Schuster.

Gunst, L. (1995). Born Fi' Dead, A Journey through the Jamaican posse underworld. Edinburgh, Scotland: Payback Press.

Haring, C. H. (1947). The Spanish Empire in America. San Diego, CA: Harcourt Brace Jovanovich. 
Harriott, A. (1997). Reforming The Jamaica Constabulary Force: From Political to Professional Policing. Caribbean Quarterly, 43(3)(September), 1-12.

Hart, R. (1998). From Occupation to Independence, A Short History of the Peoples of the English-Speaking Caribbean Region. London, UK: Pluto Press.

Headley, B. (1996). The Jamaican Crime Scene, A Perspective. Washington DC: Howard University Press.

Heidenheimer, A. J. (1970). Introduction. In A. J. Heidenheimer (Ed.), Political Corruption, Readings in Comparative Analysis (pp. 3-28). New Brunswick, NJ: Transaction Books.

Heidenheimer, A. J. (1989). Perspectives on the Perception of Corruption. In A. J. Heidenheimer, M. Johnston, \& V. T. Le Vine (Eds.), Political Corruption; $A$ Handbook (pp. 149-163). New Brunswick, NJ: Transaction Publishers.

Henry, P. (1991). Political Accumulation and Authoritarianism in the Caribbean: The Case of Antigua. Social and Economic Studies, 40(1), 1-38.

Herrera U. M. (2000, March 27). Descontento salto a las calles. La Nacion (Internet edition).

Heywood, P. (1997). Political corruption: Problems and Perspectives. In P. Heywood (Ed.), Political Corruption (1-19). Oxford, UK: Blackwell Publishers.

Hill, H. C. (1965). Roosevelt and the Caribbean. New York, NY: Russell \& Russell.

Hillman, R. S., \& D'agostino, T. J. (1992). Distant Neighbors in the Caribbean, The Dominican Republic and Jamaica in Comparative Perspective. New York, NY: Praeger.

Howe, D. (1999). How to bribe voters, Caribbean style. New Statesman, 129(April 2), 23.

Huntington, S. P. (1968). Political Order In Changing Societies. New Haven, CT: Yale University Press.

IADB (Inter-American Development Bank). (2000). Basic Socio-Economic Data. Washington DC: Inter-American Development Bank.

IMF (International Monetary Fund). (1997). Good Governance, The IMF's Role. Washington DC: International Monetary Fund. 
Jackson, R. H. (1990). Quasi-States: Sovereignty, International Relations, and the Third World. Cambridge, UK: Cambridge University Press.

Jacobs, W. R. (1978). Patterns of Political Corruption in Caribbean Society: A Comparative Study of Grenada, Jamaica and Trinidad and Tobago. St. Augustine, Trinidad: Institute of Social and Economic Research, University of the West Indies.

Jain, A. K. (Ed.). (1998a). Economics of Corruption. Boston, MA: Kluwer Academic Publishers.

Jain, A. K. (1998b). Models of Corruption. In A. K. Jain (Ed.), Economics of Corruption (pp. 13-34). Boston. MA: Kluwer Academic Publishers.

Jamaica Observer. (1999a, May 17). Get more involved, PM urges citizens. Jamaica Observer (Internet edition).

Jamaica Observer. (1999b, August 30). Observer/Stone Poll: name FINSAC debtors, $80 \%$ want politicians identified. Jamaica Observer (Internet edition).

JIS (Jamaican Information Service). (1994). Report on the 5th Regional Consultation on Values and Attitudes. Kingston, JM: Jamaican Information Service.

Johansen, E. R. (1990). Political Corruption: Scope and Resources; An Annotated Bibliography. New York, NY: Garland Publishing.

Johnson, B. T., Holmes, K. R., \& Kirkpatrick, M. (1999). 1999 Index of Economic Freedom. Washington DC: The Heritage Foundation and the Wall Street Journal.

Johnson, J. (1997a). Symbol and Strategy in Comparative Political Analysis. Newsletter of the APSA Organized Section in Comparative Politics, (Summer), 6-9.

Johnson, J. (1997b). Why Respect Culture? Unpublished Manuscript. Rochester, NY: University of Rochester.

Johnston, M. (1982). Political Corruption and Public Policy in America. Monterey, CA: Brooks/Cole Publishing Company.

Johnston, M. (1983). Corruption and Political Culture in America: An Empirical Perspective. Publius, (Winter), 19-39. 
Johnston, M. (1986). The Political Consequences of Corruption: A Reassessment. Comparative Politics, 18(4)(July), 459-77. Reprinted In A. J. Heidenheimer, M. Johnston, \& V. T. Le Vine (Eds.), (1989), Political Corruption; A Handbook (pp. 985-1006). New Brunswick, NJ: Transaction Publishers.

Johnston, M. (1994). Comparing Corruption: Conflicts, Standards and Development. Paper presented at the XVI World Congress of the International Political Science Association, Berlin, Germany.

Johnston, M. (1996a). Public Officials, Private Interests, and Sustainable Democracy: When Politics and Corruption Meet. In K. A. Elliott (Ed.), Corruption and the Global Economy (pp. 61-82). Washington DC: Institute for International Economics.

Johnston, M. (1996b). The search for definitions: the vitality of politics and the issue of corruption. International Social Science Journal, 149(September), 321-335.

Johnston, M. (1998). Fighting Systemic Corruption: Social Foundations for Institutional Reform. The European Journal of Development Research, 10(1), 85-104.

Johnston, M. (1999). A Brief History of Anticorruption Agencies. In A. Schedler, L. Diamond, \& M. F. Plattner (Eds.), The Self-Restraining State, Power and Accountability in New Democracies (pp. 217-226). Boulder, CO: Lynne Rienner Publishers.

Jones, E. (1985). Politics, Bureaucratic Corruption, and Maladministration in the Third World: Some Commonwealth Caribbean Considerations. International Review of Administrative Sciences, 51(1), 17-23.

Jones, E. (1992). Maladministration and Corruption: Some Caribbean Realities. In S. Ryan \& D. Brown (Eds.), Issues and Problems in Caribbean Public Administration (pp. 39-41). St. Augustine, Trinidad: The Institute of Social and Economic Research, The University of the West Indies.

Karatnycky, A. (1999). The 1998 Freedom House Survey, A Good Year For Freedom. New York, NY: Freedom House.

Katzenstein, P. J. (1985). Small States in World Markets. Ithaca, NY: Cornell University Press.

Kaufmann, D. (1998). Research on Corruption: Critical Empirical Issues. In A. K. Jain (Ed.), Economics of Corruption (pp. 129-175). Boston, MA: Kluwer Academic Publishers. 
Khan, M. H. (1998). Patron-Client Networks and the Economic Effects of Corruption in Asia. The European Journal of Development Research, 10(1), 15-39.

Khan-Melnyk, A. (1994). Politics and U.S. Jamaican Drug Trade in the 1980s. In B. Bagley \& W. Walker, III (Eds.), Drug Trafficking in the Americas (pp. 481-509). New Brunswick, NJ: Transaction Publishers.

Klitgaard, R. (1988). Controlling Corruption. Berkeley, CA: University of California Press.

Kneer, W. G. (1975). Great Britain and the Caribbean, 1901-1913, A study in AngloAmerican Relations. Lansing, MI: Michigan State University Press.

Knight, A. (1996). Corruption in Twentieth Century Mexico. In W. Little \& E. PosadaCarbo (Eds.), Political Corruption in Europe and Latin America (pp. 219-236). London, UK: Institute of Latin American Studies, University of London.

Knight, F. W. (1990). The Caribbean, The Genesis of a Fragmented Nationalism. (2nd ed.). New York, NY: Oxford University Press.

Knight, J. (1992). Institutions and Social Conflict. Cambridge, UK: Cambridge University Press.

Knight, J. (1995). Models, Interpretations, and Theories: Constructing Explanations of Institutional Emergence and Change. In J. Knight \& I Sened (Eds.), Explaining Social Institutions (pp. 95-119). Ann Arbor, MI: The University of Michigan Press.

Koster, R. M., \& Sanchez, G. (1990). In the Time of the Tyrants; Panama: 1968-1990. New York, NY: W. W. Norton and Company.

Krueger, A. O. (1974). The Political Economy of the Rent-Seeking Society. The American Economic Review, 64(3)(June), 291-303.

Lambsdorff, J. G. (1998). An Empirical Investigation of Bribery in International Trade. In M. Robinson (Ed.), Corruption and Development (pp. 40-59). London, UK: Frank Cass.

Lancaster, T. D., \& Montinola, G. (1997). Toward a methodology for the comparative study of political corruption. Crime, Law \& Social Change, 27, 185-206.

Langley, L. D. (1980). The United States and the Caribbean in the Twentieth Century. Athens, GA: The University of Georgia Press. 
Lasswell, H. D. (1950). Politics: Who gets what, when, and how. New York, NY: P. Smith.

Latin American Institute. (1997, May 15). Costa Rica: President Jose Maria Figueres's Administration Plagued with Corruption Scandals. Latin American Institute, University of New Mexico.

Lee, R. W., III. (1985). The Latin American Drug Connection. Foreign Policy, 61(Winter 1985-1986), 142-159.

Leff, N. H. (1964). Economic Development through Bureaucratic Corruption. American Behavioral Scientist. 8(3)(November), 8-14. Reprinted in A. J. Heidenheimer, M. Johnston, \& V. T. Le Vine (Eds.), (1989), Political Corruption; A Handbook (pp. 389-403). New Brunswick, NJ: Transaction Publishers.

Lehoucq, F. (1997). Lucha electoral y sistema politico en Costa Rica 1948-1998. San Jose, CR: Editorial Porvenir S. A.

Leiken, R. S. (1996). Controlling the Global Corruption Epidemic. Foreign Policy, 105(Winter 1996-1997), 55-73.

Lewis, G. K. (1968). The Growth of The Modern West Indies. New York, NY: Modern Reader Paperbacks.

Leys, C. (1965). What Is the Problem about Corruption? Journal of Modern African Studies. 3(2), 215-230. Reprinted in A. J. Heidenheimer, M. Johnston, \& V. T. Le Vine (Eds.), (1989) Political Corruption; A Handbook (pp. 51-66). New Brunswick, NJ: Transaction Publishers.

Lijphart, A. (1991). Size, Pluralism, and the Westminster Model of Democracy: Implications for the Eastern Caribbean. In J. Heine (Ed.), A Revolution Aborted: The Lessons of Grenada (pp. 321-340). Pittsburg, PA: University of Pittsburg Press.

Little, W., \& Herrera, A. (1996). Political Corruption in Venezuela. In W. Little \& E. Posada-Carbo (Eds.), Political Corruption in Europe and Latin America (pp. 267285). New York, NY: St. Martin's Press, Inc.

Lui, F. T. (1986). A Dynamic Model of Corruption Deterrence. Journal of Public Economics, 31(1), 215-236.

Machiavelli, N. (1970). The Discourses. London, UK: Penguin Books. 
Maingot, A. P. (1993). The Internationalization of Corruption and Violence: Threats to the Caribbean in the Post-Cold War World. In J. I. Dominguez, R. A. Pastor, \& R. D. Worrell (Eds.), Democracy in the Caribbean: Political, Economic, and Social Perspectives (pp. 42-56). Baltimore: The Johns Hopkins University Press.

Maingot, A. P. (1994a). Confronting Corruption in the Hemisphere: A Sociological Perspective. Journal of Interamerican Studies and World Affairs, 36(3)(Fall), 4974.

Maingot, A. P. (1994b). The Drug Trade in the Caribbean: Policy Options. In B. M. Bagley \& W. O. Walker, III (Eds.), Drug Trafficking in the Americas (pp. 469481). New Brunswick, NJ: Transaction Publishers.

Maingot, A. P. (1994c). The United States and the Caribbean; Challenges of an Asymetrical Relationship. Boulder, CO: Westview Press.

Maingot, A. P. (1995). Offshore Secrecy Centers and the Necessary Role of States: Bucking the Trend. Journal of Interamerican Studies and World Affairs, 37(4) (Winter), 1-24.

Manion, M. (1996). Corruption by Design: Bribery in Chinese Enterprise Licensing. Journal of Law Economics \& Organization, 12(1), 167-195.

Manzetti, L., \& Blake, C. H. (1996). Market reforms and corruption in Latin America: new means for old ways. Review of International Political Economy, 3(4)(Winter), 662-697.

Marks, F. W. (1979). Velvet on Iron, The Diplomacy of Theodore Roosevelt. Lincoln, NE: University of Nebraska Press.

Marx, J. (1992). Pirates and Privateers of the Caribbean. Malabar, FL: Krieger Publishing Company.

Matute, R., \& Solorzano, J. (1999, June 3). EE. UU. liga Hank con narco. La Nacion (Internet edition).

Mauro, P. (1995). Corruption and Growth. The Quarterly Journal of Economics, 110(August), 681-712.

Mauro, P. (1996). The Effects of Corruption on Growth, Investment, and Government Expenditure (WP/96/98-EA). Washington DC: International Monetary Fund Working Paper. 
Mauro, P. (1997a). The Effects of Corruption on Growth, Investment, and Government Expenditure: A Cross Country Analysis. In K. A. Elliot (Ed.), Corruption and the Global Economy (pp. 83-107). Washington DC: Institute for International Economics.

Mauro, P. (1997b). Why Worry About Corruption? (Economic Issues No. 6). Washington DC: International Monetary Fund.

McCann, J. A., \& Dominguez, J. I. (1998). Mexicans React to Electoral Fraud and Political Corruption: an Assessment of Public Opinion and Voting Behavior. Electoral Studies, 17(4), 483-503.

McFarlane, A. (1996). Political Corruption and Reform in Bourbon Spanish America. In W. Little \& E. Posada-Carbo (Eds.), Political Corruption in Europe and Latin America (pp. 41-64). London, UK: Institute of Latin American Studies.

McMullan, M. (1961). A Theory of Corruption. The Sociological Review, 9(July).

Merton, R. K. (1968). Social Theory and Social Structure. (Enlarged Edition). New York, NY: The Free Press.

Miami Herald. (1999, February 25). Mixed signals about Mexico in drug wars. The Miami Herald, p. 10A.

Miller, N. (1976). Stealing from America; A History of Corruption from Jamestown to Reagan. New York, NY: Paragon House.

Miller, R. (1996). Foreign Capital, The State and Political Corruption in Latin America Between Independence and the Depression. In W. Little \& E. Posada-Carbo (Eds.), Political Corruption in Europe and Latin America (pp. 65-96). London, UK: Institute of Latin American Studies.

Mills, G. E. (1997). Westminster Style Democracy, The Jamaican Experience. Kingston, JA: The Grace, Kennedy Foundation.

Monge Alfaro, C. (1976). Historia de Costa Rica. (14th ed.). San Jose, CR: Trejos.

Monroe, K. R. (1991). The Theory of Rational Action: Its Origins and Usefulness for Political Science. In K. R. Monroe (Ed.), The Economic Approach to Politics (pp. 1-32). New York: HarperCollins Publishers Inc.

Montinola, G. R. (1995). Who Guards the Guardians? The Foundations of Political Corruption. Doctoral Thesis, Stanford University, Palo Alto, CA. 
Moody-Stuart, G. (1996). The Costs of Grand Corruption. Available at: http://www.cipe.org/e22/mooE22.html (October 5, 1997).

Morris, S. D. (1991). Corruption and Politics in Contemporary Mexico. Tuscaloosa, AL: The University of Alabama Press.

Morrow, J. D. (1994). Game Theory for Political Scientists. Princeton, NJ: Princeton University Press.

Moser, C., \& Holland, J. (1997). Urban Poverty and Violence in Jamaica. Washington DC: World Bank Latin American and Caribbean Studies.

Mowry, G. E. (1958). The Era of Theodore Roosevelt. New York, NY: Harper and Row.

Moyne Commission. (1945). West India Royal Commission Report. London, UK: Her Majesty's Stationary Office.

Munroe, T. (1994). For a New Beginning, Selected Speeches 1990-1993. Kingston, JM: CARICOM Publishers Limited.

Munroe, T. (1999a). The Proposed Jamaican Corruption Prevention Act and How Our Anti-Corruption Commission Compares. In Carter Center (Ed.), Combating Corruption in Jamaica (pp. 31-54). Kingston, JM: Sangster's Bookstores Ltd.

Munroe, T. (1999b). Renewing Democracy into the Millennium, The Jamaican Experience in Perspective. Kingston, JM: The Press University of the West Indies.

Munroe, T. G. (1969). Political Change and Constitutional Development in Jamaica 1944-1962. Doctoral Thesis, Nuffield College, Oxford University, Oxford, UK.

Nadelmann, E. A. (1993). Cops Across Borders, the Internationalization of U.S. Criminal Law Enforcement. University Park, PA: The Pennsylvania State University Press.

Nas, T. F., Price, A. C., \& Weber, C. T. (1986). A Policy-Oriented Theory of Corruption. American Political Science Review, 80(1)(March), 107-119.

National Committee on Political Tribalism. (1997). Report of the National Committee on Political Tribalism. Kingston, JM.

Naylor, R. T. (1987). Hot Money and the Politics of Debt. New York, NY: The Linden Press/Simon and Schuster.

Noonan, J. T., Jr. (1984). Bribes. Berkeley, CA: University of California Press. 
Nye, J. S. (1967). Corruption and Political Development A Cost-Benefit Analysis; The Study of Corruption in Less Developed Countries. American Political Science Review, LXI(2)(June), 963-983.

OAS (Organization of American States). (1996). Inter-American Convention Against Corruption. Washington DC: Organization of American States.

OAS (Organization of American States). (2000). Inter-American Convention Against Corruption-Signing and Ratification Status. Washington DC: OAS Interamerican System of Legal Information. Available at //www.oas.org/en/prog/juridico/ english/Sigs/b-58.html (May 1, 2000).

O'Donnell, G. (1999). Horizontal Accountability in New Democracies. In A. Schedler, L. Diamond, \& M. F. Plattner (Eds.), The Self-Restraining State, Power and Accountability in New Democracies (pp. 29-51). Boulder, CO: Lynne Rienner Publishers.

Onuf, N. G. (1989). World of Our Making: Rules and Rule in Social Theory and International Relations. Columbia, SC: University of South Carolina Press.

Onuf, N. (1997a). Constructivism: A User's Manual. In V. Kubalkova, P. Kowert, \& N. Onuf (Eds.), International Relations in a Constructed World (pp. 58-78). Armonk, NY: M.E. Sharpe.

Onuf, N. (1997b). A Constructivist Manifesto. In K. Burch \& R. A. Denemark (Eds.), Constituting International Political Economy (pp. 1-17). Boulder, CO: Lynne Rienner.

Onuf, N. G. (1998). The Republican Legacy in International Thought. Cambridge, UK: Cambridge University Press.

Oppenheimer, A. (1992). Castro's Final Hour; The Secret Story Behind the Coming Downfall of Communist Cuba. New York, NY: Simon and Schuster.

Orane, D. (1999). Orane Report (Task Force to Reduce Waste in the Public Sector). Kingston, JM.

Ostrom, E. (1990). Governing the Commons, The Evolution of Institutions for Collective Action. Cambridge, UK: Cambridge University Press.

Ostrom, E., Gardner, R., \& Walker, J. (1994). Rules, Games, \& Common-Pool Resources. Ann Arbor, MI: The University of Michigan Press. 
PAHO (Pan American Health Organization). (1999). Health Situation in the Americas, Basic Indicators. Washington DC: Pan American Health Organization.

Panton, K. (1994). Leadership \& Citizenship in Post-Independence Jamaica - Whiter the partnership? Kingston, JM: The Grace, Kennedy Foundation.

Parry, J. H., Sherlock, P. M., \& Maingot, A. P. (1987). A Short History of the West Indies. New York, NY: St. Martin's Press.

Payne, A. (1993). Westminster Adapted: The Political Order of the Commonwealth Caribbean. In J. I. Dominguez, R. A. Pastor, \& R. D. Worrell (Eds.), Democracy in the Caribbean (pp. 57-73). Baltimore: The Johns Hopkins University Press.

Payne, D. W. (1992). Latin American Democracy: In Search of the Rule of Law. Freedom Review, 23(1), 48-50.

Payne, D. W. (1993). Latin America: Democracy and the Politics of Corruption. Freedom Review, 24(1), 27-30.

Payne, D. W. (1994). Latin America and the Caribbean: Giving Democracy a Bad Name. Freedom Review, 25(1), 26-31.

Payne, D. W. (1995). Latin America and the Caribbean: Ballots, Neo-Strongmen, Narcos and Impunity. Freedom Review, 26(1), 27-31.

Payne, D. W. (1996). Drugs Into Money Into Power: A Global Challenge. Freedom Review, 27(4), 9-104.

Peck, L. L. (1978). The British Case: Corruption and Political Development in the Early Modern State. In A. S. Eisenstadt, A. Hoogenboom, \& H. L. Trefousse (Eds.), Before Watergate: Problems of Corruption in American Society. Brooklyn, NY: Brooklyn College Press. Reprinted in A. J. Heidenheiner, M. Johnston, \& V. T. Levine, (Eds.), (1989), Political Corruption, A Handbook (pp. 219-231), New Brunswick, NJ: Transaction Publishers.

Peltason, J. W. (1997). Understanding the Constitution. Fort Worth, TX: Harcourt Brace College Publishers.

Peters, D. C. (1992). The Democratic System in the Eastern Caribbean. New York, NY: Greenwood Press.

Philp, M. (1987). Defining Corruption: An Analysis of the Republican Tradition. Paper presented at the International Political Science Association research roundtable on political finance and political corruption, Bellagio, Italy. 
Philp, M. (1997). Defining Political Corruption. In P. Heywood (Ed.), Political Corruption (pp. 20-46). Oxford, UK: Blackwell Publishers.

Political Risk Services. (1998a). Costa Rica. Syracuse, NY: Political Risk Services.

Political Risk Services. (1998b). Jamaica. Syracuse, NY: Political Risk Services.

Pratt, C. (1999, September 10). Buck Passed in 2nd Weeks of Fund Trial. Tico Times (Internet edition).

Proyecto Estado de la Nacion. (1995). Estado de la Nacion, en Desarrollo Humano Sostenible (1994) (1st ed.). San Jose, CR: Proyecto Estado de la Nacion.

Proyecto Estado de la Nacion. (1996). Estado de la Nacion, en Desarrollo Humano Sostenible (1995) (2nd ed.). San Jose, CR: Proyecto Estado de la Nacion.

Proyecto Estado de la Nacion. (1997). Estado de la Nacion, en Desarrollo Humano Sostenible (1996) (3rd ed.). San Jose, CR: Proyecto Estado De la Nacion.

Proyecto Estado de la Nacion. (1998). Estado de la Nacion, en Desarrollo Humano Sostenible (1997) (4th ed.). San Jose, CR: Proyecto Estado de la Nacion.

Proyecto Estado de la Nacion. (1999). Estado de la Nacion, en Desarrollo Humano Sostenible (1998) (5th ed.). San Jose, CR: Proyecto Estado de la Nacion.

Putnam, R. D. (1993). Making Democracy Work, Civic Traditions in Modern Italy. Princeton, NJ: Princeton University Press.

Ragin, C. C. (1987). The Comparative Method, Moving Beyond Qualitative and Quantitative Strategies. Berkeley, CA: University of Californai Press.

Ragin, C. C. (1994). Constructing Social Research. Thousand Oaks, CA: Pine Forge Press.

Ragin, C. C. (2000). Fuzzy-Set Social Science. Chicago, IL: University of Chicago Press.

Ramsaran, R. (1995). Challenges to Caribbean Economic Development in the 1990s. In A. T. Bryan (Ed.), The Caribbean: New Dynamics in Trade and Political Economy (pp. 111-134). Boulder, CO: Lynne Rienner Publishers.

Randall, S. J., \& Mount, G. S. (1998). The Caribbean Basin, An International History. London, UK: Routledge. 
Ricardo, D. (1960). The Principles of Political Economy and Taxation. New York, NY: E. P. Dutton \& Co. Inc.

Rico, J. M., Salas, L., Guitierrez, E., \& Cruz, C. (1988). La Justicia Penal en Costa Rica. San Jose, CR: Editorial Universataria Centroamericano.

Robotham, D. (1998). Vision \& Voluntarism, Reviving Voluntarism in Jamaica. Kingston, JM: Grace, Kennedy Foundation.

Rodrigues, S. A. (1996). The Jamaican Political Culture: A Theoretical and Empirical Exploration. Masters Thesis, The University of the West Indies-Mona, Mona, JM.

Rodriguez Echeverria, M. A. (1998). Acuerdo Presidencial No, 2-P-J . San Jose, CR: Presidente de la Republica de Costa Rica.

Rodriguez, F., Castro, S., \& Espinosa, R. (1998). El sentir democratico, Estudios sobre la cultura politica centroamericano. Heredia, CR: PROCESOS/EFUNA.

Rodriguez, J. (1993, October 5). Septiembre de 1993. La Nacion ${ }_{1}$ pp. 15A.

Roorda, E. P. (1998). The Dictator Next Door. Durham, NC: Duke University Press.

Rose-Ackerman, S. (1978). Corruption; A Study in Political Economy. New York, NY: Academic Press.

Rosenberg, M. (1981). Social Reform in Costa Rica: Social Security and the Presidency of Rafael Angel Calderon Guardia. Hispanic Historical Review, 61(2), 278-296.

Rousseau, J. J. (1978). On the Social Contract. New York, NY: St. Martin's Press.

Ryan, S. (1998). Democratic Governance and the Social Condition in the Anglophone Caribbean. In UNDP (Ed.), Governance \& Democratic Development in Latin America \& The Caribbean (pp. 37-64). New York, NY: United Nations Development Programme.

Salas, L., \& Rico, J. M. (1993). Administration of Justice in Latin America. Miami, FL: Center for the Administration of Justice, Florida International University.

Salazar, R., Hernandez, A. L., \& Rojas, F. (1999). Manuel para la participacion ciudadana. San Jose, CR: Comision Nacional para el Mejoramiento do la Administracion de Justicia (CONAMAJ).

Sandholtz, W., \& Koetzle, W. (2000). Accounting for Corruption: Economic Structure, Democracy, and Trade. International Studies Quarterly, 44(1), 31-50. 
Schedler, A. (1999). Conceptualizing Accountability. In A. Schedler, L. Diamond, \& M. Plattner (Eds.), The Self-Restraining State, Power and Accountability in New Democracies (pp. 13-28). Boulder, CO: Lynne Rienner Publishers.

Schedler, A., Diamond, L., \& Plattner, M. F. (Eds.). (1999). The Self-Restraining State, Power and Accountability in New Democracies. Boulder, CO: Lynn Reinner Publishers.

Schelling, T. C. (1960). The Strategy of Conflict. Cambridge, MA: Harvard University.

Scott, J. C. (1972). Comparative Political Corruption. Englewood Cliffs, NJ: PrenticeHall, Inc.

Scott, P. D., \& Marshall, J. (1991). Cocaine Politics, Drugs, Armies, and the CIA in Central America. Berkeley, CA: University of California Press.

Segnini, G. (1999, October 18). Caso Anglo: Reto a la Justicia. La Nacion, pp. 4A-5A.

Segura, W., \& Solis, C. (1999, October 28). Sigue morosidad con Anglo. La Republica, pp. 4A-5A.

Seligson, M. A. (1999). Nicaraguans Talk About Corruption: a Follow-Up Study of Public Opinion. Arlington, VA: Casals \& Associates, Inc.

Semana. (1991, March 12). Corruption in Colombia. Semana (Bogota). Quoted in A. Metz, 1991, The Israeli-Colombian Connection. Hemisphere, (Summer), 24-28.

Shepsle, K. A. (1989). Studying Institutions, Some Lessons From the Rational Choice Approach. Journal of Theoretical Politics, 1(2), 131-147.

Shugart, M. S., \& Mainwaring, S. (1997). Presidentialism and Democracy in Latin America: Rethinking the Terms of the Debate. In M. S. Shugart \& S. Mainwaring (Eds.), Presidentialism and Democracy in Latin America (pp. 12-54). Cambridge, UK: Cambridge University Press.

Shumer, S. M. (1979). Machiavelli; Republican Politics and Its Corruption. Political Theory, 7(1)(February), 5-34.

Smith, A. (1937). The Wealth of Nations. New York, NY: Modern Library.

Smith, D. C., Jr. (1980). Paragons, Pariahs, and Pirates: A Spectrum-Based Theory of Enterprise. Crime and Delinquency, (July), 358-386. 
Smith, T. M. (1971). Corruption, Tradition, and Change. Indonesia, 11, 21-40. Reprinted in A. J. Heidenheimer, M. Johnston, \& V. T. Levine, (Eds). (1989), Political Corruption, A Handbook (pp. 423-440). New Brunswick, NJ: Transaction Publishers.

Sterling, C. (1994). Thieves' World; The Threat of the New Global Network of Organized Crime. New York, NY: Simon and Schuster.

Stone, C. (1980). Democracy and Clientelism in Jamaica. New Brunswick, NJ: Transaction Books.

Stone, C. (1989). Forward. In P. Charles (Ed.), The Politics of Power (pp. i-ii). Kingston, JM: Kingston Publishers Limited and Associates.

Stone, C. (1992). The Jamaican Party System and Political Culture. Kingston, JM: Jamaica 30th Anniversary Symposium, Preparing for the 21st Century.

Stone Committee. (1991). Report of the Stone Committee Appointed to Advise the Jamaican Government on the Performance, Accountability and Responsibilities of Elected Parliamentarians. Kingston, JM: Bustamante Institute of Public and International Affairs.

Stone, R. (Ed.). (1994). The Stone Columns, The last years' work. A selection of Carl Stone's Gleaner articles, January 1992 to February 1993. Kingston, JM: Sangster's Book Stores Ltd.

Stone, S. Z. (1990). The Heritage of the Conquistadors, Ruling Classes in Central America from the Conquest to the Sandinistas. Lincoln, NE: University of Nebraska Press.

Sunol, J. (1974). Robert Vesco Compra Una Republica. San Jose, CR: Trejos Hnos. Sucs. S.A.

Sunol, J. (1977). la noche de los tiburones, novela sobre corrupcion politica. San Jose, CR: Libreria Imprenta y Litogrphia Lehmann, S.A.

Sussman, L. R. (1999). The News of the Century, Press Freedom 1999. New York, NY: Freedom House.

Swart, K. W. (1949). The Sale of Public Offices in the Seventeenth Century. The Hague: Martinus Nijhoff (pp. 112-127). Reprinted in A. J. Heidenheimer, (Ed.), (1970), Political Corruption, Readings in Comparative Analysis (pp. 82-90). New Brunswick, NJ: Transaction Books. 
Tamayo, J. O. (1999, July 2). Havana hospital officials forced out in corruption crackdown. The Miami Herald, pp. 12A.

Tanzi, V. (1998). Corruption Around the World: Causes, Consequences, Scope, and Cures (WP/98/63). Washington DC: International Monetary Fund Working Paper.

Tanzi, V., \& Davoodi, H. (1997). Corruption, Public Investment, and Growth (WP/97/139). Washington DC: A Working Paper of the International Monetary Fund.

Tanzi, V., \& Davoodi, H. (1998). Roads to Nowhere: How Corruption in Public Investment Hurts Growth. Washington DC: International Monetary Fund.

The Leadership Council for Inter-American Summitry. (1999). Mastering Summitry: An Evaluation of the Santiago Summit of the Americas and its Aftermath. Coral Gables, FL: The Dante B. Fascell North-South Center, University of Miami.

Theobald, R. (1990). Corruption, Development and Underdevelopment. Durham, NC: Duke University Press.

Thompson, A. O. (1997). The Haunting Past; Politics, Economics and Race in Caribbean Life. Armonk, NY: M.E. Sharpe.

Thorndike, T. (1991). Avarice in the Aviary. Corruption and Reform, 6, 171-183.

Thoumi, F. E. (1995). Political Economy of Illegal Drugs in Colombia. Boulder, CO: Lynne Rienner Publishers.

Thurlow, R. (1995). The Secret State. Oxford, UK: Blackwell.

Trager, J. (1994). The People's Chronology. New York, NY: Henry Holt and Company, Inc.

Transparency International. (1996). 1996 International Corruption Perception Index. Berlin, Germany: Transparency International.

Transparency International. (1998). 1998 Corruption Perceptions Index. Berlin, Germany: Transparency International.

Transparency International. (1999a). 1999 Bribe Payers Index, 1999 Corruption Perceptions Index. Berlin, Germany: Transparency International. 
Transparency International. (1999b). Monitoring of the Privatization Process of Panama's Telephone Company, Intel S.A. Berlin, Germany: Transparency International.

Truell, P., \& Gurwin, L. (1992). False Profits; The Inside Story of BCCI, The World's Most Corrupt Financial Empire. Boston, MA: Houghton Mifflin Company.

Tullock, G. (1989). The Economics of Special Privilege and Rent Seeking. Boston, MA: Kluwer Academic Publishers.

Umana Zuniga, R. (1995). Accion de Inconstitucionalidad No. 842-P-90 . San Jose, CR: Contraloria General de la Republica.

UNDP (United Nations Development Programme). (1998). Human Development Report 1998. New York, NY: Oxford University Press.

University of Texas at Austin. (1998). Estudio Sobre Etica, Probidad, y Responsabilidad de los Funcionarios y Empleados Publicos en Centroamerica, Tomo 1 (draft). Austin, TX: University of Texas at Austin.

Urcuyo Fournier, C. (1999). Modernizacion y Desarrollo Legislativo en el Parlamento Costarricense. In R. Rodriguez Chang (Ed.), Experiencias de Modernizacion Legislativa en America Central y Republica Dominicana. San Jose, CR: Instituto Interamericano de Derechos Humanos.

US Department of State. (1997). International Narcotics Control Strategy Report, March 1997. Washington DC: US Department of State.

US Department of State. (1999a). Costa Rica Country Report on Human Rights Practices for 1998. Washington DC: US Department of State.

US Department of State. (1999b). International Narcotics Control Strategy Report, 1998. Washington DC: US Department of State.

Vega Carballo, J. L. (1990). Political Parties, Party Systems, and Democracy in Costa Rica. In L. W. Goodman, W. M. Leogrande, \& F. Mendelson, Johanna (Eds.), Political Parties and Democracy in Central America (pp. 203-212). Boulder, CO: Westview Press.

Villalobos, C. (1999a, November 27). PLN exonora a Ayales por Fodesaf. La Nacion (Internet edition).

Villalobos, C. A. (1999b, November 2). La plata se perdio en Fodesaf. La Nacion (Internet edition). 
Villalobos, C. A. (1999c, October 27). Pais cede ante corrupcion. La Nacion, pp. 5A.

Vogl, F. (1993). Laying Corruption to Rest . Available at: http://www.cipe.org/e 10/GUEST-4.HTML (October 5, 1997).

Watson, R. L., Jr. (1976). The Development of National Power, The United States, 1900 1919. Boston, MA: Houghton Mifflin Company.

Weder, B., \& Brunetti, A. (1999). Another Tale of Two Cities, A Note on Institutions in Hong Kong and Singapore. Washington DC: World Bank Working Paper.

Weingast, B. R. (1997). The Political Foundations of Democracy and the Rule of Law. American Political Science Review, 91(2)(June), 245-263.

Weir, C. (1994). Costa Rica and the Drug Trade. In B. Bagley \& W. Walker, III, Drug Trafficking in the Americas (pp. 455-467). New Brunswick, NJ: Transaction Publishers.

Wesberry, J. P., Jr. (1998). International Financial Institutions Face the Corruption Eruption: If the IFIs Put Their Muscle and Money Where Their Mouth Is, the Corruption Eruption May Be Capped. Northwestern Journal of International Law and Business, 18(2)(Winter), 498-523.

Weyland, K. (1998). The Politics of Corruption in Latin America. Journal of Democracy, 9(2)(April), 108-121.

Whitehead, L. (1983). On Presidential Graft: The Latin American Evidence. In M. Clarke (Ed.), Corruption, Causes, Consequences and Control (pp. 781-800). London, UK: Pinter.

Wild Ambrioggio, J. (1998). La Quiebra Del Banco Anglo Costarricense, Sus Origenes y Causes. San Jose, CR: Proyecto de Apoyo a la Reforma Financiera.

Wilentz, A. (1989). The Rainy Season, Haiti Since Duvalier. New York, NY: Simon and Schuster.

Williams, E. (1970). From Columbus to Castro: The History of the Caribbean 14921969. New York, NY: Vintage Books.

Williams, P. (1994). Transnational Criminal Organizations and International Security. Survival, 36(1), 96-113.

Wilson, B. M. (1998). Costa Rica, Politics, Economics, and Democracy. Boulder, CO: Lynne Rienner Publishers. 
Wilson, M. (1992, August 21). Pindling Ousted by Bahamas Landslide. The Guardia, pp. 8.

Wilson, P. J. (1973). Crab Antics - The Social Anthropology of English-Speaking Negro Societies in the Caribbean. New Haven, CT: Yale University Press.

Wilson, R. C. (1989). Ancient Republicanism, Its Struggle for Liberty Against Corruption. New York, NY: Peter Lang.

World Bank. (1997a). Helping Countries Combat Corruption, The Role of the World Bank. Washington DC: The World Bank, Poverty Reduction and Economic Management.

World Bank. (1997b). World Bank Report 1997, The State in a Changing World . Washington DC: The World Bank.

World Bank. (1998). New frontiers in diagnosing and combating corruption. Premnotes, October(7), 1-6.

World Bank. (1999). Jamaica, Consultations with the Poor, A Study to Inform the World Development Report 2000/1 on Poverty and Development. East Sussex, UK: One World Development Network.

World Factbook. (1999). The World Factbook. Washington DC.: US Central Intelligence Agency.

Worrell, K. (1987). The Economy of Modern Jamaica, An Outline. Kingston, JM: The Bustamante Institute of Public and International Affairs. 
October 16, 1952

1974

1974-1996

1986

1996-1998

1998-1999

1999-2000
Born, Odessa, Missouri

B.S., Economics and Management

US Coast Guard Academy

New London, Connecticut

US Coast Guard Officer

M.S., Strategic Intelligence

Joint Military Intelligence College

Washington DC

Andrew Mellon Foundation

Doctoral Fellowship in Caribbean Studies

Latin American and Caribbean Center

Florida International University

Miami, Florida

Teaching Assistant

International Relations Department

Florida International University

Miami, Florida

Research Associate

Latin American and Caribbean Center

Florida International University

Miami, Florida

\section{PUBLICATIONS AND PRESENTATIONS}

Collier, M.W., (1998). Schools are vulnerable to invasion of violence. School Safety, the Journal of the National School Safety Center, (Winter), 9-13.

Collier, M.W., (November, 1998). Cultures of Violence in Miami-Dade Public Schools. A working paper published by the Florida International University Immigration and Ethnicity Institute. 
Collier, M.W., (October, 1997). State Corruption and Its Role in Armed Conflict. Paper presented at the meeting of the International Studies Association-South, North Miami, Florida. Paper awarded first runner-up in graduate student paper competition.

Collier, M.W., (February, 1998). Combating Hemispheric Corruption: A Question of Political Capacity. Paper presented at the Academic Consultation on the Presidential Summit of the Americas II, Florida International University, Latin American and Caribbean Center, Miami, Florida.

Collier, M.W., (April, 1998). Cultures of Violence in Miami-Dade Public Schools. Paper presented at the meeting of the Society for Applied Anthropology, San Juan, Puerto Rico.

Collier, M.W., (May, 1998). Corruption and Democracy in the Eastern Caribbean. Paper presented at the meeting of the Caribbean Studies Association, St. Johns, Antigua, British West Indies.

Collier, M.W., (February, 1999). Explaining Political Corruption: An Institutional Choice Approach. Paper presented at the meeting of the International Studies Association, Washington, DC. Paper awarded the Alexander George Award for best graduate student paper in the Foreign Policy Analysis Section.

Collier, M.W., (September, 1999). An Institutional Choice Approach to Explaining Political Corruption. Paper presented at the meeting of the American Political Science Association, Atlanta, Georgia.

Collier, M.W., (March, 2000). Explaining Political Corruption: The Case of Jamaica. Paper presented at the meeting of the Latin American Studies Association, Miami, Florida. 